\title{
Dyspepsia in primary care : patient expectations, symptoms, and treatment adherence
}

Citation for published version (APA):

Fransen, G. A. J. (2007). Dyspepsia in primary care : patient expectations, symptoms, and treatment adherence. [Doctoral Thesis, Maastricht University]. Universiteit Maastricht. https://doi.org/10.26481/dis.20071018gf

Document status and date:

Published: 01/01/2007

DOI:

10.26481/dis.20071018gf

Document Version:

Publisher's PDF, also known as Version of record

\section{Please check the document version of this publication:}

- A submitted manuscript is the version of the article upon submission and before peer-review. There can be important differences between the submitted version and the official published version of record.

People interested in the research are advised to contact the author for the final version of the publication, or visit the DOI to the publisher's website.

- The final author version and the galley proof are versions of the publication after peer review.

- The final published version features the final layout of the paper including the volume, issue and page numbers.

Link to publication

\footnotetext{
General rights rights.

- You may freely distribute the URL identifying the publication in the public portal. please follow below link for the End User Agreement:

www.umlib.nl/taverne-license

Take down policy

If you believe that this document breaches copyright please contact us at:

repository@maastrichtuniversity.nl

providing details and we will investigate your claim.
}

Copyright and moral rights for the publications made accessible in the public portal are retained by the authors and/or other copyright owners and it is a condition of accessing publications that users recognise and abide by the legal requirements associated with these

- Users may download and print one copy of any publication from the public portal for the purpose of private study or research.

- You may not further distribute the material or use it for any profit-making activity or commercial gain

If the publication is distributed under the terms of Article $25 \mathrm{fa}$ of the Dutch Copyright Act, indicated by the "Taverne" license above, 


\section{Dyspepsia in primary care: patient expectations, symptoms, and treatment adherence}


'Dyspepsia in primary care:

patient expectations, symptoms, and treatment adherence'

Gerdine A.J. Fransen

Thesis Maastricht University

Copyright (C2007 Gerdine A.J. Fransen

gerdinefransen@hotmail.com

No part of this book may be reproduced in any form, by print, photo print, microfilm or otherwise, without prior written permission of the author.

Niets uit deze uitgave mag worden vermenigvuldigd en/of openbaar gemaakt door middel van druk, fotokopie, microfilm of welke wijze dan ook, zonder uitdrukkelijke schriftelijke toestemming van de auteur.

II 


\title{
Dyspepsia in primary care: patient expectations, symptoms, and treatment adherence
}

\author{
PROEFSCHRIFT \\ Ter verkrijging van de graad van doctor aan de Universiteit Maastricht \\ op gezag van de Rector Magnificus, Prof. Mr. G.P.M.F. Mols \\ volgens het besluit van het College van Decanen, \\ in het openbaar te verdedigen
}

op donderdag 18 oktober 2007 om 14.00 uur

door

Gerarda Adriana Johanna Fransen 
Promotor:

Prof. dr. J.A. Knottnerus

Copromotores:

Dr. J.W.M. Muris

Dr. I. Mesters

Beoordelingscommissie:

Prof. dr. R. J. Brummer (voorzitter)

Dr. A.J.M. Drenthen (Nederlands Huisartsen Genootschap)

Prof. dr. J. Heyrman (Katholieke Universiteit Leuven)

Prof. dr. L. Lechner (Open Universiteit Heerlen/ Universiteit Maastricht)

Prof. dr. H. de Vries

Paranimfen:

Drs. C.J. van Marrewijk

Drs. S. Mujakovic

The studies presented in this thesis were conducted under auspices of the Care and Public Health Research Institute (Caphri) at the Faculty of Health, Medicine and Life Sciences of Maastricht University. Caphri is part of the Netherlands School of Primary Care Research (CaRe) which has been acknowledged since 1995 by the Royal Netherlands Academy of Art and Science (KNAW).

The studies described in Chapters 7, 8, and 9 are part of the DIAMOND-study, which was financially supported by ZonMw (grant number 945-03-052). The studies described in Chapters 5 and 6 were financially supported by AstraZeneca BV.

Financial support for publication of this thesis by AstraZeneca BV and Caphri Maastricht University is gratefully acknowledged. 


\section{Contents}

Chapter 1 General introduction 1

Chapter 2 Treatment expectations of patients with unexplained 15 dyspepsia with persistent complaints

Chapter 3 Meta-analysis: the diagnostic value of alarm symptoms for upper gastrointestinal malignancy

Chapter 4 Alarm symptoms for gastro-oesophageal malignancy: a 47 meta-analysis using individual patient data

Chapter 5 Measuring the severity of upper gastrointestinal complaints: $\quad 65$ does GP-assessment correspond with patients' selfassessment?

Chapter 6 Which patient related factors determine patient adherence to prescribed dyspepsia medication?

Chapter 7 Pragmatic trials in primary care: methodological challenges and solutions demonstrated by the DIAMOND-study

Chapter 8 Patient adherence to prescribed medication instructions for dyspepsia

Chapter 9 Which patient related factors determine patient adherence to prescribed dyspepsia medication? Results of the DIAMOND-study

Chapter 10 General discussion

Summary and conclusions

Samenvatting en conclusies

Publicaties en presentaties

Dankwoord

Curriculum vitae 



\title{
Chapter 1
}

\section{General introduction}

\author{
Gerdine A.J. Fransen
}

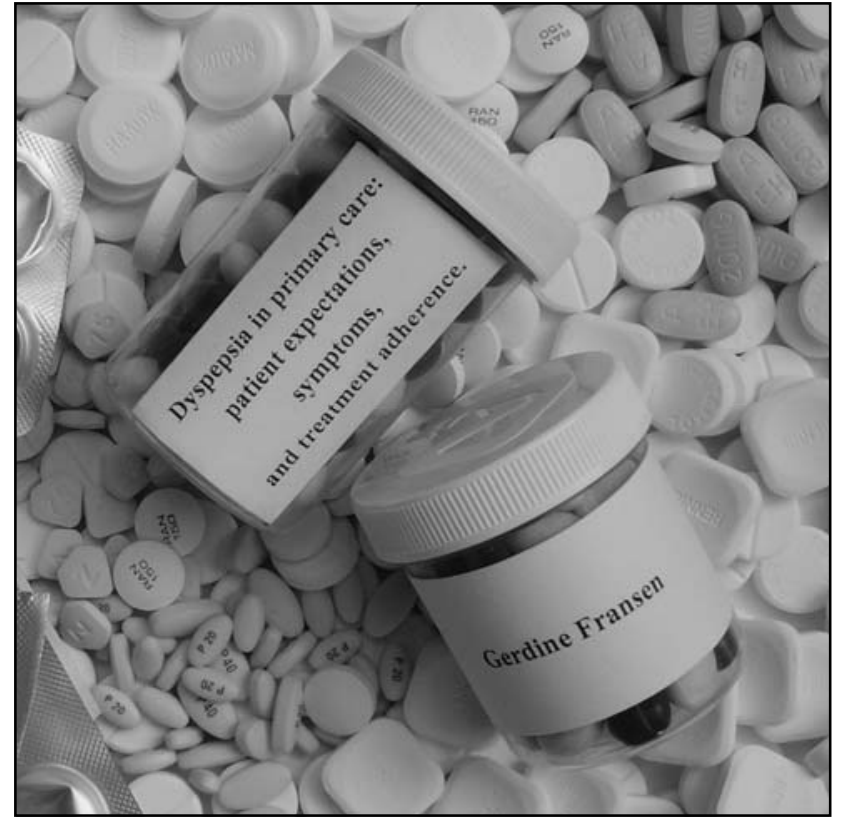


This thesis discusses the management of dyspepsia with a special focus on the patients' perspective and patient adherence. In this chapter, first a background is given on dyspepsia and the management of dyspepsia. Secondly, the research questions are stated and the studies conducted are introduced. As a substantial part of this thesis concerns the investigation of patient adherence to prescribed medication for dyspepsia, the chapter ends by explaining why it is important to investigate patient adherence in the case of dyspepsia and introduces the theoretical psychosocial model used to investigate the predictors of patient adherence.

\section{Dyspepsia and the management of dyspepsia}

The term dyspepsia refers to a cluster of symptoms thought to arise in the upper gastrointestinal tract. ${ }^{1}$ It comprises symptoms such as epigastric pain, regurgitation, heartburn, belching, nausea, vomiting, and early satiety. Dyspepsia is very common; $2-3 \%$ of all consultations in primary care concern dyspeptic complaints. This finding implies that a general practitioner (GP) sees on average four to five patients with dyspepsia a week. ${ }^{2}$ The socio-economic impact of dyspepsia is substantial: in The Netherlands $13 \%$ of the total 2001 medication budget was spent on medication for dyspepsia, more than 400 million euro. ${ }^{3}$

The management of dyspepsia is primarily focused on relieving symptoms, since in most cases no apparent cause for the complaints can be found during diagnostic investigations. ${ }^{2}$ For a new episode of dyspepsia (which means that the patient has been experiencing symptoms for less than 2-3 months, any prior episodes were at least one year ago and no diagnostic investigations were performed ${ }^{2}$ ) medical guidelines $^{2}$ recommend the provision of lifestyle advice and the prescription of short-term treatment with acid-suppressive medication such as antacida, $\mathrm{H}_{2}$-receptor antagonists $\left(\mathrm{H}_{2} \mathrm{RAs}\right)$ or proton pump inhibitors (PPIs). This acid-suppressive medication is often used as a diagnostic aid: if symptom relief is achieved, it is more likely that the complaints are acid related and confirms the diagnosis of dyspepsia; but if the symptoms are not relieved, the diagnosis needs to be reconsidered, and this often results in prolonged treatment with stronger acid-suppressants (PPIs) or referral for further diagnostic (endoscopic) evaluation. Immediate endoscopic investigation is indicated for patients with a high risk of having a serious underlying disease, such as cancer. 


\section{Outline of this thesis}

Although dyspepsia is common and its treatment is expensive in terms of money and GP time, the patient's perspective on dyspepsia and its management is scarcely investigated. It is important to gain an insight into the patients' perspective, because if the consultation or the proposed treatment is at variance with what the patients expect or with what they perceive to be the best way to manage their complaints, it is very unlikely that these patients will be satisfied with the health care provided. The proposed treatment will not be accepted, and non-adherence to the prescribed regimen will probably be the result. Because it is important, therefore, to take into account the patients' perspective since it influences patient satisfaction, patient adherence, and ultimately treatment success, we conducted a focus group study to investigate patients' expectations and perceptions about dyspepsia and its management. This study is described in Chapter two. The results of this qualitative study formed the base for this thesis, since several additional research questions arose as a consequence.

First, based on the results of the focus group study we concluded that patients feared that a serious underlying disease, such as cancer, was causing their symptoms. According to medical guidelines, patients with a higher risk of upper gastrointestinal cancer need to be referred for immediate diagnostic investigation. This risk estimation can be based on the patients' age and on the presence of alarming symptoms, such as weight loss, vomiting, dysphagia, and anaemia. However, the predictive value of these alarming symptoms and age is by no means clear. In Chapter three and Chapter four two review studies are described. These studies aimed to investigate the value of alarm symptoms and age in predicting upper gastrointestinal cancer.

Second, several of the focus group participants felt that their GP did not take the severity of their complaints seriously. This could lead to decreased patient satisfaction and, since the diagnosis of dyspepsia is mostly based on what patients tell their GP, the communication about the severity of the symptoms needs to optimal. In everyday practice, it is important to know whether patient and physician agree on the severity of the complaints, but in research this is also important. In studies concerning dyspepsia, the severity of complaints is often measured by questionnaires completed by either physicians or patients. The results of physician- 
administered questionnaires and patients' self-assessment are often compared as if there were no difference between the two; however, our experiences in the focus group study led us to reconsider whether this was indeed true. Therefore, we conducted a further study to examine the inter-rater agreement between physician and patient concerning the severity of the patient's dyspepsia. This study is described in Chapter five.

Third, medical guidelines advocate empirical treatment for dyspepsia to control the symptoms, but during the focus group interviews patients indicated that they disliked the idea of using medication that did not permanently eliminate their complaints. Disappointing patient adherence rates to medication are confirmed in a couple of studies investigating dyspepsia. ${ }^{4,5}$ In order to improve patient adherence, insight is needed into factors determining patient adherence in the case of dyspepsia. Chapter six reports on a study that aimed to investigate which patient related factors are associated with patient adherence to PPI prescriptions for dyspepsia. In this study, a theoretical framework (Figure 1.1) was used to explain self-perceived adherence.

In a large multi-centre randomized controlled trial in primary care investigating the most effective medical treatment for newly diagnosed dyspepsia, the design of which is described in Chapter seven, patient adherence was also investigated. Chapter eight reports on the degree to which patients implemented the medication instructions. Chapter nine describes which patient related factors are associated with patient adherence to prescribed acid-suppressive treatment for newly diagnosed dyspepsia, again using the theoretical framework (Figure 1.1) described later in this general introduction chapter.

\section{Why is patient adherence to prescribed dyspepsia medication important?}

Treatment effectiveness leading to optimal outcomes in population health is determined jointly by the efficacy of the treatment and the extent of adherence to the treatment. Despite the availability of efficacious interventions, treatment adherence is the single most important modifiable factor that comprises treatment outcome, cost, and effectiveness across therapeutic areas. ${ }^{6}$

This thesis mainly concerns patients with newly diagnosed dyspepsia. As medical guidelines recommend, ${ }^{2}$ medication for newly diagnosed dyspepsia is often used as 
a diagnostic tool. Therefore, the effects of medication need to be properly evaluated to verify whether or not the symptoms are acid related. In this evaluation it is essential to determine patient adherence, especially when the symptoms are not relieved. Treatment failure may be caused by non-adherence. The identification of patient non-adherence as a possible cause of treatment failure may prevent physicians from wrongly assuming that the prescribed medication was not effective, and may lead to a different treatment course. On the other hand, if it is determined that a patient was adherent and the medication was not effective, it may be wiser to switch treatment instead of prolonging it.

For the acid-suppressive medication to be as effective as possible the patient needs to take at least an adequate number of the prescribed pills as well as follow the specific medication instructions concerning timing, dose, frequency and way of intake. For instance, for maximal efficacy a PPI should be taken approximately half an hour before a meal. ${ }^{7}$ The importance of such instructions is supported by a studydemonstrating a significantly better gastric acid control when a PPI was taken 15 minutes before breakfast compared to use at the same time without breakfast. ${ }^{8}$ Some patients may take their PPI at bedtime, again reducing its efficacy by not consuming it prior to a meal. ${ }^{8}$ Many patients may be unaware of the need to take PPIs prior to a meal, because these instructions may not have been properly addressed by physicians or pharmacists. ${ }^{7}$

Non-adherence to prescribed acid-suppressants minimizes the chance of achieving potential treatment success, precludes a proper evaluation of treatment effects (especially in the case of treatment failure), and is associated with a waste of expensive medicines. ${ }^{9}$ Therefore, patient adherence needs to be improved.

\section{Theoretical model to explain patient adherence}

In order to optimize adherence to prescribed acid-suppressants, insight is needed into the determinants of patient adherence. Psychosocial theories may help to provide a theoretical framework to explain patient adherence. Bosworth and Voils ${ }^{10}$ state that further development and integration of theories explaining patient behaviour are needed to improve patient adherence. They conclude that existing psychosocial models, such as the Health Belief Model and the Integrated Change Model (I Change Model), have found wide applicability in health behaviour research but not have received as much attention in adherence research. ${ }^{10}$ Hence, a psycho- 


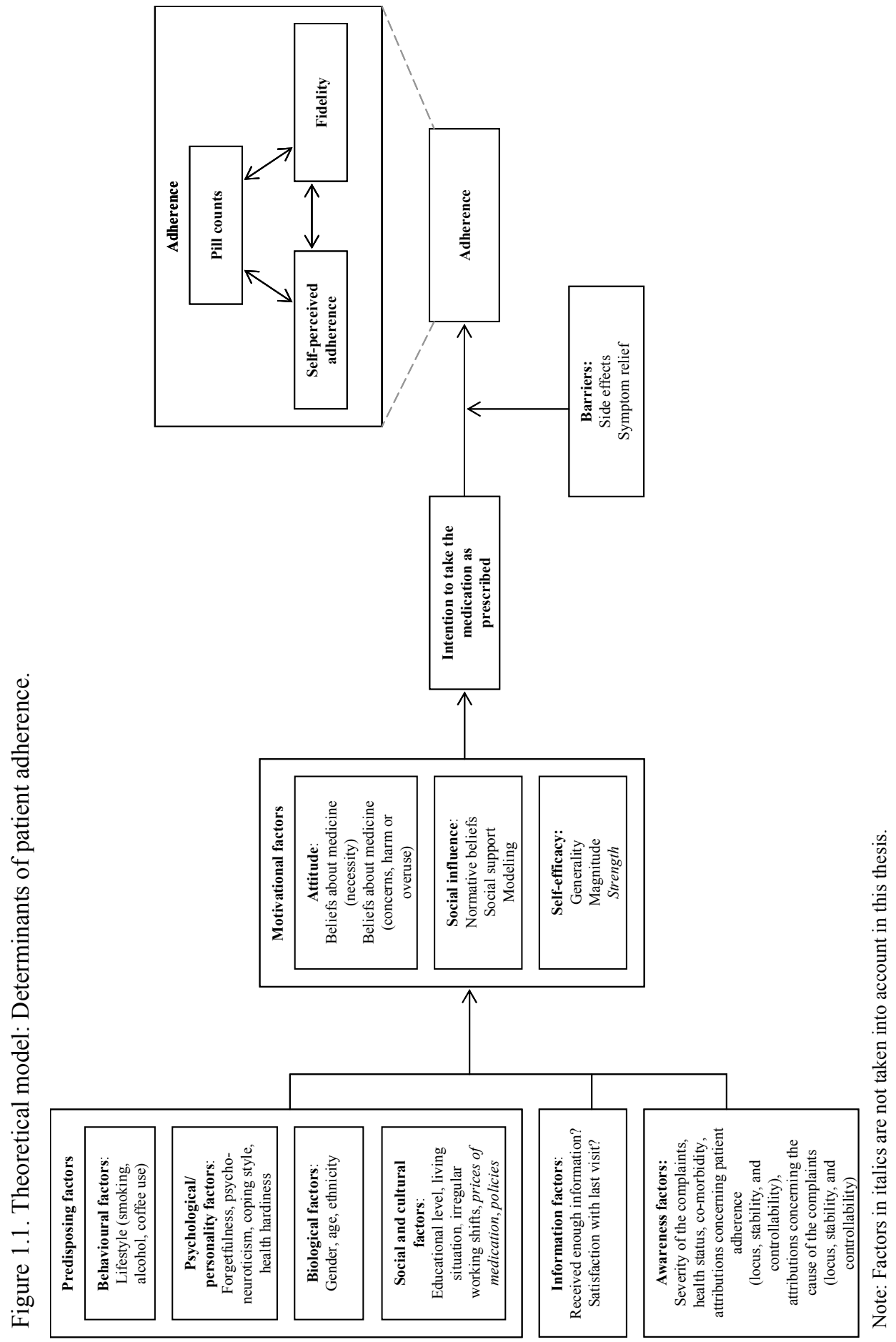


social model that integrates several psychosocial theories and models guided the studies on adherence described in this thesis (Figure 1.1). Patient adherence is influenced by several factors: patient related factors, treatment or disease related factors, physician-related factors, and policy. ${ }^{11}$ Although recognizing the important influence of the physician-patient interaction on patient adherence, this thesis focuses on the patient related factors and their possible association with adherence to acid-suppressive medication for dyspepsia.

\section{Adherence}

A gold standard for measuring adherence does not exist, since it is impossible to observe patients actually taking their medication is impossible. ${ }^{12}$ Several adherence measures are used in practice such as self-report, pill counts, Medication Event Monitoring Systems (MEMS) and pharmacy refills. Electronic monitors can provide information on the timing and frequency of opening the medication jar, on which an estimation of pattern of intake can be based. However, electronic monitors are not widely available and are relatively expensive. Pharmacy refills are often used in the case of chronic diseases, but this measure is not applicable for examining short-term medication adherence for dyspepsia. DiMatteo advocates using multiple adherence measures to get more insight into the reliability and validation of these measures, ${ }^{12}$ since adherence measures do not always result in similar adherent rates. ${ }^{13,14}$ Therefore, in this thesis three different adherence outcome measures were used (Figure 1.1): pill counts and two self-reported measures namely self-perceived adherence and intake fidelity. Pill counts were carried out in two different ways: in one study (described in Chapter six) the GPs reported the number of pills left after treatment, and in two other studies (described in Chapters eight and nine) the patients were asked to return their medication jars and the number of pills left were counted by the researchers. For both ways, the number of pills used per treatment day was calculated. For self-perceived adherence the patients were asked to indicate the degree to which they followed the medication instructions, for intake fidelity patients were asked how they took their medication (number of pills per intake, frequency, timing, and way of intake). The concepts of fidelity and self-perceived adherence both reflect self-reported adherence, but with the important difference that for fidelity the researchers judge degree to which the instructions were followed, whereas for self-perceived adherence the patients themselves make the judgement. The correlation between the adherence outcome measures is investigated in this thesis. 


\section{Intention}

The I Change Model $^{15}$ states that the most proximal determinants of health behaviour are people's goals and intentions. These intentions and cognized goals present people's motivating factors for action. Thus, intentions are assumed to indicate how hard people are willing to try and how much effort they are willing to exert to execute a behaviour. According to this model, intentions are the strongest predictors of actual behaviour: generally, the stronger a person's intention, the higher the probability that the behaviour will be actually performed.

\section{Facilitators and barriers}

When a person has formed an intention to perform a certain behaviour, diverse factors can either promote or hinder its performance. These facilitators and barriers can disturb the intention-behaviour relation. For example, although patients intend to take their medication as prescribed, they may experience side effects and consequently not succeed in being adherent throughout the whole treatment period. Side effects are indicated in several studies to be a reason for non-adherence. ${ }^{11,16,17}$ Furthermore, if patients do not feel rewarded for their adherence, for example because they do not experience symptom relief, they are less likely to continue their medication use. ${ }^{11}$

\section{Motivational factors}

Consequently, according to the I Change Model intention has three interdependent determinants: attitude, social influence and self-efficacy. A person's attitude consists of the perceived cognitive and emotional advantages and disadvantages of the behaviour. This is closely related to the concepts of perceived benefits and perceived barriers from the Health Belief Model. ${ }^{18}$ The Health Belief Model is frequently used in studies on adherence and suggests that patients weight the perceived benefits of an action (e.g., taking medication will reduce the complaints) against the perceived barriers to the action (e.g. experiencing side-effects). There is some evidence that beliefs about benefits and barriers are associated with adherence measures, particularly those self-reported. ${ }^{11}$ In this thesis attitude was measured using the Beliefs about Medicine Questionnaire (BMQ). ${ }^{19}$ The BMQ originally consisted of four constructs: necessity (which can be considered as perceived benefits of medication use), concern, harm, and overuse (which together can be considered as barriers to medication use). 
According to the I Change Model social influence consists of the perceived social norm, which is based upon beliefs about the likelihood that important other people, such as family members or the physician, will approve or disapprove of the patient's adherence behavior, the perception of significant others being adherent (social modelling), and perceived support of significant others in being adherent (social support). The concept of self-efficacy is based on Bandura's Social Cognitive Theory of Self-Regulation. ${ }^{20}$ Bandura suggests that just knowing what to do is not sufficient for one to behave; rather, one must also be confident that one is capable of performing the specific behaviour. In the I Change Model self-efficacy is constructed by three concepts: magnitude, generality and strength. Magnitude assesses the patient's beliefs about the difficulty he/she will experience in being adherent in general. Generality refers to the patient's beliefs about the difficulty he/she will experience in being adherent in specific situations (e.g. at the weekend, during holidays, in the company of others). Strength refers to the patient's beliefs about whether he/she will be able to take the medication according to the instructions.

\section{Distal factors}

Furthermore, the I Change Model assumes that attitude, social influences, and selfefficacy are determined by various distal factors: predisposing factors, information factors and awareness factors. Predisposing factors are divided into lifestyle behavioural factors, psychological or personality factors, biological factors, social and cultural factors. The lifestyle behavioural factors considered in this study were smoking habits, coffee use and alcohol use. These three behaviours were chosen because they may aggravate dyspeptic complaints. It was hypothesized that patients with a healthy lifestyle are also more likely to be adherent.

There is some support for the proposition that psychological or personality factors influence patient adherence. Depression and anxiety are associated with decreased adherence, ${ }^{11,21}$ and how an individual actually copes with his/her disease is likely to be a good predictor of patient adherence. ${ }^{21}$ Furthermore, Meichenbaum and Turk indicate that forgetfulness can decrease adherence. ${ }^{17}$

The biological factors included in this study were patient characteristics such as gender, age and ethnicity. Although no consistent relation with adherence has been found for these factors, ${ }^{17}$ patient characteristics may play a role in patient adherence to dyspepsia medication prescriptions. Maybe elderly patients are more experienced in taking medication and are therefore more likely to be adherent. On the other hand, 
they may have co-morbidities for which they also have to take medicines, and this may decrease adherence. Furthermore, non-Caucasian patients (as non-native Dutch speakers) may have problems understanding the medication instructions, and this again may decrease adherence; or maybe their cultural background influences their attitudes, social influence and self-efficacy and consequently influences their intention and adherence.

Other patient characteristics are described as social and cultural factors in the model. Individuals with low levels of education are more likely to be non-adherent to their medication regimen. ${ }^{22}$ This may be due to a low understanding of medication instructions or may be related to low income and not giving high priority to spending money on medication. The latter, however, may not play a role in this thesis since all treatment medication was either free for patients or reimbursed by health insurance. Policies are not likely either to influence adherence to short-term treatment with acid-suppressants and therefore are not taken into account. Although no consistent relation between adherence and marital status has been found, ${ }^{17}$ social support is indicated to increase adherence. Therefore, living with a partner is hypothesized to be associated with adherence. Furthermore, medication use may be easier when it is part of a daily routine. This daily routine may be problematic when a patient has irregular working hours.

Information factors include whether patients think that they have received enough information about their treatment and their satisfaction with the last consultation. In order to take acid-suppressants according to the instructions, patients need to understand and recall the instructions given. So, it is important that patients feel that they have received sufficient information to be able to be adherent. As dissatisfied patients are more likely to reject recommended treatment, ${ }^{23}$ patients' satisfaction with their last GP consultation was taken into account.

Awareness of the necessity of medication use is assumed to be determined by the severity of the complaints, ${ }^{16}$ health status and the attributions patients make: if they think that their complaints can be controlled and altered by medication, they are more likely to be adherent. The latter is guided by Weiner's attribution theory. ${ }^{24}$ Weiner suggests that the performance of certain behaviour is determined by the perceived success or failure in performing the behaviour in the past or in comparable situations. Three dimensions in attributions are described: locus, stability and controllability. Locus refers to whether a person perceives the success (or failure) as attributable to himself (internal locus) or to others (external locus). Stability concerns the degree to which a person thinks the success or failure can be attributed 
to stable or unstable causes and, for example, whether being adherent can be changed. Controllability refers to the degree to which a person thinks the success or failure can be controlled and, for example, whether being adherent can be controlled. We hypothesize that attributions made concerning adherence and attributions made concerning the cause of the dyspeptic complaints may be associated with patient adherence.

The theoretical framework explained in this chapter will be used in the studies described in Chapters six and nine.

\section{References}

1. Heading RC. Definitions of dyspepsia. Scand J Gastroenterol 1991; 26 (Suppl. 182): 1-6.

2. The Dutch Institute for Healthcare Improvement (CBO), Dutch College of General Practitioners (NHG). Multidisciplairy Guideline Stomachcomplaints (Multidisciplinaire Richtlijn Maagklachten). 2004. Alphen aan den Rijn, Van Zuiden Communications.

3. Health Care Insurance Board (College Voor Zorgverzekeringen). GIPsignal Use of acid-suppressive medication 1996-2001 (GIPsignaal Gebruik van Maagmiddelen 1996-2001). 2002. Amstelveen, Health Care Insurance Board (College Voor Zorgverzekeringen).

4. Krol N, Muris JW, Schattenberg G, Grol R, Wensing M. Use of prescribed and non-prescribed medication for dyspepsia. Scand J Prim Health Care 2004; 22: 163-7.

5. Van Soest EM, Siersema PD, Dieleman JP, Sturkenboom MC, Kuipers EJ. Persistence and adherence to proton pump inhibitors in daily clinical practice. Aliment Pharmacol Ther 2006; 24: 377-85.

6. Sankaranarayanan, J. Drug therapies leading to noncompliant activity. In Patient compliance with medications, issues and opportunities. Edited by Fincham, JE. New York: Pharmaceutical Products Press; 2007.

7. Fass R, Shapiro M, Dekel R, Sewell J. Systematic review: proton-pump inhibitor failure in gastro-oesophageal reflux disease - where next? Aliment Pharmacol Ther 2005; 22: 79-94. 
8. Kuo B, Castell DO. Optimal dosing of omeprazole $40 \mathrm{mg}$ daily: effects on gastric and esophageal $\mathrm{pH}$ and serum gastrin in healthy controls. Am J Gastroenterol 1996; 91: 1532-38.

9. Butler CC, Rollnick S. Compliance. London: Elsevier Limited; 2004.

10. Bosworth HB, Voils CI. Theoretical models to understand treatment adherence. In Patient treatment adherence. Concepts, interventions and measurement. Edited by Bosworth HB, Oddone EZ, Weinberger M. New Jersey: Lauwrence Erlbaum Associates Inc.; 2006.

11. Bosworth HB. Medication treatment adherence. In Patient treatment adherence. Concepts, interventions and measurement. Edited by Bosworth HB, Oddone EZ, Weinberger M. New Jersey: Lauwrence Erlbaum Associates Inc.; 2006.

12. DiMatteo MR. Variations in patients' adherence to medical recommendations: a quantitative review of 50 years of research. Med Care 2004; 42: 200-209.

13. Dunbar J, Dunning EJ, Dwyer K. Compliance measurement with arthritis regimen. Arthritis Care Res 1989; 2: S8-16.

14. Waterhouse DM, Calzone KA, Mele C, Brenner DE. Adherence to oral tamoxifen: a comparison of patient self-report, pill counts, and microelectronic monitoring. J Clin Oncol 1993; 11: 1189-97.

15. Vries H, Mesters I, van de SH, Honing C. The general public's information needs and perceptions regarding hereditary cancer: an application of the Integrated Change Model. Patient Educ Couns 2005; 56: 154-165.

16. Hungin AP, Rubin G, O'Flanagan H. Factors influencing compliance in longterm proton pump inhibitor therapy in general practice. Br J Gen Pract 1999; 49: 463-4.

17. Meichenbaum D, Turk DC. Factors affecting adherence. In Facilitating treatment adherence. A practitioner's guidebook. Edited by Meichenbaum D, Turk DC. New York: Plenum Press; 1987:41-70.

18. Janz NK, Becker MH. The Health Belief Model: a decade later. Health Educ Q 1984; 11: 1-47.

19. Horne R, Weinman J. Patients' beliefs about prescribed medicines and their role in adherence to treatment in chronic physical illness. J Psychosom Res 1999; 47: 555-67.

20. Bandura A. Social cognitive theory of self regulation. Organ Behav Hum Decis Processes 1991; 50: 248-485. 
21. Dunbar J, Schlenk EA, Burke LE. Predictors of patient adherence: patient characteristics. In The handbook of health behavior change. Edited by Schumaker S, McBee WL, Schron E, Ockene J. New York: Springer; 1998.

22. Shulman N, Cutter G, Daugherty R, Sexton M, Pauk G, Taylor MJ et al. Correlates of attendance and compliance in the hypertension detection and follow-up program. Control Clin Trials 1982; 3: 13-27.

23. Wroth TH, Pathman DE. Primary medication adherence in a rural population: the role of the patient-physician relationship and satisfaction with care. J Am Board Fam Med 2006; 19: 478-86.

24. Weiner B: An attributional theory of motivation and emotion. New York: Springer-Verlag Inc; 1986. 
Dyspepsia in primary care: patient expectations, symptoms, and treatment adherence 


\section{Chapter 2}

Treatment expectations of patients with unexplained dyspepsia with persistent complaints

G.A.J. Fransen, I. Mesters, R. Jones, E. Bonten \& J.W.M. Muris

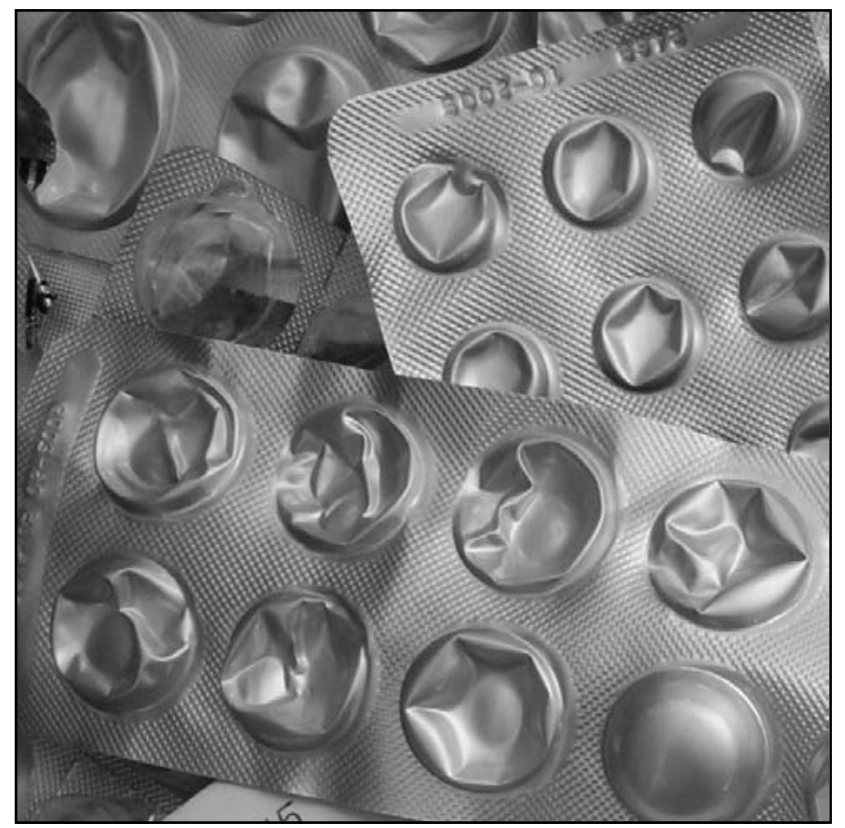




\begin{abstract}
Background: Dyspepsia is very common and in most cases no apparent cause can be found if investigated. Therefore, treatment is focused on symptom suppression. As patients' expectations of health care affect patient satisfaction, adherence and treatment success, it is essential to determine which expectations there are. However, little is known about the expectations of patients with dyspepsia. This study assessed primary care patients' expectations concerning dyspepsia and its management.
\end{abstract}

Patients and methods: 41 Dutch primary care patients with uninvestigated or functional dyspepsia engaged in focus group interviews.

Results: Most participants thought that the most salient cause of their complaints is biological and could be discovered with appropriate investigation. At first participants expected the physician to investigate and find the cause of their complaints and did not accept the long-term empirical treatment provided since it did not permanently cure their complaints and did not identify the believed cause of their complaints. For most patients interviewed, the expectations regarding symptom relief were not fulfilled, resulting in non-adherence and dissatisfaction with treatment, especially among those who felt not being listened to.

Conclusion: The patients' expectations contrast with current medical views advocating empirical treatment and reserving immediate investigation for elderly patients and those with alarm symptoms. To improve the patients' acceptation of empirical treatment, patient satisfaction with health care and adherence to treatment, physicians need to identify and address possible high expectations of investigation and treatment, and explain treatment options and their expected effectiveness clearly. 


\section{Introduction}

The expectations of patients with dyspepsia regarding their treatment have not been extensively studied. ${ }^{1}$ Evidence support the view that consultations are more successful when general practitioners (GPs) elicit, consider and address patients' underlying concerns. ${ }^{2}$ Exploring patients' ideas, fears and expectations is key to patient-centred practice. ${ }^{3}$ Patient-centred practice can lead to an improved health status and an increased efficiency of care by reducing diagnostic tests and referrals. ${ }^{4}$ Insight in patient expectations is important since they affect patient satisfaction, adherence, and treatment success. ${ }^{5,6}$

Dyspepsia is very common: on average a GP sees four patients with dyspepsia per week. ${ }^{7}$ When history taking and medical examination indicate that the problems are related to dyspepsia, Dutch medical guidelines advocate initiating treatment with lifestyle changes and acid-suppressive medication. ${ }^{1}$ Initial treatment is focused on controlling symptoms: if a patient responds well to this treatment, diagnosis based on symptoms and initial treatment only is considered appropriate. ${ }^{8}$ If complaints persist, other medication (e.g. stronger acid-suppressants) can be prescribed or patients can be referred for further investigation, such as upper gastrointestinal endoscopy. However, in most cases further diagnostic investigation does not reveal a cause. ${ }^{9}$ Ultimately, more than two percent of all patients in primary care has persisting or relapsing complaints and has to continue to rely on lifestyle changes and chronic use of acid-suppressants. ${ }^{10}$

This study assessed primary care patients' expectations and perceptions concerning unexplained dyspepsia and its long-term management. We chose to use a qualitative research approach by conducting focus group interviews to provide a first exploration of expectations and perceptions of patients with persistent complaints.

\section{Materials and Methods}

\section{Recruitment}

The local research ethics committee approved the study. Adult, Dutch speaking patients with current complaints of dyspepsia were invited. Participants were recruited by means of advertisements in three local newspapers in the south of the Netherlands, to attract patients who were willing to talk about their dyspepsia and who could provide relevant information. An independent physician determined each patient's eligibility: because of dyspepsia all patients must have visited their GP in 
the last three months prior to the interview and the cause of their dyspepsia had to be unknown, either because this had never been investigated (uninvestigated dyspepsia) or could not be identified during investigations (functional dyspepsia).

\section{Procedures}

Participants were invited to the focus group interview by phone; procedures in general and concerning confidentiality were explained. A structured questionnaire used for descriptive purposes was sent prior to the interview. The questionnaire asked about age, gender, severity of the symptoms (using the Gastrointestinal Symptom Rating Scale (GSRS)), ${ }^{11}$ general health status (using the RAND-36), ${ }^{12}$ anxiety and depression (subscales of the SCL90, ranging from 10=none to $50=$ extremely for anxiety and $16=$ none to $80=$ extremely for depression), ${ }^{13}$ and attributions concerning the cause of their complaints. ${ }^{14}$ The questionnaires could be returned anonymously and free of charge by mail or at the start of the interview. All participants provided written informed consent. The participants formed four groups with an equal distribution of men and women. A moderator (a senior health behaviour scientist) guided the interviews, using predetermined questions to increase validity. ${ }^{15}$ This topic guide was based on literature and developed by a GP/senior scientist and a senior health behaviour scientist; copies of this topic guide are available on request. Besides the moderator, a GP and and an assistant were present during the interviews. The GP helped the moderator to react to disease-related responses of the participants. An assistant took notes and kept an account of the topics that had been covered. These notes were used to give a summary before topic transition, using the iterative method to assess whether the moderator interpreted the findings correctly and check no important findings were missed. The moderator was experienced in conducting focus group interviews, neutral towards the topic, and both the moderator and the GP were not involved in the health care of the patients participating. At the end of each interview participants received a small gift and reimbursement of travel expenses. The group discussions were recorded with the responder's permission and transcribed verbatim.

\section{Data analysis}

At first a preliminary code list was made based on the questions in the interview guide. This code list was further refined throughout the reading, coding and analysing process, supported by $\mathrm{NUD}^{*} \mathrm{IST}^{\circledR} 4.0$ (N4). All quotes were grouped according to the key themes of this code list (Figure 2.1). Two researchers 
independently analysed the data. After categorisation the content was analysed lineby-line to look for trends and patterns that reappeared within either a single or multiple focus groups. In this article the descriptive summaries and interpretations of key themes are presented, supported and illustrated by quotes from the raw data.

Figure 2.1. Coding list.

1. Complaints
a. Physical
b. Duration of complaints
c. Psychological
d. Perceptions

2. Consequences of the complaints
a. Physical
b. Social
c. Psychological

3. Causes of the complaints
a. Physical
b. Genetic predisposition
c. Helicobacter pylori
d. Psychological
e. Lifestyle
I. Stress
II. Eating habits
III. Drinking habits
IV. Smoking
V. Other

4. Solutions

a. Medication use
I. Adverse events
II. Duration of medication use
III. Compliance
IV. Expectations

b. Changing eating habits

c. Changing drinking habits

d. Smoking reduction

e. Acceptation

f. No solutions

$$
\text { I. Fear }
$$

g. Other

5. Expectations towards health care
a. General practitioner
b. Specialist
c. Dietician 


\section{Results}

\section{Population}

Fifty-four participants responded to the advertisement, but 13 did not meet the inclusion criteria or were not able to attend one of the four meetings. The mean age of the participants was 58 years (SD 13, range 30-85) and 51\% was male. According to the questionnaires participants all had mild dyspepsia (Figure 2.2), and a lower general health status than the healthy Dutch population ${ }^{12}$ (Figure 2.3).

Figure 2.2. Severity of the gastrointestinal complaints.

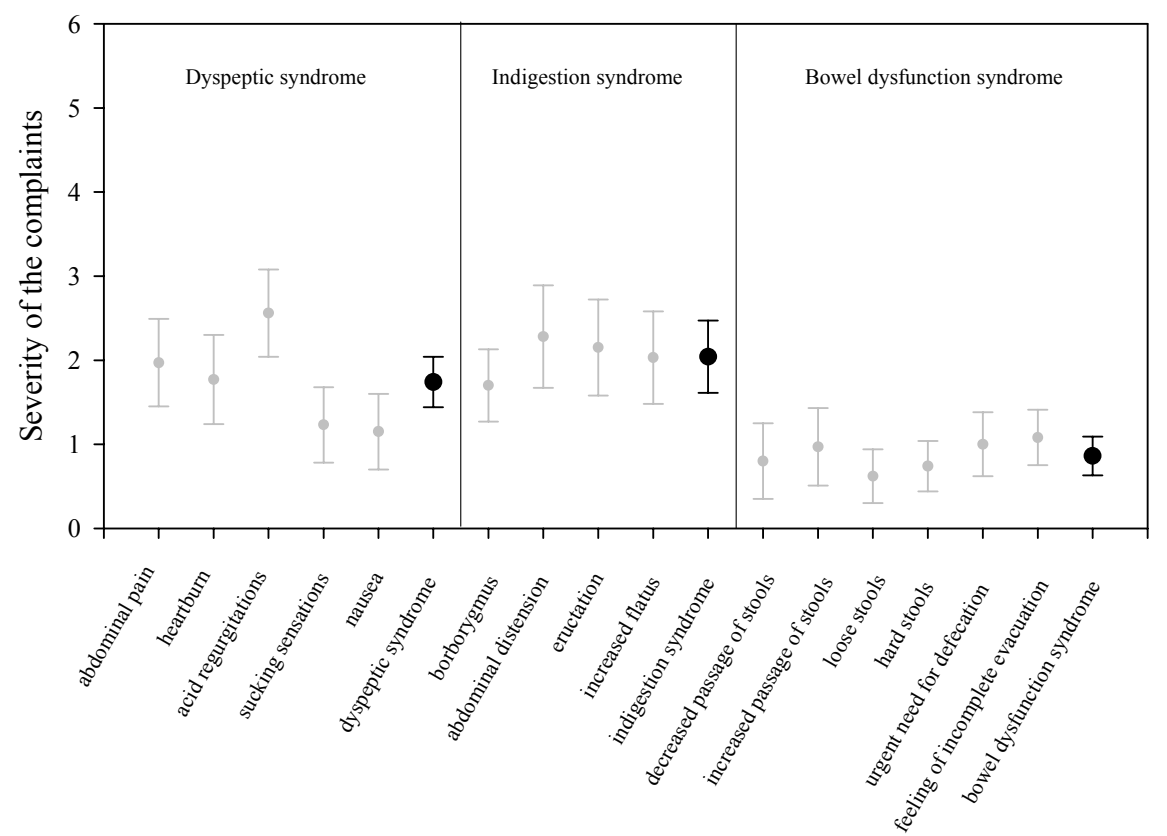

The Gastrointestinal Symptoms Rating Scale was used. Means with 95\% confidence intervals are shown for individual symptoms (in gray) as well as the dimensions (in black). The dimensions Dyspeptic syndrome, Indigestion syndrome and Bowel dysfunction syndrome are the mean scores for the indicated symptoms.

The duration of the complaints varied among participants from a couple of months to more than 20 years. According to the SCL90, participants were more anxious and more depressed than the healthy Dutch population. ${ }^{13}$ the mean anxiety score was 17.9 (SD 7.9, range 10-37) for men and 21.6 (SD 10.3, range 10-44) for women; the mean depression scores was 30.6 (SD 13.7, range 16-63) for men and 34.2 (SD 14.7, 
range 18-80) for women. Most participants attributed their complaints to a physical cause (Figure 2.4). The treatment by the physician was indicated to be the most salient solution to decrease their complaints. Although most participants thought their complaints were related to certain foods or stress, they did not think that solutions such as adjusting their eating habits would be effective.

Figure 2.3. General health status measured with the RAND-36 (means with 95\% confidence intervals).

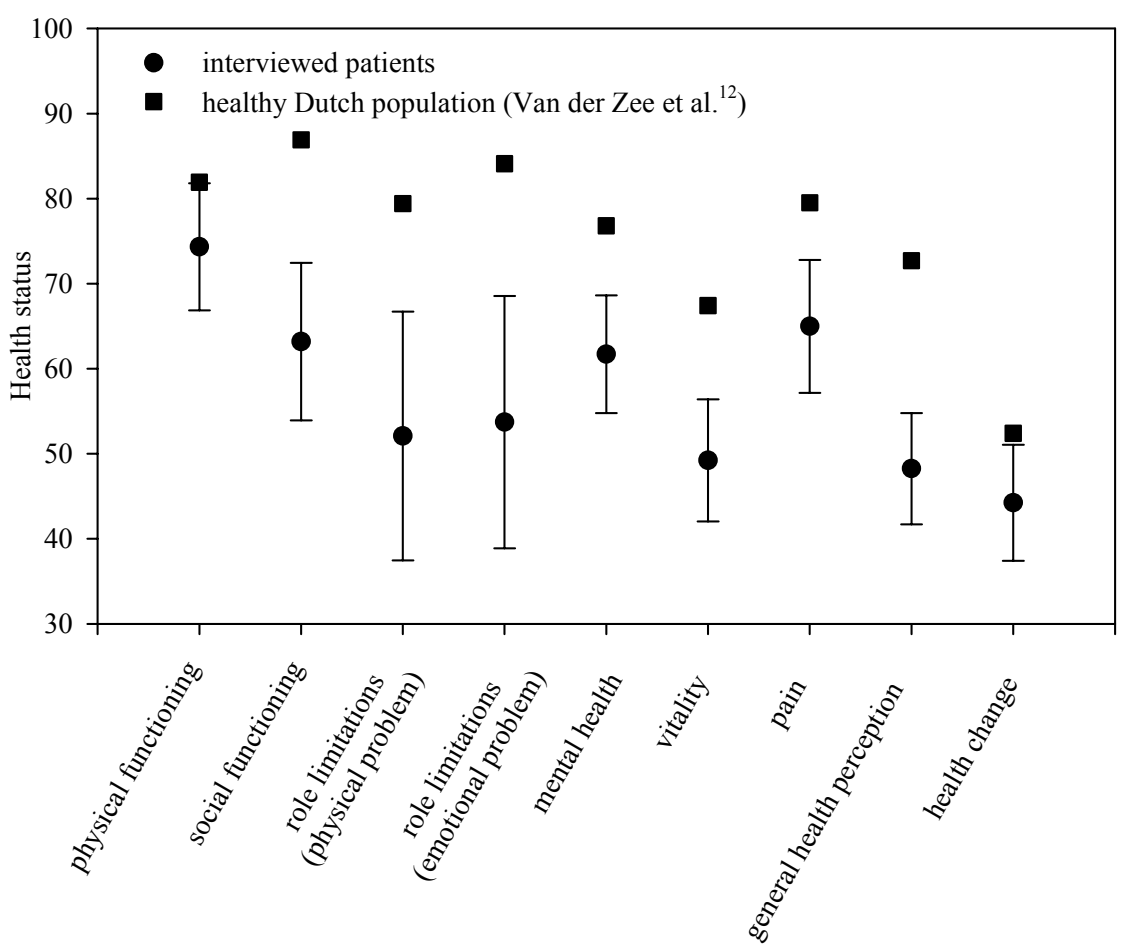


Figure 2.4. Patient attributions regarding the cause of their complaints (means with $95 \%$ confidence intervals).

1. Stomach pain has something to do with my intestines (stomach/gut/bladder).

2. My stomach pain is caused by stress.

3. I am afraid I have cancer.

4. Stomach pain is caused by constipation.

5. My stomach pain is caused by eating certain foods.

6. My stomach pain increases when I menstruate.

7. Stomach pain is common in my family.

8. My complaints will decrease if treated by the physician or specialist.

9. My complaints will decrease if I adjust my eating habits.

10. My complaints will decrease if I adjust my stress coping style.

11. My complaints will decrease if I lower my alcohol use.

12. My complaints will decrease if I stop smoking.

13. My complaints decreased but I can't explain why.

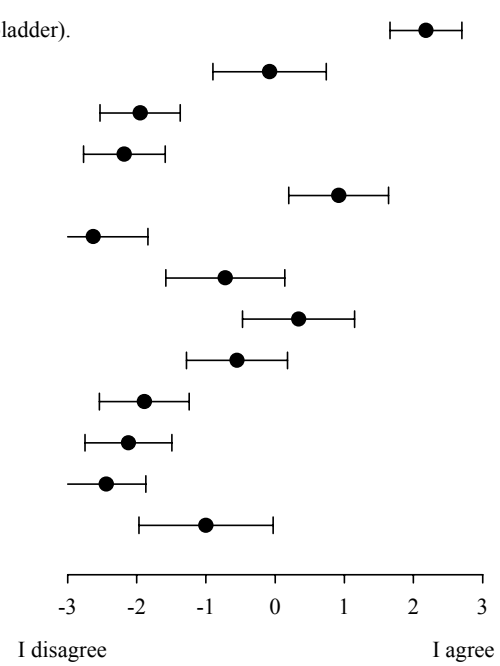

Focus group results

Complaints

The evaluation of the persistence of symptoms differed between participants with a short duration of symptoms and patients with long-lasting symptoms. Participants who had experienced symptoms for a relatively short period believed their complaints would be cured in the near future and often insisted that the GP must cure them:

'You are suffering from your complaints for eight years? I can't understand; I have suffered for one year now, and I don't want to suffer any longer. I want my doctor to do something drastic, so my complaints are permanently solved.'

On the other hand, participants with long-lasting symptoms or family members with similar complaints were less hopeful about the cure-possibilities as one respondent said:

'I'll probably take it with me into my grave.'

Physical cause and fear

Some participants believed that their complaints were caused by hiatal hernia, irritable bowel syndrome, or a disturbance in the functioning of the gastric mucosa. One participant mentioned kidney stones and another stated a disorder of the gall 
bladder. Most of them were frustrated or unsatisfied, because they believed that these causes were not treated or because they thought these possible causes had not been attended to:

'Then they looked into my stomach and there appeared to be a hiatal hernia, but they thought it was not serious enough to operate. I do have medication, but it is not effective. Still, I have to take it everyday.'

Most participants believed that their complaints had physical causes, which should be found during thorough diagnostic investigations. They felt misunderstood and not taken seriously. The fear of cancer or overlooking the physical cause was present:

'At a certain moment I became anxious because the pain worsened and I felt some sort of knob and I worried what that could mean. Not directly cancer, no, but I thought there was something wrong.'

Another participant said:

'I am afraid I have cancer. I often think that.'

In general, each focus group contained a number of patients who wanted to be referred for further investigations (especially the ones who had never been referred), a small number of patients were reluctant to be referred fearing unpleasant investigations, and other patients declined further investigation since previous hospital investigation did not present a solution.

Helicobacter pylori

The possibility that $H$. pylori could cause complaints appeared to be of great interest among some participants. This might be explained by several recent publications in popular media on H. pylori or increased awareness among GPs. The participants had many questions concerning 'how do you know that you have it?' or 'do symptoms really disappear after treatment for $H$. pylori?' Although several participants had heard of this bacterium, only a few had consulted their GP to test for this infection. This might be explained by the patients' expectations that they again would not be taken seriously, or because they expected the infection would be determined by endoscopic examination, which they feared. Some participants mentioned experiencing adverse events of $H$ pylori eradication:

'When the seven days with antibiotics for Helicobacter pylori were over, I thought I was going to die, I lost a lot of weight because of the antibiotics.'

This kind of observed stories may prevent other patients from requesting similar treatments. 


\section{Medication}

Medication often relieved the complaints:

'I am glad there is a medicine that decreases my complaints, this medicine makes me feel human again; less pain, no more nausea.'

Another participant stated:

'I use Losec ${ }^{\circledR}$ and I can't cope without it.'

However, most participants indicated that they were not satisfied with their medication, because it did not resolve their complaints or because the complaints returned when they stopped taking the medication. For example, two participants discussed:

'... my first prescription, 24 pills, and you feel fine, you can do everything you want to do. But then you run out of pills and the complaints return. So I don't want these pills, I want a permanent solution for my stomach, it disappoints me.' 'Yes, the moment you stop, it doesn't work anymore and the symptoms return.'

Participants clearly stated a preference for medication that cures their dyspepsia instead of just suppressing the symptoms:

'These pills are makeshift solutions' and 'I had the idea that medication was the solution, but that appeared to be wrong. It is not a medicine or cure, because it doesn't cure!'

Furthermore, participants disliked the idea of chronic medication use:

'The idea that I have to take this medicine daily for the rest of my life, something chemical that must be piling up somewhere in my body. This idea causes some kind of aversion against medication use for me.'

One participant argued:

'If you use medication continuously, I can imagine it can have fatal consequences, because it disrupts your balance.'

Some participants stated that they used the medication exactly as prescribed, but most of them took their medication 'on demand', as one participant stated:

'When I don't have complaints I don't want to use medication.'

Evidently, several participants stopped with their medication because the medication did not help. Whether discontinuation or on demand use was discussed with their physician was not clear.

Adverse events were mentioned by several participants, some claimed to 'be unable to bear any medication', others mentioned that all the adverse events described on the package worried them. 
Psychological causes

Participants discussed whether feelings of anxiety, fatigue or depression were the cause or the consequence of the complaints. One participant said:

'I can accept the idea of mental problems causing my stomach complaints, but I can not accept it when it is the other way around. Imagine that there is a physical cause in spite my frequent visits to the physician. Then I would say: why didn't they find that?'

Lifestyle changes

Most participants tried a lot of different lifestyle adjustments to decrease their complaints, and some were at least temporarily successful. Participants stated that they did not receive much information about lifestyle changes from health care providers and 'figured it out themselves', which could easily lead to misconceptions (Table 2.1).

Expectations and satisfaction regarding provided health care GPs were expected to investigate the cause of patients' complaints:

'When I first came to the physician with stomach complaints, I immediately received Losec $\AA$. I believe he should have looked for the cause, but he prescribed me something to suppress the pain. The whole process is not aimed at finding the cause. He has only fifteen minutes to help you and then you can go home.'

Many participants felt that they had not been properly examined and that the real cause of the disease was overlooked but could have been found by thorough investigation:

'They don't look far enough.'

Some participants even had the idea that 'GPs delay referral to the specialist because they can not admit that they have failed'. 
Table 2.1. Lifestyle and lifestyle changes.

\begin{tabular}{ll}
\hline Subject & Examples and citations \\
\hline Stress & 'I can eat and drink everything, but the minute I am \\
\hline Association with & stressed, and that barrier is very low, my complaints \\
increased complaints & 'I noticed that when I am worried, I easily get \\
& complaints.' \\
'I believe that my complaints have nothing to do with \\
No association with & stress, because when I am stressed I get a headache or \\
complaints & pain in my bowel, not in my stomach...' \\
& 'Who said it is stress? I don't work anymore, I have a \\
& good life with my wife alone, and I still have \\
complaints. So it is not stress in my case, but what \\
then? I don't know.' \\
'Try to relax and be occupied. I try to swim, walk and \\
cycle; do as much relaxing things as possible. And \\
Stress reduction: \\
relaxation, yoga, or going \\
for a walk after diner was \\
in some cases successful my mind, try to think of other things beside my \\
complaints... Yes I believe that's effective.' \\
'For years it helped to lie on the floor and relax .... \\
But that was years ago and it does not work anymore.'
\end{tabular}

\section{Eating habits}

Association with increased complaints

The products believed to cause the symptoms were personal and varied from incident to incident, which was very difficult to cope with

Eating habits were based on personal beliefs about what causes the complaints, which could easily lead to misconceptions
Common triggers mentioned were: red pepper, onion, young cheese, vegetables such as cauliflower or green cabbage, chips, peanuts, chocolate and oranges.

'It is a gamble, one day I eat chips and it goes well, the other day I eat it and I have symptoms.'

'My diet? I figured it out myself. I cannot eat meat because meat provokes my stomach pain. So my diet includes: a lot of fish, raw or baked doesn't matter as long as it is fish, easily digestible food, such as rice or salads, and, of course, not to much herbs.' 
Table 2.1. Lifestyle and lifestyle changes (continued).

\begin{tabular}{|c|c|}
\hline Subject & Examples and citations \\
\hline \multicolumn{2}{|l|}{ Drinking habits } \\
\hline $\begin{array}{l}\text { Association with } \\
\text { increased symptoms } \\
\text { Similar to eating habits } \\
\text { very personal and } \\
\text { unpredictable for the } \\
\text { participants. Participants } \\
\text { tried a lot of different } \\
\text { things to decrease their } \\
\text { complaints }\end{array}$ & $\begin{array}{l}\text { Common triggers mentioned were: coffee, wine, beer } \\
\text { and milk. } \\
\text { 'I have too little gastric acid and when I notice that } \\
\text { my digestion stops because of a lack of stomach acid, } \\
\text { I have to drink a little bit of orange juice, very } \\
\text { carefully. ... And water also works. Water is not only } \\
\text { good for the fish, but also for dyspeptic patients!' } \\
\text { 'When my complaints are very severe, I take some } \\
\text { bamboo coffee with milk.' } \\
\text { 'White wine causes complaints, but red wine does } \\
\text { not.' }\end{array}$ \\
\hline \multicolumn{2}{|l|}{ Smoking } \\
\hline $\begin{array}{l}\text { Most participants saw no } \\
\text { association with the } \\
\text { complaints }\end{array}$ & $\begin{array}{l}\text { 'I stopped smoking } 14 \text { years ago, before that, I } \\
\text { suffered from heartburn. And afterwards I still had } \\
\text { heartburn, so smoking does not make a difference.' }\end{array}$ \\
\hline \multicolumn{2}{|l|}{ Other solutions } \\
\hline $\begin{array}{l}\text { Several participants } \\
\text { searched for solutions on } \\
\text { their own initiative, } \\
\text { mostly because they were } \\
\text { unsatisfied with their } \\
\text { treatment }\end{array}$ & $\begin{array}{l}\text { 'You have to figure it out yourself.' } \\
\text { Alternative treatments such as acupressure, } \\
\text { acupuncture or homoeopathy. } \\
\text { Some participants indicated that these solutions were } \\
\text { at least temporarily helpful; others did not feel any } \\
\text { relief. }\end{array}$ \\
\hline
\end{tabular}

Some participants felt that their problems did not receive enough attention, and GPs prescribed medication too soon and too often:

$$
\text { 'He just prescribed me something to get rid of me'. }
$$

On the contrary, other participants were satisfied with their GP because they believed that their GP tried to help them as much as possible, but nothing could be done:

'I have greatly appreciated that he listened to me. That he can't help me is not his fault.'

Some participants hesitated to consult their GP again for the same complaints because they believed that their GP was not receptive for their complaints or did not know the solution either.

In spite of the wish to be referred to a specialist and to find the cause, the investigations were often anticipated as troublesome and painful. Some even refused 
investigations such as endoscopy. Furthermore, several referred participants were disappointed that the specialist could not find a cause either.

\section{Discussion}

This study showed that most participants felt that the most salient cause of their complaints is biological and would be discovered with appropriate investigation. At first participants expected the physician to investigate and find the cause of their complaints and did not accept the long-term empirical

\section{Key points}

Treatment of dyspepsia is primarily aimed on symptom suppression. As discrepant patient expectations as opposed to medical views largely influence patient satisfaction and adherence, it is essential to determine these patients' expectations concerning the treatment of dyspepsia.

- The participants expected the treatment to be aimed at identifying and resolving the believed cause of their complaints.

- $\quad$ For most patients interviewed, the expectations regarding symptom relief were not fulfilled, resulting in non-adherence and dissatisfaction with treatment.

- The long-term empirical treatment provided was not accepted since it did not permanently cure their complaints, especially among those who felt not being listened to.

treatment provided since it did not permanently cure their complaints and did not identify the believed cause of their complaints. For most patients interviewed, the expectations regarding symptom relief were not fulfilled, resulting in non-adherence and dissatisfaction with treatment, especially among those who felt not being listened to.

Interesting is that, despite the need to find a cause, it should be noted that some patients felt ambivalent towards medical investigations because they feared that investigations might be aggravating and painful, and some even refused endoscopy. This is confirmed by other studies. ${ }^{16,17}$ For example Seinela et al. ${ }^{17}$ showed that although elderly patients preferred a proper examination and treatment, they regarded endoscopy as very unpleasant.

Although to our knowledge no research has been done in this area, the results presented here may not be surprising and may even seem logical. Nevertheless, our results indicate the presence of an important problem in health care. Discrepant patient expectations as opposed to medical views largely influence patient satisfaction and adherence, which can affect treatment success, costs and quality of health care. ${ }^{5,6}$ Recent guidelines advocate empirical treatment, reserving immediate investigation only for elderly patients and patients with alarming symptoms. ${ }^{1,18}$ 
Empirical treatment with acid-suppressants is based on the fact that in most cases no apparent cause is found after further diagnostic investigation. ${ }^{8,9}$ Even if a cause is found, this often is acid-related and, therefore, can be treated with acid-suppressants. Nevertheless, one cannot get around patients' views when the aim is to achieve treatment adherence, since patients in this study clearly show the negative impact of feeling not being taken seriously.

To increase concordance in expectations between dyspeptic patient and care provider, physicians need to address the patient's health-related beliefs ${ }^{19}$ and need to explain in a clear way what the causes of dyspepsia can be, what the available possibilities for investigations and treatment are, and what patients can expect from investigations or treatment. Maybe the method of patient empowerment can be a useful tool for physicians since this method is based on the idea that when a patient feels more in control of a situation (e.g. his treatment or symptoms) this improves patient adherence and satisfaction. ${ }^{20}$ One way to empower patients is to discuss possible causes and possible treatment strategies with the patient and let the patient choose. Additionally, physicians can emphasize that they rely in their advice on the patient's evaluation of the treatment. Therefore, it is very important that the patient closely monitors his/her complaints during treatment. In that way a patient feels more in control because his evaluation influences possible follow-up treatment.

Our study has some limitations that need to be considered. The group of participants was small although comparable to other focus group studies, ${ }^{21,22}$ and the fourth interview did not reveal any new insights, indicating saturation. It is possible that several opinions of participants were reinforced by the group discussion, which might cause participants to seem more dissatisfied than they really were. However, we did not get this impression, because, although some recognized their story in others, all participants merely wanted to tell their story. Several participants did not complain about their GPs and even thought very highly of their GPs because they listened to them.

Recruitment via an advertisement is a very popular way to recruit participants for focus group interviews. However, advertisements may attract the more assertive or more unsatisfied patients. Therefore, these results cannot be simply generalised to all dyspeptic patients. However, the characteristics of the participants indicate some representativeness of the sample. The GSRS-scores showed that the participants had on average mild dyspepsia, which is comparable to patients with functional dyspepsia during treatment. ${ }^{23,24}$ The health status of participants was slightly worse but comparable to $H$. pylori positive functional dyspeptic patients from Finland. ${ }^{25}$ 
The results of the interviews indicated that participants were anxious and slightly depressed ('don't feel up to anything'), which is confirmed by the results of the SCL90. So, even if the participants may not be representative for all dyspeptic patients, they are comparable to participants in other (quantitative) studies regarding the severity of their complaints and regarding their health status.

Furthermore, other research conducted in this area confirms our findings. A quantitative study by Krol et al. ${ }^{26}$ of patients with upper gastrointestinal symptoms showed similarly high expectations for prescribed medication. Delaney ${ }^{16}$ showed that the perceived threat of cancer and the need for reassurance were key influences to consult physicians. Moreover, the expectations of our participants were comparable with the expectations of patients with irritable bowel syndrome, also a functional gastrointestinal disorder. Most IBS-patients found it hard to accept that their symptoms could not be explained by science and expected to be treated effectively, ${ }^{27}$ they expected reassurance and diagnostic work-up. ${ }^{28}$

We conclude that our study provides a first description of the expectations of patients with unexplained dyspepsia. To improve the patients' acceptation of empirical treatment, patient satisfaction with health care and adherence to treatment, physicians need to identify and discuss expectations of investigation and treatment and explain treatment options and their expected effectiveness clearly.

\section{References}

1. The Dutch Institute for Healthcare Improvement (CBO), Dutch College of General Practitioners (NHG). Multidisciplinaire Richtlijn Maagklachten (Multidisciplinairy Guideline Stomach complaints). Alphen aan den Rijn: Van Zuiden Communications; 2004.

2. Stewart M, Brown JB, Weston WW, McWhinney IR, McWilliam CL, Freeman TR. Patient-centered Medicine: Transfoming the Clinical Method. Thousand Oaks, CA: Sage Publications; 1995.

3. Dowell J, Jones A, Snadden D. Exploring medication use to seek concordance with 'non-adherent' patients: a qualitative study. Br J Gen Pract 2002; 52: 24-32.

4. Stewart M, Brown JB, Donner A, McWhinney IR, Oates J, Weston WW, et al. The impact of patient-centered care on outcomes. J Fam Pract 2000; 49: 796804.

5. Kravitz RL, Cope DW, Bhrany V, Leake B. Internal medicine patients' expectations for care during office visits. J Gen Intern Med 1994; 9: 75-81. 
6. Rao JK, Weinberger M, Kroenke K. Visit-specific expectations and patientcentered outcomes: a literature review. Arch Fam Med 2000; 9: 1148-55.

7. Van Bommel MJ, Numans ME, de Wit NJ, Stalman WA. Consultations and referrals for dyspepsia in general practice - a one year database survey. Postgrad Med J 2001; 77: 514-8.

8. Jones R. Gastro-oesophageal reflux disease: a re-appraisal. Br J Gen Pract 2006; 56: $739-40$.

9. Heikkinen M, Farkkila M. Long-term outcome of functional dyspepsia: effect of Helicobacter pylori infection. A 6- to 7-year follow-up study. Scand J Gastroenterol 2002; 37: 905-10.

10. Majumdar SR, Soumerai SB, Farraye FA, Lee M, Kemp JA, Henning JM, et al. Chronic acid-related disorders are common and underinvestigated. Am J Gastroenterol 2003; 98: 2409-14.

11. Svedlund J, Sjodin I, Dotevall G. GSRS - a clinical rating scale for gastrointestinal symptoms in patients with irritable bowel syndrome and peptic ulcer disease. Dig Dis Sci 1988; 33: 129-34.

12. Van Der Zee KI, Sanderman R. Het meten van de algemene gezondheidstoestand met de RAND-36. Een handleiding (Measuring the general health status with the RAND-36. A guideline). Groningen: Noordelijk Centrum van Gezondheidsvraagstukken; 1993.

13. Arrindell WA, Ettema JHM. SCL-90: handleiding bij een multidimensionele psychopathologie-indicator (SCL-90: manual for a multidimensional psychopathologic indicator). Lisse: Swets Test Service; 1986.

14. Van der Horst HE, van Dulmen AM, Schellevis FG, van Eijk JT, Fennis JF, Bleijenberg G. Do patients with irritable bowel syndrome in primary care really differ from outpatients with irritable bowel syndrome? Gut 1997; 41: 669-74.

15. Van Assema P, Mesters I, Kok G. Het focusgroep-interview: een stappenplan (The focus group interview: stepwise guidelines). T Soc Gezondheidsz 1992; 70: 431-7.

16. Delaney BC. Why do dyspeptic patients over the age of 50 consult their general practitioner? A qualitative investigation of health beliefs relating to dyspepsia. Br J Gen Pract 1998; 48: 1481-5.

17. Seinela L, Ahvenainen J, Rintala J. Attitudes of elderly patients to examinations and treatments of gastrointestinal symptoms. Scand J Gastroenterol 2002; 37: $1471-2$. 
18. Malfertheiner P, Megraud F, O'Morain C, Bell D, Bianchi PG, Deltenre M, et al. Current European concepts in the management of Helicobacter pylori infection - the Maastricht Consensus Report. The European Helicobacter pylori Study Group (EHPSG). Eur J Gastroenterol Hepatol 1997; 9: 1-2.

19. Jones R. Nonulcer dyspepsia: great expectations? Am J Gastroenterol 1996; 91: 628-9.

20. Grol R. Improving the quality of medical care: building bridges among professional pride, payer profit, and patient satisfaction. JAMA 2001 28; 286: 2578-85.

21. Beaulieu MD, Dory V, Pestiaux D, Pouchain D, Gay B, Rocher G, et al. General practice as seen through the eyes of general practice trainees: A qualitative study. Scand J Prim Health Care 2006; 24: 174-80.

22. Slettbakk R, Vaksdal NC, Malterud K. Coping with headache. Scand J Prim Health Care 2006; 24: 22-6.

23. Farkkila M, Sarna S, Valtonen V, Sipponen P. Does the 'test-and-treat' strategy work in primary health care for management of uninvestigated dyspepsia? A prospective two-year follow-up study of 1552 patients. Scand J Gastroenterol 2004; 39: 327-35.

24. Meineche-Schmidt V, Talley NJ, Pap A, Kordecki H, Schmid V, Ohlsson L, et al. Impact of functional dyspepsia on quality of life and health care consumption after cessation of antisecretory treatment. A multicentre 3-month follow-up study. Scand J Gastroenterol 1999; 34: 566-74.

25. Koskenpato J, Farkkila M, Sipponen P. Helicobacter pylori eradication and standardized 3-month omeprazole therapy in functional dyspepsia. Am J Gastroenterol 2001; 96: 2866-72.

26. Krol N, Muris JW, Schattenberg G, Grol R, Wensing M. Use of prescribed and non-prescribed medication for dyspepsia. Scand J Prim Health Care 2004; 22: 163-7.

27. Dixon-Woods M, Critchley S. Medical and lay views of irritable bowel syndrome. Fam Pract 2000; 17: 108-13.

28. Bijkerk CJ, de Wit NJ, Stalman WA, Knottnerus JA, Hoes AW, Muris JW. Irritable bowel syndrome in primary care: the patients' and doctors' views on symptoms, etiology and management. Can J Gastroenterol 2003; 17: 363-8. 


\section{Chapter 3}

Meta-analysis: the diagnostic value of alarm symptoms for upper gastrointestinal malignancy

G.A.J. Fransen, M.J.R. Janssen, J.W.M. Muris, R.J.F. Laheij \& J.B.M.J. Jansen

Aliment Pharmacol Ther 2004; 20: 1045-52.

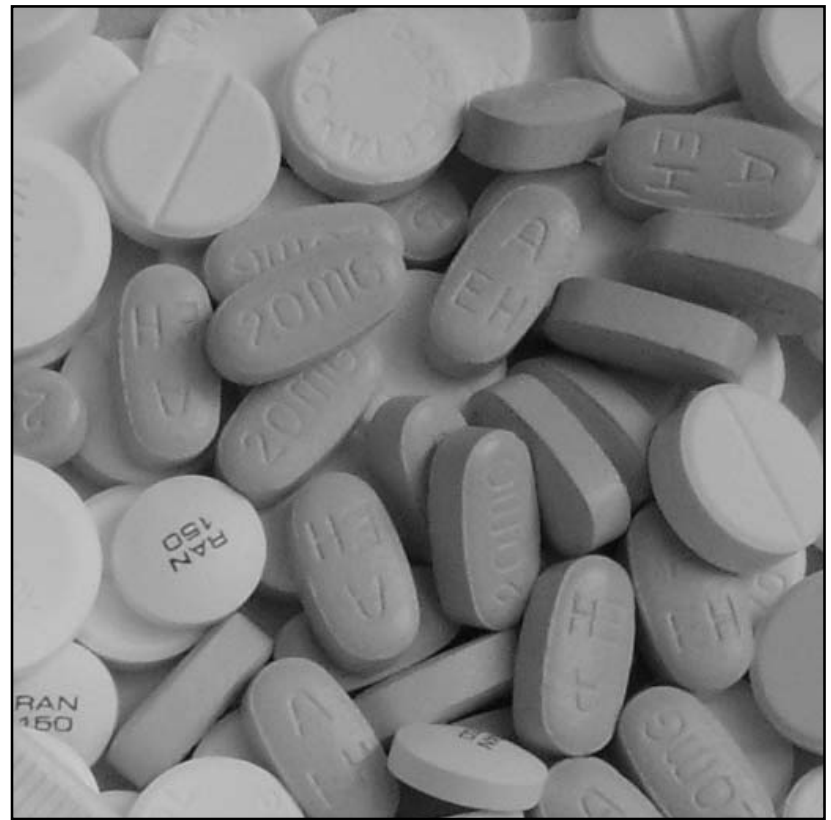




\begin{abstract}
Background: With the advent of empirical treatment strategies for patients with dyspeptic symptoms, it becomes increasingly important to select patients with a high risk of having cancer for immediate endoscopy. Usually alarming symptoms are used for this matter, but their diagnostic value is by no means clear.

Aim: To investigate the diagnostic value of alarm symptoms for upper gastrointestinal malignancy.

Methods: Meta-analysis of studies describing prevalence of alarm symptoms in patients with and without endoscopically verified upper gastrointestinal malignancy were identified through a Medline search. The prevalence, pooled sensitivity, specificity, positive and negative predictive values were calculated.

Results: About 17 case studies and nine cohort studies were selected. The mean prevalence of gastrointestinal malignancies in the cohort studies was $2.8 \%$ of 16161 patients. Five cohort studies indicated that $25 \%$ of the patients diagnosed with upper gastrointestinal malignancy had no alarm symptoms. The pooled sensitivities of individual alarm symptoms varied from 9 to $41 \%$, the pooled positive predictive value ranged from 4.6 to $7.9 \%$, and was $5.9 \%$ for 'having any alarm symptom'. The pooled negative predictive value was $99.4 \%$ for 'having any alarm symptom'.

Conclusion: The risk of upper gastrointestinal malignancy in any individual without alarm symptoms is very low, but approximately one in four patients with upper gastrointestinal cancer have no alarm symptoms at the time of diagnosis.
\end{abstract}




\section{Introduction}

With the advent of empirical treatment strategies (like Helicobacter pylori test-andtreat or acid-suppressive therapy) for patients with dyspeptic symptoms, fewer patients have upper gastrointestinal (GI) endoscopy. ${ }^{1-3}$

However, it is important not to delay diagnosis in patients with underlying malignant disease. Therefore, it becomes increasingly important to select patients with a high risk of having cancer for immediate endoscopy in order to safely treat the remaining patients empirically. On the contrary, this selection should be specific in order to prevent large number of people having unnecessary endoscopy, which is costly and troublesome to the patients. Usually alarm symptoms such as weight loss, dysphagia, nausea, vomiting and anaemia or bleeding are used for this matter. ${ }^{4-6}$ However, although generally accepted, the diagnostic value of alarm symptoms is by no means clear, in spite of the amount of research conducted in this area.

Recently Boldys et al. ${ }^{7}$ concluded that weight loss and melaena are certainly indices of more advanced cancer, and in order to diagnose gastric cancer at an early stage the occurrence of these symptoms should not be awaited. On the contrary, Meineche-Schmidt and Jørgensen ${ }^{8}$ did not find a higher risk of cancer in patients with alarm symptoms in a large cohort comprising more than 600 patients. A difficulty in the identification of factors related to diagnosis of upper GI malignancies is the low incidence of these cancers. As a result, large cohorts need to be studied, which often is not feasible. This problem may be overcome by performing meta-analysis. The aim of this study was to evaluate the diagnostic value of alarm symptoms for upper GI malignancy by means of a meta-analysis.

\section{Methods}

Identification and selection of publications

A literature search was performed in August 2003. Relevant publications were identified in Medline using key words such as 'alarm', 'sinister', 'dyspepsia' and 'gastrointestinal malignancy'. Furthermore, additional publications were retrieved by reviewing references of selected studies. In order to be selected, publications had to fulfil the following criteria: (i) the presence or absence of upper GI malignancy was established endoscopically, and (ii) the number of patients and prevalence of alarm symptoms in patients with and without upper GI malignancy were described or could be calculated. To minimize selection bias all abstracts were assessed by two 
independent reviewers; in case of a difference of opinion a third independent reviewer was consulted.

\section{Data analysis and statistical methods}

Literature search showed two types of studies eligible for inclusion: cohort studies and case studies. Cohort studies included patients with and without upper GI malignancy and measured the alarm symptoms prospectively (i.e. before endoscopic examination), while case studies included only patients with confirmed gastric or oesophageal malignancy. Sensitivity was calculated for cohort studies and case studies separately, by pooling the results of the individual studies using an approximation to the inverse variance approach. ${ }^{9}$ The estimate of the overall sensitivity is the sum of all true positives divided by the sum of all patients with upper GI cancer in the pooled studies. Additionally, for the cohort studies, overall specificity, and overall positive/negative predictive values (PPV/NPV) were calculated similarly. Analyses were performed for individual alarm symptoms separately (dysphagia, weight loss, bleeding, anaemia, nausea/vomiting) and, whenever possible, for having 'any alarm symptom' (vs. no alarm symptoms at all). Missing values were excluded from analyses.

\section{Results}

Literature search identified 305 papers. After initial review, 39 papers were retrieved to be studied in detail. Of these papers, 13 were excluded because either the prevalence of alarm symptoms or malignancy was not clearly described or because not all patients underwent upper GI endoscopy. The remaining 26 publications, 17 case studies and nine cohort studies, were included in analyses.

The case studies described 1552 patients with upper GI malignancy (Table 3.1a), mostly identified through retrospective review of hospital records. The pooled sensitivities for the individual alarm symptoms (dysphagia, anaemia/bleeding, nausea/vomiting and weight loss) were respectively $30 \%, 27 \%, 21 \%$, and $41 \%$ (Table 3.2).

When looking at having 'any alarm symptom' the pooled sensitivity was $95 \%$.

Overall 10 case studies described $63(6 \%)$ patients diagnosed with upper GI malignancy without any alarm symptom. In the cohort studies, a total of 16161 patients were described with a mean prevalence of upper GI malignancy of $2.8 \%$ (Table 3.1b). Most of the studies described patients referred for endoscopy by the 


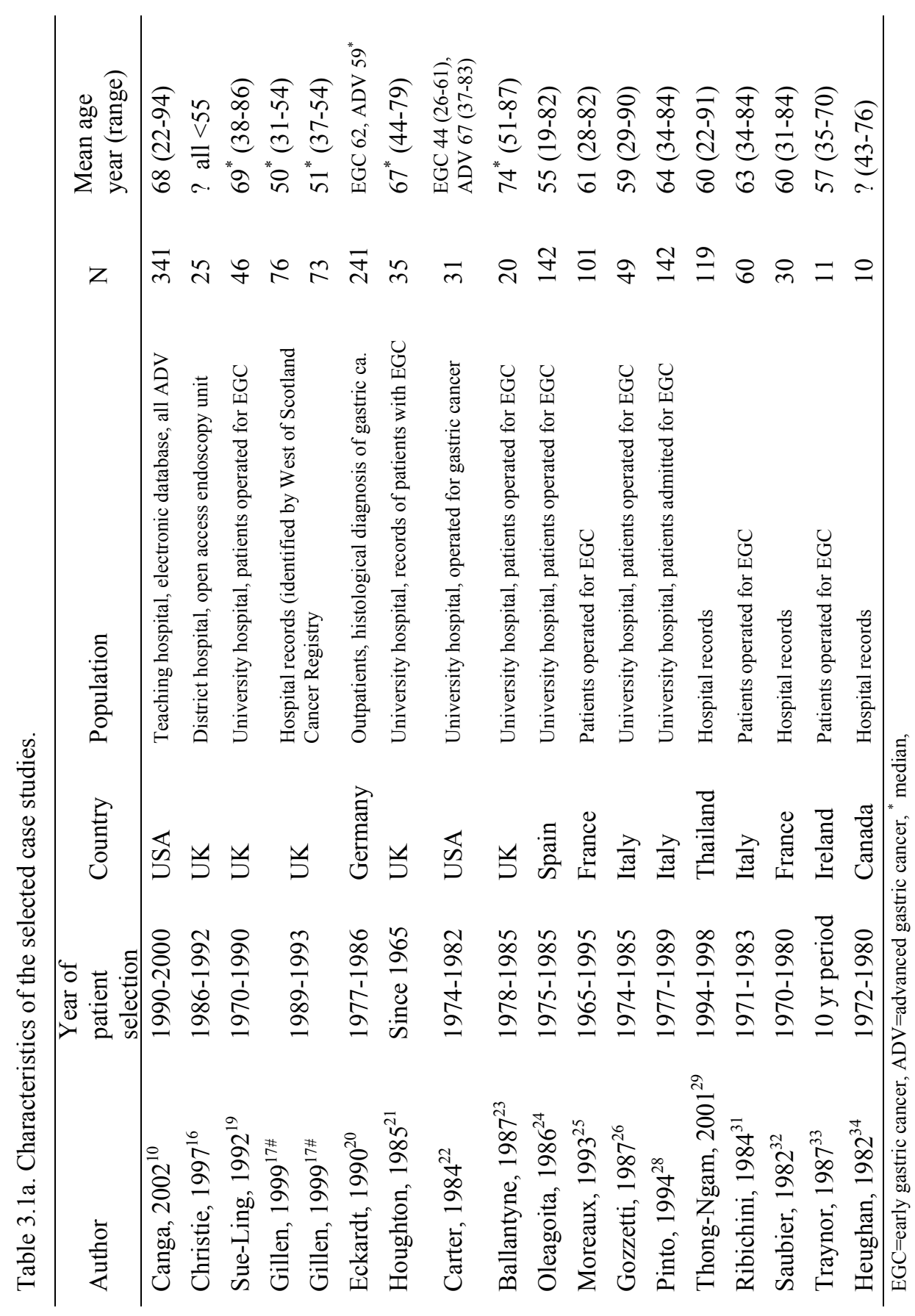




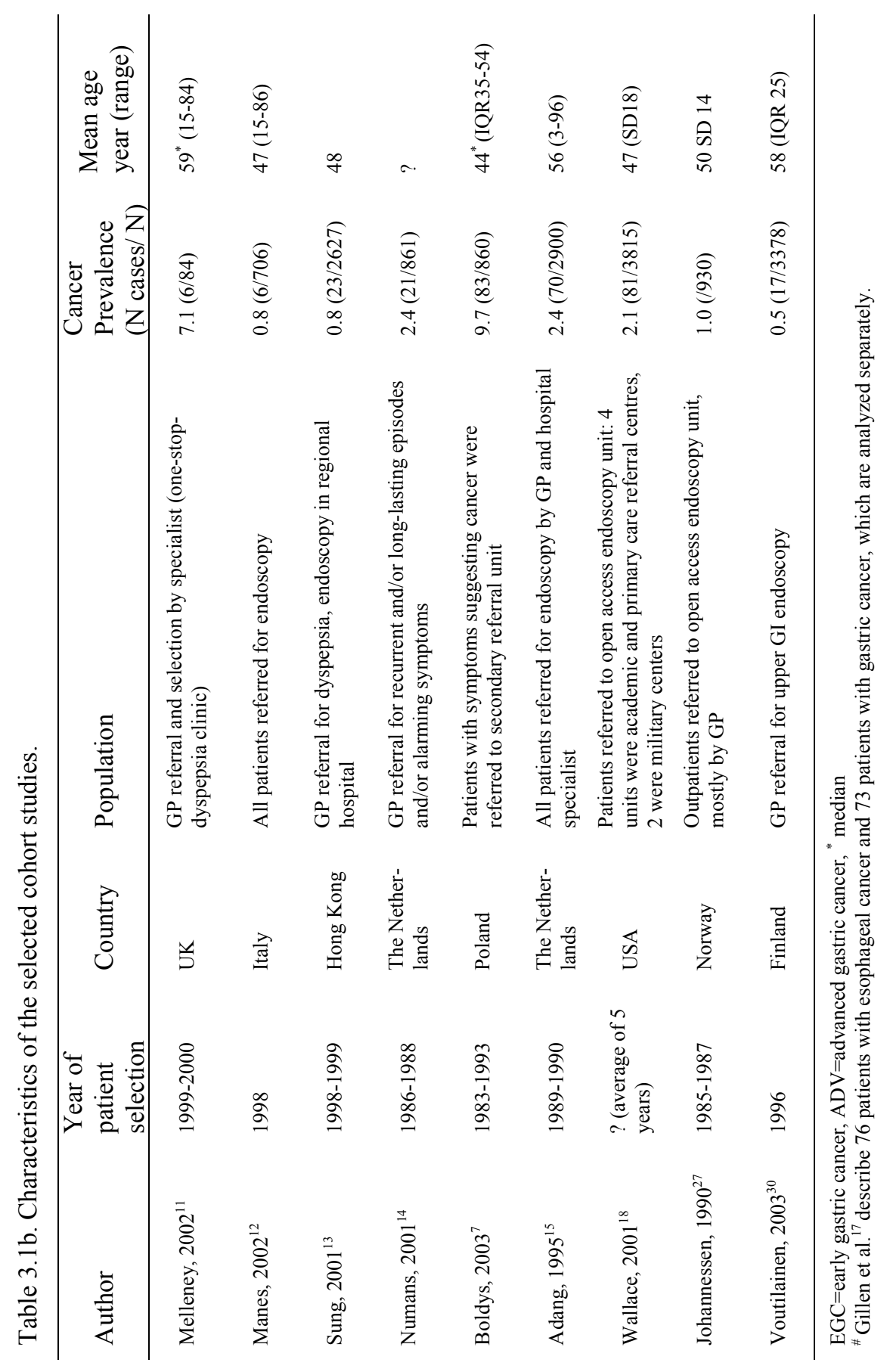


general practitioner, the reasons for referral and way of patient selection varied between the studies. For example, the studies by Melleney and Willoughby ${ }^{10}$ and Boldys et al. ${ }^{7}$ included patients with a high suspicion of upper GI malignancy, which may explain the relatively high prevalence of upper GI malignancy. The pooled sensitivities for dysphagia, anaemia/bleeding, nausea/vomiting, weight loss, and 'any alarm symptom' were respectively 25\%, 17\%, 27\%, 24\% and 75\% (Table 3.3). The pooled PPVs were respectively $6.6 \%, 4.6 \%, 7.5 \%, 7.9 \%$ and $5.9 \%$. The pooled NPVs for the individual alarm symptoms (dysphagia, anaemia/bleeding, nausea/vomiting and weight loss) were $98.8 \%, 97.9 \%, 97.5 \%$, and 94.3 respectively, for 'having any alarm symptom' it was $99.4 \%$. This means that there is approximately a 1:175 chance of missing malignancy in patients without alarm symptoms. Overall, 16 studies (2238 patients) differentiated between early and advanced stages of upper GI malignancy: 710 patients had early stage cancer and 743 had advanced stage cancer.

\section{Discussion}

Alarm symptoms are generally accepted as an indication for direct endoscopy. This is reflected in several guidelines for treatment of patients with dyspeptic symptoms ${ }^{1-}$ ${ }^{4}$ and in the exclusion criteria for patient selection of most trials. ${ }^{11,12}$ As a result, the usefulness of alarm symptoms for selection of patients with a higher risk of having upper GI malignancy is rarely questioned. However, the existing evidence does not consistently support the usefulness of alarm symptoms for this matter. Therefore, we performed a meta-analysis to study the diagnostic value of alarm symptoms. Our results show that the sensitivity of symptoms indicating malignancy is rather disappointing, both for individual alarm symptoms and for having 'any alarm symptom'. In addition to this, the pooled PPV is relatively low, indicating that only a small proportion of the patients with alarm symptoms does have cancer. On the contrary, the high NPV for having 'any alarm symptom' shows that there is little chance of missing a malignancy in patients without alarm symptoms, although this partially caused by the low prevalence of upper GI malignancy.

Moreover, it should be pointed out that the patients studied in the papers included show some selection. This is obvious for the case studies, but the cohort studies also show a degree of selection. This is reflected by the relatively high prevalence of upper GI cancer, with a mean of almost $3 \%$, ranging from 0.5 to $9.7 \%$. However, in most western countries the prevalence of upper GI malignancy is below $0.5 \%$. 
Therefore, in the general population, both the sensitivity and the PPV of alarm symptoms will be worse, although the NPV will remain high.

Table 3.2. Sensitivity of alarm symptoms in case studies.

\begin{tabular}{|c|c|c|c|c|c|}
\hline & Study & $\mathrm{N}$ & $\mathrm{TP}$ & $\mathrm{FN}$ & $\operatorname{Se}(\%(95 \% \mathrm{CI}))$ \\
\hline \multirow{6}{*}{ Dysphagia } & Canga, $2002^{10}$ & 341 & 155 & 186 & 45 \\
\hline & Christie, $1997^{16}$ & 25 & 8 & 17 & 32 \\
\hline & Gillen, $1999^{17 \#}$ & 76 & 18 & 58 & 24 \\
\hline & Gillen, $1999^{17 \#}$ & 73 & 62 & 11 & 85 \\
\hline & Thong-Ngam, $2001^{29}$ & 119 & 8 & 111 & 7 \\
\hline & Pooled & 634 & & & $40(36-43)$ \\
\hline \multirow{16}{*}{ Weight loss } & Canga, $2002^{10}$ & 341 & 145 & 196 & 43 \\
\hline & Christie, $1997^{16}$ & 25 & 14 & 11 & 56 \\
\hline & Gillen, $1999^{17 \#}$ & 76 & 47 & 29 & 62 \\
\hline & Gillen, $1999^{17 \#}$ & 73 & 46 & 27 & 63 \\
\hline & Sue-Ling, $1992^{19}$ & 46 & 10 & 36 & 22 \\
\hline & Eckardt, $1990^{20}$ & 241 & 86 & 155 & 36 \\
\hline & Houghton, $1985^{21}$ & 35 & 22 & 13 & 63 \\
\hline & Carter, $1984^{22}$ & 31 & 18 & 31 & 37 \\
\hline & Moreaux, $1993^{25}$ & 101 & 4 & 97 & 4 \\
\hline & Gozzetti, $1987^{26}$ & 49 & 13 & 36 & 27 \\
\hline & Pinto, $1994^{28}$ & 142 & 58 & 84 & 41 \\
\hline & Ribichini, $1984^{31}$ & 60 & 27 & 33 & 45 \\
\hline & Thong-Ngam, $2001^{29}$ & 119 & 64 & 55 & 54 \\
\hline & Traynor, $1987^{33}$ & 11 & 4 & 7 & 36 \\
\hline & Heughan, $1982^{34}$ & 10 & 1 & 9 & 10 \\
\hline & Pooled & 1350 & & & $41(37-44)$ \\
\hline \multirow{5}{*}{$\begin{array}{l}\text { Bleeding } \\
\text { and/or anemia }\end{array}$} & Canga, $2002^{10}$ & 341 & 87 & 254 & 26 \\
\hline & Christie, $1997^{16}$ & 25 & 7 & 18 & 28 \\
\hline & Houghton, $1985^{21}$ & 35 & 15 & 20 & 43 \\
\hline & Heughan, $1982^{34}$ & 10 & 4 & 6 & 40 \\
\hline & Pooled & 401 & & & $27(24-31)$ \\
\hline \multirow{13}{*}{ Bleeding } & Gillen, $1999^{17 \#}$ & 76 & 6 & 14 & 30 \\
\hline & Gillen, $1999^{17 \#}$ & 73 & 3 & 28 & 10 \\
\hline & Sue-Ling, $1992^{19}$ & 46 & 13 & 228 & 5 \\
\hline & Eckardt, $1990^{20}$ & 241 & 14 & 62 & 18 \\
\hline & Carter, $1984^{21}$ & 31 & 2 & 71 & 3 \\
\hline & Ballantyne, $1987^{23}$ & 20 & 5 & 44 & 10 \\
\hline & Oleagoita, $1986^{24}$ & 142 & 5 & 96 & 5 \\
\hline & Moreaux, $1993^{25}$ & 101 & 7 & 135 & 5 \\
\hline & Gozzetti, $1987^{26}$ & 49 & 5 & 41 & 11 \\
\hline & Pinto, $1994^{28}$ & 60 & 7 & 53 & 12 \\
\hline & Saubier, $1982^{32}$ & 30 & 4 & 26 & 13 \\
\hline & Thong-Ngam, $2001^{29}$ & 119 & 34 & 85 & 29 \\
\hline & Pooled & 988 & & & $11(8-13)$ \\
\hline
\end{tabular}


Table 3.2. Sensitivity of alarm symptoms in case studies (continued).

\begin{tabular}{|c|c|c|c|c|c|}
\hline & Study & $\mathrm{N}$ & $\mathrm{TP}$ & FN & $\operatorname{Se}(\%(95 \% \mathrm{CI}))$ \\
\hline \multirow{6}{*}{ Anemia } & Gillen, $1999^{17 \#}$ & 76 & 3 & 17 & 15 \\
\hline & Gillen, $1999^{17 \#}$ & 73 & 17 & 59 & 22 \\
\hline & Ballantyne, $1987^{23}$ & 20 & 4 & 69 & 5 \\
\hline & Moreaux, $1993^{25}$ & 101 & 1 & 100 & 1 \\
\hline & Saubier, $1982^{32}$ & 30 & 1 & 29 & 3 \\
\hline & Pooled & 300 & & & $9(6-11)$ \\
\hline \multirow{12}{*}{$\begin{array}{l}\text { Nausea/ } \\
\text { vomiting }\end{array}$} & Canga, 2002 & 341 & 53 & 288 & 16 \\
\hline & Gillen, $1999^{17 \#}$ & 76 & 21 & 25 & 46 \\
\hline & Gillen, $1999^{17 \#}$ & 73 & 38 & 203 & 16 \\
\hline & Sue-Ling, $1992^{19}$ & 46 & 9 & 26 & 26 \\
\hline & Eckardt, $1990^{20}$ & 241 & 27 & 49 & 36 \\
\hline & Houghton, $1985^{21}$ & 35 & 26 & 47 & 36 \\
\hline & Carter, $1984^{22}$ & 31 & 5 & 15 & 25 \\
\hline & Ballantyne, $1987^{23}$ & 20 & 9 & 133 & 6 \\
\hline & Oleagoita, $1986^{24}$ & 142 & 37 & 105 & 26 \\
\hline & Gozzetti, $1987^{26}$ & 49 & 11 & 20 & 35 \\
\hline & Pinto, $1994^{28}$ & 142 & 21 & 28 & 43 \\
\hline & Pooled & 1196 & & & $21(18-25)$ \\
\hline \multirow{12}{*}{$\begin{array}{l}\text { Any alarm } \\
\text { symptom }\end{array}$} & Canga, $2002^{10}$ & 341 & 324 & 17 & 95 \\
\hline & Christie, $1997^{16}$ & 25 & 24 & 1 & 96 \\
\hline & Gillen, $1999^{17 \#}$ & 76 & 71 & 5 & 93 \\
\hline & Gillen, $1999^{17 \#}$ & 73 & 73 & 0 & 100 \\
\hline & Sue-Ling, $1992^{19}$ & 46 & 42 & 4 & 91 \\
\hline & Oleagoita, $1986^{24}$ & 142 & 136 & 6 & 96 \\
\hline & Moreaux, $1993^{25}$ & 101 & 95 & 6 & 94 \\
\hline & Pinto, $1994^{28}$ & 142 & 137 & 5 & 96 \\
\hline & Saubier, $1982^{32}$ & 30 & 26 & 4 & 87 \\
\hline & Ribichini, $1984^{31}$ & 60 & 49 & 11 & 82 \\
\hline & Traynor, $1987^{33}$ & 11 & 7 & 4 & 64 \\
\hline & Pooled & 1047 & & & 94 (92-96) \\
\hline
\end{tabular}

${ }^{\#}$ Gillen et al. ${ }^{17}$ describe 76 patients with esophageal cancer and 73 patients with gastric cancer, which are analyzed separately. $\mathrm{TP}=$ True Positive, $\mathrm{FN}=$ False Negative, $\mathrm{Se}=$ Sensitivity

In addition to this, the prevalence of alarm symptoms is high in patients consulting their general doctors for dyspeptic symptoms. This is illustrated by MeinecheSchmidt and Jørgensen, ${ }^{13}$ who showed that $10 \%$ of primary care patients with dyspeptic symptoms had one or more alarm symptoms, whereas only $3 \%$ of investigated patients with alarm symptoms were found to have cancer. 
Table 3.3. Sensitivity, specificity and predictive value of alarm symptoms in cohort studies.

\begin{tabular}{|c|c|c|c|c|c|c|c|c|c|c|}
\hline & Author & $\mathrm{N}$ & TP & FP & FN & TN & $\begin{array}{l}\mathrm{Se} \\
\%\end{array}$ & $\begin{array}{l}\mathrm{Sp} \\
\%\end{array}$ & $\begin{array}{l}\text { PPV } \\
\%\end{array}$ & $\begin{array}{l}\text { NPV } \\
\%\end{array}$ \\
\hline \multirow{5}{*}{$\begin{array}{l}\text { Dys- } \\
\text { phagia }\end{array}$} & Sung, $2001^{13}$ & 2627 & 1 & 28 & 22 & 2576 & 4 & 99 & 3 & 99.2 \\
\hline & Numans, $2001^{14}$ & 861 & 13 & 199 & 8 & 615 & 62 & 76 & 6 & 98.7 \\
\hline & Adang, $1995^{15}$ & 2900 & 14 & 169 & 56 & 2611 & 20 & 94 & 8 & 97.9 \\
\hline & & & \multicolumn{4}{|c|}{ Pooled estimate } & 25 & 94 & 6.6 & 98.8 \\
\hline & & 7058 & \multicolumn{4}{|c|}{$95 \%$ Confidence interval } & $17-23$ & 93-94 & $\begin{array}{l}4.2- \\
9.0 \\
\end{array}$ & $\begin{array}{l}98.5- \\
99.1\end{array}$ \\
\hline \multirow{7}{*}{$\begin{array}{l}\text { Weight } \\
\text { loss }\end{array}$} & Sung, $2001^{13}$ & 2627 & 3 & 16 & 20 & 2588 & 13 & 99 & 16 & 99.2 \\
\hline & Numans, $2001^{14}$ & 861 & 14 & 195 & 7 & 645 & 67 & 77 & 7 & 98.9 \\
\hline & Adang, $1995^{15}$ & 2900 & 17 & 126 & 53 & 2654 & 24 & 95 & 12 & 98.0 \\
\hline & $\begin{array}{l}\text { Johannessen, } \\
1990^{27}\end{array}$ & 930 & 7 & 244 & 2 & 683 & 78 & 26 & 3 & 99.7 \\
\hline & Boldys, $2003^{7}$ & 860 & 9 & 1 & 74 & 776 & 11 & 99.9 & 90 & 91.3 \\
\hline & & 8178 & \multirow{2}{*}{\multicolumn{4}{|c|}{$\begin{array}{l}\text { Pooled estimate } \\
\text { 95\% Confidence interval }\end{array}$}} & 24 & 93 & 7.9 & 97.9 \\
\hline & & & & & & & $18-30$ & $92-93$ & $\begin{array}{l}5.8- \\
10.0\end{array}$ & $\begin{array}{l}97.6- \\
98.2\end{array}$ \\
\hline \multirow{6}{*}{$\begin{array}{l}\text { Blee- } \\
\text { ding } \\
\text { and/or } \\
\text { anemia }\end{array}$} & Sung, $2001^{13}$ & 2627 & 1 & 79 & 22 & 2525 & 4 & 97 & 1 & 99.1 \\
\hline & Numans, $2001^{14}$ & 861 & 3 & 62 & 16 & 732 & 16 & 92 & 5 & 97.9 \\
\hline & Boldys, $2003^{7}$ & 860 & 15 & 60 & 68 & 717 & 18 & 92 & 20 & 91.3 \\
\hline & Adang, $1995^{15}$ & 2900 & 15 & 511 & 55 & 2269 & 21 & 82 & 3 & 97.6 \\
\hline & & 7248 & \multirow{2}{*}{\multicolumn{4}{|c|}{$\begin{array}{l}\text { Pooled estimate } \\
\text { 95\% Confidence interval }\end{array}$}} & 17 & 90 & 4.6 & 97.5 \\
\hline & & & & & & & $12-23$ & $89-90$ & $\begin{array}{l}3.0- \\
6.0\end{array}$ & $\begin{array}{l}97.1- \\
97.5\end{array}$ \\
\hline \multirow{4}{*}{$\begin{array}{l}\text { Nausea } \\
\text { Vomi- } \\
\text { ting } \\
\end{array}$} & Boldys, $2003^{7}$ & 860 & 20 & 145 & 63 & 632 & 24 & 81 & 12 & 90.9 \\
\hline & Numans, $2001^{14}$ & 861 & 8 & 199 & 13 & 614 & 38 & 76 & 4 & 97.9 \\
\hline & & 1721 & \multirow{2}{*}{\multicolumn{4}{|c|}{$\begin{array}{l}\text { Pooled estimate } \\
\text { 95\% Confidence interval }\end{array}$}} & 27 & 78 & 7.5 & 94.3 \\
\hline & & & & & & & $18-35$ & $76-80$ & $\begin{array}{l}4.9- \\
10.2\end{array}$ & $\begin{array}{l}93.0- \\
95.5\end{array}$ \\
\hline \multirow{7}{*}{$\begin{array}{l}\text { Any } \\
\text { alarm } \\
\text { symp- } \\
\text { tom }\end{array}$} & $\begin{array}{l}\text { Melleney, } \\
2002^{11}\end{array}$ & 84 & 5 & 37 & 1 & 41 & 83 & 53 & 12 & 97.6 \\
\hline & Manes, $2002^{12}$ & 706 & 4 & 34 & 2 & 666 & 67 & 95 & 11 & 99.7 \\
\hline & Boldys, $2003^{7}$ & 860 & 61 & 334 & 22 & 443 & 73 & 57 & 15 & 95.3 \\
\hline & $\begin{array}{l}\text { Voutilainen, } \\
2003^{30}\end{array}$ & 3378 & 12 & 1092 & 5 & 2269 & 71 & 68 & 1 & 99.8 \\
\hline & Sung, $2001^{13}$ & 2627 & 19 & 109 & 4 & 2495 & 83 & 96 & 15 & 99.8 \\
\hline & & 7655 & \multirow{2}{*}{\multicolumn{4}{|c|}{$\begin{array}{l}\text { Pooled estimate } \\
\text { 95\% Confidence interval }\end{array}$}} & 75 & 79 & 5.9 & 99.4 \\
\hline & & & & & & & $67-82$ & $78-80$ & $\begin{array}{l}4.8- \\
7.0\end{array}$ & $\begin{array}{l}99.2- \\
99.6\end{array}$ \\
\hline \multicolumn{2}{|c|}{$\begin{array}{l}\text { Age }>45 \text {, male, } \\
\text { anaemia or } \\
\text { bleeding }\end{array}$} & 3815 & 74 & 2866 & 7 & 868 & 91 & 77 & 3 & 99.2 \\
\hline
\end{tabular}

$\mathrm{TP}=$ True Positive, $\mathrm{FP}=$ False Positive, $\mathrm{FN}=$ False Negative, $\mathrm{TN}=$ True Negative, $\mathrm{PPV}=$ Positive Predictive Value, NPV $=$ Negative Predictive Value, $\mathrm{Se}=$ Sensitivity, $\mathrm{Sp}=$ Specificity

Combining the high prevalence of alarm symptoms with their relatively poor sensitivity and PPV leads to the following conclusion: if guidelines are strictly followed, a large number of patients will have endoscopy, whereas a relatively low number of cancers will be identified, and, although the absolute chance of missing 
malignancy because of the absence of alarm symptoms is small, relatively many malignancies (up to $25 \%$ ) will be missed. This is supported by two studies in the United Kingdom that compared short-term endoscopies for high-risk patients with open-access endoscopies. ${ }^{14,15}$ The results from both studies showed that relatively few patients with cancer were identified in the 'high-risk' group while most patients with cancer were found in the open-access group. ${ }^{14,15}$

Furthermore, several studies showed that in patients with upper GI cancer the occurrence of alarm symptoms usually indicates more advanced cancer with worse prognosis. ${ }^{714-17}$ Therefore, it is questionable whether prompt endoscopy improves prognosis for patients with alarm symptoms. This is confirmed by Martin et al. ${ }^{18}$ who did not find a relationship between delay in diagnosis and prognosis for patients with gastric cancer.

Unfortunately, most studies included in this meta-analysis did not provide sufficient information about the stage of the cancers detected in relation to the presence of alarm symptoms. Therefore, it was not possible to perform a proper subgroup analysis. Possibly, a better diagnostic tool might be created by combining a selection of alarm symptoms with patient characteristics. One of the cohort studies showed a sensitivity of $91 \%$ and a specificity of $77 \%$ when using a combination of age over 45 years, male gender and anaemia or bleeding. ${ }^{19}$ This result indicates that the combined presence of alarm symptoms, especially in combination with other factors-like age, gender or smoking might be a better tool for selection of high risk patients. More research is necessary to define such a tool.

In conclusion, although alarm symptoms are generally accepted as an indication for prompt endoscopy, our results show that the diagnostic value of alarm symptoms is not optimal. Other factors such as age and family history should be taken into account when estimating a patient's risk of having upper GI cancer.

\section{References}

1. Anonymous. Helicobacter pylori in peptic ulcer disease. NIH Consens Statement 1994; 12: 1-23.

2. Malfertheiner P, Megraud F, O'Morain C, et al. Current concepts in the management of Helicobacter pylori infection - the Maastricht 2-2000 Consensus Report. Aliment Pharmacol Ther 2002; 16: 167-80.

3. European Society for Primary Care Gastroenterology. The management of $H$. pylori in primary care. J Fam Pract 2000; 17 (Suppl. 2): S1-S35. 
4. British Society of Gastroenterology (BSG). Dyspepsia Management Guidelines. London: BSG, 1996.

5. Canadian Dyspepsia Working Group. An evidence based approach to the management of uninvestigated dyspepsia in the era of Helicobacter pylori. CMAJ 2000; 162 (Suppl. 12): S3-S23.

6. Anonymous. American Gastroenterology Association medical position statement and technical review. Evaluation of dyspepsia. Gastroenterology 1998; 114: 579-95.

7. Boldys H, Marek TA, Wanczura P, Matusik P, Nowak A. Even young patients with no alarm symptoms should undergo endoscopy for earlier diagnosis of gastric cancer. Endoscopy 2003; 35: 61-7.

8. Meineche-Schmidt V, Jørgensen T. 'Alarm symptoms' in patients with dyspepsia: a three-year prospective study from general practice. Scan J Gastroenterol 2002; 37: 999-1007.

9. Deeks JJ. Systematic reviews of evaluations of diagnostic and screening tests. In: Egger, M, Davey Smith, G, Altman, DG, eds. Systematic Reviews in Health Care: Meta-analyses in Context. London: BMJ Publishing group, 2001: 248-82.

10. Melleney EMA, Willoughby CP. Audit of a nurse endoscopist based one stop dyspepsia clinic. Postgrad Med J 2002; 78: 161-4.

11. Manes G, Menchise A, De Nucci C, Balzano A. Empirical prescribing for dyspepsia: randomised controlled trial of test and treat versus omeprazole treatment. BMJ 2003; 326: 1118-24.

12. Arents NL, Thijs JC, van Zwet AA, et al. Approach to treatment of dyspepsia in primary care: a randomized trial comparing 'test-and-treat' with prompt endoscopy. Arch Intern Med 2003; 163: 1606-12.

13. Meineche-Schmidt V, Jorgensen T. 'Alarm symptoms' in dyspepsia. How does the general practitioner investigate? Scand J Prim Health Care 2003; 21: 224-9.

14. Hindmarsch A, Cheong E, Rees L, Rhodes M, Lewis M. National referral guidelines for cases of suspected upper GI cancer in the UK: are they working? Gut 2003; 52 (Suppl. VI): A17.

15. Ahmad I, Azam A. To assess the effectiveness of two-week referrals for oesophageal and gastric cancer in accordance with united Kingdom department of health guidelines. Gut 2003; 52 (Suppl. VI): A17.

16. Kubota $\mathrm{H}$, Kotoh $\mathrm{T}$, Masunaga $\mathrm{R}$, et al. Impact of screening survey of gastric cancer on clinicopathological features and survival: retrospective study at a single institution. Surg 2000; 128: 41-7. 
17. Siersema PD, Dees J, Tilanus HW, Kok TC, Hordijk ML, Van Blankenstein M. Review: Early detection and treatment of oesophageal and gastric cancer. Neth J Med 1995; 47: 76-86.

18. Martin IG, Young S, Sue-Ling H, Johnston D. Delays in the diagnosis of oesophagogastric cancer: a consecutive case series. BMJ 1997; 314: 467-70.

19. Wallace MB, Durkalski VL, Vaughan J, et al. Age and alarm symptoms do not predict endoscopic findings among patients with dyspepsia: a multicentre database study. Gut 2001; 49: 29-34.

20. Canga C, Vakil N. Upper GI malignancy, uncomplicated dyspepsia, and the age threshold for early endoscopy. Am J Gastroenterol 2002; 97: 600-3.

21. Christie J, Shepherd NA, Codling BW, Valori RM. Gastric cancer below the age of 55: implications for screening patients with uncomplicated dyspepsia. Gut 1997; 41: 513-7.

22. Sue-ling HM, Martin I, Griffith J, et al. Early gastric cancer: 46 cases treated in one surgical department. Gut 1992; 33: 1318-22.

23. Gillen D, McColl KEL. Does concern about missing malignancy justify endoscopy in uncomplicated dyspepsia in patients aged less than 55? Am J Gastroenterol 1999; 94: 75-9.

24. Eckardt VF, Gießler W, Kanzler G, Remmele W, Bernhard G. Clinical and morphological characteristics of early gastric cancer. A case-control study. Gastroenterology 1990; 98: 708-11.

25. Houghton PWJ, Mortensen NJMcC, Allan A, Williamson RCN, Davies JD. Early gastric cancer: the case for long term surveillance. BMJ 1985; 291: 305-8.

26. Carter KJ, Schaffer HA, Ritchie WP. Early gastric cancer. Ann Surg 1984; 199: 604-9.

27. Ballantyne KC, Morris DL, Jones JA, Gregson RH, Hardcastle JD. Accuracy of identification of early gastric cancer. Br J Surg 1987; 74: 618-9.

28. Oleagoita JM, Echevarria A, Santridrian JI, Ulacia MA, Hernandez-Calvo J. Early gastric cancer. Br J Surg 1986; 73: 804-6.

29. Moreaux J, Bougaran J. Early gastric cancer, a 25-year surgical experience. Ann Surg 1993; 4: 347-55.

30. Gozzetti G, Mattioli S, Gaudio M, et al. Surgical therapy in 'early gastric cancer'. Ital J Surg Sci 1987; 17: 225-31.

31. Pinto E, Roviello F, de Stefano A, Vindigni C. Early gastric cancer: report on 142 patients observed over 13 years. Jpn J Clin Oncol 1994; 24: 12-9. 
32. Thong-Ngam D, Tangkijvanich P, Mahachai V, Kullavanijaya P. Current status of gastric cancer in Thai patients. J Med Assoc Thai 2001; 84: 475-82.

33. Ribichini P, Piccinini E, Perrucci A, et al. Early gastric cancer: evaluation of diagnostic, clinicopathologic and therapeutic aspects in 60 cases. Int Surg 1984; 69: 325-30.

34. Saubier EC, Partensky C, Gouillat C, Berger F, Moulinier B. Cancer superficiel de l'estomac. 30 cas operes. J Chir (Paris) 1982; 119: 13-20.

35. Traynor O-J, Lennon J, Dervan P, Corrigan T. Diagnostic and prognostic problems in early gastric cancer. Am J Surg 1987; 154: 516-9.

36. Heughan C, Kepkay D, Cruz A-M, Idikio H. Early gastric cancer. Can J Surg 1982; 25: 83-5.

37. Manes G, Balzano A, Marone P, Lioniello M, Mosca S. Appropriateness and diagnostic yield of upper gastrointestinal endoscopy in an open-access endoscopy system: a prospective observational study based on the Maastricht guidelines. Aliment Pharmacol Ther 2002; 16: 105-10.

38. Sung JJ, Lao WC, Lai MS, et al. Incidence of gastroesophageal malignancy in patients with dyspepsia in Hong Kong: implications for screening strategies. Gastrointest Endosc 2001; 54: 454-8.

39. Numans ME, van der Graaf Y, de Wit NJ, de Melker RA. How useful is selection based on alarm symptoms in requesting gastroscopy? An evaluation of diagnostic determinants for gastro-oesophageal malignancy. Scand J Gastroenterol 2001;36: 437-43.

40. Adang RP, Vismans JF, Talmon JL, Hasman A, Ambergen AW, Stockbrugger RW. Appropriateness of indications for diagnostic upper gastrointestinal endoscopy: association with relevant endoscopic disease. Gastrointest Endosc 1995; 42: 390-7.

41. Johannessen T, Petersen H, Kleveland PM, et al. The predictive value of history in dyspepsia. Scand J Gastroenterol 1990; 25: 689-97.

42. Voutilainen M, Mantynen T, Kunnamo I, Juhola M, Mecklin JP, Farkkila M. Impact of clinical symptoms and referral volume on endoscopy for detecting peptic ulcer and gastric neoplasms. Scand J Gastroenterol 2003; 38: 109-13. 


\section{Chapter 4}

\section{Alarm symptoms for gastro-oesophageal malignancy: a meta-analysis using individual patient data}

Marcel J.R. Janssen, Gerdine A.J. Fransen, Markku Voutilainen, Robert P.R. Adang, Joseph J.Y. Sung, Mattijs E. Numans, Alan B.R. Thomson, Gianpiero Manes, Johann Hammer, Hubert Boldys, Robert J.F. Laheij \& Jan B.M.J. Jansen

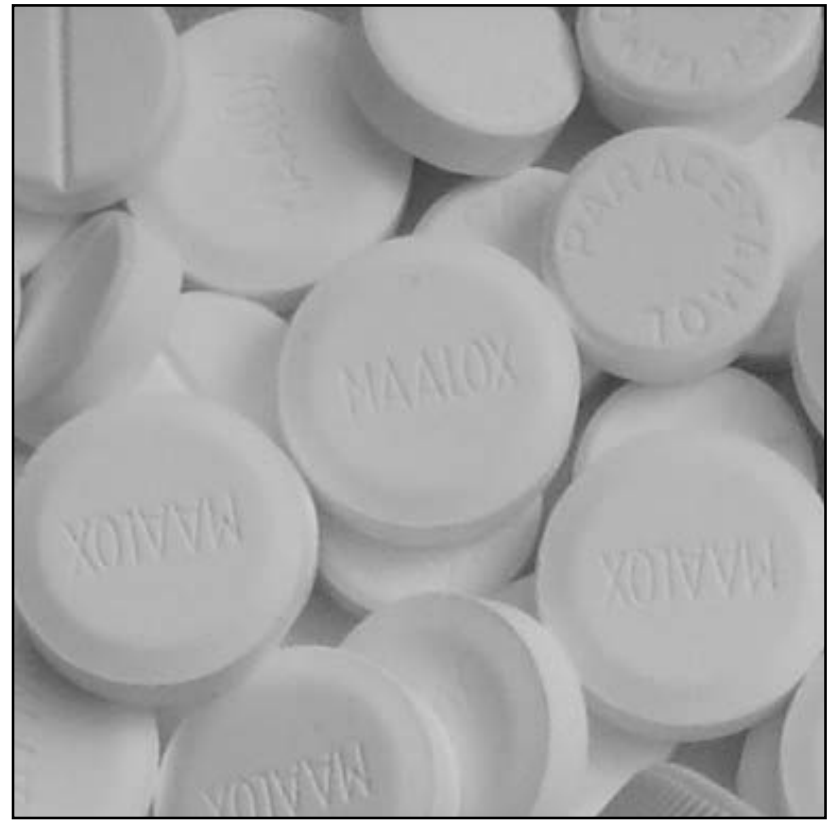




\begin{abstract}
Background: Alarm symptoms are widely used for selection of patients with a high risk of having gastro-oesophageal cancer, but the supporting evidence is not consistent. Therefore, we performed a meta-analysis using individual patient data.

Methods: Medline was searched for studies measuring alarm symptoms in primary/secondary care patients having upper gastrointestinal endoscopy. If possible, the original databases from all selected papers were retrieved, recoded, and combined.

Results: Of the 10 selected papers, patient data could be retrieved from 7, resulting in a combined database of 13,377 patients (mean age 52 years (SD: 17), 48\% male). Overall, there were $166(1.2 \%)$ patients with cancer: 133 gastric and 33 oesophageal cancers. Of these patients, 103 had alarm symptoms (weight loss, disturbed food passage, signs/symptoms of upper gastrointestinal bleeding, or persistent vomiting). Overall 3,927 (29.9\%) patients had alarm symptoms and 9,205 patients had no alarm symptoms. This resulted in a sensitivity of $62.0 \%$, a specificity of $70.5 \%$, a positive predictive value of $2.6 \%$, and a negative predictive value of $99.3 \%$ for having 'any alarm symptom'. Of the 166 patients with cancer, $19(11.4 \%)$ were younger than 50 years, of which 11 (57.9\%) reported alarm symptoms.
\end{abstract}

Conclusions: More than a third of patients with gastro-oesophageal cancer had no alarm symptoms, while only few of the patients with alarm symptoms had cancer. Therefore, alarm symptoms are far from ideal for selection of patients at risk. Other factors such as age, H. pylori status, gender, and presence of heartburn should also be taken into account when estimating each individual's risk. 


\section{Introduction}

Dyspeptic symptoms are common in the general population. ${ }^{1}$ They may be associated with gastric or oesophageal pathology such as gastro-oesophageal reflux disease, peptic ulcer disease and, rarely, gastro-oesophageal malignancy. ${ }^{2}$ Upper gastrointestinal endoscopy provides most information about the underlying cause but is expensive, troublesome to the patient, and in more than $50 \%$ of endoscopic examinations no organic disease can be identified. Therefore, non-invasive treatment strategies such as Helicobacter pylori test-and-treat or empirical treatment with acidsuppressants have been proposed, and it has become clear that these are as effective as upper gastrointestinal endoscopy followed by targeted treatment. ${ }^{3-6}$ Thus, a growing number of patients are treated without upper gastrointestinal endoscopy.

However, it is important not to delay diagnosis in patients with gastro-oesophageal malignancy. Therefore, it has become increasingly important to be able to select patients with a high risk of gastro-oesophageal cancer for immediate endoscopy. For this selection alarm symptoms such as weight loss, disturbed food passage, signs and symptoms of upper gastrointestinal bleeding, and persistent vomiting are generally accepted; most guidelines recommend immediate endoscopy in all patients with alarm symptoms. ${ }^{7-9}$

However, the evidence supporting the use of alarm symptoms as a selection criterion for endoscopy is inconsistent. Although several retrospective case series reported that most patients with gastro-oesophageal cancer had one or more alarm symptoms, some studies investigating cohorts of patients with dyspeptic symptoms were less conclusive. $^{10,11}$ Therefore, more research is necessary to definitely establish the value of alarm symptoms.

Due to the low prevalence of gastric and oesophageal cancer, large populations are needed for such research. This can be overcome by performing meta-analysis, although traditional meta-analysis is hampered by several drawbacks. In particular, only outcomes reported in the original papers can be analyzed, and various investigators may use different definitions and analyses which may make it impossible to combine the results.

These problems can be overcome by going back to the source: the individual patient. In a meta-analysis of individual patient data, the original databases are combined and reanalyzed. Furthermore, outcomes and subgroups can be re-defined and all registered variables can be used in the analysis. Therefore, the aim of this study was 
to investigate the value of alarm symptoms for selection of patients with gastric or oesophageal malignancy by means of a meta-analysis using individual patient data.

\section{Methods}

Search strategy

A bibliographical search was performed in the Medline database (to September 2004) in order to identify studies investigating alarm symptoms and upper gastrointestinal malignancy. The search was based on the key words 'alarm' or 'sinister' and 'malignancy'. Furthermore, reference lists of all identified trials and reviews were searched to identify other relevant studies. All abstracts were examined for eligibility by two independent reviewers. Disagreements were resolved by consulting a third independent reviewer.

\section{Inclusion criteria}

Population: adult primary and/or secondary care patients.

Diagnosis: upper gastrointestinal endoscopy (in all patients).

Directionality: prospective, alarm symptoms had to be registered before the endoscopy.

\section{Data recoding}

The original databases of the selected papers were retrieved. From each database data regarding age, gender, presence of alarm symptoms, and diagnosis at upper gastrointestinal endoscopy were retrieved. Alarm symptoms were defined as: weight loss, disturbed food passage, symptoms indicating upper gastrointestinal bleeding (haemathemesis, melena) and/or anaemia, and persistent vomiting. Diagnoses were categorized as: gastric cancer, oesophageal cancer, oesophagitis, gastric ulcer, duodenal ulcer, and Barrett's oesophagus. Malignancy had to be confirmed by histology. Additionally, if available, data regarding smoking behaviour, alcohol consumption, use of acetylsalicylic acid (ASA) and/or non-steroidal antiinflammatory drugs (NSAIDs), presence of heartburn, epigastric pain, and H. pylori status were retrieved. Due to limitations of the source data, all variables (except age) were dichotomized (being either present or absent). Patients without endoscopy results were excluded. In case of multiple endoscopic examinations of the same patient, only the first examination was included in the final database. 
Analysis

The prevalence of alarm symptoms was compared for patients with and without gastro-oesophageal cancer, both for the individual alarm symptoms mentioned above and for having any of these alarm symptoms. Sensitivity, specificity, positive and negative predictive values (PPV/NPV) of having 'any alarm symptom' for gastro-oesophageal cancer were calculated. Furthermore, other patient characteristics such as age, gender, H. pylori status, smoking, alcohol consumption and use of ASA/NSAIDs were compared for patients with and without gastrooesophageal cancer. Additionally, all variables were included in adjusted logistic regression analysis. Because only alarm symptoms, age, and gender were available for all patients, dummy variables were constructed for the missing values of the other patient characteristics. All analyses were performed with the $\mathrm{SAS}^{\circledR}$ statistical software package (SAS Institute Inc., Minneapolis, Minnesota, USA). Statistical significance was defined as a $\mathrm{p}$-value $<0.05$.

\section{Results}

Selection of studies

The bibliographical search resulted in 340 hits in Medline. Only ten of these studies fulfilled the predefined inclusion criteria and the authors of these papers were invited to participate. For three studies, investigating a total of 4,829 patients, the original data were not available any more. ${ }^{12-14}$ The remaining seven papers (Table 4.1) were included in this meta-analysis. ${ }^{15-21}$

Table 4.1. Characteristics of the included studies.

\begin{tabular}{|c|c|c|c|c|}
\hline Study & Study period & Region & $\mathrm{N}$ & $\begin{array}{l}\text { Gastro- } \\
\text { oesoph. } \\
\text { cancer }\end{array}$ \\
\hline Manes, et al. ${ }^{15}$ & 1998 & Italy & 697 & $0.9 \%$ \\
\hline Adang, et al. ${ }^{16}$ & 1988-1990 & The Netherlands & 2,842 & $2.4 \%$ \\
\hline Voutilainen, et al. ${ }^{17}$ & 1996 & Finland & 3,665 & $0.9 \%$ \\
\hline Hammer, et al. ${ }^{18}$ & 1994-1998 & Australia & 526 & $0.0 \%$ \\
\hline Sung, et al. ${ }^{19}$ & 1998-1999 & China (Hong Kong) & 2,626 & $0.9 \%$ \\
\hline Numans, et al. ${ }^{20}$ & 1986-1994 & The Netherlands & 1,982 & $1.8 \%$ \\
\hline Thomson, et al. ${ }^{21}$ & $1999-2000$ & Canada & 1,039 & $0.2 \%$ \\
\hline
\end{tabular}

Combined study population

The combined database included 13,377 patients (mean age 52 years (SD: 17), 6,085 (45.6\%) patients under 50 years, 6,295 (47.6\%) males). In 8,992 (67.2\%) patients no 
organic disease was found at upper gastrointestinal endoscopy. For the remaining patients, Figure 4.1 shows the prevalence of the various diagnoses. There were 166 patients $(1.2 \%)$ with upper gastrointestinal cancers (133 (1.0\%) gastric, $33(0.2 \%)$ oesophageal).

Figure 4.1. Endoscopic diagnoses (\% of study population).

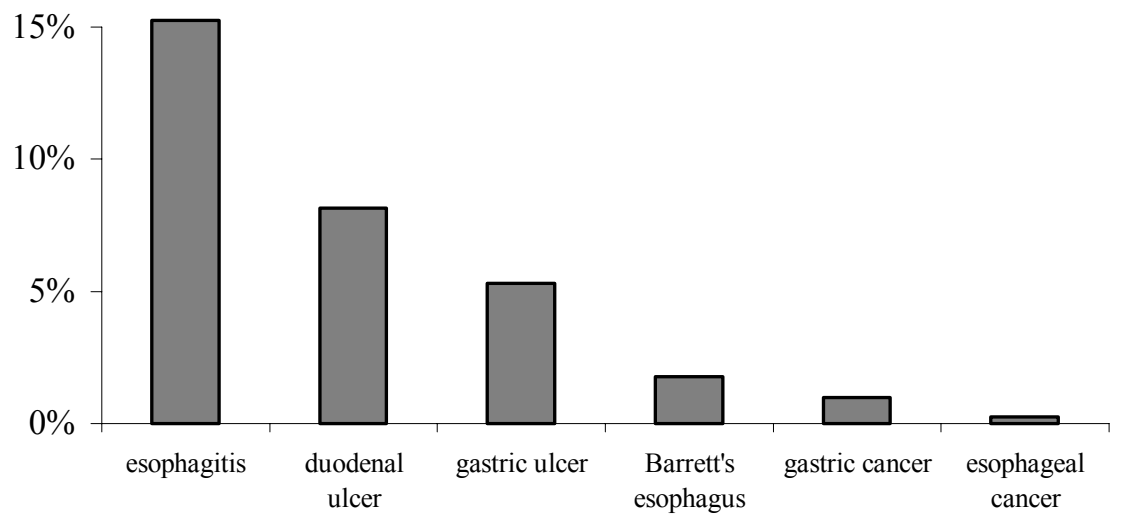

Alarm symptoms for gastro-oesophageal cancer

Table 4.2 shows that patients with gastro-oesophageal cancer more often had alarm symptoms than patients without cancer, but that the sensitivity of each individual alarm symptom was low: it ranged from $12 \%$ for persistent vomiting to $29 \%$ for weight loss.

Table 4.2. Prevalence of individual alarm symptoms in patients with and without gastro-oesophageal cancer.

\begin{tabular}{lcc}
\hline & \multicolumn{2}{c}{ Gastro-oesophageal cancer } \\
& Yes $(\mathrm{N}=166)$ & No $(\mathrm{N}=13,211)$ \\
& $\mathrm{n}(\%)$ & $\mathrm{n}(\%)$ \\
\hline Weight loss $^{*}$ & $48(28.9 \%)$ & $780(6.0 \%))$ \\
Disturbed food passage $^{*}$ & $41(24.7 \%)$ & $1,213(9.4 \%)$ \\
Anaemia and/or bleeding $^{*}$ & $35(21.1 \%)$ & $1,649(12.6 \%)$ \\
Persistent vomiting $^{*}$ & $20(12.1 \%)$ & $954(7.3 \%)$ \\
\hline${ }^{*}<0.05$ & &
\end{tabular}


Sensitivity increased when the alarm symptoms were combined into the outcome 'any alarm symptom'. Figure 4.2 shows that of the 166 patients with gastrooesophageal cancer 103 had one or more alarm symptoms. Therefore, the sensitivity of having 'any alarm symptom' was $62.0 \%$ (95\%CI: $54.7 \%-69.4 \%$ ). Of the 12,966 patients without gastro-oesophageal cancer 9,142 did not have any alarm symptom, yielding a specificity of $70.5 \%$ (95\%CI: $69.7 \%-71.3 \%$ ). Furthermore, of the 3,927 $(29.9 \%)$ with an alarm symptom 103 had gastro-oesophageal cancer, yielding a positive predictive value of $2.6 \%$ (95\%CI: $2.1 \%-3.1 \%$ ). Analogously, the negative predictive value was $99.3 \%$ (95\%CI: $99.1 \%-99.5 \%$ ) because 9,142 of the 9,205 patients without any alarm symptom did not have gastro-oesophageal cancer. If 'persistent vomiting' was not used as an alarm symptom the results were comparable: sensitivity $60.8 \%$ (95\%CI: 53.4\%-68.3\%), specificity $74.4 \%$ (95\%CI: 73.6\%-75.1\%), PPV 3.0\% (95\%CI: 2.4\%-3.5\%), NPV 99.3\% (95\%CI: $99.2 \%$ $99.5 \%)$, while $3,419(26.1 \%)$ patients had one or more alarm symptoms.

When looking at the relationship between the number of alarm symptoms and the presence of gastro-oesophageal cancer it could be calculated that of the 2,740 patients with one alarm symptom $56(2.0 \%)$ had gastro-oesophageal cancer, of the 994 with two alarm symptoms 39 (3.9\%) had gastro-oesophageal cancer, of the 78 with three alarm symptoms $7(9.0 \%)$, and ironically of the four patients with all four alarm symptoms none had gastro-oesophageal cancer.

Figure 4.2. Alarm symptoms for selection of patients with gastro-oesophageal cancer.

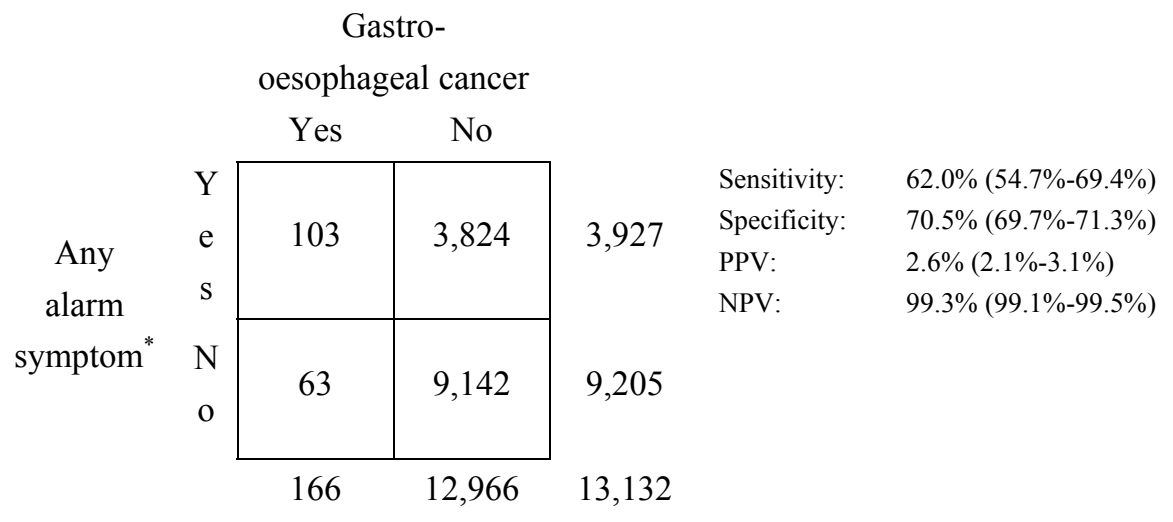

*weight loss, disturbed food passage, symptoms indicating upper gastrointestinal bleeding and/or anaemia, persistent vomiting 


\section{Alarm symptoms for any organic diagnosis}

Figure 4.3 shows that the value of alarm symptoms for selection of patients with any organic diagnosis (i.e. oesophagitis, peptic ulcer disease, Barrett's oesophagus, gastro-oesophageal malignancy, or other rare pathology such as Schatzki's rings, etc.) is disappointing. Although the prevalence of organic disease is slightly higher in patients with alarm symptoms $(37.6 \%$ vs. $30.7 \%, \mathrm{p}<0.0001)$, in $2,451(62.4 \%)$ of the 3,927 patients with alarm symptoms no organic pathology was detected.

Figure 4.3. Alarm symptoms for organic disease.

\begin{tabular}{|c|c|c|c|c|c|c|}
\hline & & Orga & disease & & & \\
\hline & & Yes & No & & & \\
\hline $\begin{array}{l}\text { Any } \\
\text { alarm }\end{array}$ & $\begin{array}{l}\mathrm{Y} \\
\mathrm{e} \\
\mathrm{s}\end{array}$ & 1,476 & 2,451 & 3,927 & $\begin{array}{l}\text { Sensitivity: } \\
\text { Specificity: } \\
\text { PPV: } \\
\text { NPV: }\end{array}$ & $\begin{array}{l}34.3 \%(32.9 \%-35.7 \%) \\
72.2 \%(71.3 \%-73.2 \%) \\
37.6 \%(36.1 \%-39.1 \%) \\
69.3 \%(68.3 \%-70.2 \%)\end{array}$ \\
\hline symptom $^{*}$ & $\begin{array}{l}\mathrm{N} \\
\mathrm{o}\end{array}$ & 2,827 & 6,378 & 9,205 & & \\
\hline & & 4,303 & 8,829 & 13,132 & & \\
\hline
\end{tabular}

*weight loss, disturbed food passage, symptoms indicating upper gastrointestinal bleeding and/or anaemia, persistent vomiting

Age cut-off

Figure 4.4 shows that there was no clear age cut-off for gastro-oesophageal cancer since the angle of inclination of the graph showing the cumulative number of patients with gastro-oesophageal cancer slowly increased between the ages of 30 and 60 , reaching a maximum at the age of 70 years. Nine-teen of 166 patients $(11.4 \%)$ with gastro-oesophageal cancer were less than 50 years of age. Eight of these patients $(42.1 \%)$ did not have any alarm symptom, while 1,532 (25.6\%) of patients $<50$ years reported alarm symptoms. Therefore, in patients under 50 years of age the sensitivity of alarm symptoms was $57.9 \%$ (95\%CI: $35.7-80.0 \%)$, the specificity was $74.5 \%$ (95\%CI: $73.4-75.6 \%)$, the PPV was $0.7 \%$ (95\%CI: $0.3-1.1 \%)$, and the NPV was $99.8 \%(95 \% \mathrm{CI}$ : $99.7-99.9 \%)$, with a $0.3 \%$ prevalence of gastrooesophageal cancer. 
Figure 4.4. Cumulative number of patients with gastro-oesophageal cancer vs. age with the cumulative number of endoscopies vs. age as a reference.

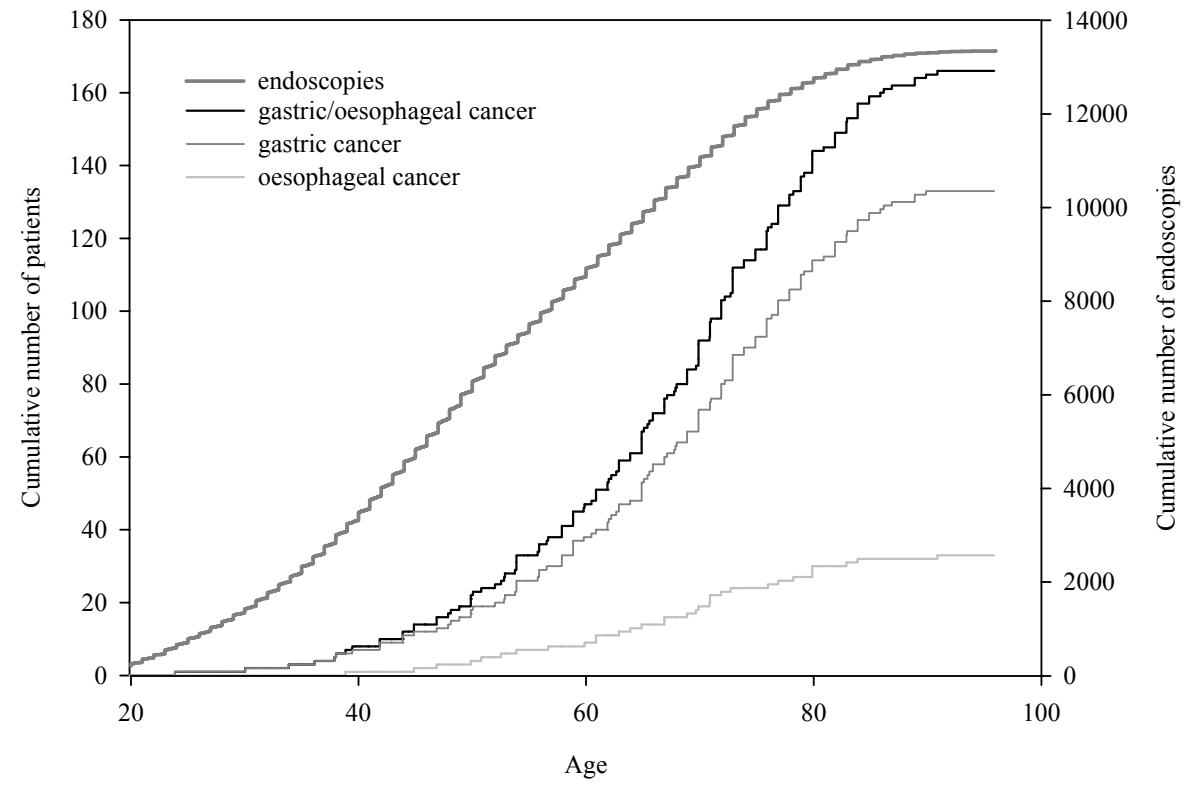

Of the 147 patients with gastro-oesophageal cancer over 50 years of age $55(37.4 \%)$ did not report any alarm symptom, while 2,377 (33.4\%) of patients in this age group reported alarm symptoms. Therefore, in patients over 50 years of age the sensitivity was $62.6 \%$ (95\%CI: $54.8-70.4 \%$ ), the specificity was $67.3 \%$ (95\% $\mathrm{CI}$ : $66.2-68.4 \%$ ), the PPV was 3.9\% (95\%CI: 3.1-4.6\%) and the NPV was 98.8\% (95\%CI: $98.5-$ $99.1 \%$ ), for a $2.1 \%$ prevalence of gastro-oesophageal cancer.

Because the majority of patients with gastro-oesophageal cancer were over 50 years of age the sensitivity and NPV can be increased to $95.2 \%$ (95\%CI: 91.9-98.4\%) and 99.8\% (95\%CI: 99.7-99.9\%) resp. by adding 'age over 50' to the alarm symptoms. However, at the cost of the specificity and PPV (34.0\% (95\%CI: 33.1-34.8\%) and $1.8 \%$ (95\%CI: $1.5-2.1 \%)$, resp.) since 8,811 (66.4\%) of all patients had an alarm symptom or were older than 50 years.

The importance of age can be illustrated by using age $\geq 50$ as sole selection criterion which had a sensitivity of $88.6 \%(95 \% \mathrm{CI}$ : $83.7-93.4 \%$ ), a specificity of $46.0 \%$ (95\%CI: 45.2-46.9\%), a PPV of 2.0\% (95\%CI: $1.7-2.3 \%$ ), and a NPV of $99.7 \%$ (95\%CI: 99.5\%-99.8\%), while 7,261 patients (54.4\%) were 50 years of age or older. 


\section{Other patient factors}

In Table 4.3 the prevalence of other patient characteristics are compared for patients with and without gastro-oesophageal cancer. Unfortunately, besides age, gender, and the four alarm symptoms, none of the other characteristics were registered in all studies. Therefore, in the second column of this table is described for how many patients each variable was available. Male gender and $H$. pylori infection were associated with gastro-oesophageal cancer, while current symptoms of heartburn and a history of peptic ulcer disease were associated with a lower risk of having gastrooesophageal cancer. Additionally, current use of ASA/NSAIDs was associated with a lower chance of a diagnosis of gastro-oesophageal cancer.

Table 4.3. Prevalence of other characteristics in patients with and without gastrooesophageal cancer.

\begin{tabular}{lccc}
\hline & $\mathrm{N}_{\text {available }}$ & \multicolumn{2}{c}{ Gastro-oesophageal cancer } \\
& & $\begin{array}{c}\text { Yes }(\mathrm{N}=166) \\
\mathrm{n}(\%)\end{array}$ & $\mathrm{No}(\mathrm{N}=13,211)$ \\
& & $\mathrm{n}(\%)$ \\
\hline Male gender $^{*}$ & 13,214 & $96(58.2 \%)$ & $6,199(47.5 \%)$ \\
Current smoking & 5,130 & $22(40.7 \%)$ & $1,952(38.5 \%)$ \\
Current alcohol consumption $^{*}$ & 5,106 & $15(29.4 \%)$ & $1,777(35.2 \%)$ \\
Use of ASA/NSAIDs $^{*}$ & 8,814 & $5(4.4 \%)$ & $896(10.3 \%)$ \\
H. pylori infection $^{*}$ & 7,789 & $31(50.8 \%)$ & $2,790(36.1 \%)$ \\
History of peptic ulcer disease $^{*}$ & 5,270 & $9(8.6 \%)$ & $827(16.0 \%)$ \\
Heartburn $^{*}$ & 7,696 & $19(22.6 \%)$ & $2,977(39.1 \%)$ \\
Epigastric pain $^{* p<0.05}$ & 7,212 & $32(40.0 \%)$ & $3,389(47.5 \%)$ \\
\hline
\end{tabular}

\section{Adjusted analysis}

Table 4.4 shows both the unadjusted and adjusted odds ratios for all aforementioned variables. The results of the adjusted analysis are comparable with the results of the unadjusted analysis. However, the results for persistent vomiting and history of peptic ulcer disease were not statistically significant after adjustment. 
Table 4.4. Factors associated with gastro-oesophageal cancer.

\begin{tabular}{|c|c|c|c|c|}
\hline \multirow[t]{3}{*}{ Factor } & \multicolumn{2}{|c|}{ Unadjusted analysis } & \multicolumn{2}{|c|}{ Adjusted analysis ${ }^{* *}$} \\
\hline & Odds & $(95 \% \mathrm{CI})$ & Odds & $(95 \% \mathrm{CI})$ \\
\hline & ratio & & ratio & \\
\hline Weight loss & $6.35^{*}$ & $(4.5-9.0)$ & $5.84^{*}$ & $(4.0-8.5)$ \\
\hline Disturbed food passage & $3.17^{*}$ & $(2.2-4.5)$ & $3.40^{*}$ & $(2.3-5.1)$ \\
\hline Anaemia and/or bleeding & $1.85^{*}$ & $(1.3-2.7)$ & $1.65^{*}$ & $(1.1-2.5)$ \\
\hline Persistent vomiting & $1.73^{*}$ & $(1.1-2.8)$ & 1.63 & $(0.9-2.8)$ \\
\hline Age $\geq 50$ years & $6.60^{*}$ & $(4.1-10.7)$ & $5.56^{*}$ & $(3.4-9.2)$ \\
\hline Male gender & $1.54^{*}$ & $(1.1-2.1)$ & $1.59^{*}$ & $(1.2-2.2)$ \\
\hline Smoking & 1.10 & $(0.6-1.9)$ & 0.98 & $(0.5-1.8)$ \\
\hline Alcohol consumption & 0.77 & $(0.4-1.4)$ & 0.90 & $(0.5-1.7)$ \\
\hline H. pylori infection & $1.83^{*}$ & $(1.1-3.0)$ & $1.78^{*}$ & $(1.1-3.0)$ \\
\hline Use of ASA/NSAIDs & $0.40^{*}$ & $(0.2-1.0)$ & $0.32^{*}$ & $(0.1-0.8)$ \\
\hline History of peptic ulcer disease & $0.49^{*}$ & $(0.2-1.0)$ & 0.56 & $(0.3-1.2)$ \\
\hline Heartburn & $0.46^{*}$ & $(0.3-0.8)$ & $0.49^{*}$ & $(0.3-0.9)$ \\
\hline Epigastric pain & 0.74 & $(0.5-1.2)$ & 0.67 & $(0.4-1.1)$ \\
\hline
\end{tabular}

\section{Discussion}

The aim of this meta-analysis was to investigate the use of alarm symptoms for selection of patients with gastro-oesophageal malignancy. Individual patient data from 7 studies were combined. In the combined population of more than thirteen thousand patients the prevalence of gastro-oesophageal malignancy was $1.2 \%$. In patients with alarm symptoms this was only moderately higher $(2.6 \%)$. The results show that alarm symptoms are far from ideal for selection of patients with gastrooesophageal cancer: firstly, because they are not adequately sensitive; and secondly, because the overall prevalence of alarm symptoms is high, while the prevalence of gastro-oesophageal cancer is low.

Although the prevalence of alarm symptoms (weight loss, disturbed food passage, signs and symptoms of upper gastrointestinal bleeding or anaemia, and persistent 
vomiting) was higher in patients with gastro-oesophageal cancer, especially for weight loss and disturbed food passage, none of the individual alarm symptoms identified more than $30 \%$ of patients with gastro-oesophageal cancer. When used in combination ('having any alarm symptom') sensitivity increased, but still more than a third of all patients with gastro-oesophageal cancer would have been missed. This is contradictory to the results of several retrospective case series reporting that more than $90 \%$ of patients with gastro-oesophageal cancer had alarm symptoms. ${ }^{10}$ This discrepancy may be explained by the fact that the latter patients may have had more advanced cancers which are less often asymptomatic, ${ }^{22}$ as well as by recall bias leading to an overestimation of the prevalence of alarm symptoms before endoscopy.

The low sensitivity of alarm symptoms is supported by several other studies. Lieberman et al. ${ }^{23}$ who studied a very large database of endoscopy reports and showed that only $56 \%$ of patients with gastro-oesophageal cancer had alarm symptoms. In that study disturbed food passage was not used as an alarm symptom because this was an exclusion criterion. Marmo et al. ${ }^{24}$ studied over six thousand patients (of whom 58 with gastro-oesophageal cancer) and found a sensitivity of alarm symptoms of $62 \%$. However, a recent study by Bowrey et al. ${ }^{25}$ found a sensitivity of $85 \%$ in a population of four thousand patients $(3 \%$ prevalence of gastro-oesophageal cancer), although they stated that especially patients with curable cancers were not found when using alarm symptoms.

Our results are in concordance with another recent meta-analysis (not using individual patient data). Vakil et al. ${ }^{26}$ found a pooled sensitivity of $67 \%$ and a pooled specificity of $66 \%$ in a large population in which $19 \%$ of the patients reported one or more alarm symptoms.

Additionally, our data show that many patients, almost a third of the study population, reported one or more alarm symptoms. However, if vomiting was not taken into account this could be reduced to a quarter of the patients. This still is higher than the $11 \%$ prevalence of alarm symptoms in primary care patients with dyspeptic symptoms reported by Meineche-Schmidt et al. ${ }^{11}$ This difference can be explained by the fact that all patients in our meta-analysis were referred for endoscopy, while Meineche-Schmidt studied patient files of primary care patients, irrespective of endoscopy. Because having alarm symptoms is one of the indications to refer a patient for endoscopy, it seems plausible that the prevalence of alarm symptoms was higher in our study population than in the general population. Some 
degree of selection is also reflected by the relatively high prevalence of gastrooesophageal cancer in our study compared to the $0.5 \%$ prevalence of gastrooesophageal cancers reported by Meineche-Schmidt et al. ${ }^{11}$

Furthermore, the high prevalence of alarm symptoms may have been caused by the special focus on alarm symptoms. Most of the studies included in this meta-analysis used questionnaires asking specifically about alarm symptoms which may have led to the detection of a higher number of patients with relatively mild alarm symptoms. The same phenomenon may explain that Vakil et al. ${ }^{26}$ also found a high prevalence of alarm symptoms in a meta-analysis $(19 \%$, not including vomiting as an alarm symptom). Notably, Lieberman et al. ${ }^{23}$ found a lower prevalence of alarm symptoms $(14.5 \%)$ when using routine endoscopy reports. Furthermore, the type of questionnaire may also play a role since Marmo et al. ${ }^{24}$ found a lower prevalence of alarm symptoms (7\%) even although they also used patient questionnaires and not referral indications. Unfortunately, the severity of the alarm symptoms (such as the amount of weight loss) could not be taken into account in our analyses because all included studies used different definitions of alarm symptoms. However, the relative over-reporting of alarm symptoms in our study would not have decreased sensitivity. In fact, it would rather have led to an overestimation of the sensitivity (and specificity). Therefore, given the high prevalence of alarm symptoms in our study it may be deduced that the sensitivity and specificity of alarm symptoms in routine clinical practice may be even lower.

Additionally, alarm symptoms may have other causes besides gastro-oesophageal cancer, such as peptic ulcer disease. However, in more than $60 \%$ of patients with alarm symptoms, no organic disease was found at upper gastrointestinal endoscopy, and the prevalence of organic disease was only marginally higher than in patients without alarm symptoms. Therefore, in the majority of patients the alarm symptoms could not be explained by pathology in the upper gastrointestinal tract.

Thus, if of all patients in our database only those with alarm symptoms would have had endoscopy, this would have saved about three quarters of all endoscopies, but more than a third of all patients with gastro-oesophageal cancer would have been missed. And even though the prevalence of gastro-oesophageal cancer was twice as high in patients with alarm symptoms as in the study population as a whole, still only few of these patients had gastro-oesophageal cancer. In fact, the majority of these patients did not even have organic pathology detected at endoscopy. 
Therefore, besides alarm symptoms, other factors should be taken into account when selecting patients for endoscopy.

Our results show that age is an important factor. Unfortunately, there is a gradual increase in the risk of gastro-oesophageal cancer without a clear age cut-off, but nonetheless, in this population almost $90 \%$ of patients with gastro-oesophageal cancer were over 50 years of age. Endoscoping all patients over 50 in addition to those with alarm symptoms would have increased sensitivity and negative predictive value, but at the cost of specificity and positive predictive value. Applying this strategy would have saved a third of all endoscopies, while missing 5\% of gastrooesophageal cancers. In comparison, if only age over 50 would have been used to select patients for endoscopy irrespective of the presence of alarm symptoms, this would have saved $46 \%$ of endoscopies, while $11 \%$ of patients with gastrooesophageal cancer would have been missed. This emphasizes the important role for age.

Ideally, the exact age cut-off for each setting should be determined using data from the local population, since the age distribution of gastro-oesophageal cancer may vary. For example Boldys et al. ${ }^{27}$ showed that in a high-risk tertiary care population in Poland as many as $24 \%$ of patients with gastric cancer were under 45 years.

Moreover, there were other factors associated with gastro-oesophageal cancer. $H$. pylori infection and male gender were associated with a higher risk of gastrooesophageal cancer, while heartburn and current use of ASA/NSAIDs were associated with a lower risk. $H$. pylori infection is a known risk factor for gastric cancer and is associated with a 6-8 times higher risk of developing gastric (but not oesophageal) cancer. ${ }^{28}$ The higher risk for males has been confirmed by several other studies, but the aetiology is not clear. ${ }^{12,27}$ Possibly, gender is associated with other risk factors. It seemed somewhat surprising that the presence of heartburn was associated with a lower risk of gastro-oesophageal cancer, because several studies found an association of heartburn with Barrett's oesophagus and oesophageal cancer. However, Lieberman et al. ${ }^{23}$ found the same protective effect of heartburn for gastro-oesophageal cancer. This observation may be explained by the predominance of gastric malignancies in our population. And gastric cancer often arises from gastric atrophy which is associated with low acid production. ${ }^{29}$ Therefore, patients with heartburn symptoms probably have a lower risk of having gastric cancer. 
Interestingly, the use of ASA/NSAIDs was associated with a lower risk of gastrooesophageal cancer. Maybe, this can be explained by the role of ASA/NSAIDs in several cellular processes such as the induction of cell-cycle arrest, restoration of apoptosis and inhibition of angiogenesis. ${ }^{30}$ The chemo-preventive effect of ASA/NSAIDs has been studied most thoroughly for colon cancer, and regular intake of ASA/NSAIDs is associated with a decreased risk of developing colon adenomas and adenocarcinomas. ${ }^{31}$ The same mechanism is probably also important for the development of other malignancies. Several case-control studies suggest that ASA/NSAIDs may have a chemo-preventive effect for oesophageal and gastric cancer as well. ${ }^{32-34}$ Our data further support this hypothesis. Unfortunately, we had no data regarding the duration of ASA/NSAID therapy. Therefore, it could not be determined whether this effect was limited to long-term users.

In conclusion, more than a third of patients with gastro-oesophageal cancer had no alarm symptoms, while only few of the patients with alarm symptoms had gastrooesophageal cancer. Therefore, alarm symptoms are far from ideal for selection of patients at risk. Other factors such as age, H. pylori infection, gender, use of ASA/NSAIDs, and presence of heartburn symptoms should be taken into account when estimating each individual's risk.

\section{References}

1. Heading RC. Prevalence of upper gastrointestinal symptoms in the general population: a systematic review. Scand J Gastroenterol 1999; 34 (Suppl.): 2-8.

2. Talley NJ, Weaver AL, Tesmer DL, Zinsmeister AR. Lack of discriminant value of dyspepsia subgroups in patients referred for upper endoscopy. Gastroenterology 1993; 105: 1378-86.

3. McColl KE, Murray LS, Gillen D, Walker A, Wirz A, Fletcher J, Mowat C, Henry E, Kelman A, Dickson A. Randomised trial of endoscopy with testing for Helicobacter pylori compared with non-invasive $H$. pylori testing alone in the management of dyspepsia. BMJ 2002; 324: 999-1002.

4. Lassen AT, Pedersen FM, Bytzer P, Schaffalitzky de Muckadell OB. Helicobacter pylori test-and-eradicate versus prompt endoscopy for management of dyspeptic patients: a randomised trial. Lancet 2000; 356: 45560 . 
5. Laheij RJF, Severens J, van de Lisdonk E, et al. Randomised controlled trial of omeprazole or endoscopy in patients with persistent dyspepsia: a costeffectiveness analysis. Aliment Pharmacol Ther 1998; 12: 1249-56.

6. Delaney BC, Innes MA, Deeks J, et al. Initial treatment strategies for dyspepsia (Cochrane Review). In: The Cochrane Library, Issue 3, 2002. Oxford: Update Software.

7. Eisen GM and the Standards of Practice Committee. The role of endoscopy in dyspepsia. Gastrointest Endosc 2001; 114: 582-95.

8. American Gastroenterology Association medical position statement and technical review. Evaluation of dyspepsia. Gastroenterol 1998; 114: 579-95.

9. Malfertheiner P, Megraud F, O’Morain C, Hungin AP, Jones R, Axon A, et al. Current concepts in the management of Helicobacter pylori infection - the Maastricht 2-2000 Consensus Report. Aliment Pharmacol Ther 2002; 16: 16780.

10. Fransen GAJ, Janssen MJR, Muris JWM, Laheij RJF, Jansen JBMJ. The diagnostic value of alarm symptoms for upper gastrointestinal malignancy: a meta-analysis. Aliment Pharmacol Ther 2004; 20: 1-8.

11. Meineche-Schmidt V, Jørgensen T. 'Alarm symptoms' in patients with dyspepsia: a three-year prospective study from general practice. Scan J Gastroenterol 2002; 7: 999-1007.

12. Wallace MB, Durkalski VL, Vaughan J, Palesch YY, Libby ED, Jowell PS, et al. Age and alarm symptoms do not predict endoscopic findings among patients with dyspepsia: a multicentre database study. Gut 2001; 49: 29-34.

13. Melleney EMA, Willoughby CP. Audit of a nurse endoscopist based one stop dyspepsia clinic. Postgrad Med J 2002; 78: 161-4.

14. Johannessen T, Petersen H, Kleveland PM, Dybdahl JH, Sandvik AK, Brenna $\mathrm{E}$, et al. The predictive value of history in dyspepsia. Scand J Gastroenterol 1990; 25: 689-97.

15. Manes G, Balzano A, Marone P, Lioniello M, Mosca S. Appropriateness and diagnostic yield of upper gastrointestinal endoscopy in an open-access endoscopy system: a prospective observational study based on the Maastricht guidelines. Aliment Pharmacol Ther 2002; 16: 105-10.

16. Adang RP, Vismans JF, Talmon JL, Hasman A, Ambergen AW, Stockbrugger RW. Appropriateness of indications for diagnostic upper gastrointestinal endoscopy: association with relevant endoscopic disease. Gastrointest Endosc 1995; 42: 390-7 
17. Voutilainen M, Mantynen T, Kunnamo I, Juhola M, Mecklin JP, Farkkila M. Impact of clinical symptoms and referral volume on endoscopy for detecting peptic ulcer and gastric neoplasms. Scand J Gastroenterol 2003; 38: 109-13.

18. Hammer J, Eslick GD, Howell SC, Altiparmak E, Talley NJ. Diagnostic yield of alarm features in irritable bowel syndrome and functional dyspepsia. Gut 2004; 53: 666-72.

19. Sung JJ, Lao WC, Lai MS, Li TH, Chan FK, Wu JC, et al. Incidence of gastroesophageal malignancy in patients with dyspepsia in Hong Kong: implications for screening strategies. Gastrointest Endosc 2001; 54: 454-8.

20. Numans ME, van der Graaf Y, de Wit NJ, de Melker RA. How useful is selection based on alarm symptoms in requesting gastroscopy? An evaluation of diagnostic determinants for gastro-oesophageal malignancy. Scand $J$ Gastroenterol 2001; 36: 437-43.

21. Thomson ABR, Barkun AN, Armstrong D, Chiba N, White RJ, Daniels A, Escobedo S, Chakraborty B, Sinclair P, Veldhuyzen van Zanten SJO. The prevalence of clinically significant endoscopic findings in primary care patients with uninvestigated dyspepsia: the Canadian adult dyspepsia empiric treatment prompt endoscopy (CADET-PE) study. Aliment Pharmacol Ther 2003; 17: 1481-91.

22. Maconi G, Kurihara H, Panizzo V, Russo A, Cristaldi M, Marelli D, Roviello F, De Manzoni G, Di Leo A, Morgagni P, Bechi P, Bianchi Porro G, Taschieri AM. Gastric cancer in young patients with no alarm symptoms: focus on delay in diagnosis, stage of neoplasm and survival. Scand J Gastroenterol 2003; 38: 1249-55.

23. Lieberman D, Fennerty MB, Morris CD, Holub J, Eisen G, Sonnenberg A. Endoscopic evaluation of patients with dyspepsia: results from the national endoscopic data repository. Gastroenterology 2004; 127: 1067-75.

24. Marmo R, Rotondano G, Piscopo R, Bianco MA, Russo P, Capobianco P, Cipoletta L. Combination of age ad sex improves the ability to predict upper gastrointestinal malignancy in patients with uncomplicated dyspepsia: a prospective multicentre database study. Am J Gastroenterol 2005; 100: 784-91.

25. Bowrey DJ, Griffin SM, Wayman J, Karat D, Hayes N, Raimes SA. Use of alarm symptoms to select dyspeptics for endoscopy causes patients with curable esophagogastric cancer to be overlooked. Surg Endosc 2006; 20: 1725-8. 
26. Vakil N, Moayyedi P, Fennerty MB, Talley NJ. Limited value of alarm features in the diagnosis of upper gastrointestinal malignancy: systematic review and meta-analysis. Gastroenterology 2006; 131: 390-401.

27. Boldys H, Marek, TA, Wanczura P, Matusik P, Nowak A. Even young patients with no alarm symptoms should undergo endoscopy for earlier diagnosis of gastric cancer. Endoscopy 2003; 35: 61-7.

28. Uemura N, Okamoto S, Yamamoto S, Matsumura N, Yamaguchi S, Yamakido M, Taniyama K, Sasaki N, Schlemper RJ. Helicobacter pylori infection and the development of gastric cancer. N Engl J Med 2001; 345: 784-9.

29. McColl KE. Review article: Helicobacter pylori and gastro-oesophageal reflux disease--the European perspective. Aliment Pharmacol Ther 2004; 20 (Suppl. 8): $36-9$

30. Huls G, Koornstra JJ, Kleibeuker JH. Non-steroidal anti-inflammatory drugs and molecular carcinogenesis of colorectal adenomas. Lancet 2003; 362: 230-2.

31. Courtney EDJ, Melville DM, Leicester RJ. Review article: chemoprevention of colorectal cancer. Aliment Pharmacol Ther 2004; 19: 1-24.

32. Corley DA, Kerlikowske K, Verma R, Buffler P. Protective association of aspirin/NSAIDs and esophageal cancer: a systematic review and meta-analysis. Gastroenterology 2003; 124: 47-56.

33. Coogan PF, Rosenberg L, palmer JR, Strom BL, Zauber AG, Stolley PD, Shapiro S. Nonsteroidal anti-inflammatory drugs and risk of digestive cancers at site other than the large bowel. Cancer Epidemiol Biomarkers Prev 2000; 9: 119-23.

34. Langman MJS, Cheng KK, Gilman EA, Lancashire RJ. Effect of antiinflammatory drugs on overall risk of common cancer: case control study in general practice research database. BMJ 2000; 320: 1642-6. 


\section{Chapter 5}

Measuring the severity of upper gastrointestinal complaints: does GP-assessment correspond with patients' self-assessment?

G.A.J. Fransen, M.J.R. Janssen, J.W.M. Muris, I. Mesters \& J.A. Knottnerus

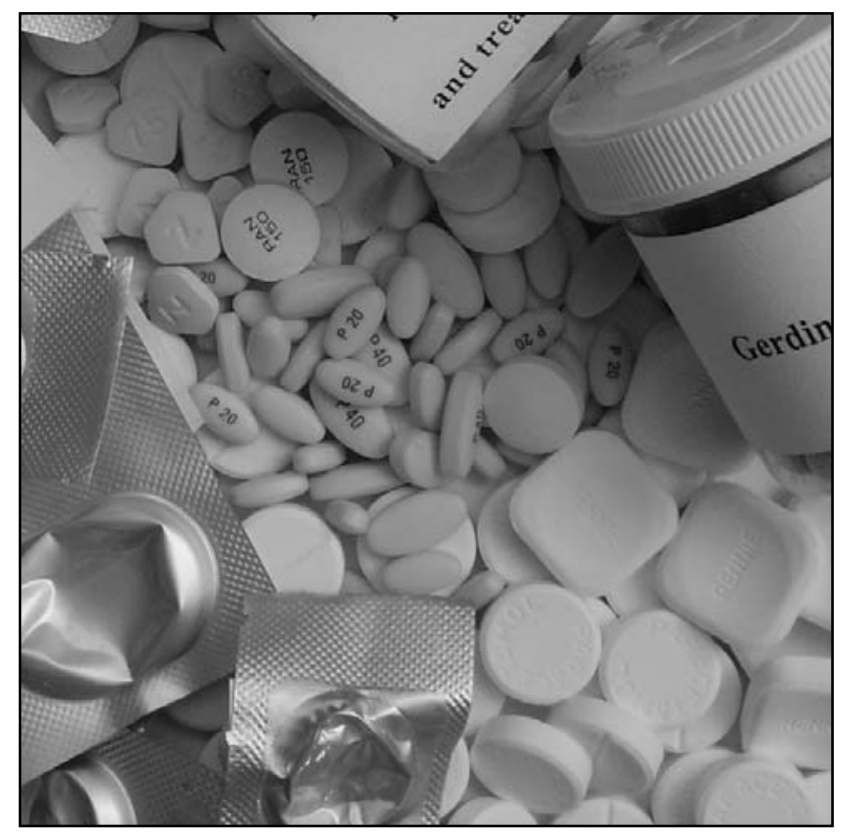




\begin{abstract}
Background: Questionnaires are frequently used to measure the severity of gastrointestinal complaints. These questionnaires can either be filled out by the physicians or by the patients, but it is not clear whether these scores correspond. This study aimed to investigate the interrater agreement between physician-reported severity and patient-reported severity concerning the patients' upper GI complaints.

Methods: In a prospective observational study the severity of 8 GI complaints was registered by both patients and GPs independently on a 7-point scale $(\mathrm{N}=316)$ before and after treatment with esomeprazole. Weighted kappa values for the agreement on the severity and simple kappa values for the agreement on the absence or presence of symptoms were calculated.

Results: The weighted kappa values ranged from 0.14 to 0.68 indicating poor to moderate agreement. The agreement on the presence or absence of symptoms was similar. Several systematic differences in scoring were found: the GPs tended to underestimate the severity of belching, nausea, early satiety, vomiting, upper and lower abdominal pain. Furthermore, the treatment effect for belching and lower abdominal pain was more often overestimated, while the treatment effect for nausea was more often underestimated by the GP.

Conclusion: The agreement between GP and patient is low. The differences in scoring should be kept in mind when comparing physician-reported outcomes with patient-reported outcomes.
\end{abstract}




\section{Introduction}

The severity of upper gastrointestinal (GI) complaints is frequently used to evaluate treatment strategies. Because of the lack of more objective clinical outcomes questionnaires are often used to measure the severity of GI complaints. ${ }^{1}$ These questionnaires can either be filled out by the physician during the interview (physician-reported outcomes), ${ }^{2}$ or be used by the patient in a self-administered way (patient-reported outcomes). ${ }^{3}$ The results of these two methods of assessment of GI complaints are often compared as if there were no difference between the two. However, Bytzer ${ }^{1}$ stated that physicians tend to be more optimistic about the treatment effect than patients; i.e. the type of assessment might influence the evaluation of effectiveness and subsequently the study outcome. In fact, few studies have investigated the interrater agreement between patient- and physicianadministered questionnaires for the severity of upper GI complaints. Therefore, in order to be able to interpret results from studies using questionnaires to measure symptom severity, it is very important to know whether the physician score does correspond with the patient score.

This study aims to examine the interrater agreement between physician and patient concerning the severity of the patients' upper GI complaints, both for baseline and follow up assessments. Furthermore, we investigated whether patient and general practitioner (GP) agreed on the change in severity of the complaints between baseline and follow up measurement, because it is possible that GP and patient disagree on severity at baseline and at follow up, but do agree on the decrease or increase of severity during treatment.

\section{Methods}

Respondents and procedure

This observational study is part of a larger prospective study investigating the effectiveness of proton pump inhibitor therapy with esomeprazole (40mg) for treatment of primary care patients with upper GI symptoms. Patients who consulted their GP for upper GI symptoms and received an esomeprazole prescription were eligible. Exclusion criteria were the presence of alarm symptoms or the use of a proton pump inhibitor during the month prior to inclusion. Each GP could include up to ten patients. When a patient was included for the effectiveness study, the GP collected basic demographic variables, information about the prescribed treatment, 
and scored the severity of the patient's upper GI complaints, all on a printed form (GP CRF).

A subgroup of the GPs participating in the effectiveness study participated in the present study comparing patient- and GP-administered GI symptom questionnaires. These GPs invited their patients to fill out questionnaires about the severity of their complaints themselves. It is possible that these GPs did not invite all eligible patients to participate in the present study, but we could not check this. The patientadministered questionnaires were to be filled out at home and returned anonymously to the investigators by a pre-stamped addressed envelope. By means of an identical pre-printed number the GP CRF and the patient questionnaire could be linked for purpose of analysis.

\section{Measurements}

Data were collected at baseline and at the follow up visit. Both GPs and patients used the same scale measuring the severity of eight upper GI complaints of the last week on a 7-point Likert scale ranging from zero (none) to six (very severe). ${ }^{4}$ This simple scale has been proven clinically useful and is used in several ongoing studies. The scale is based on other widely used validated scales and has been validated by Bovenschen et al. ${ }^{4}$

\section{Statistical analysis}

To avoid differences between GP and patient scoring due to changes in time (treatment or natural course), only questionnaires filled out at the same moment in time were compared. Therefore, we excluded patient questionnaires filled out two days or more after the consultation. To check whether this exclusion led to selective drop out, in- and excluded patients were compared for gender, age, and severity of the complaints using a $\chi^{2}$-test and two-sided Student's t-test.

Cohen's kappa is often used for measuring reliability between observers, as it compares the observed agreement with perfect agreement while correcting for chance. Because of the 7-point scale we calculated the weighted kappa, which means that observations on the diagonal in the seven by seven cross table of GP scores versus patient scores (correspondence of scores) are given a higher weight than observations further away from the diagonal; the further from the diagonal the less weight for the observation. Standardized weights were calculated with SAS statistical software, we used the default available weight type: the Cicchetti-Allison 
type. Landis and $\mathrm{Koch}^{5}$ have suggested that kappa values of 0.4 indicate poor agreement, values of $0.4-0.6$ moderate agreement, and from 0.8 excellent agreement.

Additional to reporting the chance-corrected agreement (weighted kappa values) on the 7-point scale, we also present the chance-corrected agreement between patient and GP on the presence or absence of the complaints (simple kappa values). The absence of a symptom is defined by a score of zero on the 7-point scale. As suggested by Feinstein and Cicchetti $^{6}$ also the observed agreement should be reported. Therefore, we investigated how many patients scored exactly the same as their GPs, how many patients indicated more severe and how many patients indicated less severe complaints than their GPs. Furthermore, also differences of two points or more in GP and patient scoring were investigated, because to our opinion a difference of two points or more on a 7-point scale is clinically relevant and provides a good first impression of (dis-)agreement between GP and patient.

When there is a difference between the proportions of under- and overestimation, this will result in a difference between the mean GP scores and mean patient scores, indicating systematic differences. This was tested using two-sided Student's t-tests.

These analyses are presented for each symptom at baseline, at follow up, and for the change in severity over time (baseline score minus follow up score). All statistical analyses were performed using SAS statistical software (version 8.0, SAS institute Inc., Cary, NC, USA).

\section{Results}

\section{Response to the questionnaire}

In the effectiveness study 2,905 patients were included by 346 GPs. Of these GPs, 127 participated in the present study; they together included 1,027 patients for the effectiveness study. A total of 477 baseline and 425 follow-up questionnaires were returned. Sixty-nine patients only returned the follow-up questionnaire. Thus, 53\% (546 of 1,027) of the potentially invited patients returned one or more questionnaires.

Patients who returned one or more questionnaires (responders) had a similar age and gender distribution as non-responders. However, there were some statistically significant differences in the severity scores (GP administered): the responders 
tended to have more severe complaints of heartburn, regurgitation, belching, lower abdominal pain, and early satiety (mean differences resp. 0.17 95\% CI 0.02-0.33; 0.23 95\%CI $0.08-0.38 ; 0.37$ 95\%CI $0.23-0.52 ; 0.13$ 95\%CI $0.04-0.22 ; 0.2895 \% \mathrm{CI}$ $0.12-0.44)$.

\section{Exclusion because of time-lag between GP scoring and patient scoring}

Patient questionnaires filled out more than two days after the visit were excluded, resulting in 316 baseline and 269 follow-up questionnaires available for analysis. These patients were treated by 102 GPs. No differences for age or gender were found between included and excluded patients. Patients who filled out the questionnaire after two days of treatment had less severe heartburn, regurgitation and belching than patients who filled out the questionnaire at baseline (Table 5.1). This supports our decision to exclude these patients from analysis: it is likely that the severity of these symptoms has changed over time due to treatment or natural course, and therefore it is important to only take measurements into account that were done at the same moment.

Table 5.1. Mean patient scores of the included and excluded patients.

\begin{tabular}{|c|c|c|c|c|c|c|}
\hline & \multicolumn{3}{|l|}{ At baseline } & \multicolumn{3}{|c|}{ At follow up } \\
\hline & Included $^{\#}$ & Excluded & p-value ${ }^{1}$ & Included $^{\#}$ & Excluded & p-value ${ }^{1}$ \\
\hline Heartburn & 2.67 & 2.23 & $<0.01$ & 0.86 & 1.08 & $\mathrm{NS}$ \\
\hline Regurgitation & 2.33 & 1.86 & $<0.01$ & 0.76 & 0.97 & NS \\
\hline Belching & 2.20 & 1.95 & NS & 1.08 & 1.37 & 0.04 \\
\hline Upper GI pain & 2.52 & 2.19 & 0.04 & 0.94 & 1.34 & $<0.01$ \\
\hline Lower GI pain & 0.89 & 1.01 & $\mathrm{NS}$ & 0.45 & 0.71 & $<0.01$ \\
\hline Nausea & 1.29 & 1.09 & $\mathrm{NS}$ & 0.58 & 0.66 & NS \\
\hline Vomiting & 0.44 & 0.48 & $\mathrm{NS}$ & 0.15 & 0.29 & 0.03 \\
\hline Early satiety & 1.93 & 1.78 & $\mathrm{NS}$ & 1.05 & 1.18 & NS \\
\hline
\end{tabular}

\section{Patient characteristics}

The mean age of the included patients was 53 years (SD 16) and 57\% were male. Most of them (89\%) were treated for two weeks with esomeprazole $40 \mathrm{mg}, 3 \%$ for three weeks, and $8 \%$ for four weeks. Figure 5.1 shows the patients' and the GPs' 
mean severity scores and indicates that the patients had mild GI complaints at baseline which decreased significantly during treatment.

Figure 5.1. Mean symptom severity scores according to both patient and GP. The brackets indicate the $95 \%$ confidence interval.

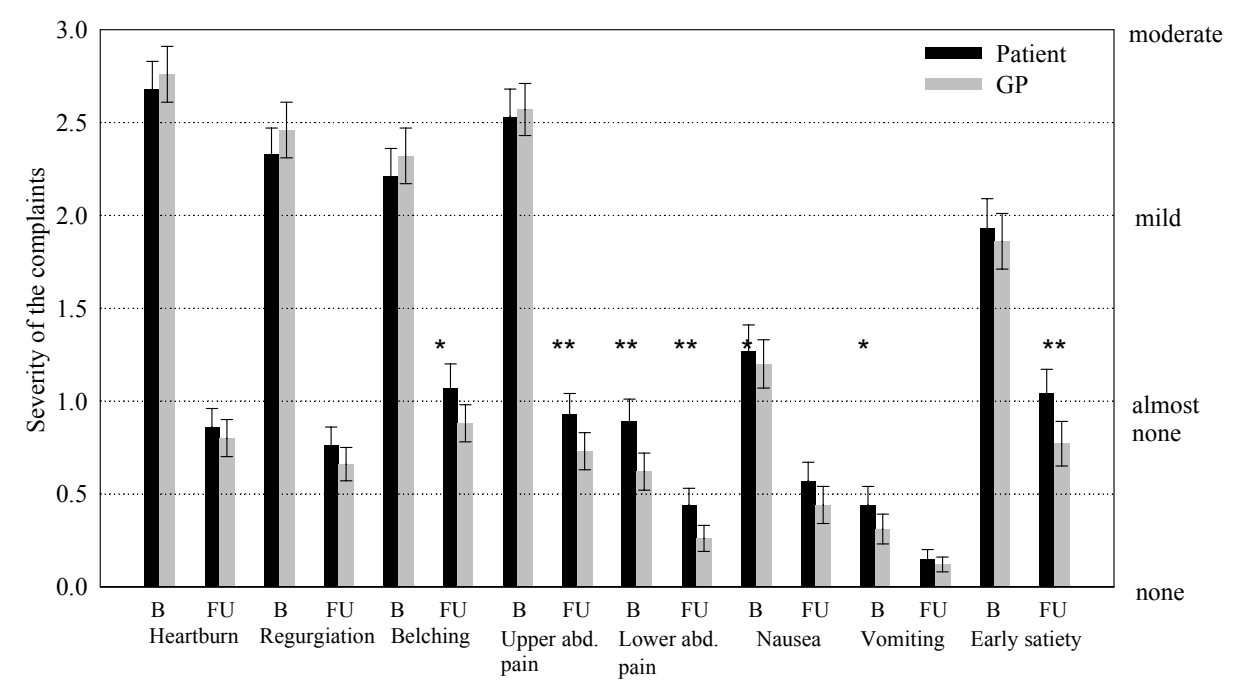

${ }^{*}$ p-value $<0.01,{ }^{*}$ p-value $<0.0001, \mathrm{~B}=$ Baseline, $\mathrm{FU}=$ Follow up.

\section{Measures of agreement}

The weighted kappa values at baseline varied from 0.48 to 0.60 , indicating moderate agreement (Table 5.2). At follow up the weighted kappa values were slightly higher and varied from 0.57 to 0.68 (Table 5.3). The simple kappa values on the presence or absence of agreement were quite comparable to the weighted kappa values, varying from 0.47 to 0.68 , indicating moderate agreement (Tables 5.2 and 5.3). For the change in severity the weighted kappa values varied from 0.14 to 0.57 , indicating poor to moderate agreement (Table 5.4).

These low rates of agreement were further investigated by looking at the proportions of cases with differences of two points or more in scoring (Table 5.2-5.4), the proportions of over- and underestimation of the severity (Table 5.2-5.4) and the differences between the mean patient score and the mean GP score (Figure 5.1 and Table 5.4). Regarding the differences of two points or more in scoring, it should be noted that these proportions were fairly large (up to $40 \%$ for the change in severity of nausea). This is in line with the low kappa values found. 


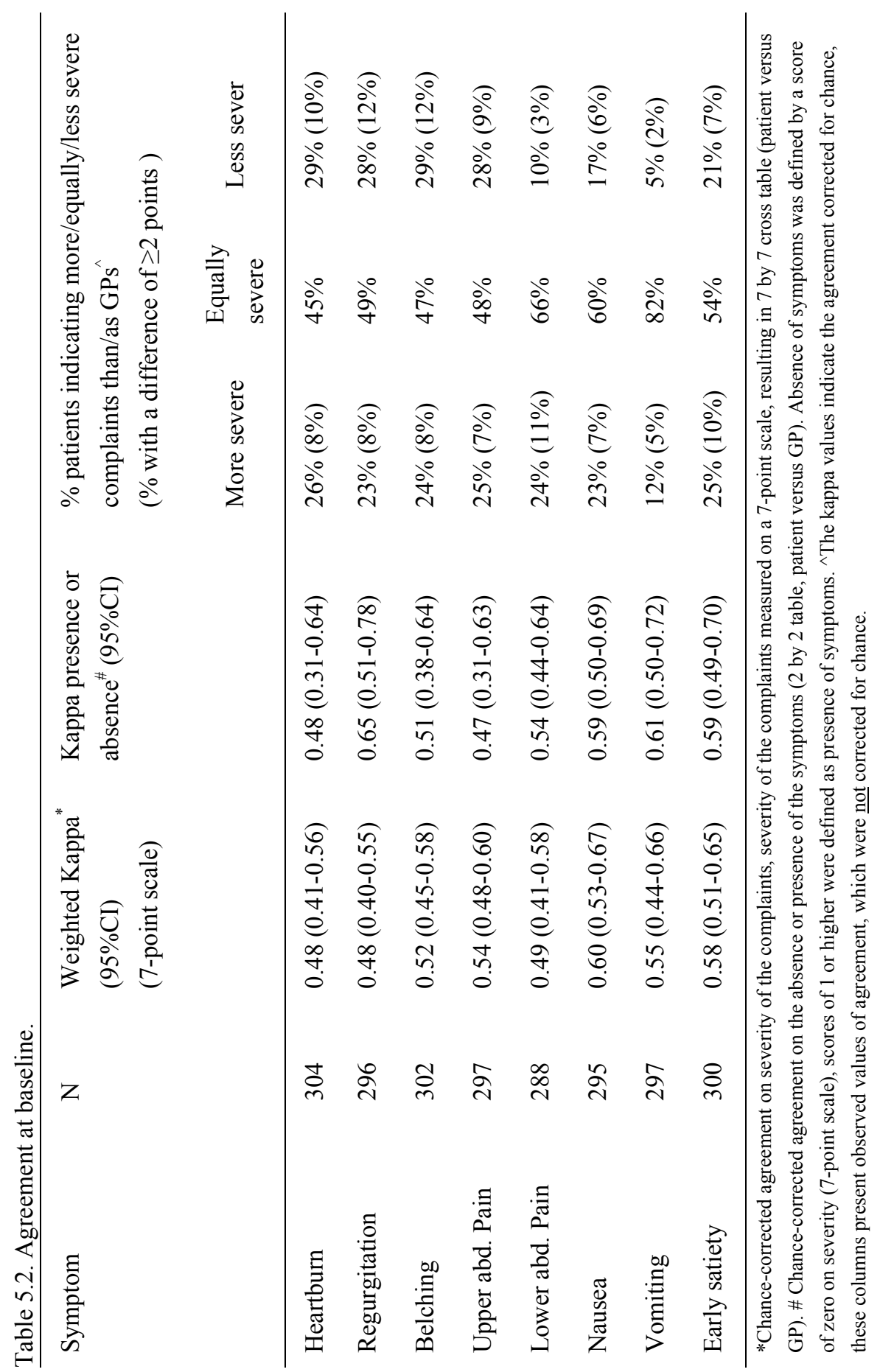




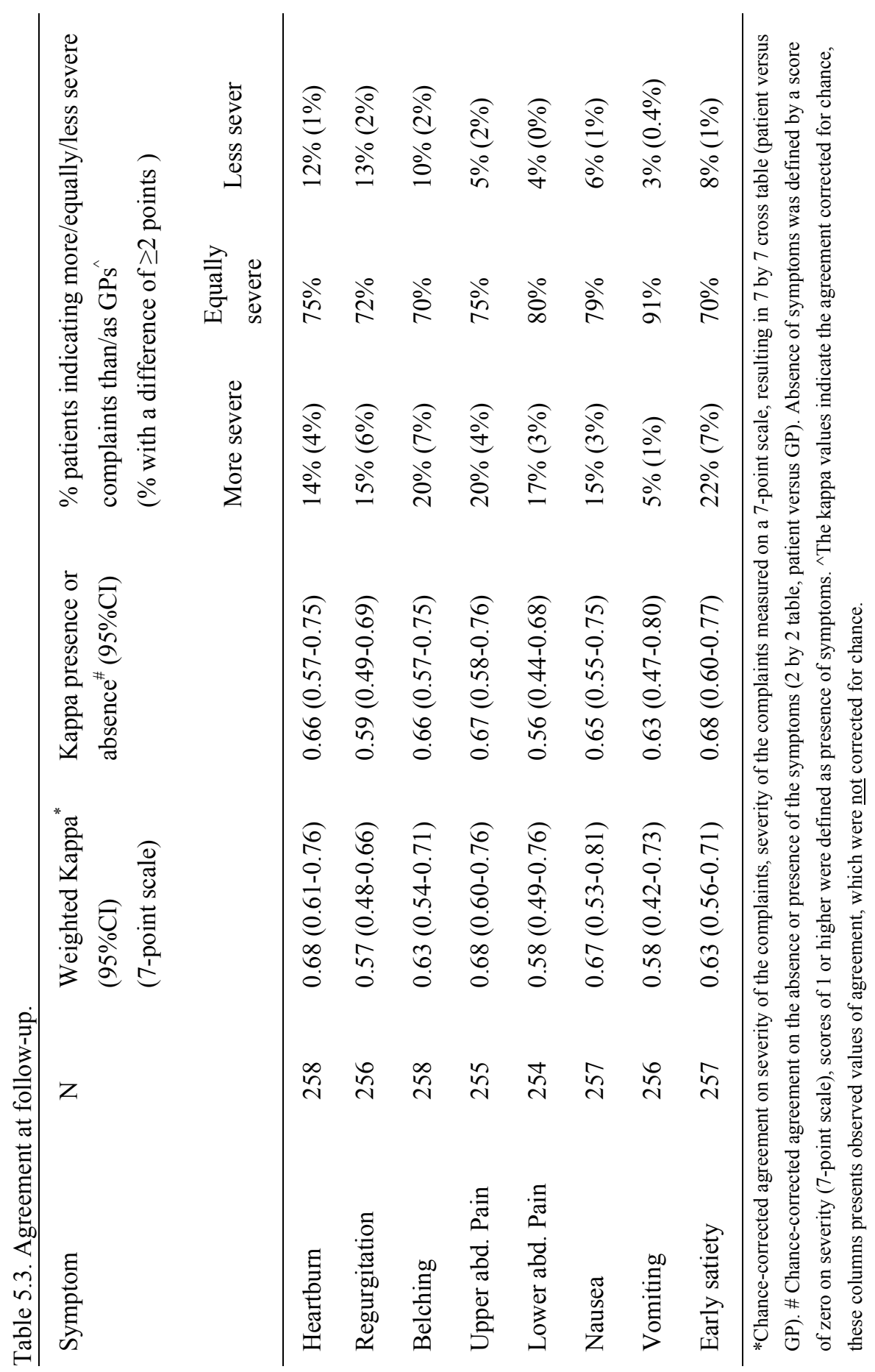




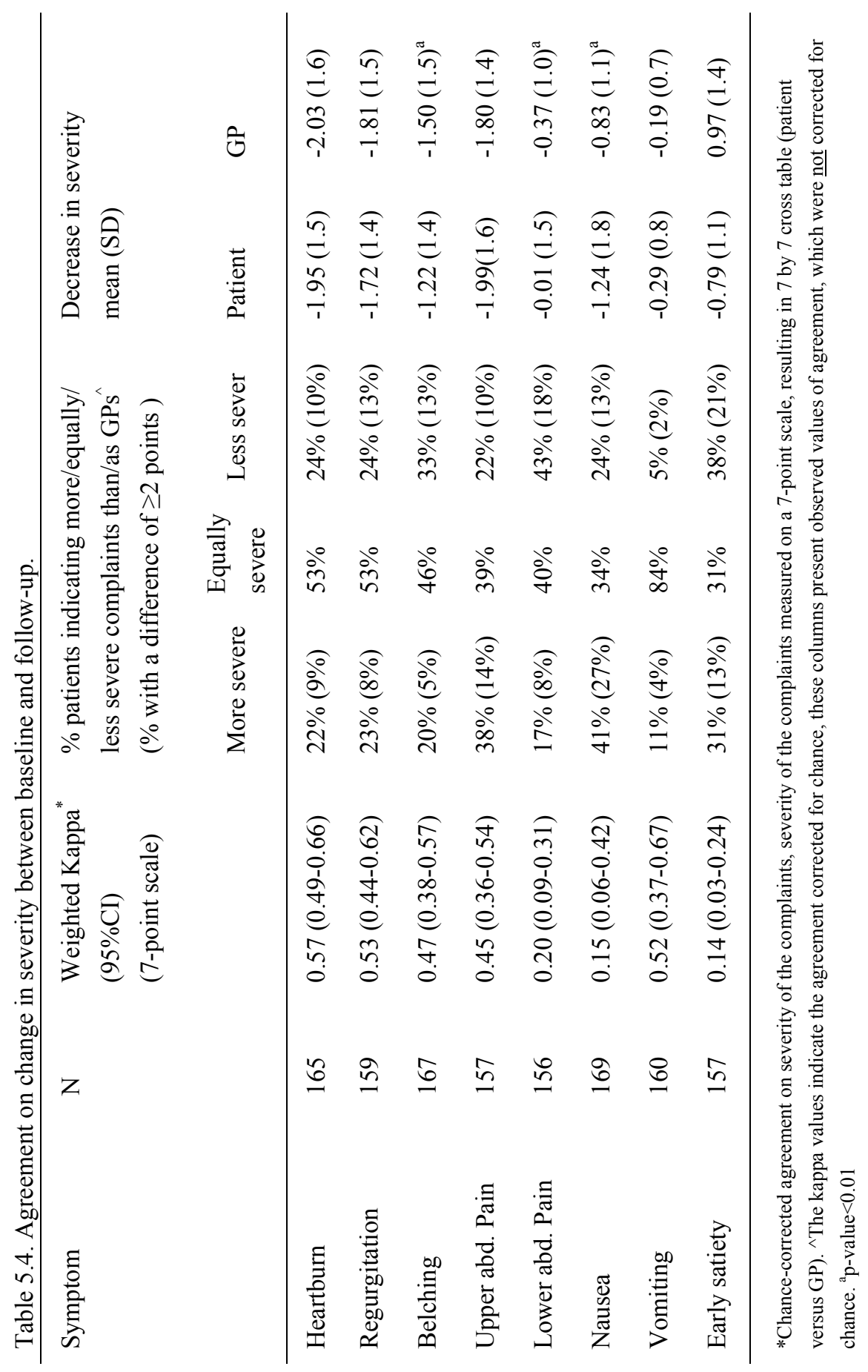


Regarding the over- and underestimation, for most symptoms, the severity was approximately as frequently underestimated as overestimated by GPs. For instance for heartburn at baseline (Table 5.2) $26 \%$ of the patients indicated more severe and $29 \%$ of the patients indicated less severe complaints than GPs. Also the proportions of cases with differences of 2 points or more were approximately similar for underand overestimation (e.g. for heartburn at baseline $8 \%$ versus $10 \%$ ). This is reflected in the small differences between the mean GP score and the mean patient score (Figure 5.1). However, although these differences tend to be small, some were statistically significant, e.g. for lower abdominal pain and vomiting at baseline. This indicates that there were systematic differences in the scores of these symptoms. Furthermore, concerning the change in severity, Table 5.4 shows that GPs were more optimistic than patients about the change in severity between baseline and follow up for belching and lower abdominal pain, but less optimistic about the change in severity of nausea.

\section{Discussion}

Studies investigating upper GI symptoms use patient-reported outcomes as well as physician-reported outcomes, but it is not clear whether these outcomes yield similar results. This study had two aims: firstly, to investigate the interrater agreement between GP and patient in measuring the severity of the patients' upper GI complaints before and after treatment, and secondly, to investigate the interrater agreement in measuring the treatment effect (change in severity). Concerning the first aim, the weighted kappa values indicated moderate agreement on the severity of the complaints. This did not improve when looking only at the agreement on the presence or absence of the complaints. Furthermore, several systematic differences in scoring were found: the GPs tended to underestimate the severity of belching, nausea, early satiety, vomiting, upper and lower abdominal pain. Concerning the second aim, the weighted kappas indicated poor to moderate agreement for the change in severity. The treatment effects for belching and lower abdominal pain were more often overestimated, while the treatment effect for nausea was more often underestimated by the GP. In general, in up to $40 \%$ of the cases the GP and patient substantially differed in their scoring.

Few other publications investigated the agreement between patient and physician concerning the severity of upper GI complaints measured on the same scale at the 
same time. Bytzer ${ }^{1}$ stated that physicians tend to be more optimistic about the treatment effect than patients, which is in line with our findings. This is also confirmed by a study of Sandmark et al. ${ }^{7}$ where the investigators rated approximately $75 \%$ of patients as completely symptom free after four weeks of omeprazole therapy, but only $55 \%$ of patients felt that their symptoms had completely resolved.

Two other studies support our findings, although their results were less thorough because they did not use the same measuring scales for physicians and patients at the same time. McColl and colleagues ${ }^{8}$ investigated the agreement between physician and patient in gastroesophageal reflux disease and found for the severity of reflux like symptoms weighted kappa values varying between 0.17 to 0.53 at baseline and 0.31 to 0.73 at follow up. Furthermore, Revicki et al. ${ }^{9}$ found that patients with more severe complaints according to the physician (based on interviews) also had higher means for severity on the self-reported scale. However, because physicians and patients used different rating scales no definite conclusions can be drawn about the agreement between physician and patient.

Another study supports our findings: Quan et al. ${ }^{10}$ validated a diabetes bowel symptom questionnaire. They used the same questionnaire for both physician interviews and patient reported severity of the GI complaints, but not at the same moment in time. The patients were interviewed only once by the physician, approximately one week after filling out the follow up questionnaire, which makes the occurrence of recall bias likely. According to Quan et al. ${ }^{10}$ the interquartile range of the kappa value of all GI items was 0.24 to 0.64 (median 0.47), when looking only at the presence/absence of symptoms. For the severity of the GI complaints they found an even poorer agreement, with a median kappa value of 0.14 and an interquartile range from -0.87 to 0.40 .

In our study the GPs and the patients used exactly the same measuring scale. Furthermore, measurements were done at the same moment in time, thus minimizing differences due to treatment or natural course between GP and patient assessment of the symptoms.

Despite our efforts to minimize sources of bias, there may be some limitations. Fifty-three percent of the patients returned one or more questionnaires, which is acceptable considering the fact that we were not able to send reminders because of the anonymity. In fact, the response rate might even be higher in reality since we were not able to check whether all 1,027 patients actually received the 
questionnaires; some GPs might not have handed out questionnaires to all their patients. Nevertheless, because participation of patients was voluntarily, there may be some response bias. Patients who returned the questionnaire may on the one hand be more communicative about their complaints, which might have led to higher agreement if they also communicated more elaborately about their symptoms with their GPs. On the other hand, some of these patients might belong to a group of patients regarded as 'complainers' by their GPs, which may lead to less agreement about the severity of their symptoms. Overall, this may probably not have had a large influence on agreement.

Furthermore, there seemed to be selection of patients with slightly more severe complaints. Maybe the severity of the complaints triggered these patients more to participate. Nevertheless, the selected patients still had only moderate dyspeptic symptoms, and do not constitute a sub group of patients with extreme symptoms.

Moreover, agreement results may depend on communication style and skills of individual GPs. Participating GPs were not extensively instructed how to use the symptom scale. It is possible that some GPs scored the severity based on their own clinical impression after history taking, which might have led to low agreement if these GPs were not completely in tune with their patients. But by including a large group of GPs from across the Netherlands we assumed that GP skills would be representative for the Dutch GPs in general. In order not to over-represent individual GP characteristics, inclusion was limited to 10 patients per GP. Therefore, our results probably are representative for the Dutch population of GPs and patients with dyspeptic symptoms.

The relatively low levels of agreement raise concerns. In every day practice the agreement between GP and patient might be even worse compared to our findings because of our patient selection. The investigated population only consisted of patients for whom physicians decided that treatment with a proton pomp inhibitor was needed. Furthermore, the patients agreed to participate in a study investigating their upper GI complaints. Therefore, one can safely assume that both GPs and patients participating in this study agreed (at least) on the presence of upper GI complaints and even on the need for treatment, which already implicates some level of agreement. In every day practice, patient and GP will not always agree on the need for treatment, so agreement in the primary care population is expected to be lower. This is supported by a study by our group ${ }^{11}$ in which the perceptions of patients with unexplained upper GI symptoms were investigated. This study 
illustrated that these patients felt that their complaints were not taken seriously by their GPs and that they were unsatisfied with their treatment. The low agreement on the severity of complaints is supported by these findings and indicates that the communication about the severity of symptoms needs to be enhanced.

In conclusion, the low agreement between GP and patients indicate that there is room for improvement concerning the communication about upper GI symptom severity between GP and patient, especially in the initial consultation. In general, GPs as frequently overestimated as underestimated the severity of reflux-like symptoms. The severity of belching, nausea, early satiety, vomiting, upper and lower abdominal pain are however more often underestimated by the GP. Compared to patients, GPs were more optimistic about the treatment effects for belching and lower abdominal pain but less optimistic for the change in severity of nausea. This should be kept in mind when comparing physician-reported outcomes with patientreported outcomes concerning the severity of their upper-GI complaints and treatment effects.

\section{References}

1. Bytzer P. Assessment of reflux symptom severity: methodological options and their attributes. Gut 2004; 53 Suppl 4: iv28-iv34.

2. Westbrook JI, Duggan AE, Duggan JM, Westbrook MT. A 9 year prospective cohort study of endoscoped patients with upper gastrointestinal symptoms. Eur J Epidemiol 2005; 20: 619-27.

3. Veldhuyzen van Zanten S., Fedorak RN, Lambert J, Cohen L, Vanjaka A. Absence of symptomatic benefit of lansoprazole, clarithromycin, and amoxicillin triple therapy in eradication of Helicobacter pylori positive, functional (nonulcer) dyspepsia. Am J Gastroenterol 2003; 98: 1963-9.

4. Bovenschen HJ, Janssen MJ, van Oijen MG, Laheij RJ, van Rossum LG, Jansen JB. Evaluation of a Gastrointestinal Symptoms Questionnaire. Dig Dis Sci 2006; 51: 1509-15.

5. Landis JR, Koch GG. The measurement of observer agreement for categorical data. Biometrics 1977; 33: 159-74.

6. Cicchetti DV, Feinstein AR. High agreement but low kappa: II. Resolving the paradoxes. J Clin Epidemiol 1990; 43: 551-8. 
7. Sandmark S, Carlsson R, Fausa O, Lundell L. Omeprazole or ranitidine in the treatment of reflux esophagitis. Results of a double-blind, randomized, Scandinavian multicenter study. Scand J Gastroenterol 1988; 23: 625-32.

8. McColl E, Junghard O, Wiklund I, Revicki DA. Assessing symptoms in gastroesophageal reflux disease: how well do clinicians' assessments agree with those of their patients? Am J Gastroenterol 2005; 100: 11-8.

9. Revicki DA, Wood M, Wiklund I, Crawley J. Reliability and validity of the Gastrointestinal Symptom Rating Scale in patients with gastroesophageal reflux disease. Qual Life Res 1998; 7: 75-83.

10. Quan C, Talley NJ, Cross S, Jones M, Hammer J, Giles N, et al. Development and validation of the Diabetes Bowel Symptom Questionnaire. Aliment Pharmacol Ther 2003; 17: 1179-87.

11. Fransen GAJ, Mesters I, Bonten E, Muris JWM. Expectations of patients regarding the management of gastrointestinal problems. Gut 2004; 53 suppl 4: A284. 
Dyspepsia in primary care: patient expectations, symptoms, and treatment adherence 


\section{Chapter 6}

Which patient related factors determine patient adherence to prescribed dyspepsia medication?

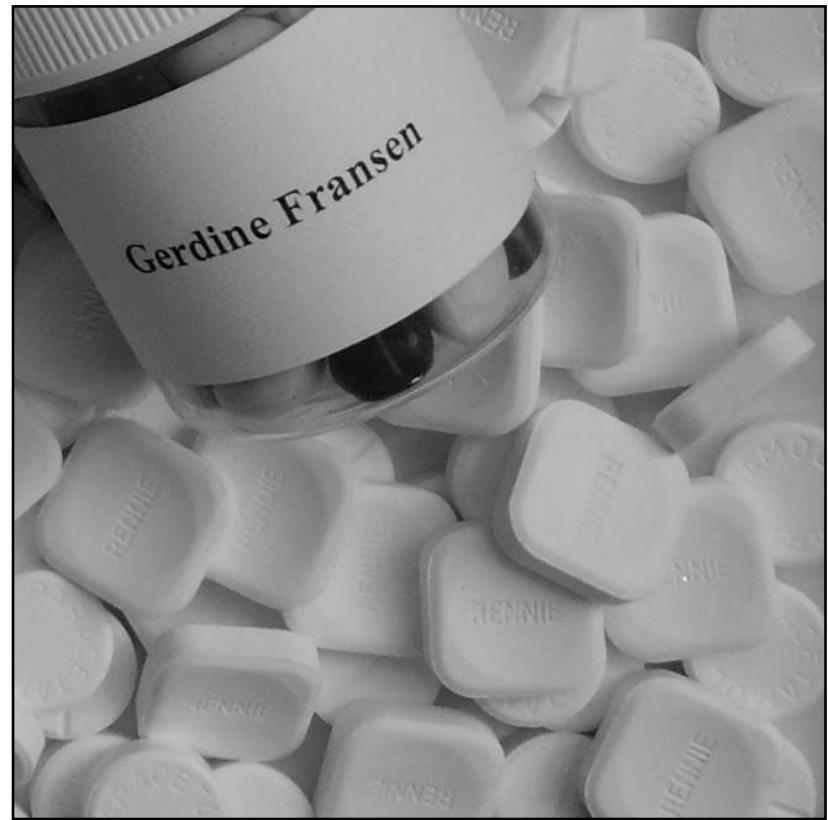




\begin{abstract}
Background: Patient adherence to medical treatment for dyspepsia is disappointing, whereas adherence is crucial for a proper evaluation of treatment.

Methods: This prospective study used elements of the Integrated Change Model and Weiner's Attribution Theory to describe patients' important cognitions and their interrelationships regarding adherence to short-term medical treatment for dyspepsia. Patient questionnaires measured the predictors before treatment and selfperceived adherence after treatment.

Results: Approximately one quarter of the patients indicated that they were nonadherent $(\mathrm{N}=347)$. Univariate and multiple linear regression analyses revealed several significant predictors that explained $44 \%$ of the variance in self-perceived adherence. Patients with a low educational level, patients who claimed to regularly forget their medication in general, patients with a low self-efficacy, or a low intention were less likely to be adherent.

Discussion: These results may indicate targets for interventions designed to improve adherence to medical treatment for dyspepsia. For instance, asking about expected difficulties in taking acid-suppressants (e.g. forgetfulness or medication use at weekends) and making action plans to overcome these difficulties (e.g. using reminders) may result in improved adherence rates. Such an approach may reach a substantial number of patients, since one in five patients in our study experienced some difficulties in taking medication.
\end{abstract}




\section{Introduction}

This prospective study investigated patient adherence to medical treatment for dyspepsia and adherence predictors. Dyspepsia is very common in general practice: approximately four times a week a general practitioner (GP) sees a patient with dyspepsia. ${ }^{1}$ The socio-economic impact of dyspepsia is considerable; in The Netherlands, $13 \%$ of the medication budget is spent on acid-suppressants, i.e. more than 400 million euros per year. ${ }^{2}$ Clinical guidelines ${ }^{1}$ recommend short-term treatment with acid-suppressive medication, the effects of which should be properly evaluated to verify that the symptoms are acid-related and to confirm the diagnosis of dyspepsia. There are several types of acid-suppressants; the most frequently used, the most effective but also the most expensive, acid-suppressants are proton pump inhibitors (PPIs), available only on physician prescription. This study focuses on the use of PPIs. Several studies have shown that $25 \%{ }^{3}$ to $45 \%{ }^{4}$ of patients take less than $80 \%$ of their prescribed PPIs during treatment. Non-adherence to prescribed acidsuppressants minimizes the chances of potential treatment success, precludes a proper evaluation of treatment effects (especially in the case of treatment failure) and is associated with a waste of expensive medicines.

To improve our understanding of the variation in PPI adherence, social cognitive predictors were assessed. Determinants of adherence in general were summarized by Meichenbaum and Turk ${ }^{5}$ and Bosworth. ${ }^{6}$ They mentioned several patient related determinants, for instance inadequate patient beliefs, patient dissatisfaction, lack of understanding and lack of social support. However, it is not known whether these determinants are associated with adherence in the case of dyspepsia. Results from a qualitative study by our group indicated that patients were reluctant to use PPI medication because they believed that this medication did not permanently eliminate their complaints and only masked them, with the implication that a more serious disease, such as cancer, ${ }^{7}$ might go unnoticed. A literature search for influential factors in respect of adherence in patients with dyspepsia revealed only one brief report from the UK. ${ }^{8}$ The UK study concluded that the absence of severe symptoms and the desire to remain in personal control, together with the higher fear of side effects and a lack of knowledge about the drugs, negatively influenced patient adherence to long-term PPI prescriptions. However, in this brief report no effect sizes of any kind were reported, and we were not able to judge the presence and magnitude of the difference between adherent and non-adherent patients. 


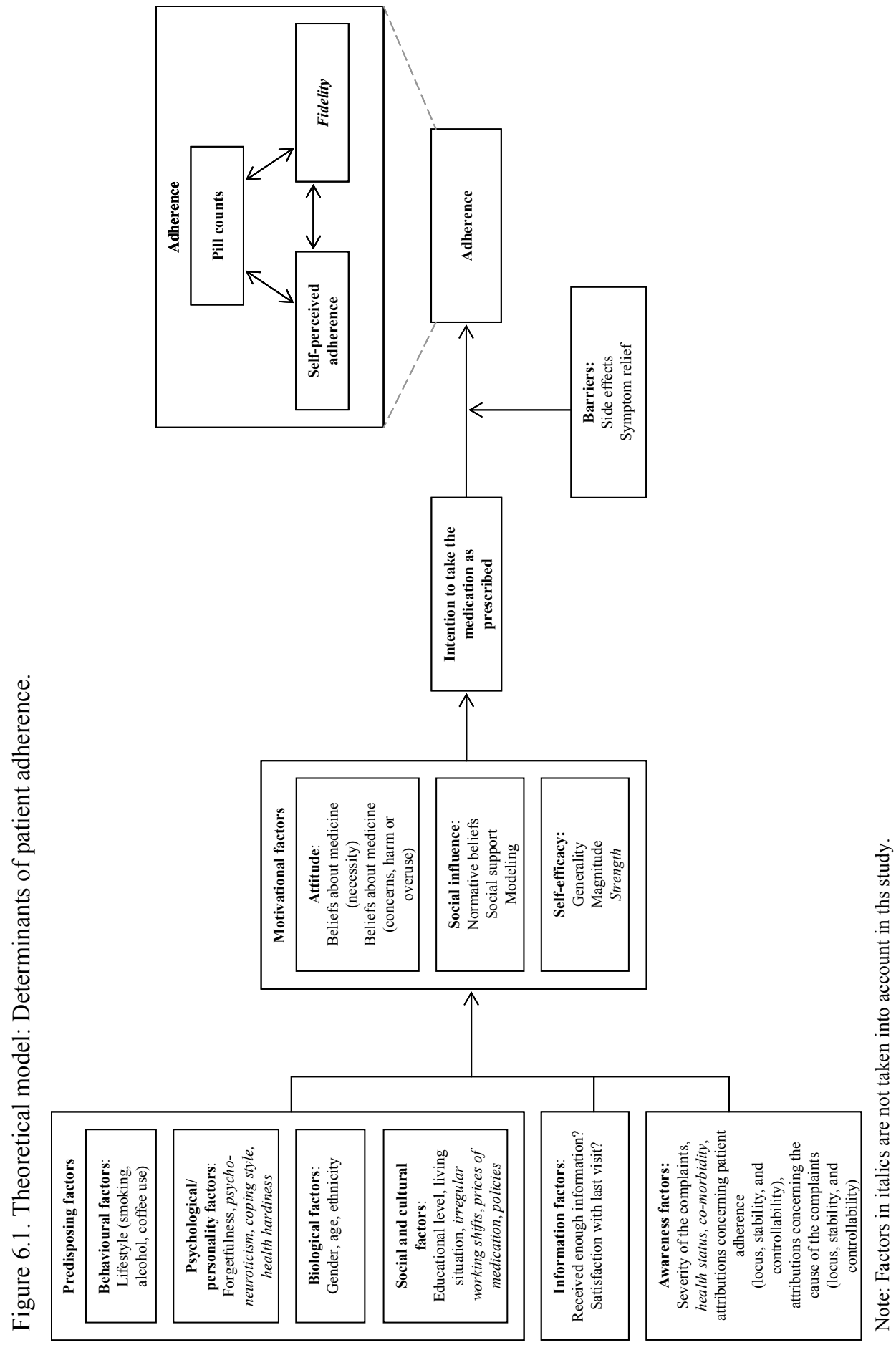


Psychosocial models may help to understand adherence behaviour by identifying patient related predictors of non-adherence. We composed a hypothetical model (Figure 6.1) guided by constructs of the Integrated Change Model $^{9}$ (I Change Model) (incorporating several theories such as the Theory of Planned Behaviour and the Health Belief Model) and the determinants known from literature. The goal of this study was to identify patient related factors that determine patients' adherence to short-term treatment with PPIs using the theoretical model described in Figure 6.1.

\section{Theoretical framework}

For adherence to PPI prescriptions, a person's attitude is expected to be determined by his/her beliefs about medicines: if the person thinks medicines are necessary, he/she is more likely to be adherent. However, if a patient has serious concerns about medication use and thinks that medication can be harmful, the patient is less likely to be adherent. Social influences consist of the perception of significant others being adherent (social modelling), the perceived norms that significant others have with respect to being adherent (social norms), and perceived support of significant others in being adherent (social support). Self-efficacy refers to the patient's perception of his/her capability to be adherent. Furthermore, the I Change Model assumes that these motivational factors are determined by various distal factors: predisposing factors, awareness factors and information factors. Predisposing factors are divided into behavioural factors (e.g. lifestyle), psychological or personality factors (e.g. forgetfulness), biological factors (e.g. age, gender), social and cultural factors (e.g. education level, policies, price of medication). A healthy lifestyle is hypothesized to be a behavioural factor. It is expected that, compared to patients with an unhealthy lifestyle, patients with a healthy lifestyle are more often motivated to act healthily in general and be adherent. Smoking habits, alcohol use and coffee use were chosen as lifestyle factors because they may aggravate dyspeptic complaints. Policies or price of medication are not expected to be of major influence on adherence to prescribed acid-suppressants because the cost of this medication is reimbursed by health care insurance. Awareness of the necessity of medication use is assumed to be determined by the severity of the symptoms, quality of life and the attributions patients make: if they think that their symptoms can be controlled and altered by medication, they are more likely to be adherent. The latter is guided by Weiner's attribution theory. ${ }^{10}$ Locus refers to whether a person perceives the success (or failure) as attributable to himself (internal locus) or to others (external locus). Stability concerns the degree to which a person thinks the success or failure can be 
attributed to stable or unstable causes and, for example, whether being adherent can be changed. Controllability refers to the degree to which a person thinks the success or failure can be controlled and, for example, whether being adherent can be controlled. We hypothesize that attributions made concerning adherence and attributions made concerning the cause of the dyspeptic complaints may be associated with patient adherence.

All patients who receive a prescription from their GP are thought to be able to perform the desired behaviour (taking one pill every day for two, three or four weeks). Although patients are motivated and able to be adherent, several barriers may prevent adherence, for example when adherence is not rewarded by a decrease in symptom severity or when a patient experiences side effects.

\section{Methods}

\section{Recruitment}

This prospective study was part of a larger Dutch study that investigated the effectiveness of PPIs for dyspeptic complaints. In this observational study GPs prospectively collected data from adult patients. Data collection started when these patients visited their GP complaining of dyspepsia and were prescribed PPI therapy with esomeprazole (40mg, 1 daily dose). Exclusion criteria were the presence of alarm symptoms or the use of a PPI during the month prior to inclusion. The treatment duration and the scheduling of a follow-up visit could be decided by the GPs. Each GP could include up to ten patients.

\section{GP measures}

The GPs were asked to fill out a form before and after PPI treatment for each eligible patient. At the baseline consultation, they provided information about the prescribed treatment (duration of treatment in weeks), the consultation date, and they stated the age (years) and gender $(\mathrm{M} / \mathrm{F})$ of the patient. GPs scored the severity of the complaints on eight items on a 7-point scale $(0=$ none $-6=$ very severe $)$, for which a sum score was calculated $(0=$ no complaints, $48=$ very severe complaints) (for a further description see Table 6.1). The GP severity scores were used to analyze differences between participants and non-participants.

At the follow-up consultation, the GPs indicated the consultation date, the presence of side effects, and the number of days with complaints during the last week (none, 1 or 2 days, 3 or 4 days, or more). Furthermore, the GP asked the patient how many 
of the prescribed pills were left. Based on the information about the treatment days (follow-up consultation date minus baseline consultation date), the number of pills used per day was calculated.

\section{Patient measures}

For the present study investigating the predictors of adherence, GPs informed eligible patients about this study and invited them to complete two questionnaires about adherence. These patient questionnaires were provided at the baseline consultation and at the follow-up consultation. The patient questionnaires could be completed at home and returned anonymously to the investigators using a pre-paid stamped addressed envelope. By means of an identical pre-printed number, the GP form and the patient questionnaire could be linked.

All items from the baseline and follow-up questionnaires and factors derived from these items are described in Table 6.1. Most items were derived from the I Change questionnaire ${ }^{9}$ and were measured on a 7 -point scale from $0=\mathrm{I}$ totally disagree to $6=\mathrm{I}$ totally agree, unless indicated otherwise. For all factors presented, factor analyses were performed confirming the presence of one factor. Furthermore, within each factor maximally one missing item was replaced by the patient's mean on the other items within that subscale.

Table 6.1. Concepts used in adjusted and unadjusted regression analyses (items).

\begin{tabular}{|c|c|c|c|c|c|}
\hline Factor & Scale & $\mathrm{N}$ & $\begin{array}{l}\text { Al- } \\
\text { pha }\end{array}$ & $\begin{array}{l}\text { Median/ } \\
\text { Mean }\end{array}$ & $\mathrm{SD}$ \\
\hline $\begin{array}{l}\text { Self-perceived adherence } \\
\text { (dep. variable)* } \\
\text { 'Do you understand the medication } \\
\text { instructions?' } \\
\text { 'Do you follow the medication instructions?' } \\
\text { 'Do you follow the medication instructions } \\
\text { carefully?' } \\
\text { 'Do you deviate from the medication } \\
\text { instruction?' } \\
\text { 'Do you use less medication than prescribed?' } \\
\text { 'Do you use more medication than } \\
\text { prescribed?' }\end{array}$ & $\begin{array}{l}0=\text { not adherent, } \\
24=\text { perfectly } \\
\text { adherent }\end{array}$ & 347 & 0.78 & $22 / 21.12$ & 2.9 \\
\hline Gender & $0=$ female & 347 & - & $0 / 0.42$ & 0.5 \\
\hline Age & In years & 346 & - & $55 / 54$ & 14 \\
\hline Educational level\# & $0=$ no, $7=$ academic & 341 & - & $3 / 3.18$ & 1.8 \\
\hline Living situation & $\begin{array}{l}0=\text { alone, } 1=\text { not } \\
\text { alone }\end{array}$ & 341 & - & $1 / 0.74$ & 0.4 \\
\hline Coffee use & $0=$ no, $1=$ yes & 347 & - & $1 / 0.87$ & 0.3 \\
\hline
\end{tabular}

Table 6.1. Concepts used in adjusted and unadjusted regression analyses (cont.). 


\begin{tabular}{|c|c|c|c|c|c|}
\hline Factor & Scale & $\mathrm{N}$ & $\begin{array}{l}\text { Al- } \\
\text { pha }\end{array}$ & $\begin{array}{l}\text { Median/ } \\
\text { Mean }\end{array}$ & SD \\
\hline Alcohol use & $0=$ no, $1=$ yes & 347 & - & $1 / 0.68$ & 0.5 \\
\hline Smoking & $0=$ no, $1=$ yes & 347 & - & $0 / 0.24$ & 0.4 \\
\hline $\begin{array}{l}\text { Information } \\
\text { 'I received too little information about my } \\
\text { medication' }\end{array}$ & $\begin{array}{l}0=\mathrm{I} \text { agree, } 6=\mathrm{I} \\
\text { disagree }\end{array}$ & 332 & - & $6 / 5.10$ & 1.7 \\
\hline $\begin{array}{l}\text { Satisfaction } \\
\text { 'I am completely satisfied with my last GP } \\
\text { consultation' }\end{array}$ & $\begin{array}{l}0=\mathrm{I} \text { disagree, } 6=\mathrm{I} \\
\text { agree }\end{array}$ & 339 & - & $6 / 5.23$ & 1.5 \\
\hline $\begin{array}{l}\text { Forgetfulness } \\
\text { 'I often forget to use my medication' }\end{array}$ & $\begin{array}{l}0=\mathrm{I} \text { often forget, } \\
6=\mathrm{I} \text { do not forget }\end{array}$ & 338 & - & $6 / 5.34$ & 1.4 \\
\hline $\begin{array}{l}\text { LOC: Intern/extern (adherence) } \\
\text { 'Not taking medication according to } \\
\text { instructions is to blame on me (6) /others ( }(0) \text { ' }\end{array}$ & $\begin{array}{l}0=\text { extern, } \\
6=\text { intern }\end{array}$ & 337 & - & $6 / 5.61$ & 1.0 \\
\hline $\begin{array}{l}\text { LOC: changeable and controllable } \\
\text { (adherence) } \\
\text { 'Not taking medication according to instruct- } \\
\text { tions is not changeable (0)/changeable (6)' } \\
\text { 'Not taking medication according to } \\
\text { instructions is in control (6)/not in control } \\
(0) \text { ' }\end{array}$ & $\begin{array}{l}0=\text { unstable and } \\
\text { not controllable, } \\
12=\text { stable and } \\
\text { controllable }\end{array}$ & 333 & 0.61 & $11 / 9.56$ & 3.2 \\
\hline $\begin{array}{l}\text { LOC: intern/extern and control } \\
\text { (cause complaints) } \\
\text { 'The cause of my complaints is internal } \\
\text { (6)/external (0)' } \\
\text { 'My complaints can be controlled (6)/not be } \\
\text { controlled (0)' }\end{array}$ & $\begin{array}{l}0=\text { extern and not } \\
\text { controllable, } \\
12=\text { intern and } \\
\text { controllable }\end{array}$ & 334 & 0.69 & $4 / 4.42$ & 3.3 \\
\hline $\begin{array}{l}\text { LOC: changeable (complaints) } \\
\text { 'My complaints can be decreased (6)/not } \\
\text { decreased (0)' }\end{array}$ & $\begin{array}{l}0=\text { stable } \\
6=\text { unstable }\end{array}$ & 327 & - & $5 / 4.11$ & 1.8 \\
\hline $\begin{array}{l}\text { Severity of complaints (baseline) } \\
\text { During the last week, how severe were your } \\
\text { complaints of: } \\
\text { Heartburn } \\
\text { Regurgitation } \\
\text { Upper abdominal pain } \\
\text { Lower abdominal pain } \\
\text { Nausea } \\
\text { Belching } \\
\text { Vomiting } \\
\text { Early satiety }\end{array}$ & $\begin{array}{l}0=\text { none, } 48=\text { very } \\
\text { severe }\end{array}$ & 315 & 0.77 & $13 / 13.57$ & 6.9 \\
\hline $\begin{array}{l}\text { Necessity of medication } \\
\text { 'My health, at present, depends on my } \\
\text { medicines' } \\
\text { 'My life would be impossible without my } \\
\text { medicines' } \\
\text { 'Without my medicines I would be very ill' } \\
\text { 'My health in the future will depend on my } \\
\text { medicines' } \\
\text { 'My medicines protect me from becoming } \\
\text { worse' } \\
\text { Table 6.1. Concepts used in adjuste }\end{array}$ & $\begin{array}{l}0=\text { not necessary, } \\
30=\text { necessary }\end{array}$ & 332 & 0.85 & $12 / 12.98$ & 8.4 \\
\hline
\end{tabular}




\begin{tabular}{|c|c|c|c|c|c|}
\hline Factor & Scale & $\mathrm{N}$ & $\begin{array}{l}\text { Al- } \\
\text { pha }\end{array}$ & $\begin{array}{l}\text { Median/ } \\
\text { Mean }\end{array}$ & SD \\
\hline $\begin{array}{l}\text { Concerns about medication } \\
\text { 'Having to take medicines worries me' } \\
\text { 'I sometimes worry about the long-term } \\
\text { effects of my medicines' } \\
\text { 'My medicines are a mystery to me' } \\
\text { 'Doctors use too many medicines' } \\
\text { 'People who take medicines should stop their } \\
\text { treatment for a while every now and again' } \\
\text { 'Most medicines are addictive' } \\
\text { 'Natural remedies are safer than medicines' } \\
\text { 'All medicines are poisons' } \\
\text { 'Doctors place too much trust in medicines' } \\
\text { 'If doctors had more time with patients they } \\
\text { would prescribe fewer medicines' }\end{array}$ & $\begin{array}{l}0=\text { no concerns, } \\
60=\text { great } \\
\text { concerns }\end{array}$ & 319 & 0.76 & $20 / 20.37$ & 11.0 \\
\hline $\begin{array}{l}\text { Social influence } \\
\text { 'Most people I know think that I should take } \\
\text { my medication according to the instructions' } \\
\text { 'Most people I know support me in taking my } \\
\text { medication' } \\
\text { 'Most people I know use their medication } \\
\text { according to the instructions }\end{array}$ & $\begin{array}{l}0=\text { no support, } \\
18=\text { fully } \\
\text { supported }\end{array}$ & 327 & 0.68 & $15 / 13.71$ & 4.3 \\
\hline $\begin{array}{l}\text { Self-efficacy } \\
\text { 'I find it very difficult to use my medication } \\
\text { according to the instructions' } \\
\text { 'During holidays I find it very difficult to take } \\
\text { my medications according to the instructions' } \\
\text { 'During the weekend I find it very difficult to } \\
\text { take my medications according to the } \\
\text { instructions' } \\
\text { 'In the company of others I find it very } \\
\text { difficult to take my medications according to } \\
\text { the instructions' }\end{array}$ & $\begin{array}{l}=\text { no self- } \\
\text { efficacy, } \\
24=\text { high self- } \\
\text { efficacy }\end{array}$ & 339 & 0.80 & $21 / 18.64$ & 6.4 \\
\hline $\begin{array}{l}\text { Intention } \\
\text { I intend to take my medication according to } \\
\text { the instructions' } \\
\text { 'I intend to take my medication carefully } \\
\text { according to the instructions' }\end{array}$ & $\begin{array}{l}0=\text { no intention, } \\
12=\text { high } \\
\text { intention }\end{array}$ & 341 & 0.93 & $12 / 11.58$ & 1.5 \\
\hline $\begin{array}{l}\text { Days of complaints at follow-up* } \\
\text { 'How many days of complaints did you } \\
\text { experience during the last week?' }\end{array}$ & $\begin{array}{l}0=0,1=1-2,2=3- \\
4,3=5-7 \text { days }\end{array}$ & 343 & - & $1 / 1.41$ & 1.7 \\
\hline *Measured with the follow-up questionnaire & & & & & \\
\hline
\end{tabular}

Attitude was measured with the Beliefs about Medicine Questionnaire (BMQ),${ }^{11}$ which was translated into Dutch by several scientific investigators. Then an English teacher, blind from the original questionnaire, translated the Dutch questionnaire back to English. This translation was compared with the original questionnaire to 
check whether it was translated properly. The BMQ originally consisted of four constructs: necessity, concern, harm, and overuse. However, factor analyses revealed two factors: necessity and a combination of the other three more negative constructs. Therefore, sum scores were calculated for these two factors (Table 6.1).

The outcome measure, self-perceived adherence, was measured at follow up with six questions derived from the asthma problem behaviour checklist. ${ }^{12}$ These questions were measured on a 5 -points scale $(0=$ never, $1=$ =almost never, $2=$ sometimes, $3=$ usual, 4=always) (Table 6.1). Since the last three questions were measured negatively, the answers were recoded ( $4=$ never $-0=$ always). This results in a sum score for self-perceived adherence: a score of 0 indicates non-adherence and 24 indicates perfect adherence.

\section{Statistical analysis}

SPSS 14.0 was used for data analysis. Differences between participants (returned one or two questionnaires) and non-participants (rest of the potential population), between patients who returned one questionnaire and patients who returned both questionnaires, and between patients included in the regression analysis and respondents excluded due to missing values were analysed using t-tests (in the case of normally distributed data) or Mann-Whitney U test (in the case of non-normality) and $\chi^{2}$ tests.

For the purpose of cross validation the correlation between self-perceived adherence and the number of pills used per day was analysed. We hypothesize that patients with a lower score for self-perceived adherence also use fewer pills than prescribed. All concepts from the hypothetical model (Figure 6.1) were tested in unadjusted linear regression analyses. Since the presence of side effects was reported for only six patients, the variance was nearly zero, and therefore side effects are not included in the analyses. The dependent variable was self-perceived adherence. The assumptions for the applicability of linear regression analysis were checked and were satisfactory. To identify the predictors of self-perceived adherence, multiple linear regression analysis was conducted using the enter-method. The regression model enclosed three blocks. Block 1 contained the distal factors, information factors and awareness factors; block 2 added the motivational factors (attitude, social influence and self-efficacy); block 3 added the intention and the symptoms at follow-up. 


\section{Results}

Characteristics of the sample

In the effectiveness study, 2,905 patients were included by 346 GPs. Of these GPs, 127 agreed to participate in the present study, and together accounted for 1,027 patients in the effectiveness study. A total of 477 baseline and 425 follow-up questionnaires were returned, of which in 69 cases only the follow-up questionnaire was returned. Thus, 53\% (546 of 1027) of the potentially invited patients returned one or more questionnaires.

No statistically significant differences between participants (patients who returned one or both questionnaires) and the rest of the 2,905 patients were found for age and gender. Participants (mean $=1.08$ pills/day) used statistically significantly more pills per day than non-participants (mean $=0.97$ pills/day) $(U=374,730, p<0.05)$. The participants tended to have more severe complaints at baseline (mean GP sum scores 13.60 versus $12.30, \mathrm{U}=533,638, \mathrm{p}<0.001)$.

Patients who returned both questionnaires had a higher educational level than those who returned only one (mean 3.21 versus $2.84, \mathrm{t}=-2.21, \mathrm{p}<0.05$ ). No significant differences were found for age, gender, living situation, severity of the complaints and number of pills used per day.

Ultimately, 347 patients were included; the rest were excluded because they did not return two questionnaires or due to multiple missing values on the dependent variable. Their mean age was 54 years (SD 14) and 58\% were male. Most of them $(90 \%)$ were treated for two weeks, $2 \%$ for three weeks and $8 \%$ for four weeks. One in five patients had a very low score for self-efficacy (a score of 12 or less), indicating that they experienced some difficulties in using medication in general or in specific situations such as at the weekend.

Differences between patients included $(\mathrm{n}=261)$ and patients excluded (due to missing values) $(\mathrm{n}=86)$ in multiple regression analyses were tested for all concepts in the hypothetical model. Patients included were younger (mean 52 versus 58, $\mathrm{t}=3.12, \mathrm{p}<0.01$ ), had a higher level of education (mean 3.28 versus $2.84, \mathrm{t}=-2.04$, $\mathrm{p}<0.05$ ), lower self-efficacy (mean 18.20 versus $20.10, \mathrm{U}=8,570, \mathrm{p}<0.05$ ), and had a higher score for locus of control about their complaints (mean 4.83 versus 2.93, $\mathrm{t}=4.66, \mathrm{p}<0.0001$ ). Furthermore, $82 \%$ of the men could be analysed in the multiple regression analysis compared to $70 \%$ of the women $\left(\chi^{2}=6.58, p<0.05\right)$. 
Correlation between self-perceived adherence and number of pills used per day Self-perceived adherence scores were high: the median score was 22 (maximum was 24), $25 \%$ of the patients scored less than 20 and $5 \%$ scored 15 or less. Figure 6.2 shows the number of pills used per day in relation to self-perceived adherence. The correlation between self-perceived adherence and the number of pills used per day was low and not statistically significant ( $N=296$; Spearman's $r=0.09 ; \mathrm{p}=0.14$ ).

Figure 6.2. Correlation between self-perceived adherence and number of pills used per day $(\mathrm{n}=296)$.

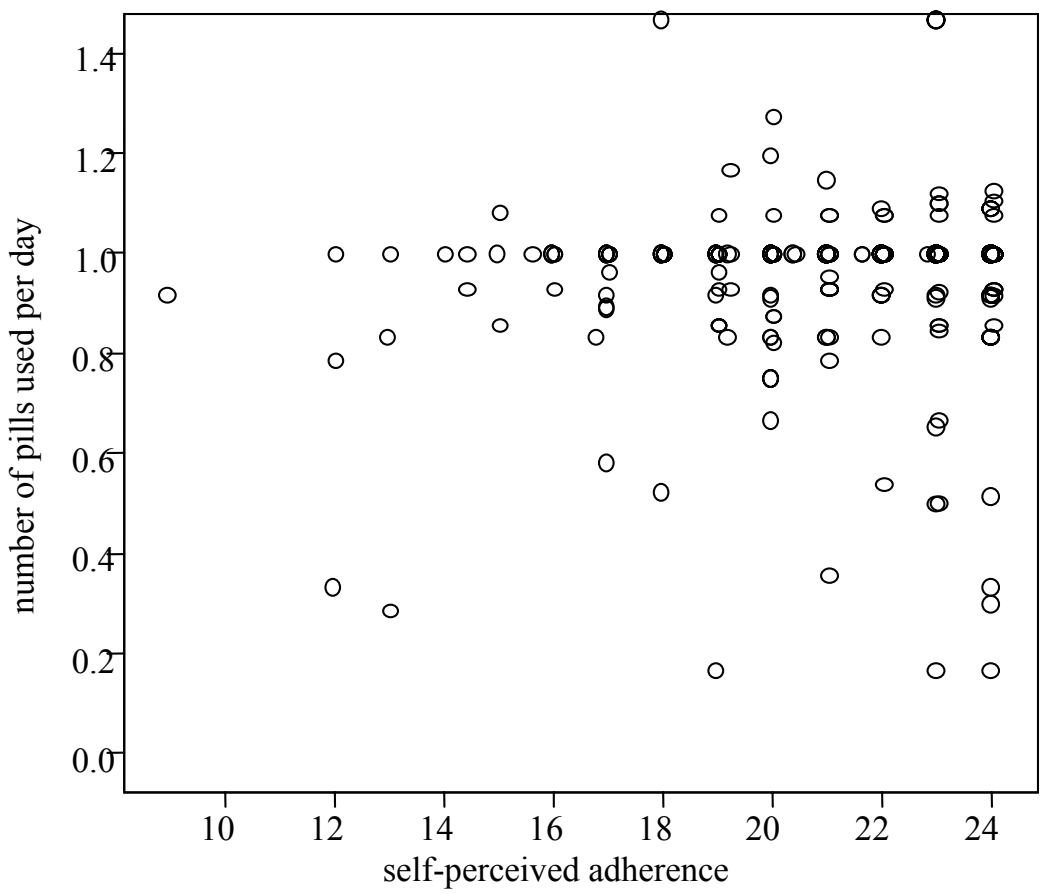

NB. 1 daily dose was prescribed

\section{Factors identified in unadjusted regression analyses}

Table 6.2 shows the results of the unadjusted regression analyses. The results indicate that patients were less likely to be adherent when they had a lower education level, claimed to regularly forget medication in general, stated that they had not received enough information, were not satisfied about their last GP consultation, when they blamed themselves less for being non-adherent, or believed that adherence could not be changed or could not be controlled. Furthermore, when 
a patient believed that his/her complaints could not be changed, had concerns about the use of medication, felt less social support, had a lower self-efficacy, had a lower score for intention or had more days of complaints at follow-up, the patient was less likely to be adherent.

Table 6.2. Predictors identified during unadjusted regression analysis.

\begin{tabular}{|c|c|c|c|c|c|}
\hline Factor & $\mathrm{N}$ & $\mathrm{R}^{2}$ & Constant & $\begin{array}{l}\text { Unstan- } \\
\text { dardized } \\
\text { coeffi- } \\
\text { cient }\end{array}$ & $\mathrm{P}$ \\
\hline Gender & 347 & 0.001 & 21.22 & -0.22 & 0.49 \\
\hline Age & 346 & 0.008 & 20.13 & 0.02 & 0.09 \\
\hline Educational level & 341 & 0.033 & 20.20 & 0.30 & 0.001 \\
\hline Living situation & 341 & 0.013 & 20.57 & 0.76 & 0.03 \\
\hline Coffee use & 347 & 0.022 & 20.02 & 1.28 & 0.006 \\
\hline Alcohol use & 347 & 0.004 & 20.87 & 0.38 & 0.26 \\
\hline Smoking & 347 & 0.002 & 21.19 & -0.29 & 0.43 \\
\hline Information & 332 & 0.067 & 18.86 & 0.45 & $<0.001$ \\
\hline Satisfaction & 339 & 0.025 & 19.59 & 0.30 & 0.004 \\
\hline Forgetfulness & 338 & 0.209 & 15.94 & 0.98 & $<0.001$ \\
\hline $\begin{array}{l}\text { Attributions: locus: intern/extern } \\
\text { (adherence) }\end{array}$ & 337 & 0.079 & 16.26 & 0.86 & $<0.001$ \\
\hline $\begin{array}{l}\text { Attributions: changeable/controllable } \\
\text { (adherence) }\end{array}$ & 333 & 0.027 & 19.68 & 0.15 & 0.003 \\
\hline $\begin{array}{l}\text { Attributions: locus/controllable } \\
\text { (cause complaints) }\end{array}$ & 334 & 0.000 & 21.10 & -0.03 & 0.96 \\
\hline $\begin{array}{l}\text { Attributions: changeable (cause } \\
\text { complaints) }\end{array}$ & 327 & 0.021 & 20.12 & 0.24 & 0.008 \\
\hline Severity of complaints (baseline) & 315 & 0.007 & 21.63 & -0.04 & 0.14 \\
\hline Necessity of medication & 332 & 0.003 & 21.35 & -0.02 & 0.32 \\
\hline Concerns about medication & 319 & 0.110 & 22.95 & -0.09 & $<0.001$ \\
\hline Social influence & 327 & 0.008 & 20.31 & -0.06 & 0.11 \\
\hline Self-efficacy & 339 & 0.188 & 17.44 & 0.20 & $<0.001$ \\
\hline Intention & 341 & 0.084 & 14.48 & 0.57 & $<0.001$ \\
\hline Days of complaints follow-up & 343 & 0.038 & 21.58 & -0.34 & $<0.001$ \\
\hline
\end{tabular}

\section{Factors identified in multiple regression analyses}

Table 6.3 shows the results of the adjusted regression analyses. Male patients, patients with a low educational level, patients who did not drink coffee, who were not satisfied with their last GP visit, who claimed to regularly forget their medication, who had a more external locus of control concerning being adherent, who did not feel social supported, who had a low self-efficacy, or a low intention 
were less likely to be adherent. The factors educational level, forgetfulness, selfefficacy and intention were statistically significant in all three models.

Table 6.3. Predictors identified during multiple regression analysis $(\mathrm{N}=261)$.

\begin{tabular}{|c|c|c|c|c|c|c|c|c|c|}
\hline & \multicolumn{3}{|c|}{$\begin{array}{l}\text { Block 1: } \\
\mathrm{R}^{2}=0.314 \\
\text { Adj. } \mathrm{R}^{2}=0.272 \\
\text { F Change }=7.464 \\
\text { Sign. F Change }=0.000\end{array}$} & \multicolumn{3}{|c|}{$\begin{array}{l}\text { Block 2: } \\
\mathrm{R}^{2}=0.382 \\
\text { Adj. } \mathrm{R}^{2}=0.333 \\
\mathrm{~F} \text { Change }=6.622 \\
\text { Sign. F Change }=0.000\end{array}$} & \multicolumn{3}{|c|}{$\begin{array}{l}\text { Block 3: } \\
\mathrm{R}^{2}=0.438 \\
\text { Adj. } \mathrm{R}^{2}=0.389 \\
\text { F Change }=11.983 \\
\text { Sign. F Change }=0.000\end{array}$} \\
\hline & $\begin{array}{l}\text { Part } \\
\text { Corr. }^{2} \\
\end{array}$ & $\begin{array}{l}\text { Unst. } \\
\text { Coeff. }\end{array}$ & $\begin{array}{c}\mathrm{P}- \\
\text { value }\end{array}$ & $\begin{array}{l}\text { Part } \\
\text { Corr. }^{2}\end{array}$ & $\begin{array}{l}\text { Unst. } \\
\text { Coeff }\end{array}$ & $\begin{array}{c}\mathrm{P}- \\
\text { value }\end{array}$ & $\begin{array}{l}\text { Part } \\
\text { Corr. }^{2}\end{array}$ & $\begin{array}{l}\text { Unst. } \\
\text { coeff. }\end{array}$ & $\begin{array}{c}\mathrm{P}- \\
\text { value }\end{array}$ \\
\hline Constant & & 9.56 & $<0.001$ & & 11.06 & $<0.001$ & & 7.52 & $<0.001$ \\
\hline Gender & 0.006 & -0.48 & 0.13 & 0.012 & -0.65 & 0.03 & 0.008 & -0.55 & 0.06 \\
\hline Age & 0.004 & 0.01 & 0.23 & 0.007 & 0.02 & 0.10 & 0.006 & 0.02 & 0.11 \\
\hline Education & 0.012 & 0.20 & 0.04 & 0.018 & 0.25 & 0.009 & 0.017 & 0.25 & 0.008 \\
\hline Living situation & 0.002 & 0.28 & 0.44 & 0.001 & 0.24 & 0.50 & 0.002 & 0.32 & 0.35 \\
\hline Coffee use & 0.012 & 1.01 & 0.04 & 0.009 & 0.89 & 0.07 & 0.009 & 0.91 & 0.05 \\
\hline Alcohol use & 0.000 & 0.04 & 0.91 & 0.000 & 0.05 & 0.90 & 0.000 & -0.04 & 0.91 \\
\hline Smoking & 0.000 & 0.08 & 0.98 & 0.000 & -0.05 & 0.88 & 0.000 & 0.14 & 0.68 \\
\hline Information & 0.006 & 0.16 & 0.13 & 0.000 & 0.04 & 0.73 & 0.001 & 0.08 & 0.47 \\
\hline Satisfaction & 0.015 & 0.26 & 0.02 & 0.006 & 0.17 & 0.13 & 0.004 & 0.13 & 0.22 \\
\hline Forgetfulness & 0.078 & 0.72 & $<0.001$ & 0.018 & 0.39 & 0.008 & 0.018 & 0.39 & 0.007 \\
\hline Attr.: locus (adherence) & 0.008 & 0.32 & 0.09 & 0.001 & 0.12 & 0.51 & 0.000 & -0.02 & 0.90 \\
\hline $\begin{array}{l}\text { Attr.:changeable } \\
\text { /control (adher.) }\end{array}$ & 0.005 & 0.07 & 0.19 & 0.001 & 0.03 & 0.51 & 0.001 & 0.03 & 0.57 \\
\hline $\begin{array}{l}\text { Attr.: locus/control } \\
\text { (cause complaints) }\end{array}$ & 0.000 & 0.08 & 0.99 & 0.000 & 0.02 & 0.70 & 0.000 & -0.01 & 0.86 \\
\hline $\begin{array}{l}\text { Attr.:changeable } \\
\text { (cause complaints) }\end{array}$ & 0.007 & 0.15 & 0.11 & 0.004 & 0.11 & 0.21 & 0.001 & 0.05 & 0.59 \\
\hline $\begin{array}{l}\text { Severity of complaints } \\
\text { (baseline) }\end{array}$ & 0.002 & 0.02 & 0.40 & 0.000 & 0.01 & 0.71 & 0.001 & 0.02 & 0.53 \\
\hline Necessity of medication & & & & 0.000 & 0.00 & 0.96 & 0.001 & -0.01 & 0.59 \\
\hline $\begin{array}{l}\text { Concerns about } \\
\text { medication }\end{array}$ & & & & 0.006 & -0.03 & 0.12 & 0.002 & -0.02 & 0.32 \\
\hline Social influence & & & & 0.014 & 0.09 & 0.02 & 0.006 & 0.06 & 0.12 \\
\hline Self-efficacy & & & & 0.041 & 0.12 & $<0.001$ & 0.034 & 0.11 & $<0.001$ \\
\hline Intention & & & & & & & 0.045 & 0.47 & $<0.001$ \\
\hline $\begin{array}{l}\text { Days of complaints } \\
\text { Follow-up }\end{array}$ & & & & & & & 0.008 & -0.17 & 0.07 \\
\hline
\end{tabular}

\section{Discussion}

Our results show that approximately one quarter of the patients had low scores for self-perceived adherence, this is consistent with non-adherence rates found in other (Dutch) studies investigating gastrointestinal diseases. ${ }^{3,4}$ The proportion of variance explained by the predictors was high (44\%) and comparable to percentages found in other studies using the I Change Model or its precursor, the ASE Model. ${ }^{13,14}$ The 
most powerful predictors identified were educational level, forgetfulness, selfefficacy and intention.

The scores for both necessity and concerns about medication use were low, especially in comparison with other diseases, ${ }^{11}$ indicating that patients perceived that their health does not depend on acid-suppressant use and that they have little concern about using acid-suppressants. Possible explanations for these low scores may be associated with the expected short-term treatment (mostly two weeks) and the relatively low scores for severity of the complaints at baseline. Furthermore, because of the recurring character of dyspepsia, patients may be familiar with the effects of acid-suppressants because they may have used them before.

In this study the I Change Model was used as a theoretical framework. The questionnaire used to assess the concepts of this theoretical model was selfdeveloped based on literature and other validated questionnaires. As the results show, the theoretical model proved to be relevant for explaining self-perceived adherence to prescribed acid-suppressants for dyspepsia. However, further research is needed in order to get more insight into the validity of the concepts assessed and to find out whether the assessments of the different concepts of the model can be further improved.

After more than 25 years of adherence investigations, researchers are still in search of the gold standard of adherence measurement. ${ }^{15}$ Like Bosworth, ${ }^{6}$ we think that patients reporting non-adherence have no reason to lie about this, and these answers are considered to be reliable, whereas patients reporting adherence may give socially desirable answers that may not be reliable. DiMatteo ${ }^{15}$ advocates using multiple adherence measures to get more insight into the reliability and validation of these measures, since adherence measures do not always result in similar adherent rates. ${ }^{16,17} \mathrm{We}$ compared the subjective measure (self-perceived adherence) with a more visual measure (number of pills taken per treatment day) and also found a very low non-significant correlation between these measures. However, the reliability of the measure, number of pills used per day, may be questionable. The GP was asked to state on the GP form how many pills were left at follow-up. We assume that, for most patients, the number of pills left had to be estimated (by the patients), since it is unlikely that most patients brought their pills to the follow-up consultation to enable an actual pill count. Thus, social desirability, rounding off the number of pills and recall bias could all have influenced this estimation. These biases will probably lead to an overestimation of the number of pills used. Furthermore, we noticed that approximately $5 \%$ of the patients used more than one pill per day, whereas one pill a 
day was prescribed. Although it is possible that these patients took more pills than prescribed, it is also possible that the report of the treatment duration in relation to the number of pills taken is not reliable in these cases. Further research with reliable measures of pill counts and treatment duration, in addition to self-perceived adherence, is necessary in order to validate adherence measures.

One important limitation of the present study concerning patient selection arises because of non-response to the questionnaires or refusal to participate, and incompleteness of the data. Ultimately, $53 \%$ of the patients participated, and due to missing values approximately half of them could be analyzed in the multiple regression analyses. These patients differ from non-participants on several points. Participants had a higher educational level than non-participants. Nevertheless, educational level proved to a statistically significant predictor for adherence, and might even be a stronger predictor in the general population of patients with dyspepsia. Since non-participants on average used fewer pills per day and had less severe symptoms than participants, it is possible that, in practice, non-adherence rates may be even worse since patients with less severe complaints may not feel the necessity to take their acid-suppressive medication as prescribed. For long-term treatment, non-adherence may not be problematic and on-demand use may be even preferred, but, in the diagnostic phase, non-adherence can have great negative consequences, especially if symptoms are not relieved and non-adherence is not identified. This probably results in prolonged treatment with stronger medicines and more consultations or referral for diagnostic investigation, whereas the persistence of symptoms may be due to non-adherence.

Some recommendations can be made based on these first findings. It is striking that one in five patients expected to experience some difficulties in taking their medications in general and/or in specific situations such at the weekend (these patients had a score of 12 or less for self-efficacy, where high self-efficacy is indicated by a score of 24), despite the fact that no complex medical regimen was required: the prescription was to take one pill a day for a short period of time. This implicates that asking whether a patient expects to experience difficulties in medication use, even in the case of non-complex treatment regimens, and making action plans to overcome these difficulties (e.g. using reminders) may result in improved adherence rates in a substantial number of patients. Interventions designed to enhance adherence to acid-suppressants in the diagnostic phase should be focused on patients with less severe symptoms and low educational levels and should address forgetfulness, self-efficacy and intention, because these factors are 
associated with patient PPI adherence. Bosworth ${ }^{6}$ suggests that questioning the patient is the simplest, most time-efficient adherence management tool available to clinicians, and Williams ${ }^{18}$ proposes some questioning techniques that promote medication adherence. The process should be designed to determine whether an adherence problem exists, to define the problem and propose a solution in collaborative negotiation with the patient. ${ }^{6}$ In the case of dyspepsia, the clinician could for instance ask: 'Many patients find it difficult to take their medication regularly. Do you ever skip or forget to take your medicines?' This question may facilitate the process of enhancing adherence. The results of this study could be a promising starting point for an intervention study, for example to investigate the effectiveness of questioning to enhance adherence to prescribed acid-suppressants for dyspepsia.

\section{References}

1. The Dutch Institute for Healthcare Improvement (CBO), Dutch College of General Practitioners (NHG). Multidisciplairy Guideline Stomachcomplaints (Multidisciplinaire Richtlijn Maagklachten). Alphen aan den Rijn: Van Zuiden Communications; 2004.

2. Health Care Insurance Board (College Voor Zorgverzekeringen). GIPsignal Use of acid-suppressive medication 1996-2001 (GIPsignaal Gebruik van Maagmiddelen 1996-2001). Amstelveen: Health Care Insurance Board (College Voor Zorgverzekeringen); 2002.

3. Krol N, Muris JW, Schattenberg G, Grol R, Wensing M. Use of prescribed and non-prescribed medication for dyspepsia. Scand J Prim Health Care 2004; 22: 163-7.

4. Van Soest EM, Siersema PD, Dieleman JP, Sturkenboom MC, Kuipers EJ. Persistence and adherence to proton pump inhibitors in daily clinical practice. Aliment Pharmacol Ther 2006; 24: 377-85.

5. Meichenbaum D, Turk DC. Factors affecting adherence. In: Meichenbaum D, Turk DC, editors. Facilitating treatment adherence. A practitioner's guidebook.New York: Plenum Press; 1987. p. 41-70.

6. Bosworth HB. Medication treatment adherence. In: Bosworth HB, Oddone EZ, Weinberger M, editors. Patient treatment adherence. Concepts, interventions and measurement.New Jersey: Lauwrence Erlbaum Associates Inc.; 2006. 
7. Fransen GAJ, Mesters I, Bonten E, Muris JWM. Expectations of patients regarding the management of gastrointestinal problems. Gut 2004; 53 Suppl 4: A284.

8. Hungin AP, Rubin G, O'Flanagan H. Factors influencing compliance in longterm proton pump inhibitor therapy in general practice. Br J Gen Pract 1999; 49: 463-4.

9. Vries H, Mesters I, van de SH, Honing C. The general public's information needs and perceptions regarding hereditary cancer: an application of the Integrated Change Model. Patient Educ Couns 2005; 56: 154-65.

10. Weiner B: An attributional theory of motivation and emotion. New York: Springer-Verlag Inc; 1986.

11. Horne R, Weinman J. Patients' beliefs about prescribed medicines and their role in adherence to treatment in chronic physical illness. J Psychosom Res 1999; 47: 555-67.

12. Creer TL, Wigal JK, Tobin DL, Kotses H, Snyder SE, Winder JA. The Revised Asthma Problem Behavior Checklist. J Asthma 1989; 26: 17-29.

13. Lechner L, Oenema A, de NJ. Testicular self-examination (TSE) among Dutch young men aged 15-19: determinants of the intention to practice TSE. Health Educ Res 2002; 17: 73-84.

14. Nierkens V, Stronks K, van Oel CJ, de VH. Beliefs of Turkish and Moroccan immigrants in The Netherlands about smoking cessation: implications for prevention. Health Educ Res 2005; 20: 622-34.

15. DiMatteo MR. Variations in patients' adherence to medical recommendations: a quantitative review of 50 years of research. Med Care 2004; 42: 200-9.

16. Dunbar J, Dunning EJ, Dwyer K. Compliance measurement with arthritis regimen. Arthritis Care Res 1989; 2: S8-16.

17. Waterhouse DM, Calzone KA, Mele C, Brenner DE. Adherence to oral tamoxifen: a comparison of patient self-report, pill counts, and microelectronic monitoring. J Clin Oncol 1993; 11: 1189-97.

18. Williams AB. Adherence to HIV regimens: 10 vital lessons. Am J Nurs 2001; 101: 37-43. 


\section{Chapter 7}

\section{Pragmatic trials in primary care: methodological challenges and solutions demonstrated by the DIAMOND-study}

G.A.J. Fransen, C.J. van Marrewijk, S. Mujakovic, J.W.M. Muris, R.J.F. Laheij, M.E. Numans, N.J. de Wit, M. Samsom, J.B.M.J. Jansen \& J.A. Knottnerus.

BMC Med Res Meth 2007; 7: 16.

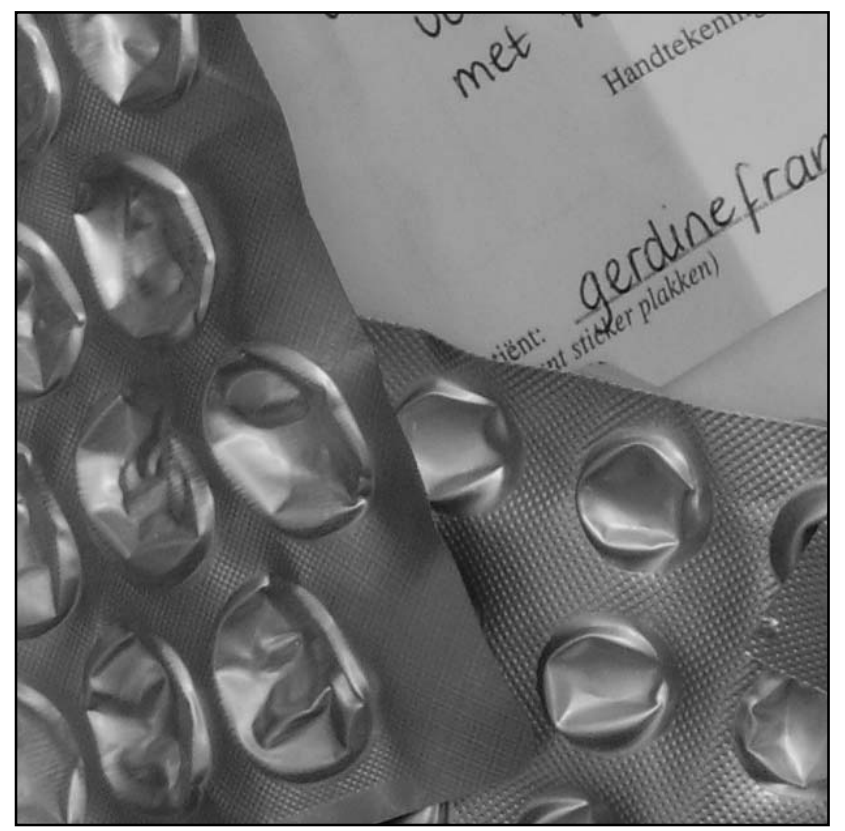




\begin{abstract}
Background: Pragmatic randomised controlled trials are often used in primary care to evaluate the effect of a treatment strategy. In these trials it is difficult to achieve both high internal validity and high generalisability. This article will discuss several methodological challenges in designing and conducting a pragmatic primary care based randomised controlled trial, based on our experiences in the DIAMONDstudy and will discuss the rationale behind the choices we made. Future pragmatic trials may benefit from the successes as well as the problems we experienced.

Discussion: The first challenge concerned choosing the clinically most relevant interventions to compare and enable blinded comparison, since two interventions had very different appearances. By adding treatment steps to one treatment arm and adding placebo treatment to both treatment arms both internal and external validity were optimized. Nevertheless, although blinding is essential for a high internal validity, it should be warily considered in a pragmatic trial because it decreases external validity. Choosing and recruiting a representative selection of participants was the second challenge. We succeeded in retrieving a relatively large, representative patient sample by carefully choosing (few) inclusion and exclusion criteria, by random selection, by paying much attention to participant recruitment and taking the participant's reasons to participate into account. Good and regular contact with the GPs and patients was to our opinion essential. The third challenge was to choose the primary outcome, which needed to reflect effectiveness of the treatment in every day practice. We also designed our protocol to follow every day practice as much as possible, although standardized treatment is usually preferred in trials. The aim of this was our fourth challenge: to limit the number of protocol deviations and increase external validity.

Summary: It is challenging to design and conduct a pragmatic trial. Thanks to thorough preparation, we were able to collect highly valid data. To our opinion, a critical deliberation on forehand of where on the pragmatic-explanatory spectrum you want your trial to be, in combination with consulting publications especially on patient recruitment procedures, has been helpful in conducting a successful trial.
\end{abstract}




\section{Introduction}

Pragmatic trials are designed to investigate how effective a treatment strategy is in everyday practice. ${ }^{1}$ The hypothesis and study design in pragmatic trials are developed specifically to answer questions of decision makers ${ }^{2}$ and should compare new with existing interventions in the indicated population using relevant health outcomes. ${ }^{3}$ Researchers face a number of methodological challenges and need to make several choices in the design and conduct of pragmatic trials. This is especially true for primary care based trials where the broad spectrum of disease presentation and early clinical stage challenges the selection of an adequate study population. Though these challenges greatly influence the external and internal validity as well as the eventual significance of the study results, most publications do not elaborate on the choices made. This paper discusses several challenges in designing and conducting pragmatic primary care based trials we experienced in a large scale multicentre randomised trial on dyspepsia. This might be helpful for other researchers especially in the planning stage of new trials. Our objective is to contribute to quality improvement of pragmatic primary care based trials.

This paper will discuss three challenges in designing a study: choosing the right intervention and blinding treatment allocation, choosing an appropriate study population, and choosing the essential outcome measures. Subsequently the challenges in conducting a study will be discussed focusing on recruitment of participating general practitioners (GPs) and patients, and on dealing with protocol deviations. Each section will start with a brief introduction of pitfalls in general, followed by the rationale behind the choices made within the DIAMOND-study and a speculation of the consequences of our choices. The paper will end with conclusions describing the consequences of our choices for the expected usefulness and relevance of the DIAMOND results.

\section{The DIAMOND trial}

The Dutch study of InitiAl Management Of Newly diagnosed Dyspepsia (DIAMOND) investigates the effectiveness of two treatment strategies for dyspepsia: the 'step-up' treatment strategy and the 'step-down' treatment. The 'step-up' treatment starts with antacids and, if the symptoms persist or recur, builds up to stronger medication, while the 'step-down' treatment starts with the strongest drug (proton pump inhibitor (PPI)) and reduces stepwise to $\mathrm{H}_{2}$-Receptor Antagonists $\left(\mathrm{H}_{2} \mathrm{RAs}\right)$ and antacids as long as the symptoms persist or recur. In Box 7.1-7.4 and 
Figure 7.1-7.2 the design and research questions of the DIAMOND-study are described.

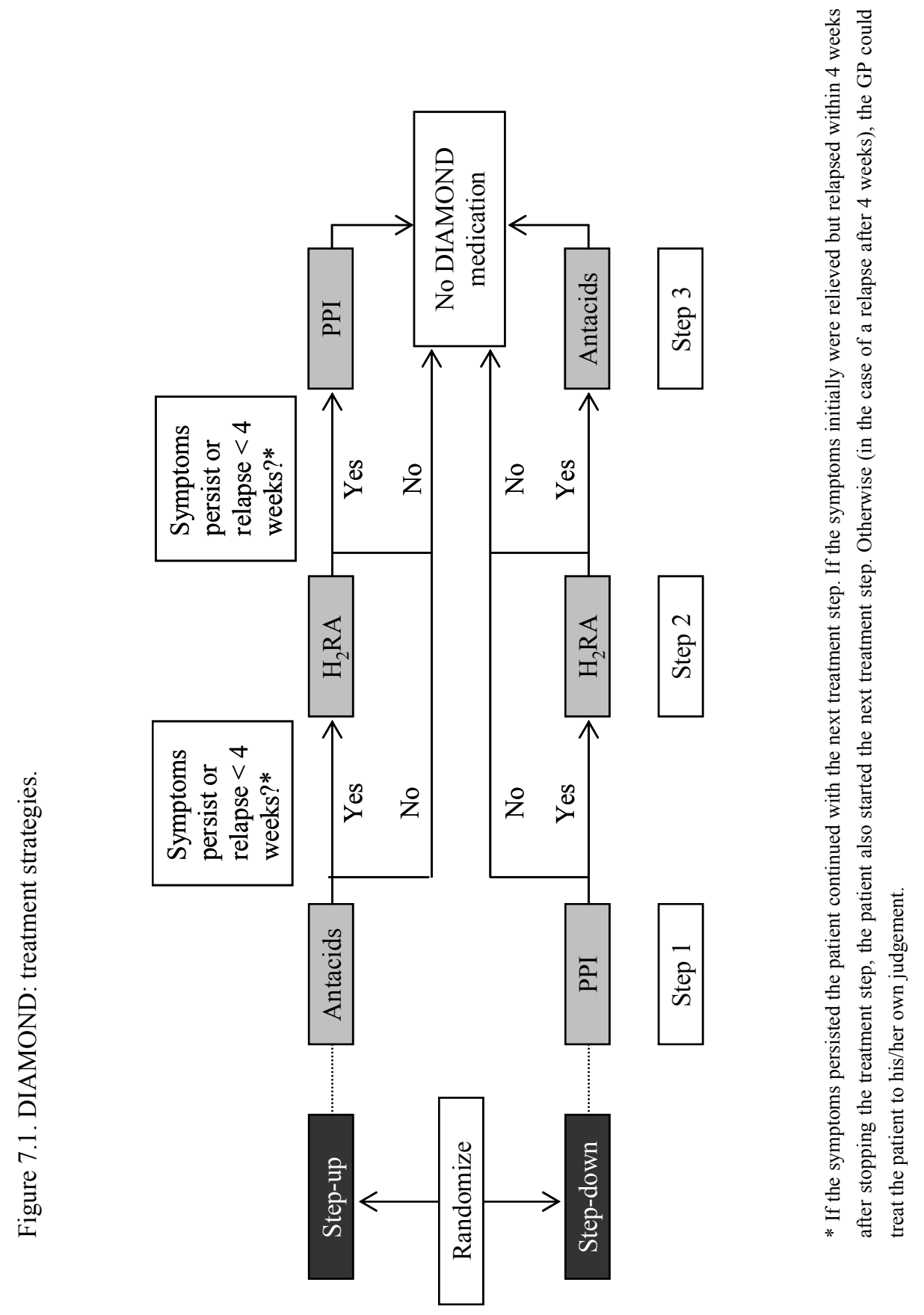




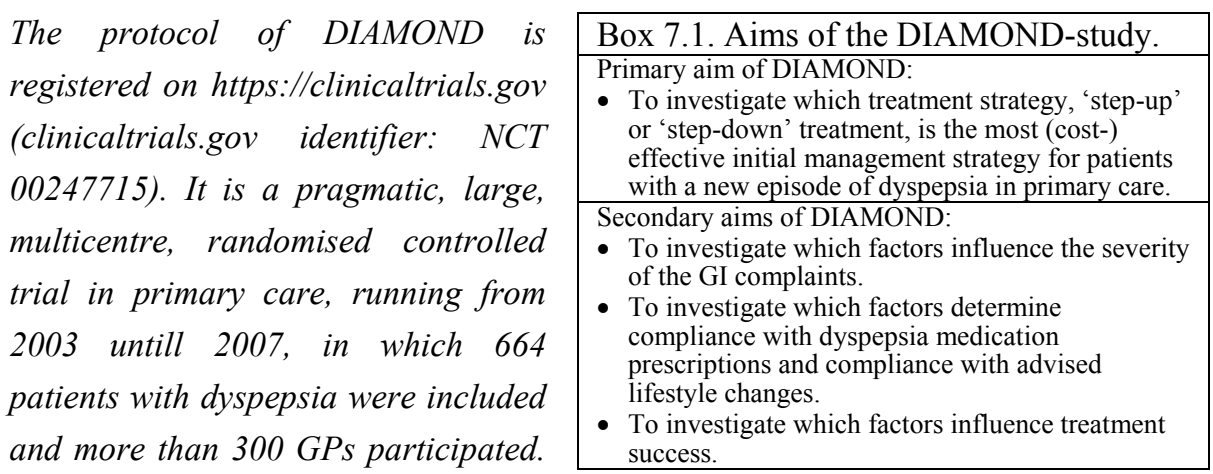

The study is conducted with the joint expertise of three academic research centres from both primary and secondary care. While within DIAMOND besides effectiveness also cost-effectiveness will be analysed, this paper will focus on the evaluation of clinical end-points. Economic evaluation trials are facing specific methodological challenges, which are described for instance by Ramsey et al. ${ }^{3}$ and Tunis et al. ${ }^{4}$

\section{Challenges in designing a study}

Choosing the right intervention and blinding treatment allocation

Pragmatic trials evaluate the beneficial effect of a treatment strategy for clinical practice when applied by any clinician to any patient with the disorder studied. The intervention must be relevant and feasible to be generalised to clinical practice and it must be compared to the best available usual care (reference care). Randomisation and blinding caregivers, participants, and investigators for treatment allocation are used in trial settings to increase the internal validity and aims to ensure that an effect is solely caused by the intervention. ${ }^{5}$ Inadequate blinding in trials proved to result in $30 \%$ lower odds ratios than adequate blinding. ${ }^{6}$ However, in every day practice treatment is not blinded, and may be influenced by prejudices of GPs or patients. While blinding is important to increase internal validity, it may limit the generalisability of results. Furthermore, blinding treatment allocation is often difficult to achieve in pragmatic trials, because of differences in the appearances of various treatments (for instance operation versus medication) or differences in the consultation scheme.

One possible solution is cluster randomisation, ${ }^{5}$ where one group of caregivers exclusively prescribes the experimental treatment and another group exclusively the 
reference treatment. When all physicians within one centre are allocated to the same treatment arm, contamination will be reduced and all patients within one centre get the same treatment. Nevertheless, prejudices of caregivers, patients or researchers might still cause biases, for instance if the treatment is terminated preliminarily when physicians or patients do not expect the treatment to work. Although this reflects every day practice and might not be a problem in pragmatic trials (as long as patients are still included in analyses), observation bias decreases internal validity. Furthermore, because differences between caregivers can bias the results, one should then adjust for these differences with multi-level analysis.

The rationale behind our choices

The DIAMOND project was designed to compare a 'step-up' treatment strategy (Figure 7.1) (which is advocated in recent Dutch guidelines) with PPI-treatment (which is practised by many GPs). The appearances of both strategies differ too much to be suitable for blinding. Therefore, we decided to compare the 'step-up' treatment strategy with a 'step-down' treatment strategy, in which the PPI-treatment is followed by two treatment steps (Figure 7.1). Both treatment strategies were now made comparable in drug distribution and appearances by using placebos (Figure 7.2). This had several advantages; first, this design enables to investigate whether patients experience symptom relief on other (non-PPI) acid-suppressants when initial PPI-treatment fails. Second, PPIs can have a known rebound effect. In the 'step-down' group it is possible to investigate whether patients, who initially responded well on PPIs but got a relapse, respond equally well on other (cheaper) acid-suppressants. Third, when patients needed all three medication steps, both groups received the same medication, only in a different order, so the influence of the order of medication on for example patient satisfaction can be investigated.

Our design also had some disadvantages. Our organisation of 'step-down' treatment does not reflect usual care, which might affect generalisability. Some argued it is unethical to 'step-down' when the strongest drug is not effective. However, in our opinion patients can safely try the other two kinds of medication, before further investigation is established. Furthermore, in both groups patients had to use a placebo along with normal treatment. This can be a burden, since it means taking extra pills in step one and step three, and it differs from everyday practice too. 


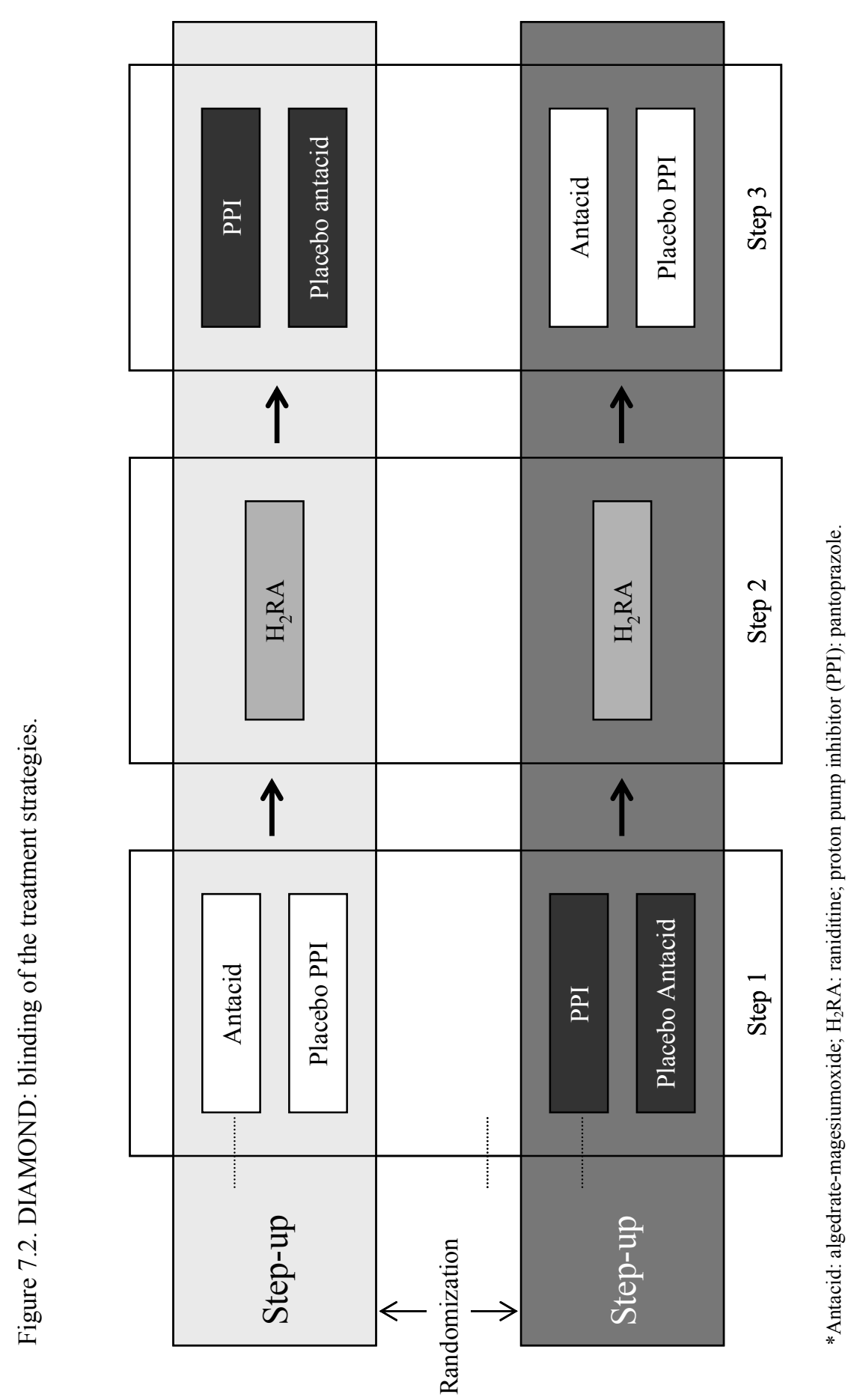


Although heavily aimed for, we were not able to find completely identical placebos. However, patients would not be able to tell their treatment allocation and to ensure that GPs would not recognize the pills, non-transparent medication jars packed in sealed paper bags were used. Clustered randomisation as discussed above could have induced more bias as the treatment allocation would have been recognized easily by GPs after completing the first patient in their cluster.

We chose to disclose treatment allocation at six months, just after measuring primary outcome. We reached high internal validity at the cost of decreasing external validity. Primary outcome (adequate symptom relief according to the patient) was measured at six months, which could be three to four months after prolonged prescription of any medication chosen by the GPs after completing the trial. In usual care the GP would repeat prescription of the most effective on recurrence of the symptoms. However, because of the 'late' disclosure of treatment allocation in DIAMOND, our GPs may have assumed that symptom relief may have occurred during the use of PPIs and prescribed this after the trial medication was finished, while maybe the patient responded on the antacid. Consequently, blinding might have caused convergence of treatment after trial medication in both strategies, which decreases differences in measured effectiveness.

Infection with Helicobacter pylori can influence the effectiveness of treatment as well as relapse rates of symptoms. Therefore blood samples for serology were taken at baseline. The H. pylori test results were also disclosed at six months to avoid the treatment or costs to be influenced by $H$. pylori management before measuring primary outcome. Incidentally GPS requested to disclose $H$. pylori test results earlier, in which case, the (theoretical) costs of H. pylori testing were included for the cost evaluation of treatment. The medical ethics committee agreed with postponed disclosure since H. pylori infection takes place early childhood and has no imminent association with the onset of symptoms. Early H. pylori testing in this trial may have caused GPs to be more aware of $H$. pylori infection and may have urged them to inform about the test results more often than in normal practice. However, the alternatives, drawing blood samples only when a test is requested by the GP or after follow-up is completed, would have caused more drop-outs. The choice to communicate $H$. pylori test results at six months and take theoretical costs into account when requested sooner is a clear example of a way to control the treatment, while it probably decreases the external validity. 
Our choices may all influence treatment effects. We believe that blinding the treatment allocation and the use of placebo led to more comparable treatment strategies, which probably led to a smaller difference between the true effects of both treatment strategies than in every day practice would exist.

\section{Choosing an appropriate study population}

Regarding internal validity, according to Kleinbaum et al. $^{7}$ selection bias is a distortion in the estimate of effect resulting from the manner in which subjects are selected from the target population. Within DIAMOND all patients were randomly allocated to either the 'step-up' or 'step-down' treatment strategy, which makes selection bias unlikely.

Regarding external validity, it is very important that the investigated population should represent the target population, but how can optimal representation be achieved? First, the target population needs to be clearly defined by using inclusion and exclusion criteria. Second, the method of patient selection greatly influences representation (see 'Patient recruitment'). The best way is to select patients randomly, but this is very challenging because it is difficult to avoid self-selection. Responding to an advertisement is a clear example of self-selection. Also GPs may be self-selected if they responded to an invitation letter to participate. This can be a problem when the participation of the GPs is associated with certain patient characteristics (education level, co-morbidity).

A representative patient sample must reflect all patients in the target population, including patients from minority groups, especially when treatment effects are supposed to be influenced by population characteristics. Translated questionnaires should enable immigrants to participate. Consideration should always be given to motivate patients expected to have low participation rates, for instance by tailoring patient information to gender or age.

There are several practical or judgemental reasons (lack of time, symptoms, preference, willingness) for a patient not to be included although eligible. Therefore, registration of all eligible patients and monitoring reasons for non-inclusion is preferred, to be able to judge inclusion selection. However, this is time consuming and researchers still would question the completeness of the registration. When available, electronic medical records might be helpful in estimating the proportion of non-included eligible patients. However, routine electronic medical records might also lack data to check eligibility (e.g. duration of symptoms) and will not always provide insights in the reasons for non-inclusion. 
The rationale behind our choices We chose to focus on 'adult patients with a new episode of dyspepsia', because the most effective treatment for these patients was unknown. Careful consideration with all the experts in the research board led to a limited number of inclusion and exclusion criteria to define these patients. The criteria were based on recent guidelines and were judged to be feasible and clear (Box 7.2).

Box 7.2. In- and exclusion criteria of DIAMOND.

Inclusion criteria:

- Visiting the GP for complaints of which the GP thinks that they originate from the upper GI tract and for which acid-suppressive medication can be effective;

- 18 years or older.

Exclusion criteria:

- Usage of prescribed acid-suppressive medication in the last 3 months before inclusion;

- Gastroscopy during the year prior to inclusion;

- Presence of alarming symptoms;

- Presence of contraindications for prescribing acidsuppressive medication, such as pregnancy, liver or kidney malfunction;

- Inability to fill out (Dutch) questionnaires, for example because of language problems.

Regarding the representation of minority groups, it was not possible to make all relevant language adjustments, but translation from Dutch into English was provided. Some participating immigrants who spoke other languages had help from their relatives to fill out the questionnaires.

Patients were recruited by participating GPs. We invited as many GPs as possible within our geographic boundaries, resulting in 312 participating GPs distributed over the Netherlands (Figure 7.3). It is possible that especially GPs with a special interest in the gastrointestinal (GI) field were responding. This can be a problem if participation of the GPs is associated with effect modifying patient characteristics. However, it is likely that the heterogeneous group of participating GPS (GPS from urban as well as rural regions with solo, duo, or group practices) has resulted in a heterogeneous patient sample, which represents the primary care population.

To investigate initial treatment of patients with a 'new' episode of dyspeptic symptoms, patients who used prescribed acid-suppressive drugs in the last 3 months were excluded. However, since patients with mild symptoms are more likely to be without medication for more than three months than patients with severe symptoms, this might have resulted in a patient sample with overrepresentation of patients with mildly severe dyspepsia. Moreover, maybe the GPs only invited patients with mildly severe dyspepsia, because they did not want to risk patients with more severe complaints to be treated with the 'step-up' treatment strategy. Finally the representativeness of our sample will be investigated by comparing several relevant patient characteristics to results from other (preferably population based) studies. Hypothetically, the difference in treatment effect between PPIs and antacids might be smaller in patients with mild symptoms. As a consequence the difference between 
the two treatment strategies might have been smaller than in every day practice where also patients with more severe complaints are treated.

\section{Choosing the essential outcome measurements}

The value of study results is greatly determined by the definition of the primary outcome and choice of measurements. When the primary outcome is an objective measure, e.g. survival, it is easy to measure and define it. However, the outcome of many diseases in primary care needs more subjective evaluation, and selection and definition of the outcome may prove to be difficult. A proper definition can be based on literature or expert opinion. Furthermore, it needs to reflect what decision makers want to know. The endpoint also needs to be clear, and preferably comparable with other studies.

Concerning the measurements, the validity and reliability should always be critically assessed. To increase response rates questionnaires must be as short as possible. This is challenging, especially when several additional research questions are investigated as in our study (see Box 7.4). The additional value of every question in the questionnaire needs to be critically judged and a pilot study is preferred to estimate the feasibility and burden for GPs and patients.

\section{The rationale behind our choices}

Choosing the primary outcome measure for DIAMOND was not easy because $e^{8}$ the presence or absence of 'dyspepsia' can not be measured objectively. Furthermore, dyspepsia is characterized by periods of remission followed by symptom relapse. We used 'adequate symptom relief at six months, according to the patient' as primary outcome, following expert recommendations (Rome II criteria) and because this reflects the decision to stop or continue treatment in every day practice. It is generally accepted that symptomatic response can be used in dyspepsia because this is what GPs have to rely on in clinical practice. Besides, more objective measurements (e.g. endoscopy) poorly correlate with symptom severity. To enable a comparison with results from other studies we analysed the change in severity of the gastrointestinal symptoms and quality of life as secondary outcomes.

Additionally, choosing the right timing of the measurement of the primary outcome in a study with multi-step treatment strategies is difficult. Choosing a six month time interval is convenient for policy makers and feasible in trial practice. But the downside is that patients received trial medication for variable periods of time. Good responders may only have had the first treatment step, and if they remained 
symptom-free for four weeks after finishing treatment they did not start with the second treatment step. In the case of relapse after four weeks or after finishing treatment step three treatment was left up to the GP. As mentioned above, the primary outcome might be influenced more by the GP prescribed medication than by the study medication at the time of six months. This may have decreased differences between the treatment strategies at six months. We also measured short term outcomes (at two weeks, four weeks, etc.) to be able to determine the short-term efficacy of the individual treatment strategies.

We investigated the validity of the questionnaire for the severity of gastrointestinal complaints. ${ }^{9,10}$ A pilot study among non-experts to investigate the burden of filling in our questionnaires showed that at baseline as well as at follow-up 15 to 30 minutes were needed for a complete response. This was judged to be acceptable and patients were informed of this time estimation before providing

Box 7.3. Measurements.

Primary health outcome:

- Adequate symptom relief at 6 months according to patients.

Secondary health outcomes:

- Severity of the GI complaints (at 2 weeks and after the treatment step);

- Quality of life at 6 months (at 2 weeks and after the treatment step).

Additional research questions investigated:

- The cost-effectiveness of both treatment strategies;

- The association between genetic determinants and dyspepsia and treatment success;

- Compliance with prescribed medication advices and lifestyle advices and which factors influence compliance;

- The association between psychosocial determinants and dyspepsia and treatment success.

Self-administered questionnaires used:

- General questionnaire to measure effect of the treatment, costs, work absenteeism, demographical determinants, co-medication used and life-style;

- Gastrointestinal Symptoms Questionnaire;

- EuroQol 5D;

- SF 36;

- Compliance Questionnaire;

- SCL 90;

- Health Hardiness;

- Utrechts Coping List;

- Major Life Events. informed consent to participate.

\section{Challenges in conducting a study}

\section{Patient recruitment}

Many studies fail to recruit enough patients which compromise statistical power. A review by Mc Donald showed that only 31\% of randomised controlled trials were able to reach their goals concerning patient recruitment. ${ }^{11}$ There are several ways to recruit patients: from medical records, by advertisement or during consultation. The usage of medical records increases effective recruitment because it does not depend on patient presentation to recruiters during the inclusion period. However, this method can not be used when incident cases are required. Sellors et al. ${ }^{12}$ found 
barriers such as the availability of electronic medical records, the experience of office staff and GPs to produce patient sampling frames and ethical considerations. Another method is patient recruitment via advertisements in (local) media or via flyers at the GP's office. However, patients responding to such advertisements may differ from patients not responding which leads to selection bias and hampers external validity. The conventional way to recruit patients is by the GP during consultation (incident cases). This way of recruitment approximates routine practice the most, which increases external validity. However, it poses a huge burden on the GP and is not always successful. There might simply be a lack of eligible patients or trial procedures can be too restrictive. According to Van Der Windt et al. ${ }^{13}$ the main reasons for not referring eligible patients to the research centre by participating GPs were: busy surgery hours, forgetfulness, or the conviction that a patient would benefit more from a specific intervention. De Wit et al. ${ }^{14}$ found that successful patient recruitment in a dyspepsia trial was determined more by the motivation of GPs by the research group than by financial incentives, research topic, or research experience. Foy et al. ${ }^{15}$ investigated in a meta-analysis the impact of interventions on patient recruitment and concluded that organisational characteristics (e. g. strong trial infrastructure) seemed to be important. Furthermore, many interventions on patient recruitment were not evidence-based but based on the experience of the investigator. $^{15}$

Additionally, successful patient recruitment depends on the patients' motivation. Chang et al. ${ }^{16}$ found that the reasons for patients to participate could be divided into six general categories: 1) benefit to self; 2) benefit to others; 3) gratitude to the physician; 4) positive comments by the trusted professional; 5) the appearance, personality, manner and gender of the recruiter; 6) monetary compensation. We agree with Chang et al. ${ }^{16}$ that the most effective recruitment involves a direct and personal approach. Patients appeared to enjoy being noticed and sorted out for something presented to them as important and special. The patient information and the GP need to address possible reasons and advantages for patients to participate.

\section{The rationale behind our choices}

Since we focused on patients with a new episode of complaints, we chose to recruit incident cases during consultations by the GP. To our experience successful patient recruitment depends on: 1) Close monitoring of recruitment statistics and extra measures to boost recruitment if necessary; 2) flexibility of the research protocol: it must be possible to adapt the protocol when GPs cannot use it in practice or when 
selection criteria are not clear or too strict; 3) good and regular contact with the GP or an assistant (preferably face-to-face or by telephone), which enables to remind and motivate them and notice and resolve difficulties. We visited the GPS after each new included patient to collect the patient's blood sample and provide new materials. The purpose of this visit was to reinforce the patient inclusion, but not to discuss how the included patient was treated to avoid an extra educational intervention. Furthermore, a monthly newsletter was sent to the GPs to remind them and to keep them posted. We tried to minimize the burden for the GPS and the assistants (for instance by taking blood samples ourselves when necessary) and answered questions promptly implying easy accessibility. Despite these efforts to motivate and assist the GPS, only 48\% of the participating GPS recruited one or more patients (Figure 7.4).

Figure 7.4. Patient recruitment and number of (successful) GP participants.

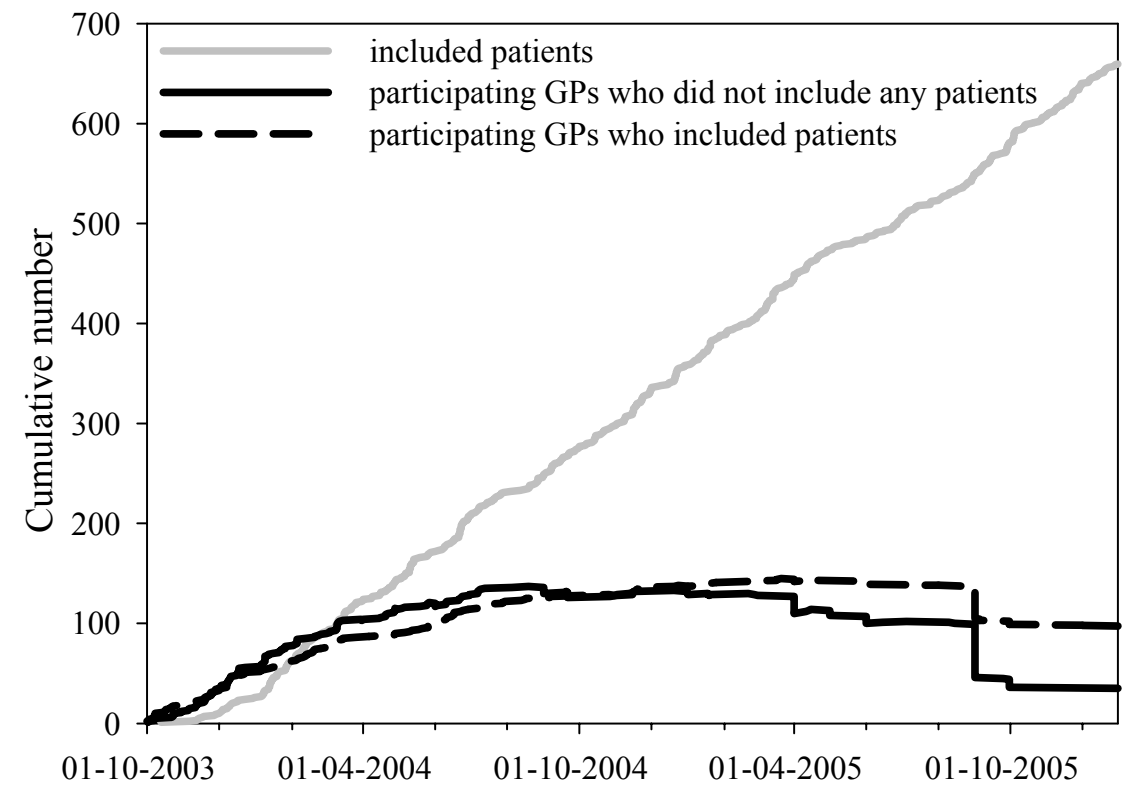

We can only speculate on the reasons for this disappointing number: maybe the inclusion and treatment was expected to be too time-consuming or maybe these GPS simply forgot to invite eligible patients despite of several reminders. Social desirability may have caused GPs to participate who were less motivated to include patients. Although ultimately successful, patient recruitment was very time consuming and needed sufficient budget for recruitment personnel. The intended 
inclusion period of two years had to be prolonged in October 2005 to include the desired number of patients. Only GPs who were expected to include several patients before the end of 2005 ('promising' GPs) were invited to continue patient recruitment.. This explains the sudden fall in participating GPs in Figure 4. Interestingly, this did not decrease the patient inclusion in the last months, which suggests that it may be more efficient to only include highly motivated and 'promising' GPs. Exclusion of reluctant GPS may hardly decrease inclusion rates but does decrease the workload for the researchers.

GP recruitment

Patient recruitment in primary care based trials often depends on the cooperation of GPs. Since the demand on GPs to participate in research is growing and it is hard to keep the balance between research participation and daily practice, ${ }^{14}$ GPs must be very critical in their decision to participate. Factors known to influence the physician's decision to participate include: ${ }^{17-19} 1$ ) a personal interest in the research topic; 2) the relevance of the research question; 3) the personal connection with the researchers; 4) the collective ownership of the project; 5) the support of stakeholders or respected members of the professional community; 6) the revenue of costs associated with research participation; 7) the simplicity of protocols with low interference with patient care; 8) the availability of practice staff to assist the enrolment; 9) the timeliness of patient recruitment; 10) the satisfaction with study participation. Van Der Windt et al. ${ }^{13}$ also mentioned that (accredited) postgraduate training is a reason for GPs to participate, and involvement in too many other studies is a reason not to participate.

A strategy for approaching primary care settings as proposed by Murphy et al ${ }^{17}$ and Kocken et al. ${ }^{20}$ recommends identification of stakeholders and regional opinion leaders, using support letters by relevant professional organisations and supplying adequate, but concise, information. It is important to consider and address the reasons for GPs to participate during the recruitment.

The rationale behind our choices

For GP recruitment we wanted to invite as many GPS as possible within our geographical boundaries to gather a large heterogeneous GP sample. We retrieved the addresses of all eligible primary care settings from a registration at the three participating universities. The GPs received an invitation letter with information 
about the research together with a recommendation letter from the Dutch College of General Practitioners and the Dutch Institute for Healthcare Improvement.

Figure 7.3. GP recruitment.

\section{GPs invited to participate by letter}

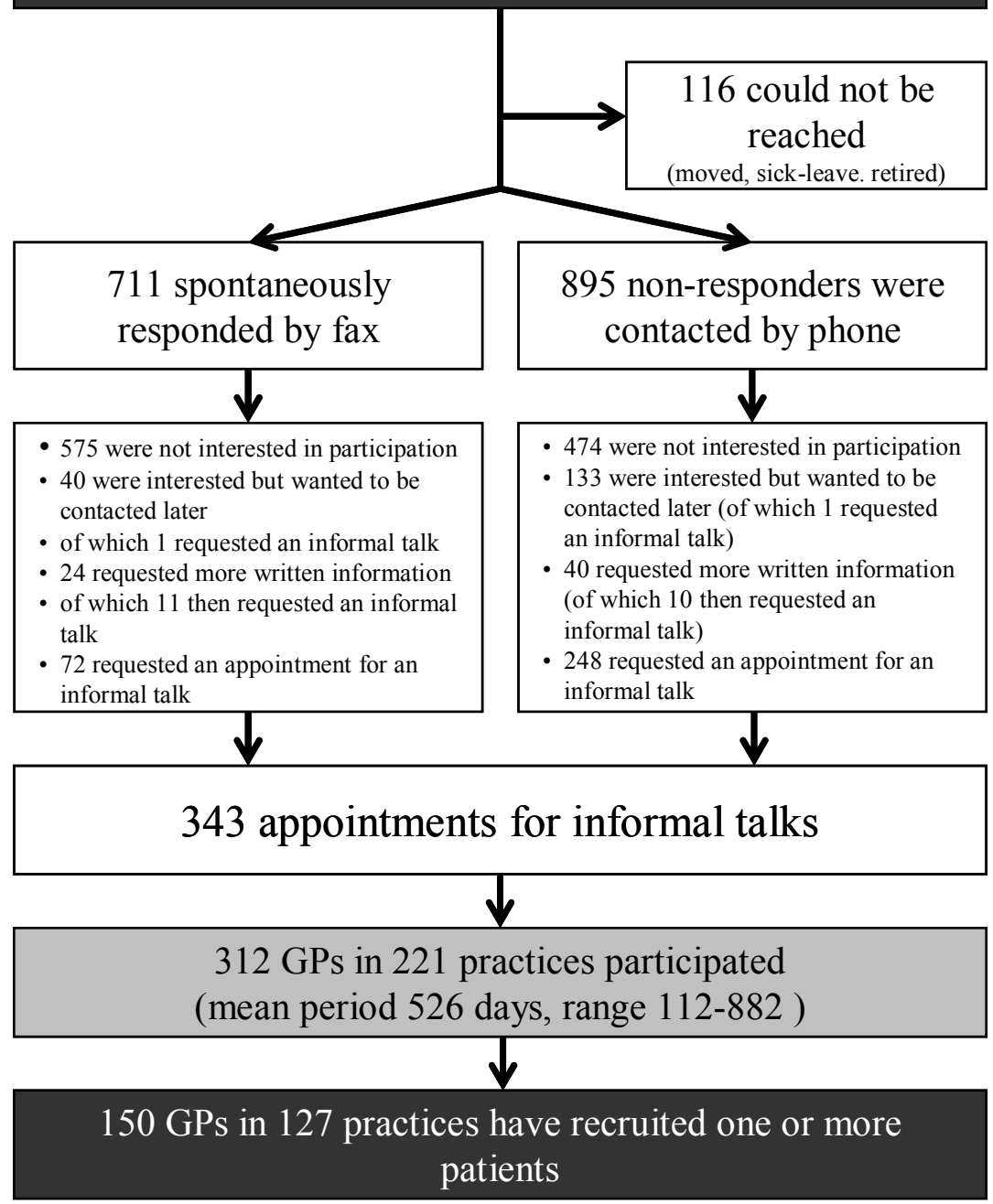

A reply form was offered to respond by fax. In the case of non-response the GP was invited again by means of a telephone call. After an informal appointment at the GP's office, the GP decided whether or not to participate. For practical reasons the 
GP recruitment was spread out over the first period of patient inclusion. The results of GP recruitment are given in Figure 7.4. To our experience, however ultimately successful, the GP recruitment was very time consuming because of the many phone calls and visits. Although difficult, personal contact with the GP more positively influenced participation than leaving a message with the assistant. Spreading out the GP recruitment period gave us the opportunity to adjust the information letters and to approach more GPS to boost patient recruitment when the inclusion lagged behind. Our method of GP recruitment probably has resulted in a heterogeneous and representative relatively large GP sample, which is likely to have a positive influence on the generalisability of the results.

\section{Protocol deviations}

Protocol deviation or protocol non-adherence by patients, GPs or researchers is common. Examples of protocol deviations are: drop-out, inclusion of ineligible patients, not receiving the allocated treatment, unplanned interruption or abortion of treatment; and not taking the trial medication as prescribed. Drop-outs are patients who stop their trial medication but remain available for follow-up. ${ }^{21}$ Patients can also be 'lost to follow-up', when they are no longer accessible to the investigators. ${ }^{21}$ Eligibility errors are relatively common. ${ }^{21}$ Objective eligibility criteria are less prone to error than subjective ones. If eligibility is checked before randomisation, the consequences of such errors will be minimal. However, in pragmatic trials commonly the eligibility is checked e.g. with blood measurements or patient selfreports, which are often only available after randomisation.

Bias can be introduced when protocol deviation affects both treatment groups differently. ${ }^{21}$ Researchers therefore investigate whether the protocol deviation is caused by systematic or random errors, and whether it causes differences between both treatment groups. When protocol deviation is associated with one treatment arm (e.g. if the experimental treatment has more side-effects), it is important to take this into account because protocol deviations will also happen in every day practice. In a per-protocol analysis all patients with a protocol deviation will be excluded, ${ }^{22}$ which contrasts with the purpose of conducting a pragmatic trial. Exclusion of patients can result in bias when the patients that stay included are no longer representative for the study population. Therefore, a per-protocol analysis is less suitable than an intention-to-treat analysis for pragmatic trials. Some pragmatic trials perform a per-protocol analysis additionally to an intention-to-treat analysis, but difficulties arise when both analysis produce different results. Whereas the results of 
a per-protocol analysis may provide additional insights in why a treatment has (or lacks) effect in every day practice, in pragmatic trials the intention-to-treat analysis is the way to determine the overall effect.

Protocol deviations can partly be prevented by writing simple and clear protocols, providing proper patient information, and by closely monitoring GPs and patients during a pilot study and adjusting the protocol if required.

\section{The rationale behind our choices}

To reflect every day practice as much as possible we chose to write a flexible treatment protocol, in which for instance the GP was free to decide when patients could return for consultation (after four weeks was recommended) or how the consultation was done, by phone or personal. This has probably minimized our number of protocol deviations. We can only present some preliminary data at this moment, since not all analyses have yet been finished. No non-eligible patients were included. Eleven patients gave an informed consent but changed their mind shortly after and they did not start using our trial medication. One patient did not use medication step 1 for unknown reasons, but started medication step 2 approximately two weeks after baseline. Table 7.1 shows the questionnaire response rates and suggests that number of patients 'lost to follow up' was limited. For the intention-totreat analysis, preliminary results indicate that for $98 \%$ of the patients the primary outcome at six months is present. We are able to achieve such a high response rate by contacting all non-responders or drop-outs by phone or via the GP (except for patients indicating not to be willing/able to participate anymore) and asking them to answer the question: has symptom relief been adequate since the start of the treatment? Most patients are willing to answer this single question.

Some patients do not return the initial six month questionnaire, because they think that when their complaints are resolved they do not need to return questionnaires. To prevent this bias we send reminders pointing out the importance of always returning the questionnaire and contact non-responders by phone or via their GPs. The preliminary response rates for all questionnaires are given in Table 7.1. The response rates slowly decrease in time as can be expected. The length of the baseline questionnaire and the high number of questionnaires during the first month caused several patients to stop their participation. Although tested in a pilot study and explained in the patient information, this could not be completely prevented. Maybe in the near future easier ways to monitor complaints and retrieve important 
data (e.g. via the internet) will become accessible and can facilitate patient cooperation and prevent drop-out.

Table 7.1. Preliminary results*: the patient questionnaire response rates.

\begin{tabular}{llllllll}
\hline $\mathrm{N}=664^{*}$ & $\begin{array}{l}\text { At } \\
\text { baseline }\end{array}$ & $\begin{array}{l}\text { At 2 } \\
\text { weeks }\end{array}$ & $\begin{array}{l}\text { After } \\
\text { step 1 }\end{array}$ & $\begin{array}{l}\text { After } \\
\text { step 2\# }\end{array}$ & $\begin{array}{l}\text { After } \\
\text { step 3\# }\end{array}$ & $\begin{array}{l}\text { At 6 } \\
\text { months }\end{array}$ & 1 year \\
\hline $\begin{array}{l}\text { Sent out } \\
\text { Returned }\end{array}$ & $664^{*}$ & $613^{*}$ & $643^{*}$ & $595^{*}$ & $587^{*}$ & $659^{*}$ & $566^{*}$ \\
$\begin{array}{l}\text { Response } \\
\text { rate }\end{array}$ & $95 \%$ & 843 & 525 & 474 & 454 & 646 & 373 \\
\hline
\end{tabular}

*Not all follow-up questionnaires were sent out, for instance when patients started step 2 within 2 weeks, or patients reported they no longer whish to receive questionnaires.

\#if medication of this step was not started, questionnaires were sent out at 2 resp. 3 months.

${ }^{\wedge}$ In the case of non-response a reminder is sent out after all questionnaires except after 1-year, since this is an additional measurement to the original research protocol. This explains the low response rate.

\section{The consequences of our choices for the usefulness and relevance of the DIAMOND results}

The results of this study are useful/relevant for policy makers, patients, GPs and researchers because a large population of well defined patients, which is generalisable to the Dutch population of patients with a new episode of dyspeptic symptoms. The study has a high internal validity because of the random treatment allocation, and the concealment of treatment allocation/blinding, which increases the value of the results for policy makers. However, the external validity is decreased by the use of 'step-down' treatment instead of PPI-treatment (which is more common in every day practice) and by the blinding. Consequently, it is difficult to say what the effect of both treatment strategies will be if performed in every day practice.

In order to adapt the study protocol to routine daily practice, a multistep protocol was designed. Although this resembles everyday practice it makes analysis more difficult, because not all patients are in the same treatment step at a certain point in time, and because the period of time between finishing the trial medication and registration of the primary outcome may vary from patient to patient. In case this period is long, the primary outcome may be influenced by follow-up treatment chosen by the GP. This may decrease any differences between the treatment strategies, but on the other hand the primary outcome does provide essential 
information about the effectiveness of actual primary care treatment for dyspepsia. Furthermore, the differences between the two treatment strategies can be analyzed in more detail by analyzing the secondary endpoints (at 4 weeks, 12 weeks, etc...). Therefore, the trial design as presented will provide important insights in various strategies for treatment of dyspepsia in primary care.

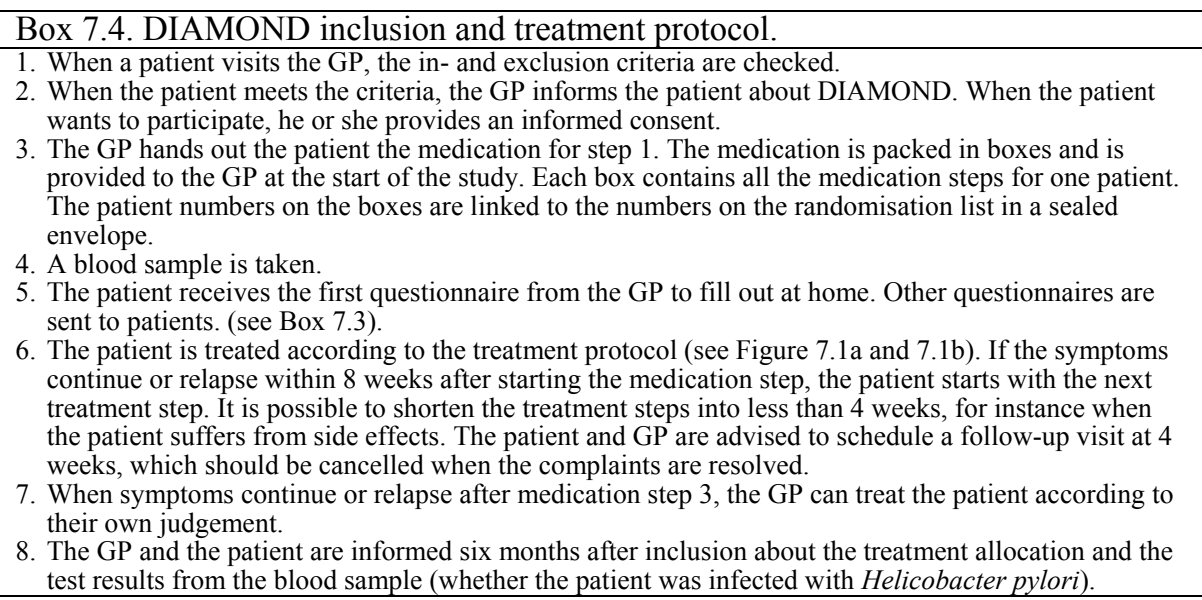

\section{Summary}

Pragmatic trials must ensure a high generalisability without compromising internal validity, which is very challenging. ${ }^{23}$ Therefore, a critical appraisal of the planned design and method to conduct the trial before actually starting to collect data is essential. When several publications on patient recruitment or other pitfalls in designing/conducting a pragmatic trial are consulted, one may increase the likelihood of conducting a successful trial. Furthermore, it is very important to set priorities beforehand where on the 'spectrum from explanatory to pragmatic' you want your trial to be: do you want to know the 'unbiased' effect of the treatment (as in explanatory trials) or are you more interested in the effects in daily primary care (as in pragmatic trials)? For instance, we chose to blind treatment allocation because otherwise prejudices of GPs, patients and researchers might have biased the results, although blinding contrasts with the purpose to reflect every day practice in pragmatic trials. On the other hand, we chose to use flexible treatment protocol to reflect every practice, what again might contrast with using standardized treatment in explanatory trials. 
This paper shows that while we did not compare the two most frequently used treatment strategies in the DIAMOND-study, we were still able to collect highly valid data because of the blinded randomised treatment, the randomly selected heterogeneous patient sample and the research protocol that closely fits to normal practice. Although it is very difficult to recruit as many GPs and patients as needed, success can be determined by careful consideration of how the GPs and patients will be optimally recruited and what their reasons to participate or to refuse participation will be. Our experiences with the DIAMOND-study give an indication of what success rates regarding GP and patient recruitment and questionnaire response can be expected in similar studies.

\section{References}

1. Macpherson H. Pragmatic clinical trials. Complement Ther Med 2004; 12: 13640.

2. Tunis SR, Stryer DB, Clancy CM. Practical clinical trials: increasing the value of clinical research for decision making in clinical and health policy. JAMA 2003; 290: 1624-32.

3. Ramsey S, Willke R, Briggs A, Brown R, Buxton M, Chawla A et al. Good Research Practices for Cost-Effectiveness Analysis Alongside Clinical Trials: The ISPOR RCT-CEA Task Force Report. Value in Health 2005; 8: 521-33.

4. Tunis SL, Johnstone BM, Kinon BJ, Barber BL, Browne RA. Designing Naturalistic Prospective Studies of Economic and Effectiveness Outcomes Associated with Novel Antipsychotic Therapies. Value in Health 2000; 3: 23242.

5. Knottnerus JA. Gezondheidszorgonderzoek in extramurale settings (Health care research in community and primary care). In Ethiek en recht in gezondheidszorg (Ethics and law in health care). Edited by Ten Have HAMJ, Blijham G, Engberts DP. Deventer: Kluwer; 1997:151-198.

6. Juni P, Altman DG, Egger M. Systematic reviews in health care: Assessing the quality of controlled clinical trials. BMJ 2001; 323: 42-6.

7. Kleinbaum DG, Kupper LL, Morgenstern H. Epidemiologic research. Principles and quantitative methods. New York: Van Nostrand Reinhold; 1982.

8. Bytzer P. Assessment of reflux symptom severity: methodological options and their attributes. Gut 2004; 53 Suppl 4: iv28-iv34. 
9. Bovenschen HJ, Janssen MJ, van Oijen MG, Laheij RJ, van Rossum LG, Jansen JB. Evaluation of a Gastrointestinal Symptoms Questionnaire. Dig Dis Sci 2006; 51: 1509-15.

10. Fransen GAJ, Janssen MJR, Muris JWM, Mesters I, Knottnerus JA. Measuring the severity of upper gastrointestinal complaints: does GP-assessment correspond with patients' self-assessment? Family Practice 2007; 24: 252-8.

11. McDonald AM, Knight RC, Campbell MK, Entwistle VA, Grant AM, Cook JA et al. What influences recruitment to randomised controlled trials? A review of trials funded by two UK funding agencies. Trials 2006; 7: 9.

12. Sellors J, Cosby R, Trim K, Kaczorowski J, Howard M, Hardcastle L, et al. Recruiting family physicians and patients for a clinical trial: lessons learned. Fam Pract 2002; 19: 99-104.

13. Van der Windt DA, Koes BW, van AM, Heemskerk MA, Bouter LM. Practical aspects of conducting a pragmatic randomised trial in primary care: patient recruitment and outcome assessment. Br J Gen Pract 2000; 50: 371-4.

14. De Wit NJ, Quartero AO, Zuithoff AP, Numans ME. Participation and successful patient recruitment in primary care. J Fam Pract 2001; 50: 976.

15. Foy R, Parry J, Duggan A, Delaney B, Wilson S, Lewin-Van Den Broek NT et al. How evidence based are recruitment strategies to randomized controlled trials in primary care? Experience from seven studies. Fam Pract 2003; 20: 8392.

16. Chang BH, Hendricks AM, Slawsky MT, LoCastro JS. Patient recruitment to a randomized clinical trial of behavioral therapy for chronic heart failure. BMC Med Res Methodol 2004; 4: 8.

17. Murphy E, Spiegal N, Kinmonth AL. 'Will you help me with my research?' Gaining access to primary care settings and subjects. Br J Gen Pract 1992; 42: $162-5$.

18. Croughan M. Factors influencing physician participation in practice-based research network studies: a call for further research. J Fam Pract 2001; 50: 9789.

19. Prescott RJ, Counsell CE, Gillespie WJ, Grant AM, Russell IT, Kiauka S et al. Factors that limit the quality, number and progress of randomised controlled trials. Health Technol Assess 1999; 3: 1-143.

20. Kocken RJ, Knottnerus JA, Smeets PE. GPs as participants in scientific research. Br J Gen Pract 1993, 43: 305-6. 
21. Piantadosi S: Clinical trials: a methodologic perspective. New York: John Wiley and Sons, Inc.; 1997.

22. Fisher LD, Dixon DO, Herson J, Frankowski RK, Hearron MS, Peace KE: Intention-to-treat in clinical trials. In Statistical issues in drug research and development. Edited by Peace KE. New York: Marcel Dekker; 1990.

23. Godwin M, Ruhland L, Casson I, MacDonald S, Delva D, Birtwhistle R et al. Pragmatic controlled clinical trials in primary care: the struggle between external and internal validity. BMC Med Res Methodol 2003; 3: 28. 
Dyspepsia in primary care: patient expectations, symptoms, and treatment adherence

122 


\section{Chapter 8}

\section{Patient adherence to prescribed medication instructions for dyspepsia}

G.A.J Fransen, I. Mesters, J.W.M. Muris, C.J. Van Marrewijk, S. Mujakovic, R.J.F. Laheij, M.E. Numans, N.J. De Wit, M. Samsom, J.B.M.J. Jansen \& J.A. Knottnerus

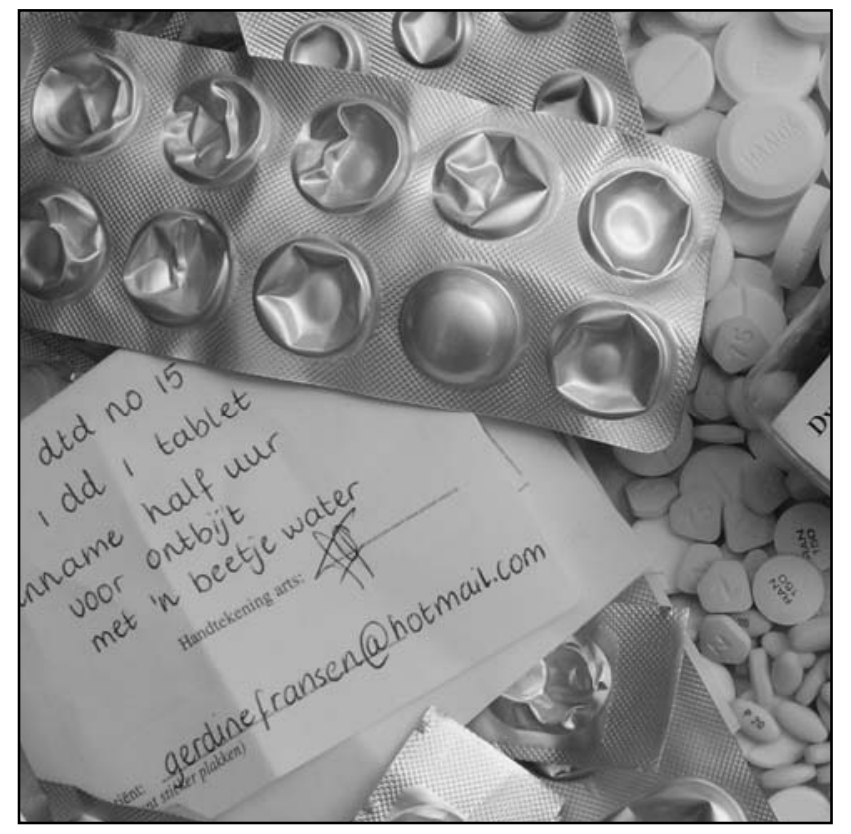




\begin{abstract}
Background: Insight into patient adherence is needed to enable an effect evaluation of medication.

Aim: This study explored adherence in patients with dyspepsia, investigating the completeness and fidelity of medication intake. Completeness indicates the number of pills taken per day, whereas intake fidelity indicates the degree to which patients adhered to specific medication instructions concerning timing, frequency, dose and way of intake.
\end{abstract}

Design of the study: Evaluation of adherence in the context of a pragmatic randomized controlled trial in which the effectiveness of a 'step-down' treatment strategy was compared with a 'step-up' treatment strategy.

Setting: Primary care.

Methods: Dyspeptic patients $(\mathrm{N}=653)$ were instructed to use 5 pills/day for maximally 30 days in treatment step 1: in the 'step-up' group, an antacid 4 times daily plus a placebo once daily, in the 'step-down' group, a proton pump inhibitor once daily plus a placebo 4 times daily. Treatment step 2 was started using a $\mathrm{H}_{2}$ receptor antagonist if the complaints persisted or returned, and, if necessary, subsequently treatment step 3, again using 5 pills/day (placebo and verum vice versa from step 1). To assess completeness, pill counts were carried out. For intake fidelity, patient questionnaires were used.

Results: No relevant differences for adherence between the two study arms were found. In treatment step 1, patients used on average 3.9 pills/day, in step 2, 1.7 pills/day and in step 3, 3.6 pills/day. For the 4 times daily pills, half of the patients used less than $80 \%$ of the prescribed pills per day. The corresponding figure for the twice daily pills was one third and for the once daily pills one quarter. There were no differences between active or placebo medication. Completeness for the 4 times daily pills was significantly lower than completeness for the other pill regimens. As regards intake fidelity, $70 \%$ of the patients made one or more errors in the medication intake. The most common errors were made in the frequency of intake and in timing in relation to meals.

Conclusion: The results show that there is room for improvement in adherence rates. 


\section{Introduction}

In order to evaluate the effectiveness of a drug, it is essential to know the degree to which the drug is actually used according to the instructions. Therefore, it is important to take patient adherence to the medication regimen into account when judging the effectiveness of trial medication as well as when determining whether or not a patient is responding to therapy in everyday practice.

In determining adherence two aspects are important: completeness, i.e. the number of pills taken per day, and intake fidelity, i.e. concordance with instructions concerning dosing, timing in relation to meals, and way of medication intake. ${ }^{1}$

The present study focuses on adherence to acid-suppressive medication for newly diagnosed dyspepsia. Adherence in the case of newly diagnosed dyspepsia is crucial, since acid-suppressive medication is often used as a diagnostic aid: ${ }^{2}$ The relief of symptoms makes it more likely that the complaints are acid-related, but if symptoms are not relieved, the diagnosis needs to be reconsidered; this often results in prolonged treatment or referral for further diagnostic evaluation. ${ }^{2}$

Treatment failure may, however, be caused by non-adherence. When patient nonadherence is identified as a possible cause of treatment failure, physicians may be prevented from wrongly assuming that the prescribed medication was not effective. On the other hand, when it is determined that a patient was adherent and the medication was not effective, one can more confidently switch treatment instead of prolonging it.

Evidence concerning the effectiveness of how, and how often, medication was taken revealed the following. Regarding completeness, continuous as against on-demand use of acid-suppressants is associated with fewer recurrences and better outcomes for newly diagnosed dyspepsia. ${ }^{3}$ Furthermore, the more days the medication is used, the higher the chance of achieving symptom resolution and the longer the symptom free period. ${ }^{4}$ Regarding intake fidelity, proton pump inhibitors (PPIs) used with a meal are more effective than PPIs used without a meal, even when taken at the same time during the day, ${ }^{5}$ twice daily dosing with $\mathrm{H}_{2}$-receptor antagonists $\left(\mathrm{H}_{2} \mathrm{RAs}\right)$ is more effective than once daily, ${ }^{6}$ and chewing on antacid tablets is more effective than just swallowing the tablets. ${ }^{7}$

Because of the importance of determining patient adherence, we elaborately investigated completeness and intake fidelity in a pragmatic randomized trial to compare the effectiveness of two treatment strategies for dyspepsia in primary care. ${ }^{8}$ 
This paper provides insight into patient adherence to acid-suppressive medication that can be used as an aid to judge adherence in everyday practice.

\section{Methods}

\section{The Intervention}

This study is part of the Dutch study of InitiAl Management Of Newly Diagnosed Dyspepsia (DIAMOND) ${ }^{8}$ This is a pragmatic randomized controlled trial in primary care comparing a 'step-up' antacid treatment strategy with a 'step-down' antacid treatment strategy (Figure 8.1a.). Both treatment strategies comprised maximally three antacid treatment steps: if complaints persisted or recurred after step 1, patients started with step 2 , and if necessary subsequently step 3 . The duration of each step was maximally four weeks: in consultation with their general practitioner (GP), patients were allowed to proceed with the next step before the four weeks ended (e.g. when the severity of the symptoms increased).

In step 1, all patients were instructed to use 5 pills a day, spread out over the day: 4 placebo pills and 1 PPI pill per day for patients randomized to the 'step-down' treatment strategy, 4 antacid pills and 1 placebo pill per day for patients in the 'stepup' treatment strategy (Figure 8.1b). Treatment allocation was concealed from patients, GPs and researchers.

The antacids and placebo antacids are referred to as 4 times daily pills (q.i.d. pills), the PPIs and placebo PPIs as once daily pills (o.d. pills), and the $\mathrm{H}_{2} \mathrm{RAs}$ (step 2) as twice daily pills (b.i.d. pills).

The instructions about how to use the medication (Box 8.1) were described in the trial information leaflet and on all medication jars. Additionally, the GPs were asked to instruct the patients verbally as they would do in everyday practice.

\begin{tabular}{|c|c|}
\hline Box 8.1. Medication instructions. & \\
\hline Treatment step 1 and Treatment step 3 & Treatment step 2 \\
\hline $\begin{array}{l}\text { Large medication jar: } \\
\text { (Antacid or placebo) } \\
\text { - } 1 \text { pill } 4 \text { times daily } \\
\text { - Use } 1 \text { hour after a meal and before bedtime } \\
\text { - Chew properly } \\
\text { Small medication jar: (PPI or placebo) } \\
\text { - Once daily } 1 \text { pill } \\
\text { - Use before or during breakfast } \\
\text { - No chewing, take with a little water }\end{array}$ & $\begin{array}{l}\text { H2-receptor antagonist: } \\
\text { - } 1 \text { pill } 2 \text { times daily } \\
\text { - Use in the morning and before bedtime } \\
\text { - Take with a little water, swallow whole }\end{array}$ \\
\hline
\end{tabular}




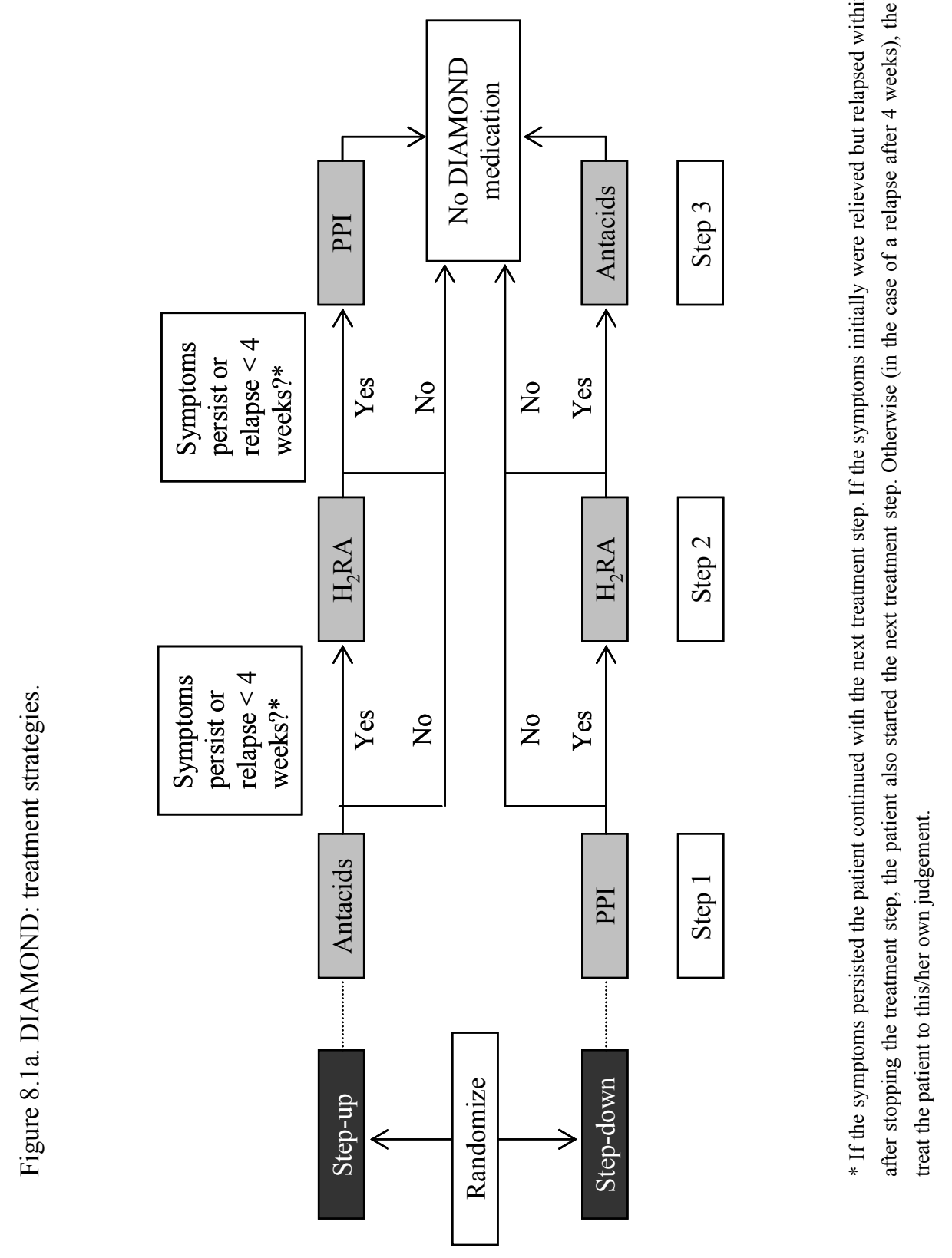




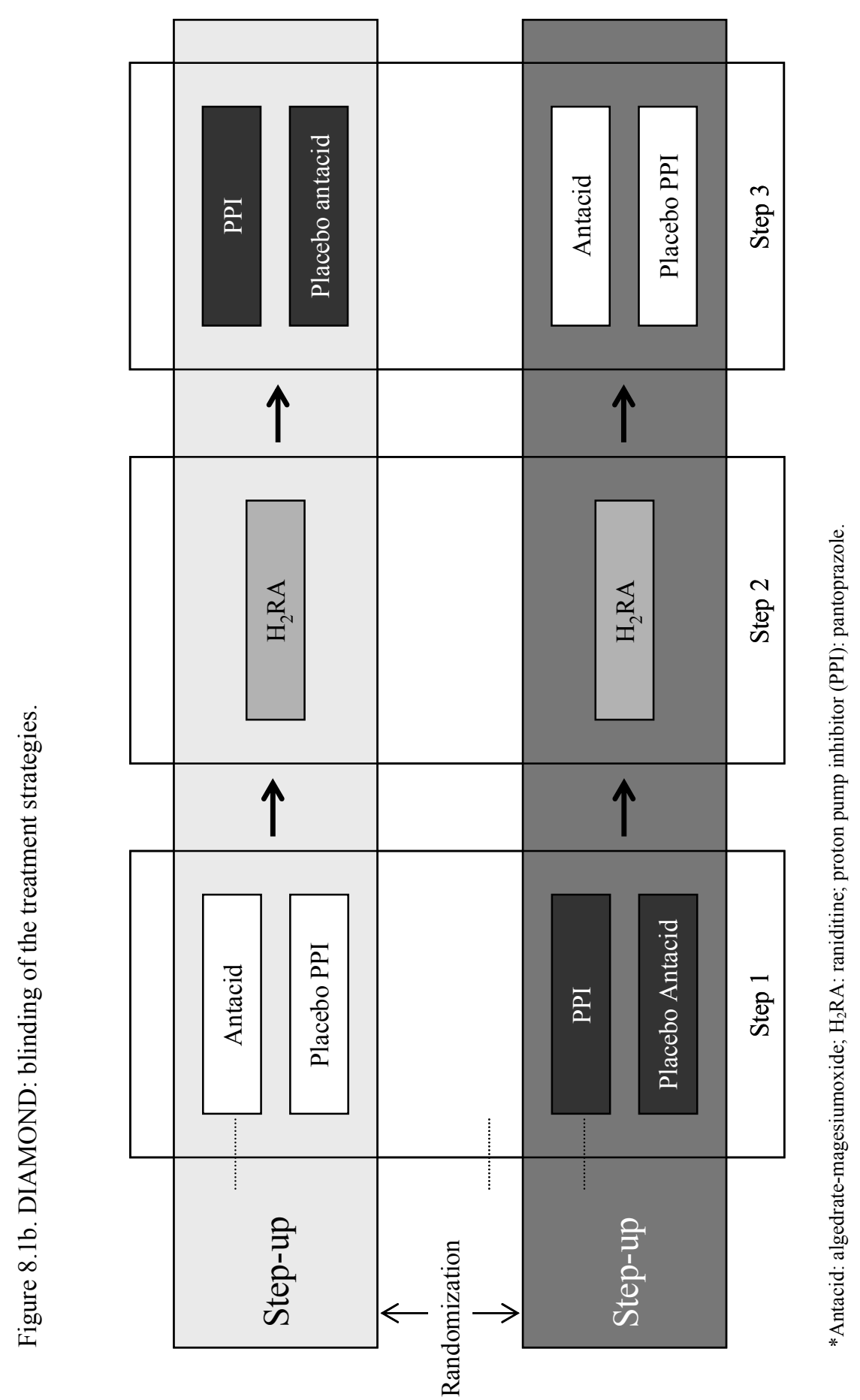




\section{Recruitment}

Patients were recruited by GPs during consultation. Adult patients presenting with a new episode of dyspepsia (i.e. they had not used any prescribed acid-suppressants during the previous three months and had not had an endoscopy during the last year) were considered eligible if they were able to complete (Dutch) questionnaires and if there were no contra-indications for using acid-suppressants. Patients giving a written informed consent received the trial information leaflet and the study medication for 30 days (120 q.i.d. pills and 30 o.d. pills).

\section{Measurements}

Completeness was measured by pill counts. Patients were instructed via the trial information leaflet, via yellow stickers on the medication jars, and verbally by the GPs, to return the medication jars (marked with a patient number) to their GPs after each step. To avoid counting errors, two researchers independently counted the returned pills. In the event of disagreement, the pills were counted a third time. Based on the duration of medication use (in days) and the pill counts, the number of pills used per day was calculated. The duration of medication use was based on the consultation dates, except when other starting and stopping dates were indicated, for example when the medication was returned prior to the follow-up consultation or when medication was stopped prematurely because of side effects.

Intake fidelity was measured by patient questionnaires (Table 8.1) sent out two weeks after the start of treatment. To reduce recall bias, it is important to measure intake fidelity during or directly after treatment. Therefore, we chose to measure intake fidelity at two (rather than four) weeks to increase the likelihood that patients were still using medication. Consequently, only the intake fidelity for step 1 was investigated. Intake fidelity sum scores were calculated, rewarding correct answers with 1 point and partly correct answers with 0.5 points. This results in a maximum score of 9 points indicating perfect intake fidelity. The questionnaire with a preprinted patient number could be returned using a pre-stamped envelope. Reminders were sent out after two weeks. The GP ascertained demographic data at the baseline consultation and monitored treatment. 
Table 8.1. Intake fidelity.

\begin{tabular}{|c|c|c|}
\hline $\begin{array}{l}\text { Intake fidelity concerning Antacids or placebo (q.i.d. pills): } \\
\text { Items with answering scales }\end{array}$ & \multicolumn{2}{|c|}{ Number of patients } \\
\hline $\begin{array}{l}\text { How do you usually take the medication from the large } \\
\text { medication jar? } \\
\text { I take the pills with water } \\
\text { I dissolve the pills in water } \\
\text { I dissolve the pills in another beverage, such as milk or } \\
\text { lemonade } \\
\text { I chew on the pills } \\
\text { I swallow the pills without chewing } \\
\square \text { Other }\end{array}$ & $\begin{array}{l}\text { Correct* } \\
\text { Incorrect }\end{array}$ & $\begin{array}{r}462(92 \%) \\
43(9 \%)\end{array}$ \\
\hline $\begin{array}{l}\text { How often per day do you take the medication from the large } \\
\text { medication jar?.... times a day }\end{array}$ & $\begin{array}{l}\text { Correct (4 times) } \\
\text { Incorrect (other) }\end{array}$ & $\begin{array}{r}431(88 \%) \\
60(12 \%)\end{array}$ \\
\hline $\begin{array}{l}\text { How many pills from the large medication jar do you take per } \\
\text { time?.... pills per time }\end{array}$ & $\begin{array}{l}\text { Correct (1 pill) } \\
\text { Incorrect (other) }\end{array}$ & $\begin{array}{r}457(98 \%) \\
8(2 \%) \\
\end{array}$ \\
\hline $\begin{array}{l}\text { When do you take the medication from the large jar? (more } \\
\text { answers possible) } \\
\begin{array}{lll}\text { After a meal } & \text { When I get up } \\
\text { Before a meal } & \square & \text { When I go to bed } \\
\text { During a meal } & \square & \text { Other }\end{array}\end{array}$ & $\begin{array}{r}2 \text { Correct answers* } \\
1 \text { Correct answer* } \\
\text { Incorrect }\end{array}$ & $\begin{array}{r}359(72 \%) \\
55(11 \%) \\
83(17 \%)\end{array}$ \\
\hline $\begin{array}{l}\text { Intake fidelity concerning PPI or placebo (o.d. pills): } \\
\text { Items with answering scales }\end{array}$ & Num & of patients \\
\hline $\begin{array}{l}\text { How do you usually take the medication from the small } \\
\text { medication jar? } \\
\text { I take the pills with water } \\
\text { I dissolve the pills in water } \\
\text { I dissolve the pills in another beverages, such as milk or } \\
\text { lemonade } \\
\text { I chew on the pills } \\
\text { I swallow the pills without chewing } \\
\text { Other }\end{array}$ & $\begin{array}{l}\text { Correct* } \\
\text { Incorrect }\end{array}$ & $\begin{array}{r}502(99 \%) \\
4(1 \%)\end{array}$ \\
\hline $\begin{array}{l}\text { How often per day do you take the medication from the small } \\
\text { medication jar?.... times a day }\end{array}$ & $\begin{array}{l}\text { Correct (once daily) } \\
\text { Incorrect (other) }\end{array}$ & $\begin{array}{r}482(98 \%) \\
12(2 \%)\end{array}$ \\
\hline $\begin{array}{l}\text { How many pills from the small medication jar do you take per } \\
\text { time?.... pills per time }\end{array}$ & $\begin{array}{r}\text { Correct (1 pill) } \\
\text { Incorrect (other) }\end{array}$ & $\begin{array}{r}486(99 \%) \\
4(1 \%) \\
\end{array}$ \\
\hline $\begin{array}{l}\text { When do you take the medication from the small jar? (more } \\
\text { answers possible) }\end{array}$ & $\begin{array}{l}\text { Correct* } \\
\text { Incorrect }\end{array}$ & $\begin{array}{r}436(86 \%) \\
69(10 \%)\end{array}$ \\
\hline $\begin{array}{llll}\square & \text { After a meal } & \square & \text { When I get up } \\
\square & \text { Before a meal } & \square & \text { When I go to bed } \\
\square & \text { During a meal } & \square & \text { Other }\end{array}$ & & \\
\hline $\begin{array}{l}\text { How late do you take the medication from the large medication } \\
\text { jar? } 1^{\text {st }} \text { time: } \ldots \\
\text { How late do you take the medication from the small medication } \\
\text { jar? } 1^{\text {st }} \text { time: ... }\end{array}$ & $\begin{array}{r}\text { Correct (o.d. before } \\
\text { q.i.d.) } \\
\text { Partly incorrect (o.d. } \\
\text { together with q.i.d.) } \\
\text { Incorrect (o.d. after } \\
\text { q.i.d.) } \\
\end{array}$ & $\begin{array}{r}318(68 \%) \\
128(27 \%) \\
22(5 \%)\end{array}$ \\
\hline
\end{tabular}

* Correct answers are given in bold.

\# The o.d. pill needs to be taken before or during breakfast, and the q.i.d. pill needs to be taken after breakfast. 
Data analysis

SPSS version 14.0 was used for data analysis. A two-sided significance level of 0.05 was used. In respect of completeness, means with standard deviations (SDs) were calculated for the number of pills used for each step and for each medication jar (q.i.d. pills step 1; o.d. pills step 1; b.i.d. pills step 2; q.i.d. pills step 3; o.d. pills step 3). A Friedman test was carried out to test whether there were statistically significant differences between these five types of medication. Mann-Whitney $U$ tests were undertaken to test whether there were statistically significant differences between placebo pills and active pills. To check whether completeness is consistent over time, firstly, the Spearman's correlation between step 1 and step 2, and the Spearman's correlation between step 2 and step 3 were calculated. Secondly, the proportions of partially adherent and adherent patients were calculated for each treatment step. For this purpose, we recoded completeness: patients who used less than $80 \%$ or more than $120 \%$ of the pills prescribed per day are considered partially adherent, patients who used $80-120 \%$ are considered to be adherent. Although $80 \%$ and $120 \%$ are arbitrary values, they are commonly used to indicate optimal adherence. ${ }^{9}$ Frequency tables were produced in respect of intake fidelity, and the mean intake fidelity sum score with SD was calculated.

\section{Results}

\section{Patient characteristics}

A total of 664 patients agreed to participate in the DIAMOND-study, but 11 patients changed their mind shortly after inclusion and did not use any study medication. One patient did not use the medication for step 1 for unknown reasons, but started with step 2 approximately two weeks after inclusion. This patient was regarded as non-adherent for step 1 and, since the patient used trial medication during step 2, he/she is included in the analysis. Thus, a total of 653 patients (mean age 47 (SD 15) years, $46 \%$ males, $6 \%$ non-Caucasians) were included; 334 randomised to the 'stepup' and 319 to the 'step-down' strategy.

For 176 patients completeness was unknown because the medication $(n=105)$ was not returned or the treatment duration $(n=81)$ was unknown; for 248 patients no intake fidelity sum scores could be calculated due to non-response to the questionnaire $(n=147)$ or missing items $(n=101)$. Pill counts were more often available for women, Caucasians and patients who started with step 2 (Table 8.2). 
Except for gender, the same accounted for the availability of the intake fidelity sum scores.

Table 8.2. Differences between patients with and patients without missing values.

\begin{tabular}{lccc|ccc}
\hline & \multicolumn{3}{c|}{ Completeness score } & \multicolumn{3}{c}{ Intake fidelity sum score } \\
& for treatment step 1 (pill count) & & & \\
\hline & $\begin{array}{c}\text { Present } \\
(\mathrm{n}=477)\end{array}$ & $\begin{array}{c}\text { Missing } \\
(\mathrm{n}=176)\end{array}$ & $\mathrm{p}$-value & $\begin{array}{c}\text { Present } \\
(\mathrm{n}=405)\end{array}$ & $\begin{array}{c}\text { Missing } \\
(\mathrm{n}=248)\end{array}$ & $\mathrm{p}$-value \\
\hline Mean Age (SD) & $48(15)$ & $45(14)$ & $\mathrm{ns}$ & $47(14)$ & $47(16)$ & $\mathrm{ns}$ \\
Male & $43 \%$ & $52 \%$ & $<0.05$ & $43 \%$ & $50 \%$ & $\mathrm{~ns}$ \\
Non-Caucasian & $4 \%$ & $12 \%$ & $<0.001$ & $4 \%$ & $9 \%$ & $<0.05$ \\
Started with & $63 \%$ & $42 \%$ & $<0.001$ & $63 \%$ & $48 \%$ & $<0.001$ \\
treatment step 2 & & & & & & \\
\hline
\end{tabular}

Figure 8.2. Medication used during treatment steps.

Treatment step 1

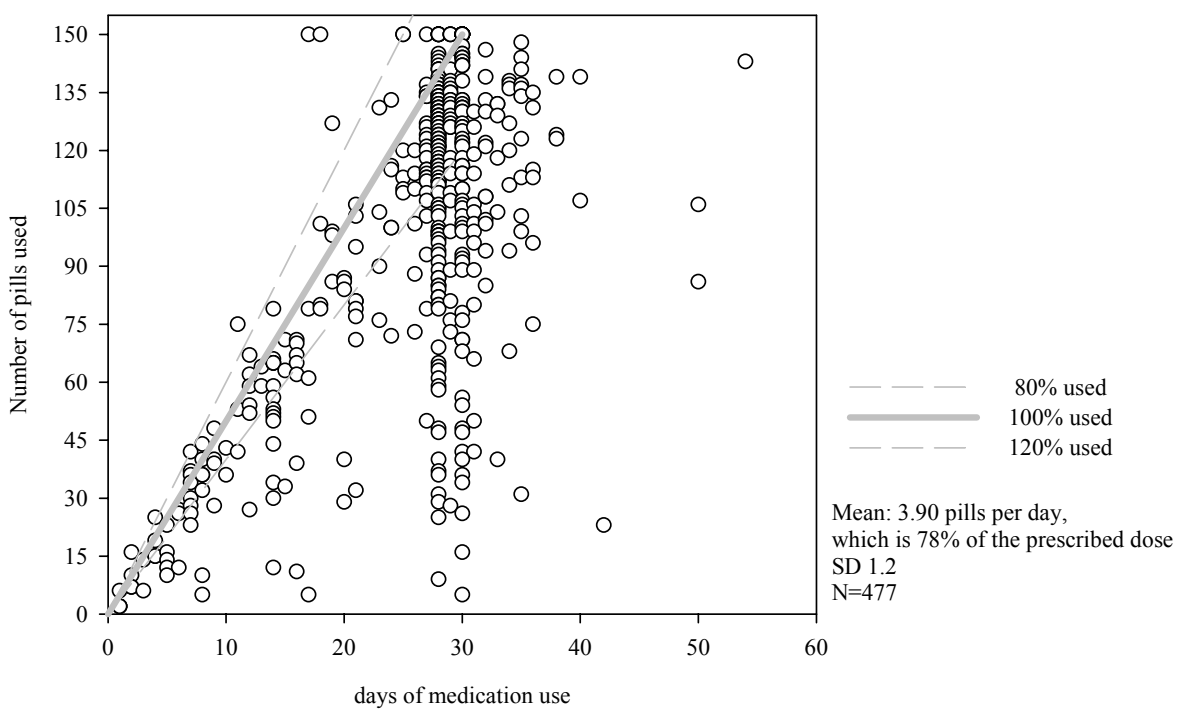




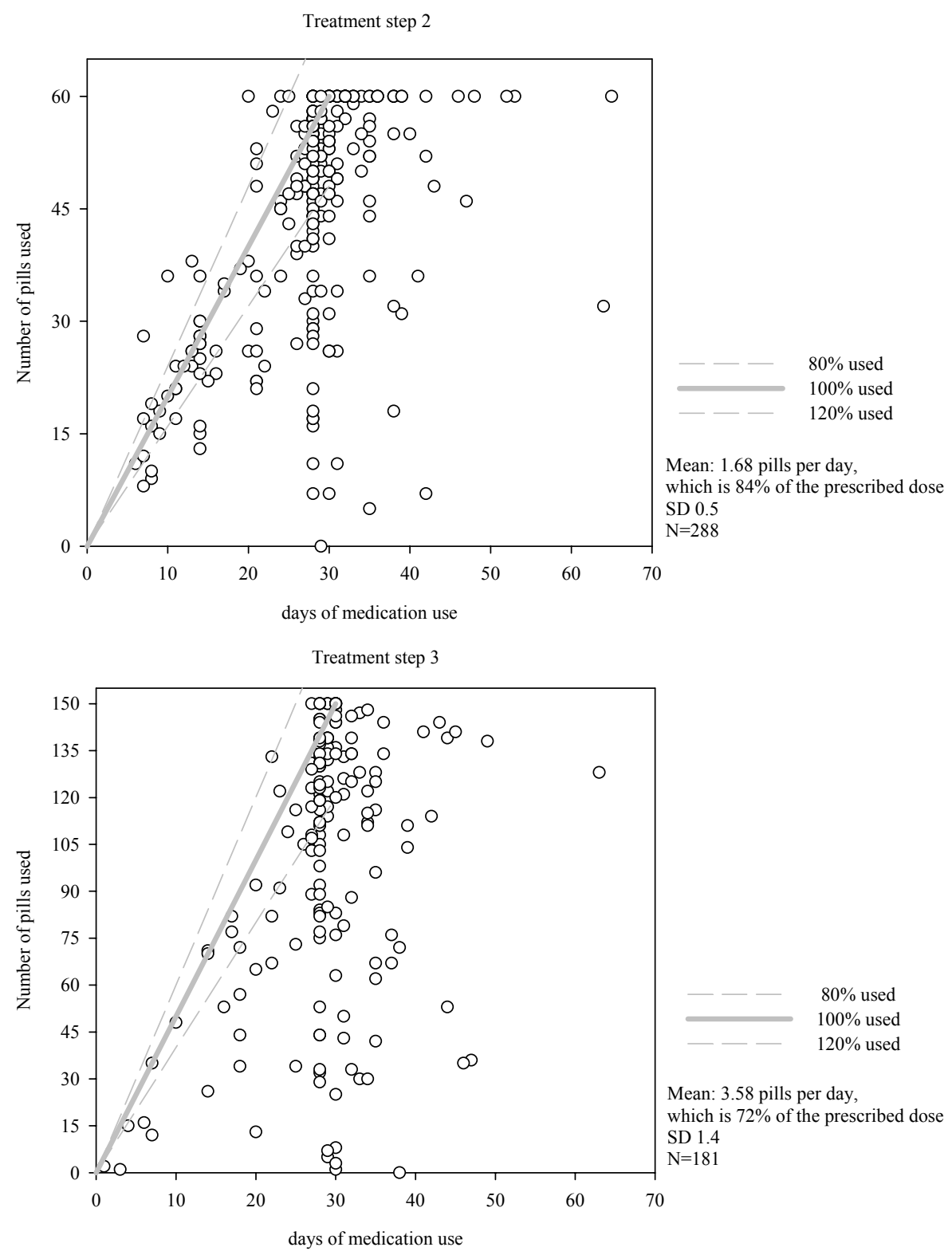

\section{Completeness}

Figure 8.2 shows that, although there is a group of patients using approximately $100 \%$ of the prescribed dose per treatment day, there is a large group using less than $80 \%$, for all treatment steps. Table 8.3 also shows that partial adherence is very prevalent: for the q.i.d. pills one in two patients and for the o.d. pills one in four 
patients used less than $80 \%$ of the prescribed pills per day. Completeness for the q.i.d. pills was lower than for the other pills (mean \% of prescribed dose taken per day: the q.i.d. pills $78 \%$ (i.e. on average 3.12 pills/day, $100 \%=4$ pills/day) (step 1) and $68 \%$ (step 3); the o.d. pills $92 \%$ (step 1) and $84 \%$ (step 3); the b.i.d. pills $86 \%$ (step 2) $(\mathrm{p}<0.001, \mathrm{~N}=131))$.

Table 8.3. Completeness: number of pills used per day.

\begin{tabular}{|c|c|c|c|c|c|c|c|c|}
\hline \multicolumn{2}{|c|}{ Treatment step } & $\mathrm{N}$ & Mean (SD) & Range & $\begin{array}{l}\% \text { of } \\
\text { pre- } \\
\text { scribed } \\
\text { dose }\end{array}$ & $\begin{array}{l}\# \text { of } \\
\text { partially } \\
\text { adherent } \\
\text { patients } \\
(<80 \%) \\
\end{array}$ & $\begin{array}{l}\text { \# of } \\
\text { adherent } \\
\text { patients } \\
(80 \%- \\
120 \%)\end{array}$ & $\begin{array}{l}\# \text { of } \\
\text { partially } \\
\text { adherent } \\
\text { patients } \\
(>120 \%)\end{array}$ \\
\hline \multicolumn{2}{|c|}{$\begin{array}{l}\text { Step 1: } 5 \text { pills/day } \\
\text { (q.i.d. plus o.d. pills) }\end{array}$} & 477 & $3.90(1.2)$ & $0-8.8$ & $78 \%$ & $200(42 \%)$ & $271(57 \%)$ & $6(1 \%)$ \\
\hline \multirow[t]{3}{*}{ q.i.d. pills } & All q.i.d. & 487 & $3.01(1.0)$ & $0-7.1$ & $75 \%$ & $240(49 \%)$ & $239(49 \%)$ & $8(2 \%)$ \\
\hline & $\begin{array}{l}\text { Antacid } \\
\text { (step-up) }\end{array}$ & 246 & $2.99(1.0)$ & $0-6.7$ & $75 \%$ & $125(51 \%)$ & $118(48 \%)$ & $3(1 \%)$ \\
\hline & $\begin{array}{l}\text { Placebo } \\
\text { (step-down) }\end{array}$ & 241 & $3.02(1.1)$ & $0.1-7.1$ & $75 \%$ & $115(48 \%)$ & $121(50 \%)$ & $5(2 \%)$ \\
\hline \multirow[t]{3}{*}{ o.d. pills } & All o.d. & 477 & $0.89(0.2)$ & $0-2.0$ & $89 \%$ & $103(22 \%)$ & $359(75 \%)$ & $15(3 \%)$ \\
\hline & $\begin{array}{l}\text { Placebo } \\
\text { (step-up) }\end{array}$ & 242 & $0.87(0.2)^{*}$ & $0-2.0$ & $87 \%$ & $59(24 \%)$ & $177(73 \%)$ & $6(3 \%)$ \\
\hline & $\begin{array}{l}\text { PPI } \\
\text { (step-down) }\end{array}$ & 235 & $0.92(0.2)^{*}$ & $0.1-2$ & $92 \%$ & $44(19 \%)$ & $182(77 \%)$ & $9(4 \%)$ \\
\hline \multicolumn{9}{|c|}{ Step 2: b.i.d. pills } \\
\hline & All b.i.d. & 288 & $1.68(0.5)$ & $0-4.0$ & $84 \%$ & $96(33 \%)$ & $182(63 \%)$ & $10(4 \%)$ \\
\hline & Step-up & 158 & $1.66(0.5)$ & $0-4.0$ & $83 \%$ & $55(35 \%)$ & $98(62 \%)$ & $5(3 \%)$ \\
\hline & Step-down & 130 & $1.72(0.5)$ & $0.1-3.6$ & $86 \%$ & $41(32 \%)$ & $84(65 \%)$ & $5(4 \%)$ \\
\hline \multicolumn{2}{|c|}{$\begin{array}{l}\text { Step 3: } 5 \text { pills/day } \\
\text { (q.i.d. plus o.d. pills) }\end{array}$} & 181 & $3.58(1.4)$ & $0-6.1$ & $72 \%$ & $89(49 \%)$ & $91(50 \%)$ & $1(1 \%)$ \\
\hline \multirow[t]{3}{*}{ q.i.d. pills } & All q.i.d. & 181 & $2.78(1.2)$ & $0-4.7$ & $70 \%$ & $100(55 \%)$ & $81(45 \%)$ & - \\
\hline & $\begin{array}{l}\text { Antacid } \\
\text { (step-up) }\end{array}$ & 90 & $2.66(1.3)$ & $0-4.7$ & $67 \%$ & $50(56 \%)$ & $40(44 \%)$ & - \\
\hline & $\begin{array}{l}\text { Placebo } \\
\text { (step-down) }\end{array}$ & 91 & $2.91(1.1)$ & $0.2-4.4$ & $73 \%$ & $50(55 \%)$ & $41(45 \%)$ & - \\
\hline \multirow[t]{3}{*}{ o.d. pills } & All o.d. & 182 & $0.84(0.2)$ & $0-1.4$ & $84 \%$ & $54(30 \%)$ & $125(69 \%)$ & $3(2 \%)$ \\
\hline & $\begin{array}{l}\text { Placebo } \\
\text { (step-up) }\end{array}$ & 90 & $0.85(0.2)$ & $0-1.4$ & $85 \%$ & $26(29 \%)$ & $62(69 \%)$ & $2(2 \%)$ \\
\hline & $\begin{array}{l}\text { PPI } \\
\text { (step-down) }\end{array}$ & 92 & $0.84(0.2)$ & $0-1.3$ & $84 \%$ & $28(30 \%)$ & $63(69 \%)$ & $1(1 \%)$ \\
\hline
\end{tabular}

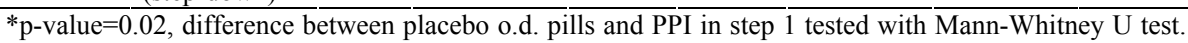
o.d. = once daily; b.i.d. $=$ twice daily; q.i.d. $=$ four times daily.

Differences in completeness between the two trial arms were investigated, and we only found a small though statistically significant difference in completeness for o.d. pills in step 1 (Table 8.3). Completeness was lower for placebo o.d. pills than for the active PPI (means resp. 0.88 versus 0.92 pills per day, $\mathrm{p}<0.05$ ). This may indicate that patients recognized the placebo pills. If this were so, however, then it would 
seem logical that they would only take the antacid pills but no differences were found for the antacids and placebo-antacids. Furthermore, no differences in completeness between the two trial arms in step 2 and 3 could be identified either. Therefore, it seems that the treatment allocation was adequately concealed.

Table 8.4. Adherence over time.

\begin{tabular}{|c|c|c|}
\hline Treatment step 1 & Treatment step 2 & Treatment step 3 \\
\hline 653 patients started step 1 & $\begin{array}{l}\text { Of which } 372 \text { started step } 2 ; \\
106(28 \%) \text { partially adherent } \\
182(49 \%) \text { were adherent }\end{array}$ & $\begin{array}{l}\text { Of which } 231 \text { started step 3, } \\
90(39 \%) \text { were partially adherent } \\
91(39 \%) \text { were adherent }\end{array}$ \\
\hline \multirow{9}{*}{$\begin{array}{l}\text { Partially adherent: } 206 \text { pts } \\
(32 \%) \text { (Including } 1 \text { patient } \\
\text { who started with treatment } \\
\text { step 2) }\end{array}$} & \multirow{3}{*}{$\begin{array}{l}\text { Partially adherent: } 47 \text { of } 114 \text { pts } \\
(41 \%)\end{array}$} & Partially adherent: 17 of $27(63 \%)$ \\
\hline & & Adherent: 4 of $27(15 \%)$ \\
\hline & & Pill count missing: 6 of $27(22 \%)$ \\
\hline & \multirow{3}{*}{ Adherent: 46 of 114 pts ( $40 \%)$} & Partially-adherent: 20 of $37(54 \%)$ \\
\hline & & Adherent: 13 of $37(35 \%)$ \\
\hline & & Pill count missing: 4 of $37(11 \%)$ \\
\hline & \multirow{3}{*}{$\begin{array}{l}\text { Pill count missing: } 21 \text { of } 114 \text { pts } \\
(18 \%)\end{array}$} & Partially adherent: 3 of $5(60 \%)$ \\
\hline & & Adherent: 2 of $5(40 \%)$ \\
\hline & & Pill count missing: 0 \\
\hline \multirow{9}{*}{ Adherent: 271 pts (42\%) } & \multirow{3}{*}{$\begin{array}{l}\text { Partially adherent: } 44 \text { of } 184 \\
(24 \%)\end{array}$} & Partially adherent: 11 of $24(46 \%)$ \\
\hline & & Adherent: 5 of $24(21 \%)$ \\
\hline & & Pill count missing: 8 of $24(33 \%)$ \\
\hline & \multirow{3}{*}{ Adherent: 108 of $184(59 \%)$} & Partially adherent: 24 of $78(31 \%)$ \\
\hline & & Adherent: 42 of $78(54 \%)$ \\
\hline & & Pill count missing: 12 of $78(15 \%)$ \\
\hline & \multirow{3}{*}{$\begin{array}{l}\text { Pill count missing: } 32 \text { of } 184 \\
(17 \%)\end{array}$} & Partially adherent: 5 of $18(28 \%)$ \\
\hline & & Adherent: 5 of $18(28 \%)$ \\
\hline & & Pill count missing: 8 of $18(44 \%)$ \\
\hline \multirow{9}{*}{$\begin{array}{l}\text { Pill count missing: } 176 \text { pts } \\
(27 \%)\end{array}$} & \multirow{3}{*}{ Partially adherent: 15 of 74 (20\%) } & Partially adherent: 4 of $11(36 \%)$ \\
\hline & & Adherent: 5 of $11(46 \%)$ \\
\hline & & Pill count missing: 2 of $11(18 \%)$ \\
\hline & \multirow{3}{*}{ Adherent: 28 of $74(38 \%)$} & Partially adherent: 4 of $19(21 \%)$ \\
\hline & & Adherent: 14 of $19(74 \%)$ \\
\hline & & Pill count missing: 1 of $19(5 \%)$ \\
\hline & \multirow{3}{*}{ Pill count missing: 31 of $74(42 \%)$} & Partially adherent: 2 of $12(17 \%)$ \\
\hline & & Adherent: 1 of $12(8 \%)$ \\
\hline & & Pill count missing: 9 of $12(75 \%)$ \\
\hline
\end{tabular}

NB. Patients who used less than $80 \%$ or more than $120 \%$ of the pills prescribed per day are considered partially adherent, patients who used $80-120 \%$ are considered to be adherent. For treatment steps 1 and 3 $100 \%$ means 5 pills per day, in treatment step $2100 \%$ means 2 pills per day. For the patients who have a missing pill count, the number of pills per day could not be calculated because the medication jars were not returned or the treatment duration was unknown. 
Table 8.4 shows that a small proportion of the patients who started all treatment steps were consistently partially adherent or completely adherent over time. This is reflected in medium correlation coefficients: the correlation between step 1 and step 2 concerning completeness was $0.38(\mathrm{p}<0.001, \mathrm{~N}=245)$ and the correlation between step 2 and step 3 was $0.23(\mathrm{p}<0.05, \mathrm{~N}=163)$.

\section{Intake fidelity}

Table 8.1 shows that the most frequent deviations were not taking the q.i.d. pills 4 times a day ( $12 \%$ of the patients), and not taking the medication in relation to meals or bedtime ( $17 \%$ for q.i.d pills and $10 \%$ for the o.d. pills). The mean intake fidelity sum score was 8.13 (SD $0.94, \mathrm{~N}=405$ ); $30 \%$ of the patients had a score of 9 indicating perfect adherence (no incorrect answers); another 30\% scored 8.5 indicating almost perfect adherence (one partly incorrect answer). There were no differences in intake fidelity between the two trials arms.

\section{Discussion}

To effectively evaluate dyspepsia medication, it is important to have insight into patient adherence to the medication regimen. Therefore, the present study investigated completeness and intake fidelity in respect of acid-suppressive medication. Regarding completeness, our results show that half of the patients were partially adherent in respect of the q.i.d. pills (when taking 5 pills per day; q.i.d. pills plus o.d. pills), one third in respect of the b.i.d pills and one quarter in respect of the o.d. pills (when taking 5 pills per day; q.i.d. pills plus o.d. pills). Thus, the adherence rates are low. Furthermore, medium correlations between the treatment steps indicate that few patients were consistently adherent or partially adherent over time. Regarding intake fidelity, one third of the patients reported medication intake in concordance with the medication instructions. The rest deviated on one or more instructions, most often in the frequency of intake and timing of usage in relation to meals.

There may be several reasons for the low completeness scores. First, patients may discontinue the medication because they think it is not effective; they may be unaware that it may take some time for the medication to become effective. Second, patients tend to discontinue medication as soon as distressing symptoms disappear, ${ }^{9,10}$ or use their medication on-demand, i.e. only when symptomatic. ${ }^{10}$ Not 
completing the treatment course may lead to earlier recurrence of symptoms, ${ }^{4}$ and, although on-demand use may be as effective as continuous use in chronic users, ${ }^{3}$ it is generally not recommended for initial treatment. ${ }^{2}$ As already indicated, for initial treatment, acid-suppressive medication is often used as an diagnostic aid to demonstrate an acid-related background to the symptoms, and this process requires optimal adherence. Therefore, the instruction to use the dyspepsia medication ondemand was not given in our study. Nevertheless, it is possible that several patients took their medication on-demand.

One might argue that partial adherence or on-demand use in the case of dyspepsia is not such a big problem. This may be true for patients for whom the acid-suppressive medication successfully relieves their symptoms, even though this may mean that expensive medication will be left over and may be thrown away, or symptoms may recur sooner. ${ }^{4}$ But what if the symptoms are not adequately relieved? Especially in patients who do not achieve symptom relief, it is very important to identify ondemand use and other types of non-completeness, in order to adequately judge treatment effectiveness and decide upon future treatment.

Unfortunately, few patients showed consistency in completeness over time. This has important implications for the predictability of adherence in practice: the continuation of (non-)adherence behaviour should not be assumed in prolonged treatment, and during follow-up visits adherence needs to be readdressed.

The low intake fidelity scores were mostly caused by deviation from the instructions about timing. Perhaps patients found the suggested timing inconvenient or were not fully aware of the importance of following these instructions. The latter may be explained by a lack of attention paid to the verbal communication of these medication instructions, as revealed in a recent survey study conducted by our group. ${ }^{11}$ This study showed that GPs paid little attention to timing and way of taking dyspepsia medication. Explaining the rationale and stressing the importance of following all instructions may improve adherence and consequently may increase the effectiveness of the medication.

Our study thoroughly investigated patient adherence to a medication regimen in a relatively large primary care patient population. Nevertheless, some limitations concerning the internal validity of completeness need to be addressed. Pill counts do not indicate whether the medication was actually taken (or just thrown away) and may result in overestimating completeness. ${ }^{9}$ Furthermore, for the calculation of completeness it is important to accurately measure treatment duration. It is possible 
that treatment duration was overestimated for a number of patients. If patients stopped using medication before they returned their medication, this may have resulted in underestimation of completeness. However, even of patients who did indicate that they had used the medication only for a short period of time, a large proportion used less than $80 \%$ of the prescribed dosage. Therefore, our results are probably a good approximation of the actual completeness of our study population.

As far as generalizability is concerned, the fact that patients knew that they had to return their medication, and that their completeness could be checked, may have improved completeness. Alternatively, the addition of a placebo does not reflect everyday practice. Consequently, patients may have taken fewer verum pills than they would have taken in everyday practice, and this could lower the effectiveness of our trial medication. Our results provide insight into adherence rates when 5 pills per day (step 1 and 3) or 2 pills per day (step 2) were prescribed; perhaps adherence would be better if verum pills only were prescribed. Nevertheless, our results have shown that the completeness for the q.i.d. pills was worse than for the other regimens; this implicates that, when optimal adherence is required, it is perhaps best to prescribe o.d. pills. It has been confirmed that completeness decreases with increasing complexity ${ }^{9}$ and with multiple dosing in studies concerning dyspepsia, ${ }^{12}$ hypertension $^{13}$ and psychiatric disorders. ${ }^{14}$

Furthermore, men and non-Caucasians were under-represented in our analysis. This is a common problem in research. The under-representation of men and nonCaucasians may be related to the fact that patients without a completeness score were less likely to progress to treatment step 2. These patients were also less likely to have a follow-up consultation with their GP to return their medication. Although it is likely that these patients did not revisit their GP because their symptoms had been relieved and that they forgot to return the medication jars, it is also possible that these patients did not return their medication because they did not want to reveal that they were partially or non-adherent. Overall, we think that our results may represent a slight overestimation of completeness in our patient population.

In respect of intake fidelity too, some limitations need to be discussed. Intake fidelity was measured by a patient questionnaire and therefore reflects the patient's perception of his/her own behaviour. Furthermore, the answers had to be given in general about the trial medication in step 1, so patients probably answered how they thought they used their medication most days. Patients may have given socially desirable answers. Although this requires some knowledge about what the correct 
answers are, this information could easily be derived from the medication jars and the patient information leaflet. This may have resulted in an overestimation of intake fidelity.

As far as generalizability is concerned, patients who started treatment step 2 and non-Caucasians were under-represented. Maybe patients who were symptom free at the time of receiving the questionnaire thought (incorrectly) that the questionnaire did not apply to them. Non-Caucasians may have experienced some difficulties completing the questionnaire because of language problems. If this is so, then it is also likely that they did not fully understand the instructions; this means that intake fidelity may be even worse in everyday practice.

The limited literature available on adherence to acid-suppressive medication confirms our results. Van Soest et al. ${ }^{12}$ investigated adherence using a large Dutch primary care database containing prescription data and found that approximately half of the patients with at least two PPI prescriptions used less than $80 \%$ of the PPIs prescribed. In other patient groups, taking medication at the wrong time and/or omitting one or more doses were also the most common forms of deviations, e.g. among patients with hypertension. ${ }^{15}$ Furthermore, one fifth to one half of elderly patients have difficulties understanding, or a lack of knowledge about, their medication instructions; ${ }^{16,17}$ this may explain why errors in intake were common in our study.

In conclusion, partial adherence is very prevalent: one in two antacid users and one in four PPI users used less than $80 \%$ of the prescribed medication per day, when instructed to use 5 pills per day. When instructed to use 2 pills per day in treatment step 2, one third used less than $80 \%$ of the prescribed medication per day. Most patients deviate on intake fidelity in one or more respects, mostly in timing of the medication intake in relation to meals.

These findings implicate that there is room for improvement in patient adherence to medication regimens to treat dyspepsia; this may in turn increase the effectiveness of acid-suppressants and improve the diagnostic value of a course of treatment as a means of 'testing' the nature of the symptoms. The results implicate that completeness may be improved by using o.d. or b.i.d. pills instead of q.i.d. pills for dyspepsia. Intake fidelity may be improved by clearly communicating the importance of following treatment instructions. 


\section{References}

1. Bartholomew LK, Parcel GS, Kok G. Intervention mapping: a process for developing theory- and evidence-based health education programs. Health Educ Behav 1998; 25: 545-563.

2. The Dutch Institute for Healthcare Improvement (CBO), Dutch College of General Practitioners (NHG). Multidisciplairy Guideline Stomachcomplaints (Multidisciplinaire Richtlijn Maagklachten). 2004. Alphen aan den Rijn, Van Zuiden Communications.

3. Vakil N. Increasing compliance with long-term therapy: avoiding complications and adverse events. Rev Gastroenterol Disord 2005; 5 Suppl 2: S12-S17.

4. Hunt RH, Cederberg C, Dent J, Halter F, Howden C, Marks IN et al. Optimizing acid-suppression for treatment of acid-related diseases. Dig Dis Sci 1995; 40: 24S-49S.

5. Howden CW, Chey WD. Gastroesophageal reflux disease. J Fam Pract 2003; 52: $240-7$

6. Thomson AB, Mahachai V, Bailey RJ, Kirdeikis P, Zuk L, Marriage B et al. Twice daily nizatidine or ranitidine is superior to once daily dosing in elevating $24 \mathrm{~h}$ intragastric $\mathrm{pH}$ in patients with duodenal ulcer disease. J Gastroenterol Hepatol 1996; 11: 1171-6.

7. Robinson M, Rodriguez-Stanley S, Miner PB, McGuire AJ, Fung K, Ciociola AA. Effects of antacid formulation on postprandial oesophageal acidity in patients with a history of episodic heartburn. Aliment Pharmacol Ther 2002; 16: 435-43.

8. Fransen GAJ, Laheij R.J.F. Registration protocol DIAMOND study (ZONMW 095-03-052). http://www.clinicaltrials.gov/ct/show/NCT00247715? order=9.

9. Bosworth HB. Medication treatment adherence. In Patient treatment adherence. Concepts, interventions and measurement. Edited by Bosworth HB, Oddone EZ, Weinberger M. New Jersey: Lauwrence Erlbaum Associates Inc.; 2006.

10. Krol N, Muris JW, Schattenberg G, Grol R, Wensing M. Use of prescribed and non-prescribed medication for dyspepsia. Scand J Prim Health Care 2004; 22 : 163-167.

11. Fransen GAJ, Mesters I, Van Marrewijk CJ, Mujakovic S, Knottnerus JA. Muris, JWM. Leefstijladviezen, medicatie-instructies en het belang van therapietrouw bij maagklachten. [Lifestyle changes, medication instructions and 
the importance of adherence in case of dyspepsia]. Huisarts Wet 2007; 50: 44652.

12. Van Soest EM, Siersema PD, Dieleman JP, Sturkenboom MC, Kuipers EJ. Persistence and adherence to proton pump inhibitors in daily clinical practice. Aliment Pharmacol Ther 2006; 24: 377-85.

13. Iskedjian M, Einarson TR, MacKeigan LD, Shear N, Addis A, Mittmann N et al. Relationship between daily dose frequency and adherence to antihypertensive pharmacotherapy: evidence from a meta-analysis. Clin Ther 2002; 24: 302-16.

14. Granger AL, Fehnel SE, Hogue SL, Bennett L, Edin HM. An assessment of patient preference and adherence to treatment with Wellbutrin SR: a web-based survey. J Affect Disord 2006; 90: 217-21.

15. Rudd P. Clinicians and patients with hypertension: unsettled issues about compliance. Am Heart J 1995; 130: 572-9.

16. Blenkiron $P$. The elderly and their medication: understanding and compliance in a family practice. Postgrad Med J 1996; 72: 671-6.

17. Lowe CJ, Raynor DK, Courtney EA, Purvis J, Teale C. Effects of self medication programme on knowledge of drugs and compliance with treatment in elderly patients. BMJ 1995; 310: 1229-31. 
Dyspepsia in primary care: patient expectations, symptoms, and treatment adherence

142 


\section{Chapter 9}

Which patient related factors determine patient adherence to prescribed dyspepsia medication? Results of the DIAMOND-study

G.A.J. Fransen, I. Mesters, J.A. Knottnerus, C.J. van Marrewijk, S. Mujakovic, R.J.F. Laheij, M.E. Numans, N.J. de Wit, M. Samsom, J.B.M.J. Jansen \& J.W.M. Muris

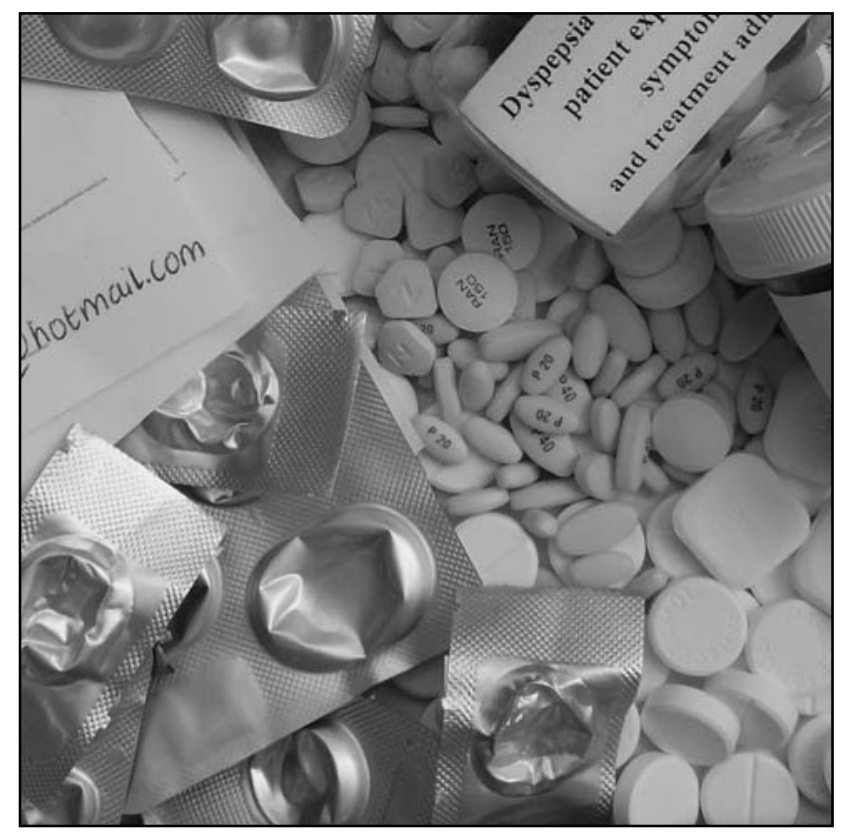




\begin{abstract}
Non-adherence to dyspepsia medication is common. Insight into patient related factors determining adherence is needed to develop interventions to improve adherence. This study uses a theoretical model to predict patient adherence. We tested the model three times using three adherence outcome measures: pill count and two self-reported measures namely self-perceived adherence and intake fidelity. The study showed that the three adherence outcomes were poorly correlated. Intention, self-efficacy, social influence, age, and forgetfulness were significantly correlated with both self-perceived adherence and pill counts in univariate analyses. In multiple regression analysis, the theoretical model best predicted self-perceived adherence, with an explained variance of $32 \%$. This analysis showed that patients with a passive reaction coping style, patients with a palliative coping style, and patients with a low self-efficacy were less likely to be adherent. The authors suggest objectives for future research and discuss the implications of the findings for general practitioners in determining and improving patient adherence to dyspepsia medication.
\end{abstract}




\section{Introduction}

Dyspeptic symptoms are common in primary care: approximately four patients per week consult their general practitioners about a new episode of dyspepsia. ${ }^{1}$ Many of these patients receive short-term treatment with acid-suppressive medication as a diagnostic tool to establish whether or not these complaints are acid related. ${ }^{2}$ However, a key factor in using acid-suppressive medication as a diagnostic aid is patient adherence. ${ }^{2}$ Patient non-adherence may cause physicians to wrongly assume that acid-suppressive medication is not effective and may lead to unnecessary use of further diagnostic investigations or more expensive acid-suppressive medication. Unfortunately, non-adherence to acid-suppressive medication is quite common: $25 \%{ }^{3}$ to $45 \%{ }^{4}$

To improve adherence, insight is needed into the determinants of adherence to acidsuppressive medication, but so far little research has been conducted in this area. Using a theoretical framework (Figure 9.1), we recently conducted a pilot study to investigate which patient related determinants were associated with patient selfperceived adherence to a specific acid-suppressant, namely, a proton pump inhibitor (PPI). The results were promising: the explained variance of the full model was $44 \%$ and the most powerful determinants were forgetfulness, educational level, selfefficacy and intention to adhere. ${ }^{5}$

However, it is not clear whether these results can be generalized to other dyspepsia patients using other acid-suppressants. Therefore, the goal of the present study was to identify patient related factors that determine patient adherence to short-term treatment with acid-suppressive medication for a new episode of dyspepsia. We used a theoretical model evaluating three different measures of adherence: one direct measure, namely, pill count, and two self-reported measures, self-perceived adherence and intake fidelity. To assess self-perceived adherence the patients were asked to indicate the degree to which they followed the medication instructions; to assess intake fidelity, patients were asked how they took their medication. The concepts of intake fidelity and self-perceived adherence both reflect self-reported adherence, but one important difference is that, for intake fidelity, the researchers judge the degree to which the instructions were followed, whereas for self-perceived adherence it is the patients who make the judgement. Thus, the present study has three aims: to identify in patients with a new episode of dyspepsia which patient related factors predict 1) the pill count, 2) self-perceived adherence and 3) intake fidelity of prescribed acid-suppressive medication. 


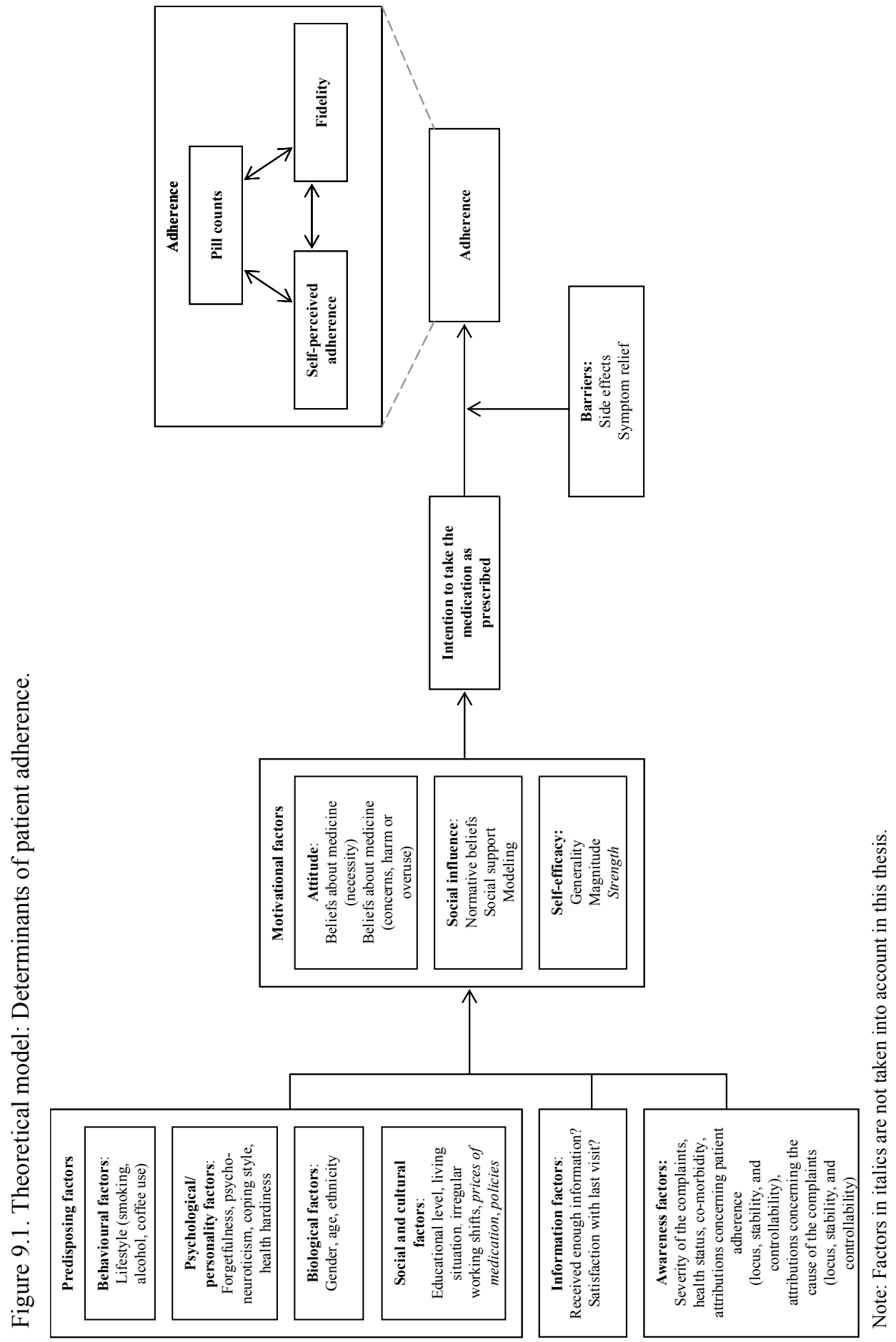




\section{Theoretical framework}

We used the constructs of the Integrated Change Model (I Change Model) ${ }^{6}$ and the determinants known from the literature (e.g. ${ }^{73}$ ) to compose a hypothetical model (Figure 9.1) to identify which factors determine patient adherence to acidsuppressive medication prescriptions. The I Change Model incorporates insights from the Theory of Planned Behaviour, ${ }^{14}$ Bandura's Social Cognitive Theory, ${ }^{15}$ and The Health Belief Model. ${ }^{16}$ The I Change Model states that behaviour is determined by a person's intention and abilities to perform the desired behaviour. Three main types of factors called motivational factors determine a person's intention: attitudes, social influences and self-efficacy expectations.

A person's attitude is expected to be determined by his/her beliefs about medicines: ${ }^{11}$ when the person for instance thinks medicines are necessary he/she is more likely to be adherent. However, when a patient has serious concerns about medication use and thinks that medication can be harmful, the patient is less likely to be adherent. Social influences consist of the perception of significant others being adherent (social modelling), the perceived norms that significant others have with respect to being adherent (social norms), and perceived support of significant others in being adherent (social support). Self-efficacy refers to the patient's perception of his/her capability to be adherent.

Furthermore, the I Change Model assumes that these motivational factors are determined by various distal factors: predisposing factors, awareness factors, and information factors. Predisposing factors are divided into behavioural factors (e.g. lifestyle), psychological or personality factors (e.g. forgetfulness, coping style), biological factors (e.g. age, gender), social and cultural factors (e.g. education level, policies, price of medication).

A healthy lifestyle is considered to be a behavioural factor. It is expected that compared to patients with an unhealthy lifestyle, patients with a healthy lifestyle are more often motivated to act healthily in general and be adherent. Although price of medication is suggested by Meichenbaum and Turk ${ }^{13}$ to influence adherence, this cannot be investigated in the present study, because the trial medication is provided free of charge.

Awareness of the necessity of medication use is assumed to be determined by the severity of the symptoms, health status and the attributions patients make: when they think that their complaints can be controlled and altered by medication, they are more likely to be adherent. The latter is based on Weiner's ${ }^{17}$ attribution theory, which indicates three dimensions in attributions: locus of control (internal versus 
external), stability and controllability. Furthermore, adherence success in the present is assumed to be determined by having been successfully adherent in the past. The attributions patients make of being adherent or being non-adherent are therefore also taken into account, besides the attributions that patients make concerning the locus, the stability and controllability of their complaints.

As far as abilities are concerned, all patients who received a prescription from their general practitioner (GP) and consented to participate in our study are thought to be able to perform the desired behaviour (taking five pills every day for four weeks). Although patients are motivated and able to be adherent, several barriers may prevent adherence, for example when adherence is not rewarded by symptom relief or when a patient experiences side effects.

\section{Methods}

\section{Recruitment}

The present study was part of a multi-centre randomized trial investigating the most effective initial medical treatment strategy for dyspepsia in primary care (DIAMOND-study), ${ }^{18}$ which was approved by local medical ethics committees. Adult patients were eligible when they consulted their GP about a new episode of dyspepsia (i.e. they had not taken any prescribed acid-suppressive medication during the previous three months and had not had an endoscopy during the previous year), they were able to complete (Dutch) questionnaires and there were no contraindications for using acid-suppressants. Patients received information about the study and signed an informed consent form.

Patients were randomized to either a 'step-up' or a 'step-down' treatment strategy (Figure 9.2a). Each strategy consisted of at least one, and in the case of persisting/recurrent symptoms maximally three treatment steps. The duration of each step was maximally four weeks: in consultation with their GP, patients were allowed to proceed with the next step before the four weeks were up (e.g. when the severity of the complaints increased). In the present study we will focus on adherence during treatment step 1. During this treatment step patients were asked to take 5 pills a day according to the instructions (Box 9.1): either 4 tablets of antacid and 1 tablet of placebo PPI, or 4 tablets of placebo antacid and 1 tablet of PPI. Treatment allocation was blinded for patients, GPs and researchers. 


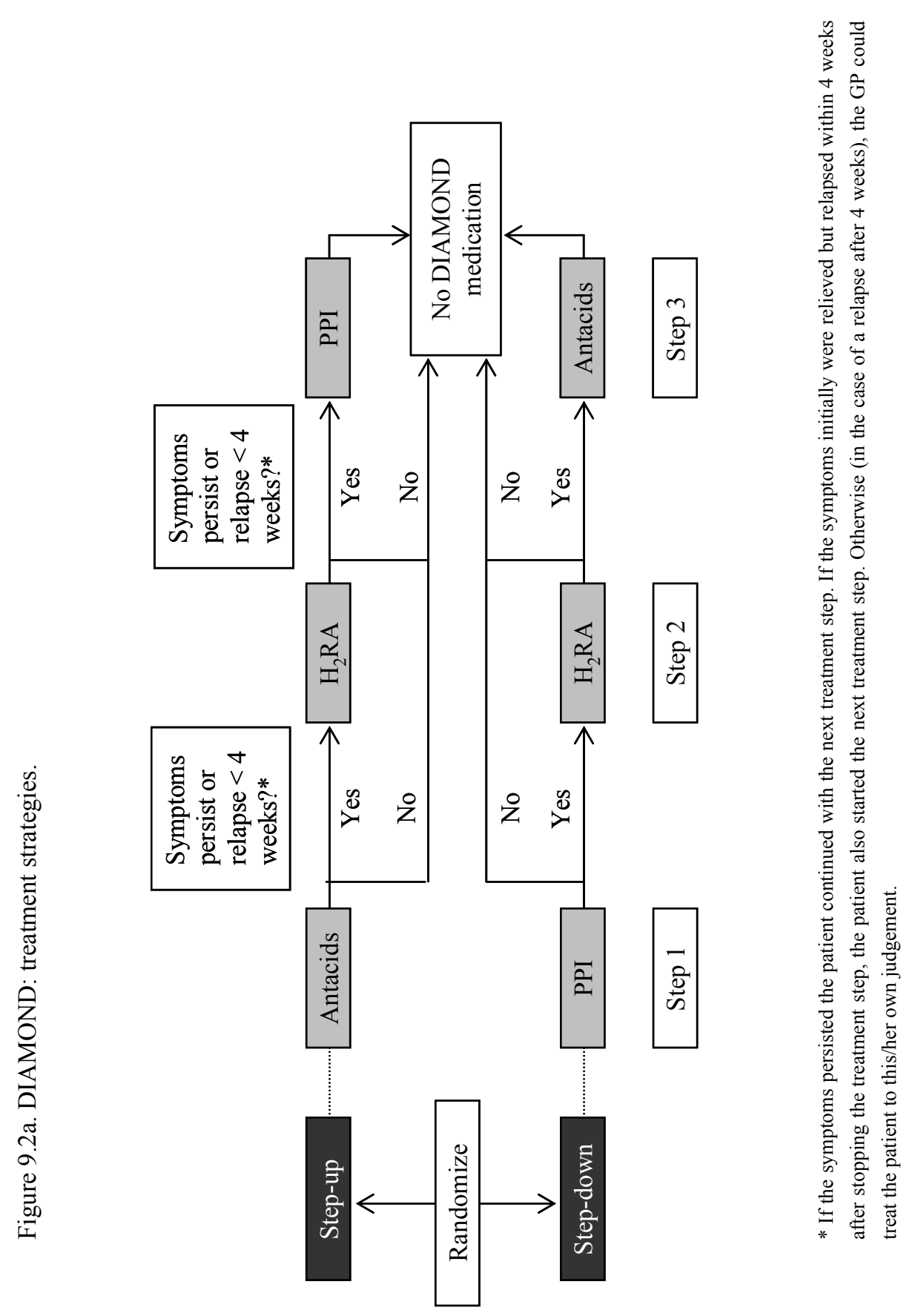




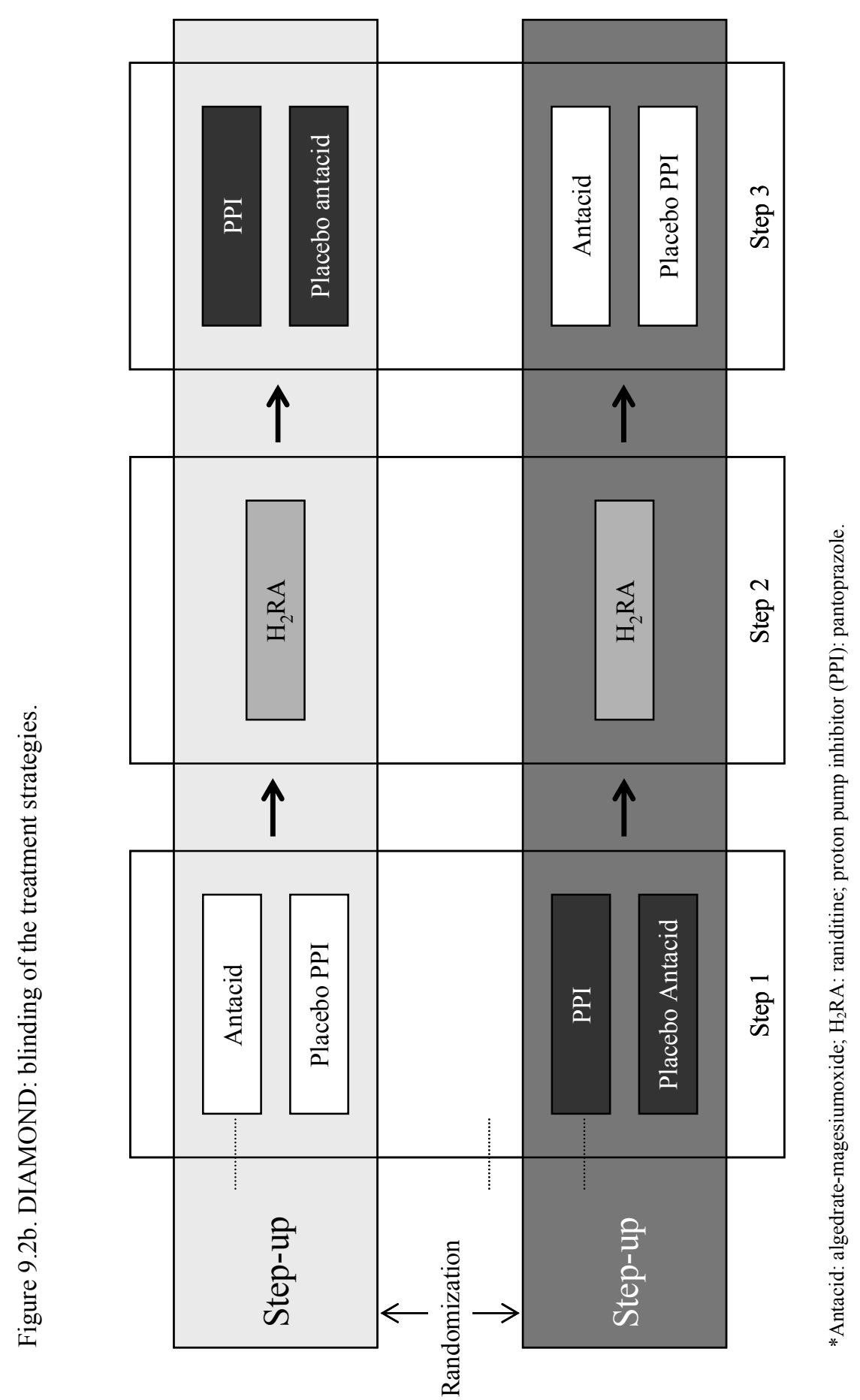




\section{Measurements}

Data were collected by GPs and via patient questionnaires. All predictors from the theoretical model and how they were measured are described in Table 9.1. All patients received questionnaires at baseline, after two weeks and after treatment step 1 (at four weeks or earlier). The questionnaires were labelled with a pre-printed patient number and could be returned with pre-paid stamped addressed envelopes. Reminders were sent out after two weeks.

Box 9.1. Medication instructions. Treatment step 1

Large medication jar:

(Antacid or placebo)

- 1 pill 4 times daily

- Use 1 hour after a meal and before bedtime

- $\quad$ Chew properly

Small medication jar:

(PPI or placebo)

- 1 pill once daily

- Use before or during breakfast

- No chewing, take with a little water

All items on the patient questionnaires (measuring the predictors from the theoretical model) were measured on a 7 -point scale $(0=$ I totally disagree, $6=$ I totally agree), unless indicated otherwise. If factor analysis confirmed the presence of one factor, a sum score of items was calculated for each predictor in the model. Within each factor maximally one missing value was replaced by the mean of the other items in that factor.

\section{GP data}

Biological factors: At the baseline consultation the GP ascertained demographic data about the patient (contact data, date of birth, gender, ethnicity (Caucasians or NonCaucasians)). Furthermore, the GP monitored the treatment and provided data about follow up consultations, for instance consultation dates and the presence of side effects.

\section{Patient questionnaires}

At Baseline

Motivational factors and Intention: A questionnaire based on the I Change Model was used to measure intention, social influence and self-efficacy. Attitude was measured by The Beliefs about Medicine questionnaire (BMQ). ${ }^{11}$ The BMQ was translated into Dutch by several scientific investigators. Then an English teacher, blinded from the original questionnaire, translated the Dutch questionnaire back into English. This translation was compared with the original questionnaire to check whether it was translated properly. The BMQ originally consisted of four constructs: necessity, concern, harm, and overuse. However, factor analyses showed two 
factors: necessity and a combination of the other three more negative constructs. Therefore, sum scores were calculated for these two factors (Table 9.1).

Table 9.1. Concepts used in adjusted and unadjusted regression analyses (items).

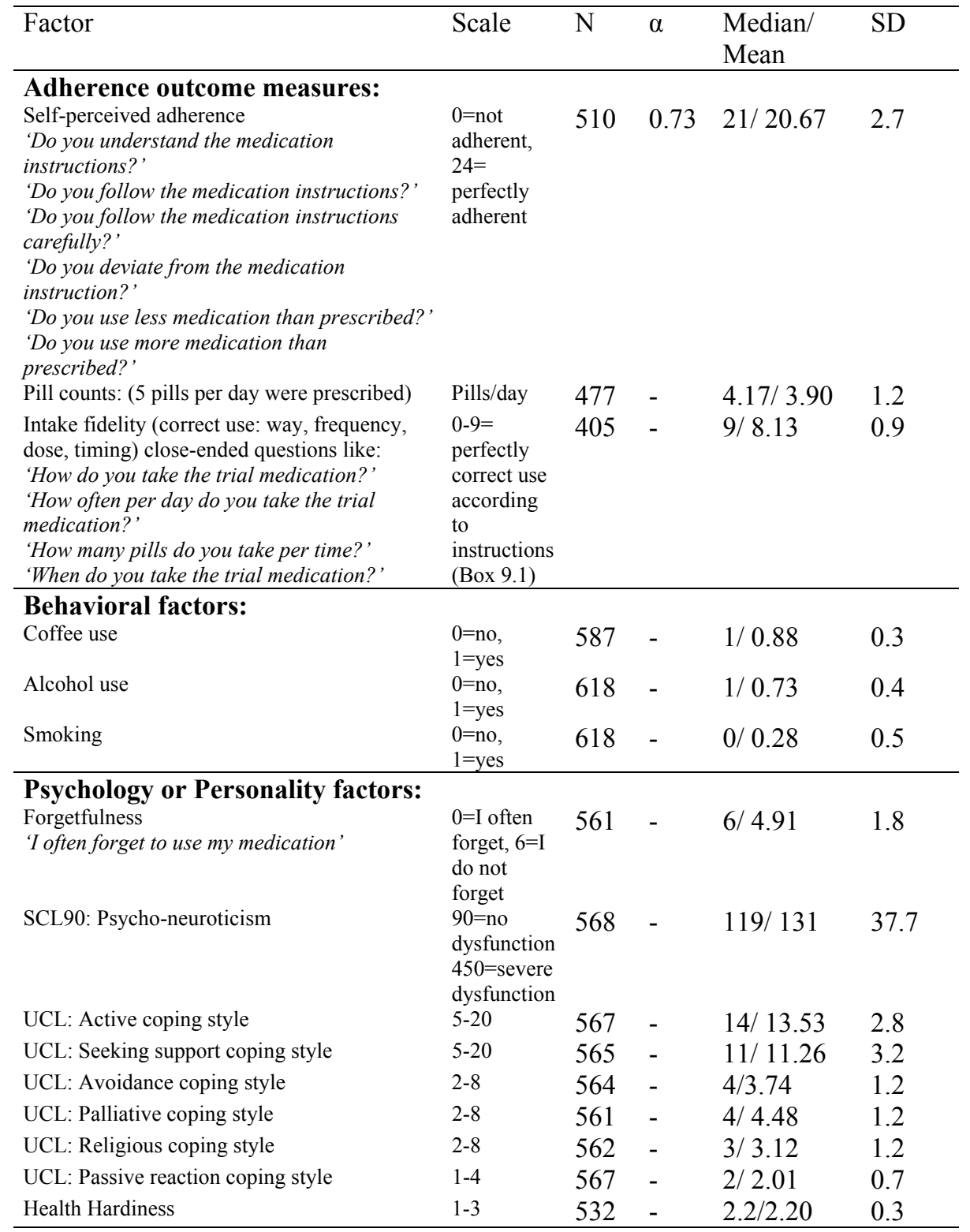


Table 9.1. Concepts used in adjusted and unadjusted regression analyses (cont.).

\begin{tabular}{|c|c|c|c|c|c|}
\hline Factor & Scale & $\mathrm{N}$ & $\alpha$ & $\begin{array}{l}\text { Median/ } \\
\text { Mean }\end{array}$ & $\mathrm{SD}$ \\
\hline \multicolumn{6}{|l|}{ Biological factors: } \\
\hline Gender & $0=$ female & 653 & - & $0 / 0.46$ & 0.5 \\
\hline Age & In years & 653 & - & $47 / 47$ & 14.6 \\
\hline Caucasian & $\begin{array}{l}0=\text { no, } \\
1=\text { yes }\end{array}$ & 648 & - & $1 / 0.94$ & 0.2 \\
\hline \multicolumn{6}{|l|}{ Social and cultural factors: } \\
\hline Educational level & $\begin{array}{l}0=\text { no, } \\
7=\text { academic }\end{array}$ & 630 & - & $4 / 3.64$ & 1.8 \\
\hline Living situation & $\begin{array}{l}0=\text { without, } \\
1=\text { with } \\
\text { partner }\end{array}$ & 634 & - & $1 / 0.77$ & 0.4 \\
\hline Irregular working shifts & $\begin{array}{l}0=\text { no, } \\
1=\text { yes }\end{array}$ & 584 & - & $0 / 0.15$ & 0.4 \\
\hline \multicolumn{6}{|l|}{ Information factors: } \\
\hline $\begin{array}{l}\text { Information } \\
\text { 'I received too little information about my } \\
\text { medication' }\end{array}$ & $\begin{array}{l}0=\mathrm{I} \text { agree, } \\
6=\mathrm{I} \\
\text { disagree }\end{array}$ & 563 & - & $6 / 4.70$ & 1.9 \\
\hline $\begin{array}{l}\text { Satisfaction } \\
\text { 'I am completely satisfied with my last GP } \\
\text { consultation' }\end{array}$ & $\begin{array}{l}0=\mathrm{I} \\
\text { disagree, } \\
6=\mathrm{I} \text { agree }\end{array}$ & 559 & - & $6 / 4.99$ & 1.7 \\
\hline \multicolumn{6}{|l|}{ Awareness factors: } \\
\hline $\begin{array}{l}\text { Severity of complaints (baseline) } \\
\text { During last week, how severe were your } \\
\text { complaints of: } \\
\text { Heartburn, regurgitation, upper abdominal } \\
\text { pain, lower abdominal pain, nausea, belching, } \\
\text { vomiting, early satiety }\end{array}$ & $\begin{array}{l}0=\text { none, } \\
48=\text { very } \\
\text { severe }\end{array}$ & 585 & 0.65 & $14 / 14.03$ & 6.1 \\
\hline $\begin{array}{l}\text { Health status (baseline), EuroQol (VAS), } \\
\text { 'My health status of the last week was ...' }\end{array}$ & $\begin{array}{l}0=\text { worst- } \\
100=\text { best } \\
\text { imaginable }\end{array}$ & 581 & - & $52 / 54.20$ & 25.0 \\
\hline $\begin{array}{l}\text { Co-morbidity } \\
\text { 'Do you have other diseases?' }\end{array}$ & $\begin{array}{l}0=\text { no, } \\
1=\text { yes }\end{array}$ & 624 & - & $1 / 0.69$ & 0.5 \\
\hline $\begin{array}{l}\text { Attributions: Locus: intern/extern (adherence) } \\
\text { 'Not taking medication according to } \\
\text { instructions is to blame on me (6) /others ( } 0 \text { )' }\end{array}$ & $\begin{array}{l}0=\text { extern, } \\
6=\text { intern }\end{array}$ & 566 & - & $6 / 5.69$ & 0.7 \\
\hline $\begin{array}{l}\text { Attributions: Stable (adherence) } \\
\text { 'Not taking medication according to instruct- } \\
\text { tions is not changeable (0)/changeable (6)' }\end{array}$ & $\begin{array}{l}0=\text { stable }, \\
6=\text { unstable }\end{array}$ & 548 & - & $5 / 4.49$ & 1.9 \\
\hline $\begin{array}{l}\text { Attributions: Controllable (adherence) 'Not } \\
\text { taking medication according to instructions is } \\
\text { in control (6)/not in control (0)' }\end{array}$ & $\begin{array}{l}0=\text { not } \\
\text { controlled, } \\
6=\text { controlled }\end{array}$ & 561 & - & $6 / 5.13$ & 1.6 \\
\hline $\begin{array}{l}\text { Attributions: Locus: intern/extern (cause } \\
\text { complaints) 'The cause of my complaints is } \\
\text { internal (6)/external (0)' }\end{array}$ & $\begin{array}{l}0=\text { extern, } \\
6=\text { intern }\end{array}$ & 559 & - & $3 / 2.59$ & 1.8 \\
\hline $\begin{array}{l}\text { Attributions: Stable (cause complaints) } \\
\text { 'My complaints can be decreased (6)/not } \\
\text { decreased (0)' }\end{array}$ & $\begin{array}{l}0=\text { stable }, \\
6=\text { unstable }\end{array}$ & 558 & - & 4/ 4.08 & 1.5 \\
\hline $\begin{array}{l}\text { Attributions: Controllable (cause complaints) } \\
\text { 'My complaints can be controlled (6)/not be } \\
\text { controlled ( } 0 \text { )' }\end{array}$ & $\begin{array}{l}0=\text { not } \\
\text { controlled, } \\
6=\text { controlled }\end{array}$ & 561 & - & $3 / 2.38$ & 1.7 \\
\hline
\end{tabular}


Table 9.1. Concepts used in adjusted and unadjusted regression analyses (cont.).

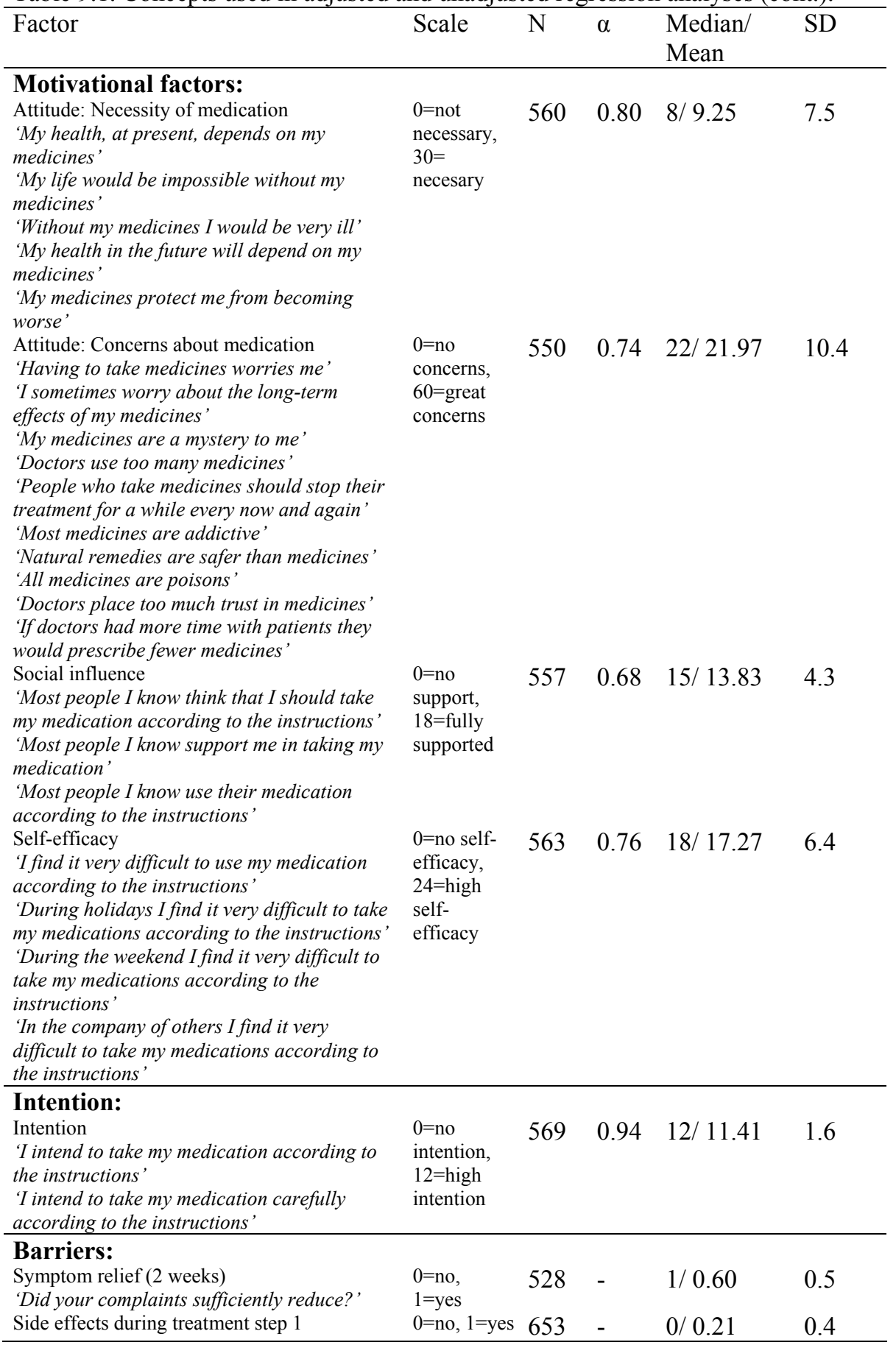


Behavioural factors: Patients were asked whether (yes/no) they consumed cigarettes, coffee or alcohol. These three behaviours were chosen, because they may aggravate dyspeptic complaints.

Psychological or personality factors: the SCL $90^{19}$ was used to measure psychoneuroticism indicating psychic or bodily dysfunction, the Utrecht Coping List $(\mathrm{UCL})^{20}$ measured coping style, and the Health Hardiness questionnaire ${ }^{21}$ measured health hardiness, all used according to their instructions. ${ }^{19-21}$ One item assessed forgetfulness in general.

Social and cultural factors: Three items assessed educational level $(0=$ none$7=$ academic), living status (living with or without a partner), and whether the patient worked in irregular working shifts (yes/no).

Information factors: One item assessed whether the patients thought they received enough information about their treatment. One item assessed patient satisfaction with their last GP consultation.

Awareness factors: The severity of the symptoms during the previous week was measured using eight items from the Gastrointestinal Symptoms Questionnaire. ${ }^{22 ; 23}$ The statement 'My health status of the last week was the best/worst imaginable', measured on a VAS on the EuroQOL5D $\mathrm{D}^{24}$ was assumed to give an adequate reflection of the patients' health status for our analyses. Patients attributions (six items) were measured on three dimensions (locus, stability and controllability) derived from the Weiner's attribution theory, ${ }^{17}$ for two different aspects: the cause of being adherent and the cause of the dyspeptic complaints.

\section{After two weeks}

Barriers: Symptom relief was measured using one item: patients were asked whether they thought that their complaints had sufficiently decreased since the start of the treatment (yes/no). The GPs indicated the presence of side effects.

Patient adherence outcome measures

Intake fidelity: Intake fidelity was measured using a short patient questionnaire two weeks after starting treatment. We chose to measure intake fidelity at two weeks to increase the likelihood that patients were still taking treatment medication at that time. Intake fidelity is measured using a nine item questionnaire, asking about the timing, dose, frequency and way of intake. Patients were asked how they had taken their medication. We compared these answers with the instructions given in Box 9.1 to indicate correct use. Each correct answer was rewarded with 1 point and each 
partly correct answer with 0.5 . Nine points indicates correct use or perfect adherence. The Intake fidelity questionnaire is described extensively elsewhere. ${ }^{25}$

Self-perceived adherence: Self-perceived adherence was measured after treatment step 1 (in most cases after four weeks) with six questions derived from the asthma problem behavior checklist. ${ }^{26}$ We chose to measure self-perceived adherence after treatment step 1 to reflect the medicine-taking behaviour patients might report to their GP when they returned for a follow up consultation. The patients were asked whether they followed the instructions. These questions were measured on a 5-point scale $(0=$ never, $1=$ almost never, $2=$ sometimes, $3=$ usually, $4=$ always) (Table 9.1). Since the last three questions were measured negatively, the answers were recoded before analysis $(4=$ never $-0=$ always). A sum score was calculated: a score of 0 indicates no adherence at all and 24 indicates perfect adherence.

Pill counts: Patients were instructed via the trial information leaflet, via yellow stickers on the medication jars, and verbally by the GPs, to return the medication jars to their GPs. The medication jars were marked with a patient number. To avoid counting errors, two researchers independently counted the returned pills. In the event of disagreement, the pills were counted a third time. Based on the duration of medication use (days) and the pill counts, the number of pills used per day was calculated. The duration of medication use was based on the consultation dates, except when other starting and stopping dates were indicated, for example when the medication was returned prior to the follow-up consultation or when medication was stopped prematurely because of side effects.

\section{Statistical analysis}

SPSS version 14.0 was used for data analysis. A two-sided significance level of 0.05 was used. Differences between patients included in multiple linear regression analysis and respondents excluded due to missing values were analyzed testing all variables in the model, using t-tests (in the case of normally distributed data) or Mann-Whitney $U$ test (in the case of non-normality) and $\chi^{2}$ tests.

Spearman correlation coefficients were calculated to investigate the correlation between the three adherence measures: self-perceived adherence, pill counts, and intake fidelity.

Since three dependent variables were used the theoretical model was tested three times using univariate and multiple regression analyses. For the univariate analyses, the correlation between each predictor in the model and each adherence measure was calculated using Spearman correlation coefficients. 
Three multiple linear regression analyses were conducted using the enter-method: one with self-perceived adherence, one with the pill counts, and one with intake fidelity as the dependent variable. All three regression models enclosed three blocks. Block 1 contained the predisposing factors and treatment randomization (step-up or step-down); block 2 added the motivational factors (attitude, social influence and self-efficacy); block 3 added the intention and the barriers. The assumptions for regression analyses were checked and proved satisfactory for predicting selfperceived adherence; it was only in predicting pill counts and predicting intake fidelity that we found slight deviations in the normal distribution of the standardized errors: kurtosis (2.11 (SE 0.29) for pill counts and skewness (-0.98 (SE 0.14)) and kurtosis $(0.79$ (SE 0.29)) for intake fidelity.

\section{Results}

Characteristics of the sample

A total of 664 patients agreed to participate in the DIAMOND-study, but 11 patients changed their mind shortly after inclusion and did not use any treatment medication; they were excluded from analysis. Thus, a total of 653 patients were included (mean age of 47 years (SD 14.6), 46\% males) (Table 9.1).

\section{Correlation between the three adherence outcome measures}

Figure 9.3 shows the correlation between self-perceived adherence and the number of pills used per day. Figure 9.4 presents all Spearman's correlation coefficients between all adherence measures: the correlation between self-perceived adherence and the pill count was 0.28 and between intake fidelity and pill counts was 0.28 , which both are medium correlations. There is little correlation between intake fidelity and self-perceived adherence $(\mathrm{r}=0.11)$. This indicates that the adherence measures are poorly correlated and are not interchangeable. 
Figure 9.3. Pill count versus self-perceived adherence.

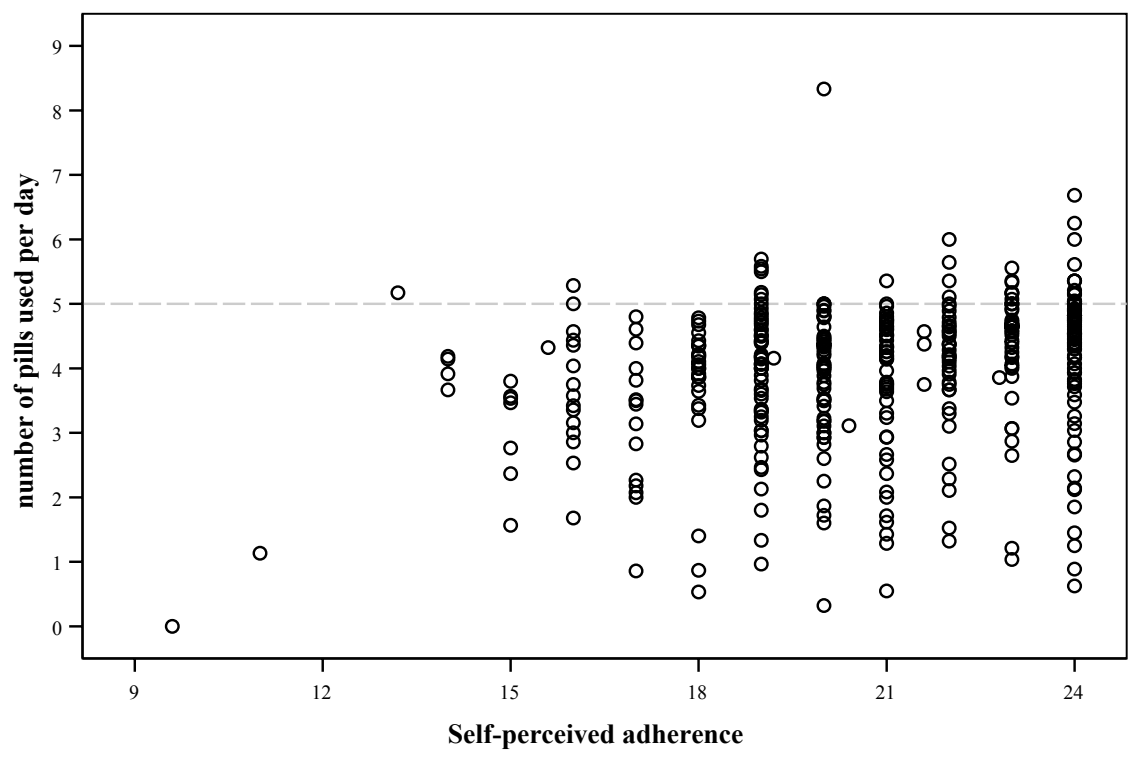

NB. Five pills per day were prescribed.

Figure 9.4. Correlation between adherence measures.

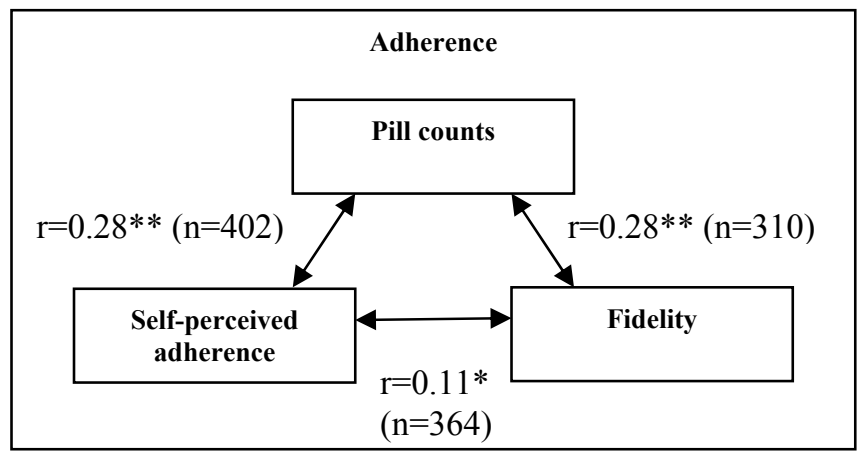

$* p<0.05 * * p<0.001$ 
Table 9.2. Correlation between predictor and adherence measure (univariate analysis).

\begin{tabular}{|c|c|c|c|}
\hline Predictor & $\begin{array}{c}\text { Self- } \\
\text { perceived } \\
\text { adherence }\end{array}$ & Pill count & $\begin{array}{l}\text { Intake } \\
\text { fidelity }\end{array}$ \\
\hline Smoking & 0.04 & -0.08 & $-0.15 * *$ \\
\hline Coffee use & 0.01 & 0.07 & 0.02 \\
\hline Alcohol use & $-0.11^{*}$ & 0.00 & 0.09 \\
\hline Forgetfulness & $0.29 * *$ & $0.17 * *$ & 0.04 \\
\hline Psycho-neuroticism & -0.05 & -0.05 & $-0.15^{* *}$ \\
\hline Active coping style & 0.02 & -0.04 & 0.01 \\
\hline Seeking support coping style & -0.04 & -0.03 & 0.08 \\
\hline Avoidance coping style & -0.02 & -0.01 & 0.05 \\
\hline Palliative coping style & -0.06 & -0.01 & 0.02 \\
\hline Religious coping style & 0.00 & -0.04 & -0.05 \\
\hline Passive reaction coping style & $-0.13 * *$ & -0.02 & 0.04 \\
\hline Health hardiness & 0.09 & 0.02 & $0.12 *$ \\
\hline Gender & $-0.10 *$ & -0.03 & -0.08 \\
\hline Age & $0.17 * *$ & $0.19 * *$ & 0.05 \\
\hline Caucasian & $0.12 * *$ & 0.08 & $0.16^{* *}$ \\
\hline Living situation & -0.08 & 0.01 & 0.00 \\
\hline Educational level & $-0.15 * *$ & 0.03 & $0.11 *$ \\
\hline Irregular working shifts & $-0.10^{*}$ & -0.02 & -0.01 \\
\hline Information & $0.23 * *$ & -0.01 & -0.01 \\
\hline Satisfaction & $0.18 * *$ & 0.06 & 0.07 \\
\hline Severity dyspepsia & 0.05 & -0.01 & 0.01 \\
\hline Health status & 0.03 & 0.00 & -0.02 \\
\hline Co-morbidity & $0.09 *$ & 0.09 & 0.01 \\
\hline $\begin{array}{l}\text { Attributions: locus (cause of non- } \\
\text { adherence) }\end{array}$ & $0.21 * *$ & 0.09 & 0.02 \\
\hline $\begin{array}{l}\text { Attributions: stability (cause of non- } \\
\text { adherence) }\end{array}$ & $0.14 * *$ & $0.10^{*}$ & -0.01 \\
\hline $\begin{array}{l}\text { Attributions: control (cause of non- } \\
\text { adherence) }\end{array}$ & $0.27 * *$ & $0.12 * *$ & -0.04 \\
\hline Attributions: locus (cause of complaints) & $-0.18 * *$ & -0.02 & 0.07 \\
\hline $\begin{array}{l}\text { Attributions: stability ( cause of } \\
\text { complaints) }\end{array}$ & 0.06 & -0.05 & -0.04 \\
\hline Attributions: control (cause of complaints) & $-0.11 *$ & 0.06 & $0.10^{*}$ \\
\hline Beliefs: necessity & 0.08 & $0.10^{*}$ & -0.03 \\
\hline Beliefs: concerns & -0.08 & -0.09 & -0.04 \\
\hline Social influence & $0.09 *$ & $0.13 * *$ & -0.01 \\
\hline Self-efficacy & $0.36 * *$ & $0.11 *$ & -0.01 \\
\hline Intention & $0.33 * *$ & $0.15^{* *}$ & 0.03 \\
\hline Side effects & 0.04 & 0.08 & $0.10^{*}$ \\
\hline Symptom relief at 2 weeks & $-0.13 * *$ & -0.05 & 0.00 \\
\hline
\end{tabular}




\section{Univariate analysis}

Table 9.2 shows the results of the univariate analyses. Self-perceived adherence is correlated in small to medium correlations with several predictors: for instance, patients who regularly forgot to take their medication, who had a passive reactive coping style, who were younger, who were non-Caucasian, who had a lower educational level, who were less satisfied with their last consultation, who had concerns about using medication, who had a lower self-efficacy, who had a lower intention to be adherent were less likely to be adherent.

Furthermore, pill count is also correlated with several predictors in small to medium correlations: for instance older patients, patients who did not regularly forget their medication, patients who saw a higher necessity of using medication, patients indicating more social influence, patients who had a higher self-efficacy, patients who had a higher intention were more likely to take more pills per day.

High intake fidelity scores were more likely among patients who did not smoke, who had a low score for psycho-neuroticism, who had a high score for health hardiness, who were Caucasian, who had a higher educational level, who experienced side-effects, and patients who believed themselves to be in control of the cause of their complaints, as indicated by small correlations.

\section{Multiple regression analyses}

Ultimately 337 patients could be included in the multiple regression analyses predicting self-perceived adherence; the rest were excluded due to missing values or non-response to the baseline or follow-up questionnaire (or both). Patients included were older (mean 48.3 versus $45.9, \mathrm{p}<0.05$ ), had a higher educational level (mean 3.89 versus $3.37, \mathrm{p}<0.01$ ), used more pills per day (mean 4.04 versus $3.62, \mathrm{p}<0.01$ ) than patients excluded. Furthermore, $80 \%$ of patients included lived with a partner compared to $73 \%$ of the patients excluded $(\mathrm{p}<0.05)$, and $97 \%$ of the included patients were Caucasian compared to $91 \%$ of the patients excluded $(p<0.01)$.

Table 9.3 shows the results of the multiple regression analysis. The explained variances for self-perceived adherence, pill counts, and intake fidelity were, respectively, 32\%, 20\%, and 17\%. For self-perceived adherence, Table 9.3 shows that the factors passive reactive coping style, palliative coping style, self-efficacy and symptom relief were statistically significant in all three models. For pill count, the strongest predictors were age and concerns about medication use. For intake fidelity, the strongest predictors were gender, ethnicity, and the presence of side effects. 
Table 9.3. Multiple regression analyses: unstandardized regression coefficients.

\begin{tabular}{|c|c|c|c|c|c|c|c|c|c|}
\hline \multirow{3}{*}{ Predictor } & \multicolumn{9}{|c|}{ Dependent variable } \\
\hline & \multicolumn{3}{|c|}{$\begin{array}{c}\text { Self-perceived } \\
\text { adherence }(n=337)\end{array}$} & \multicolumn{3}{|c|}{ Pill count $(n=285)$} & \multicolumn{3}{|c|}{ Intake fidelity $(\mathrm{n}=288)$} \\
\hline & 1 & 2 & 3 & 1 & 2 & 3 & 1 & 2 & 3 \\
\hline$\overline{\mathbf{R}^{2}}$ & 0.25 & 0.30 & 0.32 & 0.16 & 0.18 & 0.20 & 0.14 & 0.14 & 0.17 \\
\hline Adjusted R ${ }^{2}$ & 0.18 & 0.22 & 0.24 & 0.06 & 0.07 & 0.08 & 0.04 & 0.03 & 0.04 \\
\hline F Change & 3.40 & 5.63 & 2.73 & 1.62 & 1.66 & 1.73 & 1.38 & 0.23 & 2.55 \\
\hline Sign. F Change & 0.00 & 0.00 & 0.04 & 0.03 & 0.16 & 0.16 & 0.10 & 0.92 & 0.06 \\
\hline Constant & $13.59^{*}$ & $14.67^{*}$ & $14.36^{*}$ & 1.84 & 1.99 & 1.72 & $7.05 *$ & $7.15^{*}$ & $6.77^{*}$ \\
\hline $\begin{array}{l}\text { Step-up }(0) / \text { step- } \\
\text { down(1) }\end{array}$ & -0.52 & $-0.55^{\wedge}$ & -0.49 & -0.07 & -0.08 & -0.08 & -0.12 & -0.12 & -0.12 \\
\hline Smoking & 0.56 & 0.44 & 0.43 & -0.16 & -0.12 & -0.13 & -0.05 & -0.04 & -0.01 \\
\hline Coffee use & 0.59 & 0.48 & 0.42 & 0.40 & 0.41 & 0.38 & 0.19 & 0.18 & 0.15 \\
\hline Alcohol use & -0.59 & -0.54 & -0.57 & 0.10 & 0.11 & 0.12 & 0.00 & -0.03 & 0.04 \\
\hline Forgetfulness & $0.19^{\wedge}$ & 0.07 & 0.06 & 0.03 & 0.05 & 0.04 & -0.01 & -0.01 & -0.01 \\
\hline Psycho-neuroticism & 0.00 & 0.00 & 0.00 & 0.00 & 0.00 & 0.00 & 0.00 & 0.00 & 0.00 \\
\hline Active coping style & 0.06 & 0.06 & 0.03 & -0.01 & -0.01 & -0.02 & -0.01 & -0.01 & -0.01 \\
\hline Seeking support coping & -0.03 & -0.04 & -0.04 & -0.02 & -0.02 & -0.02 & 0.00 & 0.01 & 0.01 \\
\hline Avoidance coping style & 0.08 & 0.12 & 0.12 & 0.00 & 0.01 & 0.00 & -0.05 & -0.04 & -0.06 \\
\hline Palliative coping style & $-0.29^{\wedge}$ & $-0.29^{\wedge}$ & $-0.24^{\wedge}$ & -0.06 & -0.05 & -0.04 & -0.01 & -0.01 & -0.01 \\
\hline Religious coping style & -0.12 & -0.14 & -0.14 & -0.07 & -0.06 & -0.05 & -0.02 & -0.01 & -0.02 \\
\hline Passive reaction coping & $-0.54^{\wedge}$ & $-0.45^{\wedge}$ & $-0.44^{\wedge}$ & -0.07 & -0.05 & -0.06 & 0.01 & 0.01 & -0.03 \\
\hline Health hardiness & 0.75 & 0.54 & 0.58 & -0.27 & -0.12 & -0.12 & 0.23 & 0.28 & 0.29 \\
\hline Gender & -0.41 & -0.44 & -0.43 & -0.19 & -0.19 & -0.16 & $-0.28 \#$ & $-0.27^{\wedge}$ & $-0.24^{\wedge}$ \\
\hline Age & 0.01 & 0.01 & 0.01 & $0.02 *$ & $0.02 *$ & $0.02 *$ & 0.01 & 0.01 & 0.01 \\
\hline Caucasian & 1.56 & $1.69^{\wedge}$ & $1.70^{\wedge}$ & 0.39 & 0.36 & 0.42 & 0.60 & $0.61 *$ & 0.59 \\
\hline Living situation & -0.55 & -0.45 & -0.35 & -0.02 & 0.00 & 0.04 & -0.08 & -0.09 & -0.08 \\
\hline Educational level & -0.07 & -0.07 & -0.08 & 0.06 & 0.05 & 0.05 & 0.03 & 0.02 & 0.02 \\
\hline Irregular work hours & -0.40 & -0.59 & -0.54 & 0.10 & 0.15 & 0.17 & -0.05 & -0.03 & -0.03 \\
\hline Information & 0.15 & 0.11 & 0.11 & -0.03 & -0.04 & -0.05 & -0.01 & -0.01 & -0.02 \\
\hline Satisfaction & 0.16 & 0.14 & 0.11 & 0.07 & 0.05 & 0.04 & 0.06 & 0.06 & 0.06 \\
\hline Severity dyspepsia & 0.05 & 0.04 & 0.03 & 0.01 & 0.01 & 0.01 & 0.01 & 0.01 & 0.01 \\
\hline Health status & 0.00 & 0.00 & 0.00 & 0.00 & 0.00 & 0.00 & 0.00 & 0.00 & 0.00 \\
\hline Co-morbidity & 0.12 & 0.20 & 0.18 & -0.02 & -0.04 & -0.06 & -0.03 & -0.03 & -0.06 \\
\hline $\begin{array}{l}\text { Attributions: locus } \\
\text { (cause of adherence) }\end{array}$ & $0.43^{\wedge}$ & 0.18 & 0.08 & 0.11 & 0.10 & 0.05 & 0.01 & 0.00 & -0.01 \\
\hline $\begin{array}{l}\text { Attributions: stability } \\
\text { (cause of adherence) }\end{array}$ & 0.06 & 0.01 & -0.01 & 0.00 & -0.01 & -0.02 & -0.01 & -0.01 & -0.01 \\
\hline $\begin{array}{l}\text { Attributions: control } \\
\text { (cause of adherence) }\end{array}$ & 0.12 & 0.04 & 0.06 & 0.07 & 0.06 & 0.08 & 0.05 & 0.06 & 0.06 \\
\hline $\begin{array}{l}\text { Attributions: locus } \\
\text { (cause of complaints) }\end{array}$ & -0.08 & -0.04 & -0.04 & 0.03 & 0.04 & 0.04 & 0.01 & 0.02 & 0.02 \\
\hline $\begin{array}{l}\text { Attributions: stability } \\
\text { (cause of complaints) }\end{array}$ & 0.00 & -0.06 & -0.02 & 0.02 & 0.00 & 0.01 & -0.05 & -0.05 & -0.06 \\
\hline $\begin{array}{l}\text { Attributions: control } \\
\text { (cause of complaints) }\end{array}$ & 0.03 & 0.04 & 0.02 & 0.02 & 0.04 & 0.03 & 0.07 & 0.07 & 0.06 \\
\hline Beliefs: necessity & & -0.01 & -0.01 & & 0.01 & 0.01 & & 0.00 & 0.00 \\
\hline Beliefs: concerns & & -0.01 & -0.01 & & $-0.02^{\wedge}$ & $-0.02^{\wedge}$ & & -0.01 & -0.01 \\
\hline Social influence & & 0.04 & 0.03 & & 0.01 & -0.00 & & -0.01 & -0.01 \\
\hline Self-efficacy & & $0.11 *$ & $0.12 *$ & & -0.01 & -0.01 & & 0.00 & 0.00 \\
\hline Intention & & & 0.15 & & & 0.06 & & & 0.04 \\
\hline Side-effects & & & 0.15 & & & 0.23 & & & $0.28^{\wedge}$ \\
\hline Symptom relief & & & $-0.58^{\wedge}$ & & & -0.01 & & & 0.15 \\
\hline
\end{tabular}




\section{Discussion}

The study aimed to establish which patient related factors determined patient adherence to prescribed dyspepsia medication. Three outcome measures for patient adherence were used. Our results have shown that several predictors from the theoretical framework were associated with self-perceived adherence, whereas few predictors were associated with pill count and intake fidelity. Some predictors, such as intention, self-efficacy, social influence, age and forgetfulness, were significantly associated with both self-perceived adherence and pill count in the univariate analyses. However, no single predictor was significantly associated with all three adherence measures. The same holds true for testing of the full theoretical model in multiple regression analyses.

A gold standard for measuring adherence does not exist. ${ }^{9}$ DiMatteo advocates using multiple adherence measures to get more insight into the reliability and validation of these measures, ${ }^{9}$ since different adherence measures do not always result in similar adherence rates. ${ }^{27,28} \mathrm{We}$ found that the three adherence measures correlate poorly; this may be explained by the fact that these measures all focus on different aspects of following medication prescriptions. Self-perceived adherence described the patients' medicine-taking behaviour in relation to the prescriptions, whereas intake fidelity described how the medication was taken without referring to the prescriptions. However, both measures rely on adequate awareness of one's own behaviour. Pill count, on the other hand, was probably more related to patients' actual medication-taking behaviour and was not influenced by the self-reports or patients' perceptions of their own behaviour. This may explain the low correlation between pill count and the other measures: maybe patients thought that they were following the instructions perfectly, whereas in reality they often deviated from the instructions, for instance because they had forgotten their pills.

Another explanation for the low correlation may be found in the differences in timing of the self-reported measures: intake fidelity was measured at two weeks, whereas self-perceived adherence was measured after treatment step 1, which was in most cases at four weeks. Dyspeptic symptoms have a high day-to-day variability and, although this was not included in the instructions, patients may have stopped treatment (or taken tablets only when needed) when the symptoms were relieved, without consulting their GP. Therefore, the timing of adherence measurement can be essential: patients who had already stopped their medication because their symptoms were relieved might truthfully state that they were not following the instructions at 
that time, and this would result in lower adherence rates. This may explain why patients with symptom relief at two weeks were less likely to be adherent after treatment step 1. Furthermore, this may also explain why the explained variance in the present study (31\%) was lower than in the preceding study $(44 \%):^{5}$ in the preceding study, self-perceived adherence was measured after two weeks; this may have been more closely related to the predictors and to using medication at that time. The explained variance of the models predicting number of pills used per day and intake fidelity was low. These adherence measures may more accurately reflect the actual medicine-taking behaviour rather than the patient's perception of his/her own behaviour; and perhaps factors relating to the patient-physician interaction, the disease, the setting and the treatment play an important role in determining actual medicine-taking behaviour for dyspepsia. ${ }^{8}$

In respect of self-perceived adherence, we found that patients with a passive reaction coping style (i.e. reconcile themselves to the situation), patients with a palliative coping style (i.e. seek distraction), and patients with a low self-efficacy (i.e. think they are not able to follow the instructions) were less likely to be adherent. Selfefficacy was also the most important predictor among PPI users in the preceding study; unfortunately, coping style could not be assessed in the earlier study.

In respect of pill count, the results showed that younger patients and patients who had more concerns about using medication used fewer pills per day. As regards intake fidelity, men, non-Caucasians and patients without side effects were less likely to be adherent. The latter is rather strange, one would have expected the opposite. Maybe patients with side effects only reported side effects when they were certain that they were adherent, to make sure that the side effects were due to the medication and not to not using the medication. Furthermore, the fact that being a non-Caucasian is related to lower intake fidelity rates and lower self-perceived adherence rates may be explained by the fact that questionnaires were used to measure these outcomes. Maybe non-Caucasians experienced more difficulties in understanding the questions; if this is so, it is also possible that they experienced more difficulty in understanding the instructions and that this contributed to lower adherence rates.

There is limited literature available on patient adherence in the case of dyspepsia with which to compare our findings: a literature search revealed only one brief report from the UK, in relation to adherence to PPI therapy. ${ }^{12}$ The UK study concluded that the absence of severe symptoms and the desire to remain in personal control, together with the higher fear of side effects and a lack of knowledge about 
the drugs, negatively influenced patient adherence to long-term PPI prescriptions. However, in this brief report, no effect sizes of any kind were reported, and we were not able to judge the presence and magnitude of the difference between adherent and non-adherent patients.

Our findings confirm more general literature on patient adherence that states that there are relatively few consistent predictors of pharmacological adherence. ${ }^{8} \mathrm{~A}$ review of potential predictors of patient adherence concluded that most of the data are unclear and inconclusive. ${ }^{10}$ The theoretical framework used in this study was based on general patient related factors indicated in literature (e.g. ${ }^{7-13}$ ). Although some factors such as severity of the symptoms before treatment may indeed influence patient adherence to medical treatment in other situations, our results indicate that severity may not be likely to influence adherence to initial medical treatment for dyspepsia: neither in our present study nor in our preceding study was it found to be associated with adherence. This may also be the case for several coping styles and health status, but these factors were not measured in the preceding study.

\section{Study limitations}

Our study extensively investigated patient adherence to dyspepsia medication prescriptions. Nevertheless, some limitations need to be discussed. The patients included in the multiple regression analyses were somewhat different from the whole DIAMOND-patient population. Although, for instance, men, younger patients, patients with a low educational level and non-Caucasians were slightly under-represented, these factors were still associated with patient adherence. This indicates that in everyday practice these factors may be even stronger predictors than our results indicate. As to the reliability of the measures, social desirability may have influenced the self-reported outcome measures and predictors. Still, for intake fidelity, the fact that some level of understanding of the instructions was required to know what the correct answers were may have reduced the likelihood of being influenced by social desirability. Nevertheless, if social desirability has influenced our findings, this again may result in an underestimation of non-adherence and the strength of factors determining adherence in comparison with everyday practice.

\section{Implications}

Adherence and its determinants remain a complex problem in primary care. In everyday practice, it is important to determine whether or not a patient has adhered 
to a medication regimen throughout treatment in order to facilitate the use of medication as a diagnostic tool in the case of a first episode of dyspepsia. How can GPs best determine patient adherence? A self-reported measure is probably the best way for GPs to determine patient adherence at a follow-up visit, since actual pill counts are often not practical. Bosworth ${ }^{8}$ indicates that patients reporting nonadherence have no reason to lie about this, and these answers are considered to be reliable. Self-reported adherence on the other hand may be unreliable. But asking simple questions like 'How many days did you use your medication?' or 'Many patients forget a pill now and then, how was this for you?' or 'Many patients find the timing of taking medication half an hour before breakfast inconvenient, how was this for you?' can be helpful in determining patient adherence. Furthermore, nonadherence may be prevented by actively eliciting the patient's needs and concerns, providing relevant information in a clear, concise manner and prescribing treatment that can easily be implemented in the patient's lifestyle. Our study shows that several patient related factors, such as intention, self-efficacy, concerns about medication, social influence and forgetfulness are associated with patient adherence. So, interventions designed to improve dyspeptic patients' adherence to their medication regimen should be focused on these factors. More research is needed to improve the theoretical model, to get more insights into adherence measurements and to design interventions to improve adherence to dyspepsia medication prescriptions.

\section{References}

1. Van Bommel MJ, Numans ME, de Wit NJ, Stalman WA. Consultations and referrals for dyspepsia in general practice - a one year database survey. Postgrad Med J 2001; 77: 514-8.

2. The Dutch Institute for Healthcare Improvement (CBO), Dutch College of General Practitioners (NHG). Multidisciplairy Guideline Stomachcomplaints (Multidisciplinaire Richtlijn Maagklachten). Alphen aan den Rijn: Van Zuiden Communications; 2004.

3. Krol N, Muris JW, Schattenberg G, Grol R, Wensing M. Use of prescribed and non-prescribed medication for dyspepsia. Scand J Prim Health Care 2004; 22: 163-7. 
4. Van Soest EM, Siersema PD, Dieleman JP, Sturkenboom MC, Kuipers EJ. Persistence and adherence to proton pump inhibitors in daily clinical practice. Aliment Pharmacol Ther 2006; 24: 377-85.

5. Fransen GAJ, Mesters I, Janssen MJR, Knottnerus JA, Muris JWM. Which patient related factors determine patient adherence to prescribed dyspepsia medication? Submitted for publication.

6. Vries H, Mesters I, van de SH, Honing C. The general public's information needs and perceptions regarding hereditary cancer: an application of the Integrated Change Model. Patient Educ Couns 2005; 56: 154-65.

7. Bosworth HB, Voils CI. Theoretical models to understand treatment adherence. In: Bosworth HB, Oddone EZ, Weinberger M, editors. Patient treatment adherence. Concepts, interventions and measurement.New Jersey: Lauwrence Erlbaum Associates Inc.; 2006.

8. Bosworth HB. Medication treatment adherence. In: Bosworth HB, Oddone EZ, Weinberger M, editors. Patient treatment adherence. Concepts, interventions and measurement.New Jersey: Lauwrence Erlbaum Associates Inc.; 2006.

9. DiMatteo MR. Variations in patients' adherence to medical recommendations: a quantitative review of 50 years of research. Med Care 2004; 42: 200-9.

10. Dunbar J, Schlenk EA, Burke LE. Predictors of patient adherence: patient characteristics. In: Schumaker S, McBee WL, Schron E, Ockene J, editors. The handbook of health behavior change. 2 ed. New York: Springer; 1998.

11. Horne R, Weinman J. Patients' beliefs about prescribed medicines and their role in adherence to treatment in chronic physical illness. J Psychosom Res 1999; 47: 555-67.

12. Hungin AP, Rubin G, O'Flanagan $\mathrm{H}$. Factors influencing compliance in longterm proton pump inhibitor therapy in general practice. Br J Gen Pract 1999; 49: 463-4.

13. Meichenbaum D, Turk DC. Factors affecting adherence. In: Meichenbaum D, Turk DC, editors. Facilitating treatment adherence. A practitioner's guidebook.New York: Plenum Press; 1987. p. 41-70.

14. Ajzen I. The theory of planned behavior. Organ Behav Hum Decis Processes 1991; 50: 179-211.

15. Bandura A. Social cognitive theory of self regulation. Organ Behav Hum Decis Processes 1991; 50: 248-485.

16. Janz NK, Becker MH. The Health Belief Model: a decade later. Health Educ Q 1984; 11: 1-47. 
17. Weiner B. An attributional theory of motivation and emotion. New York: Springer-Verlag Inc; 1986.

18. Fransen GAJ, Laheij R.J.F. Registration protocol DIAMOND study (ZONMW 095-03-052). http://www.clinicaltrials.gov/ct/show/NCT00247715? order=9.

19. Arrindell WA, Ettema JHM. SCL-90: manual for a multidimensional psychopathologic indicator [SCL-90: handleiding bij een multidimensionele psychopathologie-indicator]. Lisse: Swets Test Service; 1986.

20. Scheurs P, Van De Willige G, Brosschot J, Tellegen B, Graus G. De Utrechtse Coping Lijst (Utrecht Coping Questionnaire). Lisse: Swess and Zeitlinger; 1993.

21. Gebhardt WA, van der Doef MP, Paul LB. The Revised Health Hardiness Inventory (RRHI-24): psychometric properties and relationship with selfreported health and health behavior in two Dutch samples. Health Educ Res 2001; 16: 579-92.

22. Bovenschen HJ, Janssen MJ, van Oijen MG, Laheij RJ, van Rossum LG, Jansen JB. Evaluation of a Gastrointestinal Symptoms Questionnaire. Dig Dis Sci 2006; 51: 1509-15.

23. Fransen GAJ, Janssen MJR, Muris JWM, Mesters I, Knottnerus JA. Measuring the severity of upper gastrointestinal complaints: does GP-assessment correspond with patients' self-assessment? Fam Pract 2007; 24: 252-8.

24. Brazier J, Jones N, Kind P. Testing the validity of the Euroqol and comparing it with the SF-36 health survey questionnaire. Qual Life Res 1993; 2: 169-80.

25. Fransen GAJ, Mesters I, Muris JWM, Van Marrewijk CJ, Mujakovic S, Laheij RJF, et al. Patient adherence to prescribed medication instructions for dyspepsia. Submitted for publication.

26. Creer TL, Wigal JK, Tobin DL, Kotses H, Snyder SE, Winder JA. The Revised Asthma Problem Behavior Checklist. J Asthma 1989; 26: 17-29.

27. Dunbar J, Dunning EJ, Dwyer K. Compliance measurement with arthritis regimen. Arthritis Care Res 1989; 2: S8-16.

28. Waterhouse DM, Calzone KA, Mele C, Brenner DE. Adherence to oral tamoxifen: a comparison of patient self-report, pill counts, and microelectronic monitoring. J Clin Oncol 1993; 11: 1189-97. 
Dyspepsia in primary care: patient expectations, symptoms, and treatment adherence 


\title{
Chapter 10
}

\section{General discussion}

\author{
G.A.J. Fransen
}

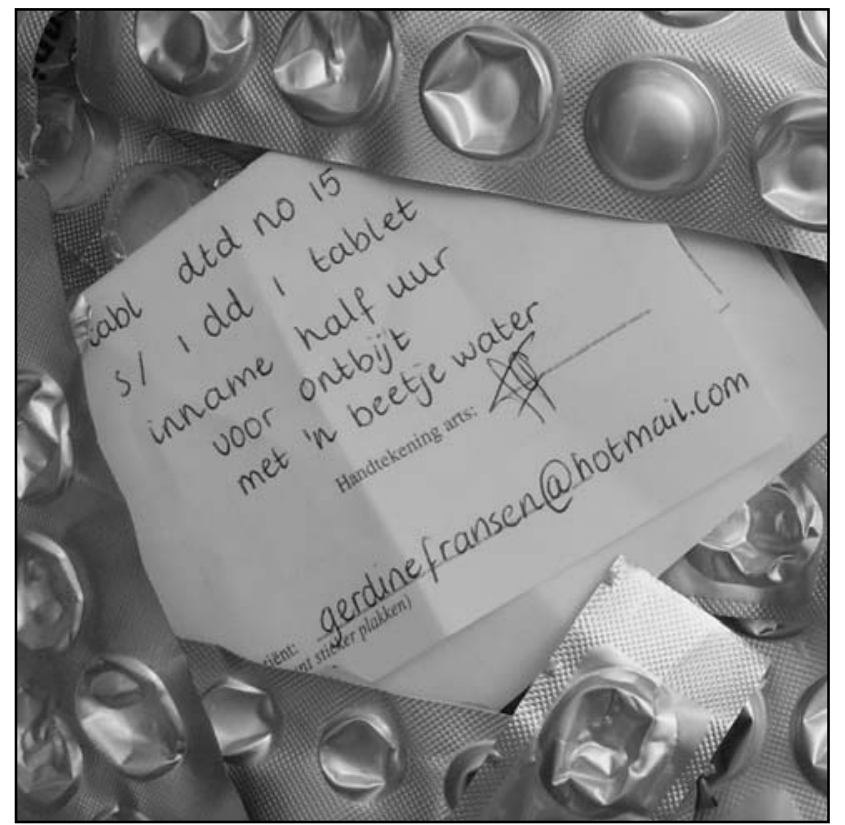




\section{Introduction}

This thesis investigated several aspects of the management of newly diagnosed dyspepsia: from the predictive value of alarm symptoms for upper gastrointestinal cancer to the interrater agreement between general practitioners (GPs) and patients on the severity of the patients' dyspeptic complaints, from patients' expectations to patient adherence. In the first section of this chapter the main findings concerning patient expectations, the predictive value of alarm symptoms for upper gastrointestinal cancer, and the agreement on dyspeptic symptom severity between GPs and patients will be summarized and the implications of these findings will be discussed. In the second section, patient adherence and its determinants will be considered starting with summarizing the main findings, reflecting on possible explanations of the results, and then discussing the implications of these findings. In the third section the main limitations and strengths of this thesis will be considered. In the fourth section the core conclusions are presented in key messages. And finally, recommendations for general practice and future research will be provided.

\subsection{Main findings and their implications}

\section{Patient expectations}

The results of a qualitative study (Chapter two) formed the starting point of this thesis. The aim of this focus group study was to investigate patients' expectations and perceptions regarding dyspepsia and the management of dyspepsia among patients with persistent complaints for whom the cause of the complaints was unknown. The results showed that patients expected at first that the acid-suppressive medication prescribed would resolve instead of suppress their complaints. Furthermore, when they noticed that the complaints were not permanently resolved by the acid-suppressants, they expected that the underlying cause of the complaints would be investigated and could be identified by careful diagnostic investigations and that permanently using acid-suppressants would disguise the real problem. So, when no cause was identified patients feared that the underlying cause was overlooked. These expectations contrast with current medical views advocating empirical treatment and reserving immediate investigation for elderly patients and those with alarm symptoms, based on the fact that in most cases no apparent cause will be found during diagnostic investigations. It is problematic when patient 
expectations are unfulfilled, because this is likely to lead to low patient satisfaction and non-adherence.

These findings imply that an improvement of the communication between patients and GPs is necessary to prevent unrealistic patient expectations, patient dissatisfaction, and non-adherence. Prior research has shown that active involvement of patients in treatment regimen decisions, creating a trusting relationship with the health care provider, and eliciting patient expectations and health beliefs can positively influence patient adherence and health outcomes. ${ }^{1-7}$ This means that GPs need to explain the rationale behind the recommended acid-suppressive treatment in a clear and concise manner: that in the case of dyspepsia immediate diagnostic investigations are not advised because in most cases no cause of the complaints is found during these investigations and that most patient experience adequate symptom relief when using acid-suppressive medication. ${ }^{8-10}$ Then, GPs need to emphasize that, since the acid-suppressants are used as a diagnostic tool, optimal adherence and a proper evaluation of the prescribed treatment are essential, and that the GPs have to rely on the patients' close monitoring of the effect of the treatment. By actively involving the patients in treatment decisions, explaining the rationale behind the prescribed treatment, and saying what the patients can expect and what is expected from the patients, patients are more likely to feel in control, to feel being taken seriously, and to have more realistic expectations, which ultimately improves patient adherence and patient satisfaction.

\section{Predictive value of alarm symptoms for upper gastrointestinal cancer}

Although guidelines recommend reserving immediate investigation for patients with alarm symptoms such as weight loss, dysphagia, signs of upper gastrointestinal bleeding, and persisting vomiting, the predictive value of alarm symptoms for upper gastrointestinal cancer seemed by no means clear. Therefore, we conducted two review studies (Chapters three and four). In the first review both cohort studies and case-control studies were included into the meta-analysis, in the second review the data of cohort studies were used in an individual patient data analysis. Both studies showed that the value of alarm symptoms for predicting the presence of upper gastrointestinal cancer is limited: approximately a third of the patients diagnosed with cancer did not have any alarm symptom, and only a small number of the patients with an alarm symptom actually had cancer.

Using the presence of alarm symptoms as an indication for immediate endoscopy is based on the fear of patients as well as physicians of failing to notice cancer in time. 
The findings of our reviews imply that besides alarm symptoms, other risk factors, such as age, smoking, or family history, need to be taken into account in the difficult task to predict this rare disease in time. Researchers and physicians should not overestimate the value of alarm symptoms: this can lead to too many unnecessary, costly, and painful endoscopies.

Agreement between GP and patient on severity of the dyspeptic complaints

The focus group study (Chapter two) showed that several patients thought that their GP did not take their complaints seriously. To know whether GPs score the severity of dyspeptic complaints in the same degree as patients do, the interrater agreement between GP and patients on this subject was investigated (Chapter five). The weighted kappa values indicated poor to moderate agreement. Several systematic differences in scoring were found: in comparison to patients GPs tended to underestimate the severity of belching, nausea, early satiety, vomiting, upper and lower abdominal pain. Furthermore, GPs were more optimistic than patients about the treatment results for belching and lower abdominal pain, but less optimistic on the treatment result for nausea.

These findings have two important implications: for general practice, the communication by GPs on symptom severity needs to be improved, for instance by explicitly asking about the severity of the patient's dyspeptic complaints. One way to do this is by asking the patient to indicate the severity of symptoms like heart burn, belching, upper and lower abdominal pain, and nausea, on a scale from zero to ten; ten indicating very severe complaints. For research, the findings imply that since GPs and patients score differently even when they use a similar questionnaire at the same moment in time, it is important to always report who is assessing the severity of the dyspeptic complaints and assess both perspectives.

\subsection{Patient adherence: main findings, explanation of the findings and implications}

The focus group study showed that patients disliked the idea of taking medication that did not permanently resolve their complaints. This led to questioning patient adherence to prescribed dyspepsia medication. To investigate patient adherence, data of two medical studies were used: one observational study investigating the effectiveness on symptom relief of proton pump inhibitors (PPIs) (Chapters five and six are based on these data) and one pragmatic randomised controlled trial (RCT) 
comparing the effectiveness of two treatment strategies with acid-suppressive medication (Chapters seven, eight and nine are based on these data). Before discussing the main findings concerning patient adherence and its determinants, I would like to make a short digression to the main findings of Chapter seven. In Chapter seven a reflection on the methodological challenges in designing and conducting a pragmatic RCT in primary care is presented. One of the main conclusions of this debate article was that in pragmatic RCTs it is difficult to ensure a high generalisability without compromising internal validity. For instance, blinding treatment allocation was considered necessary because prejudices of GPs, patients and researchers concerning the most effective treatment arm might influence the subsequent treatment and the measurement of the primary outcome (symptom relief according to patients at six months after starting treatment). In our pragmatic RCT treatment allocation was blinded by adding placebo pills to both treatment arms. But this reduced the external validity: patients were instructed to use five pills per day (i.e. placebo plus active pills) at the start of the treatment instead of one or four pills per day (i.e. only active pills) as in usual care. Consequently, although we retrieved good insight on patient adherence to trial acid-suppressive medication, patient adherence in every day care might differ and needs to be further investigated to be conclusive. This implicates that blinding in pragmatic RCTs should always be considered carefully, and when possible alternatives should be chosen (e.g. cluster randomisation) to reflect every day practice but without comprising the internal validity.

\section{Patient adherence}

This thesis showed that the patient adherence rates for prescribed acid-suppressants were disappointing. In the observational trial (Chapter six) approximately one quarter of the patients reported low self-perceived adherence scores, which was even one third of the patients in the RCT (Chapter nine). The RCT (Chapter eight) showed that half of antacid users (four times daily active pills), one third of the H2receptor antagonist users (twice daily active pills), and one quarter of the PPI users (once daily active pills) used less than $80 \%$ of the prescribed active pills per day, taken into account the fact that the antacids users and PPI users were instructed to use one or four placebo pills per day extra respectively, for the purpose of blinding treatment allocation. Furthermore, $70 \%$ of the patients made one or more errors concerning intake fidelity, mostly in the frequency of intake and in timing of usage in relation to meals. 
The three adherence outcome measures used, pill count, intake fidelity, and selfperceived adherence, were poorly correlated. This might be explained by the fact that the adherence outcome measures all relate to different aspects of adherence behaviour: from the actual number of pills taken (pill count) to how the pills were taken (intake fidelity) and the patient's perception of his/her own adherence behaviour (self-perceived adherence). Adherence can be considered to be a rather complex behaviour: patients need to follow several medication instructions (concerning timing, frequency, dose, way of intake, and treatment duration) for one or more different medicines. ${ }^{11}$ It can have a high day-to-day variability: patients might be perfectly adherent one day, but the next day only partially or even nonadherent. ${ }^{12}$ Most patients unintentionally make errors in taking medication at one time or another, usually because of forgetfulness or misunderstanding the instructions. ${ }^{13}$ Omitting one or more doses or taking medication at the wrong time are the two most common forms of non-adherence. ${ }^{14}$ This is reflected by our results: the fact that quite a number of patients used less than $80 \%$ of the prescribed pills per day might be due to omitting one or more doses and the finding that the most frequent errors were made in timing of the medication in relation to meals.

Concerning timing errors, although some patients consciously and well informed decide that the instructed timing is not convenient for them and deviate from this instruction, most patients probably deviate from this instruction because they are unaware of the importance of taking the medication at the right time. Especially for a PPI it significantly enhances the effectiveness when the PPI is taken half an hour before a meal. ${ }^{15}$ One possible explanation for this low awareness of the importance to take medication at the right time might be that GPs reported to pay little attention to this specific instruction. ${ }^{16}$ Besides, when adherence to this instruction is not highly valued by GPs and patients, patients might think that they are also adherent when they take their medication at another time, which might partially explain the low correlation between intake fidelity and self-perceived adherence as found in Chapter nine. Taking acid-suppressive medication at the right time might be improved when the importance of this instruction is stressed more by GPs and pharmacists.

Omitting one or more doses might be unintentional, for instance due to forgetfulness, but might also be more intentional as on demand use of acidsuppressive medication is common among patients with dyspepsia. ${ }^{17}$ As dyspeptic complaints have a known high day-to-day variability, it is possible that patients only use the acid-suppressants when they have complaints. Usage as needed or on 
demand is probably not problematic for chronic users, since this lowers the costs of the rather expensive medication without compromising the effectiveness, ${ }^{8,18}$ although usage on demand and taking the medication at the instructed time seems difficult to combine. Nevertheless, on demand usage is not favourable when the medication is used as a diagnostic tool for patients with a first episode of dyspeptic complaints. Then the acid-suppressive medication needs to be taken exactly according to the instructions to optimize the chance that the medication is effective. If the medication is not effective with optimal adherence, it is likely that either the medication was not strong enough or that the underlying mechanism was not acidrelated. If the adherence was not optimal while the complaints persist, it is very difficult to decide which of these options is most probable. Again, if patients think it is no problem to take the medication on demand (although on demand use was not advised by GPs as shown in a survey study by our group, ${ }^{16}$ ) then they might perceive themselves as being adherent. This might partially explain the low correlation between self-perceived adherence and the pill counts (Chapter nine). So, then patients intentionally use their medication on demand, but are unintentionally partially adherent since they were not aware of their deviation from the medication instructions. Maybe adherence in the case of a first episode of dyspepsia can be improved when, before prescribing treatment, GPs adequately explain to their patients why they want the medication to be used as prescribed. Furthermore, maybe some kind of reminder to take the medication might reduce omitting doses due to forgetfulness, like store the PPI pills (needs to be taken half an hour before breakfast) next to the morning alarm clock or insert a cue on the patient's mobile phone.

Although the Dutch guidelines ${ }^{8,19}$ in the case of newly diagnosed dyspepsia recommend to prescribe antacids (four times daily) or $\mathrm{H}_{2}$-receptor antagonists (twice daily) our findings implicate that the likelihood of reaching optimal adherence is higher when prescribing a PPI once daily. When acid-suppressants are used as a diagnostic tool optimal adherence is required, and since it is known that it is difficult for many patients to be adherent for a long treatment period, ${ }^{13}$ prescribing short treatment for two weeks is preferable. Besides, most acid-suppressants should be active quickly, so longer initial treatment periods requiring optimal adherence have no added value. If patients experience adequate symptom relief after initial treatment, on demand use can be recommended, possibly even with (cheaper and over-the-counter available) antacids or $\mathrm{H}_{2}$-receptor antagonists. ${ }^{19}$ Hence, it might be 
difficult to motivate patients to use these pills when they have good experiences with PPIs, which get reimbursed by health care insurance.

Our findings also implicate that patients are not fully aware of the importance of taking all prescribed doses during the complete period of treatment and taking the acid-suppressants at the right time. This should be pointed out in a clear manner when prescribing the acid-suppressants: verbally by the GPs, reinforced by pharmacists, by written supporting materials, and if possible by an indication on the medication jar or package to increase the likelihood of reaching optimal adherence. Furthermore, for a proper evaluation of the initial treatment at the follow-up consultation, especially when the complaints persist, GPs need to determine whether there were doses omitted or taken at the wrong time. Simply asking patients specific questions like 'how many days did you take your pills?' or 'at what time did you usually take your medication?' probably can provide a sufficient estimation of the actual adherence. When referring to the medication instructions, patients who indicate non-adherence or partial adherence most likely give a reliable impression of their adherence behaviour, because they have no reason to lie. ${ }^{13}$ Patients indicating (perfect) adherence on the other hand might give a socially desirable answer. To be more certain of patient adherence, GPs can also perform a pill count, but this is less practical to do in every day practice. Furthermore, besides determining adherence after initial treatment, it is also important to establish adherence in subsequent treatment steps for persisting complaints, when these treatment steps also need optimal adherence. The findings in Chapter eight indicate that few patients are consistently adherent or non-adherent over time, which implicates that adherence needs to determined after each treatment step.

\section{Determinants of patient adherence}

The value of the theoretical framework in predicting the adherence with various outcome measures was investigated in both the observational study (Chapter six) and the RCT (Chapter nine). The explained variance of the full model for predicting self-perceived adherence was satisfactory (44\% and 32\% respectively), but was lower for predicting pill count or intake fidelity (explained variance $20 \%$ and $17 \%$ respectively (only analysed in the RCT)). The observational study showed that patients with a low educational level, patients who claimed to regularly forget their medication in general, patients with a low self-efficacy, or a low intention were less likely to be adherent. The RCT showed that patients with a passive reaction coping style (i.e. patients who reconcile oneself to the situation), patients with a palliative 
coping style (i.e. patients who seek distraction), and patients with a low self-efficacy (i.e. patients who believe that they are not completely able to follow the medication instructions) were less likely to be adherent.

What determines patient adherence to prescribed dyspepsia medication? Based on the findings in Chapters six and nine, self-efficacy and forgetfulness seem to be the most important factors: most patients are willing to take the medication for a short period of time, they have a positive intention and attitude, but expect to experience some difficulties, for instance because they regularly had forgotten their medication in the past. Social influence does not seem to play an important role in being adherent to dyspepsia medication, maybe because the medicine-taking behaviour does not require a large behavioural change.

Although most patients did not feel a high necessity of using the medication, they also did not have many concerns about the medication (Table 10.1), maybe because it is regarded as short-term treatment and medication that can be used only when needed or on-demand. So, their attitude about taking dyspepsia medication was probably rather positive at the beginning of the treatment. This contrasts with the rather negative attitude found in the focus group study among patients with persisting complaints (Chapter two), which implicates that the patients' attitude is rather positive for initial treatment, but when the complaints are not permanently relieved by the medication the attitude towards medication use becomes more negative.

Furthermore, several patient characteristics were associated with patient adherence, which can give an indication on when to be extra alert for possible non-adherence. For instance, younger patients, male patients, patients with a low educational level, patients who tend to seek distraction, patients who reconcile themselves to having dyspeptic symptoms (a passive coping style), patients who were not satisfied about their last consultation and patients who felt that they did not receive enough information about their treatment were less likely to be adherent. Non-Caucasians or patients with a low educational level might not fully understand the medication instructions, which may lead to errors in usage.

The RCT showed that in the multiple regression analysis no single predictor was significantly correlated with all three adherence outcome measures (self-perceived adherence, pill count, and intake fidelity). This might be due to the fact that the three adherence outcome measures were poorly correlated, indicating again that these three adherence measures reflect different aspects of patient adherence. For instance, being Caucasian was significantly associated with intake fidelity, but not with the 
pill counts. One possible explanation might be that non-Caucasians had difficulties understanding the specific instructions concerning timing and way of intake, but did understand how many pills should be taken. Furthermore, women had higher selfperceived adherence scores than men, but gender was not associated with pill count or intake fidelity. Maybe women gave more socially desirable answers to indicate that they followed the instructions perfectly, but actually used the same number of prescribed pills per day as men, and deviated as often as men from the specific medication instructions.

Several predictors of self-perceived adherence as well as pill counts and intake fidelity were found to be statistically significant in univariate analysis, but not in multiple regression analysis. This can be expected when testing a theoretical model, because some factors might be very strong predictors levelling out other factors. Therefore, the multiple regression analysis was conducted using three blocks: firstly, the distal (predisposing, information, and awareness) factors were entered in the model, secondly the motivational (attitude, social influence and self-efficacy) factors were entered, and thirdly the intention and barriers were entered, resulting in the full model. For instance, in the RCT, forgetfulness was statically significant in the first block predicting self-perceived adherence, but in the second block self-efficacy was probably a stronger predictor and levelled out forgetfulness. Furthermore, it is likely that several factors are inter-correlated. ${ }^{12}$ For example, in the observational study in the univariate analysis self-efficacy explained $19 \%$ of the variance of self-perceived adherence, but in the multiple regression analysis only $3 \%$ of the $44 \%$ explained variance of the full model could be contributed to self-efficacy only and was not explained by other predictors. This indicates that the rest, $16 \%$, might be due to factors closely related to self-efficacy, such as forgetfulness or attributions concerning feeling in control over being adherent. Whether and how predictors are inter-correlated needs to be further investigated.

Several differences between the predictors measured in the observational study and the predictors measured in the RCT were found as summarized in Table 10.1. These differences might explain that a higher explained variance was found in the observational study (44\%) than in the RCT (32\%). Table 10.1 shows that patients in the RCT on average had a lower score for self-perceived adherence than the patients in the observational study. One possible explanation for this difference might be that self-perceived adherence in the RCT was measured at four weeks in most cases, while in the observational study this was measured at two weeks. Patients in the RCT might have stopped their treatment at four weeks, resulting in lower self- 
perceived adherence scores (Table 10.1). This implicates that the theoretical framework is better in predicting short-term self-perceived adherence than 'long'term, but more research is necessary to confirm this.

Other differences in predictors for instance in age and beliefs about necessity of medication might be explained by slight disparity in inclusion and exclusion criteria: in the RCT we specifically recruited patients with a new episode of complaints, and excluded patients who used a prescribed acid-suppressant during the last three months and had an endoscopic investigation during the last year. Patients in the observational study were excluded when they used a prescribed acid-suppressant during one month before inclusion, which probably has resulted in a sample of more chronic users of acid-suppressive medication. Since these differences in patient selection might have resulted in some differences in study results, this implicates that a predictor might be valuable in one situation but less valuable in others. So, in practice GPs carefully need to consider the situation (i.e. first-time users of acidsuppressants or more 'experienced' users) and at least elicit factors associated in the specific situation: for patients with persistent complaints at least elicit their beliefs about necessity or whether they have concerns about using the medication, and for new users at least elicit beliefs about forgetfulness or self-efficacy.

Table 10.1. Differences in scoring between the observational study and the RCT.

\begin{tabular}{|c|c|c|c|}
\hline \multirow{2}{*}{$\begin{array}{c}\text { Factor (scale) } \\
\text { Study }\end{array}$} & \multicolumn{3}{|c|}{ Median/Mean (SD) } \\
\hline & $\begin{array}{c}\text { Observa- } \\
\text { tional }\end{array}$ & $\mathrm{RCT}$ & $\begin{array}{c}\text { p- } \\
\text { value* }\end{array}$ \\
\hline \multicolumn{4}{|l|}{ Adherence outcome measures: } \\
\hline $\begin{array}{l}\text { Self-perceived adherence }(0=\text { not adherent- } 24=\text { perfectly } \\
\text { adherent })\end{array}$ & $22 / 21.12(2.9)$ & $21 / 20.67(2.7)$ & $<0.01$ \\
\hline Pill counts (pills per day, 5 pills/day were prescribed) & NA & $4.2 / 3.93(1.2)$ & - \\
\hline Intake fidelity ( $0=$ not adherent- $9=$ perfectly adherent $)$ & NA & $9 / 8.13(0.9)$ & - \\
\hline \multicolumn{4}{|l|}{ Behavioral factors: } \\
\hline Coffee use $(0=$ no, $1=$ yes $)$ & $1 / 0.87(0.3)$ & $1 / 0.88(0.3)$ & NS \\
\hline Alcohol use $(0=$ no, $1=$ yes $)$ & $1 / 0.68(0.5)$ & $1 / 0.73(0.4)$ & NS \\
\hline Smoking $(0=$ no, $1=$ yes $)$ & $0 / 0.24(0.4)$ & $0 / 0.28(0.5)$ & NS \\
\hline \multicolumn{4}{|l|}{ Psychology or Personality factors: } \\
\hline Forgetfulness $(0=\mathrm{I}$ often forget $-6=\mathrm{I}$ do not forget $)$ & $6 / 5.34(1.4)$ & 6/ $4.91(1.8)$ & $<0.001$ \\
\hline $\begin{array}{l}\text { SCL90: Psycho-neuroticism }(90=\text { no- } 450=\text { severe } \\
\text { dysfunction) }\end{array}$ & NA & $119 / 131(37.7)$ & - \\
\hline UCL: Active coping style (5-20) & NA & $14 / 13.53(2.8)$ & - \\
\hline UCL: Seeking support coping style (5-20) & NA & $11 / 11.26(3.2)$ & - \\
\hline
\end{tabular}


UCL: Avoidance coping style (2-8)

UCL: Palliative coping style (2-8)

UCL: Religious coping style (2-8)

UCL: Passive reaction coping style (1-4)

Health Hardiness (1-3)

\section{Biological factors:}

\begin{tabular}{lccc} 
Gender $(0=$ female) & $0 / 0.42(0.49)$ & $0 / 0.46(0.5)$ & NS \\
Age (years) & $55 / 54(14)$ & $47 / 47(15)$ & $<0.001$ \\
Caucasian $(0=$ no, $1=$ yes) & $\mathrm{NA}$ & $1 / 0.94(0.3)$ & - \\
\hline Social and cultural factors: & & & \\
Educational level $(0=$ no-7=academic) & $3 / 3.18(1.8)$ & $4 / 3.64(1.8)$ & $<0.01$ \\
Living situation $(0=$ without, $1=$ with partner) & $1 / 0.74(0.4)$ & $1 / 0.77(0.4)$ & $\mathrm{NS}$ \\
Irregular working shifts $(0=$ no, $1=$ yes) & $\mathrm{NA}$ & $0 / 0.15(0.4)$ & - \\
\hline Information factors: & & & \\
Enough information received (0=I agree-6=I disagree) & $6 / 5.10(1.7)$ & $6 / 4.70(1.9)$ & $<0.01$ \\
Satisfaction $(0=$ I disagree- $6=\mathrm{I}$ agree $)$ & $6 / 5.23(1.5)$ & $6 / 4.99(1.7)$ & $<0.001$ \\
\hline
\end{tabular}

\section{Awareness factors:}

Severity of complaints (baseline) $(0=$ none- $48=$ very severe)

Health status (baseline) (VAS: $0=$ worst-100=best imaginable)

Co-morbidity $(0=$ no, $1=$ yes $)$

NA $\quad 52 / 54.20(25)$

NA $\quad 1 / 0.69(0.5)$

Attributions: Locus (adherence) $(0=$ extern- $6=$ intern)

Attributions: Controllable (adherence) $(0=$ not controlled-

$6=$ controlled)

$11 / 9.56(3.2)$

6/ $5.13(1.6)$

Attributions: Stable (adherence) $(0=$ stable- $6=$ unstable $)$

$5 / 4.49(1.9)$

Attributions: Locus (cause complaints) $(0=$ extern-

6=intern)

Attributions: Controllable (cause complaints) $(0=$ not controlled $-6=$ controlled)

$3 / 2.59(1.8)$

$4 / 4.42(3.3)$

$$
3 / 2.38 \text { (1.7) }
$$

Attributions: Stable (cause complaints) $(0=$ stable-

$6=$ unstable)

$5 / 4.11(1.8) \quad 4 / 4.08(1.5) \quad$ NS

\begin{tabular}{|c|c|c|c|}
\hline \multicolumn{4}{|l|}{ Motivational factors: } \\
\hline Attitude: Necessity of medication $(0=$ no- $30=$ necessary $)$ & $12 / 12.98(8.4)$ & $8 / 9.25(7.5)$ & $<0.001$ \\
\hline Attitude: Concerns $(0=$ no- $60=$ great concerns $)$ & $20 / 20.37(11)$ & $22 / 21.97(10)$ & $<0.05$ \\
\hline Social influence $(0=$ no support- $18=$ fully supported $)$ & $15 / 13.7(4.3)$ & $15 / 13.83(4.3)$ & NS \\
\hline Self-efficacy $(0=$ no self-efficacy- $24=$ high self-efficacy $)$ & $21 / 18.64(6.4)$ & $18 / 17.27(6.4)$ & $<0.01$ \\
\hline \multicolumn{4}{|l|}{ Intention: } \\
\hline Intention ( $0=$ no intention- $12=$ high intention $)$ & $12 / 11.58(1.5)$ & $12 / 11.41(1.6)$ & $<0.01$ \\
\hline \multicolumn{4}{|l|}{ Barriers: } \\
\hline Symptom relief ( 2 weeks $)(0=$ no, $1=$ yes $)$ & NA & $1 / 0.60(0.5)$ & - \\
\hline Side effects during medication step $1(0=$ no, $1=$ yes $)$ & NA & $0 / 0.21(0.4)$ & - \\
\hline
\end{tabular}

*The differences between the observational study and the RCT were tested with a Wilcoxon rank test. 


\section{Communication between GP and patients: which instructions are provided?}

Besides patient related factors also the education by the GP can play an important role in patient adherence. We conducted a survey among the GPs participating in the RCT was used to investigate what medication and lifestyle instructions GPs provided in the case of dyspepsia. ${ }^{16}$ In the case of a first episode of dyspepsia $73 \%$, $69 \%$ and $60 \%$, respectively, of the GPs reported (almost) always to provide advices concerning alcohol use, smoking and nutrition. This contrasts with our finding that only one in ten patients participating in the RCT reported to have received lifestyle advice (unpublished data). GPs reported to virtually always instruct patients on the frequency, dose and treatment duration of the acid-suppressive medication, but they reported to pay less attention to timing and way of intake. Although several patients with a first episode of dyspeptic complaints omitted doses probably due to on demand use (as indicated in Chapter eight), three quarter of the GPs never advised to take acid-suppressive medication on an on demand basis. Only some GPs used written materials to support their instructions and lifestyle advices, and about half of the GPs usually asked patients whether they used the medication as prescribed.

These findings implicate another contrast between the GP's perspective and the patient's perspective: patients say that they did not receive any lifestyle advice, while GPs often report to provide these advices. And although GPs do not advice to use the medication on demand for a first episode of complaints, patients seem to use the medication on demand anyway. One possible explanation for this contrast is that the recommendations of the GPs are not completely clear to the patients. This implicates that when GPs want patients to adhere to their recommendations the communication needs to improved: explicitly explain to the patient why it is needed to take the medication on a daily base for a short period at the instructed time instead of on demand, always use written supportive materials, and always check how the medication was taken at the follow-up consultation. This offers the opportunity to give positive feedback when the patient was adherent, and provides vital information on the possible causes of why the complaints persist. Of course, based on literature, ${ }^{20-22}$ it is assumed that in the case of newly diagnosed dyspepsia, improving the provider-patient communication can improve patient adherence but this needs to be confirmed by further investigations. 


\subsection{Limitations and strengths}

One limitation of this thesis is that it merely focused on patient related factors of adherence. The influence of other factors like the interaction between GP and patients on patient adherence to prescribed dyspepsia medication is still largely unknown. Furthermore, the reliability and validity of adherence outcome measures and measurements of determinants needs to be further investigated. Validated questionnaires were used (e.g. the SCL90, ${ }^{23}$ the Utrecht Coping List, ${ }^{24}$ the EUROQoL, ${ }^{25}$ and the Beliefs about Medicine Questionnaire ${ }^{26}$ ). The absence of a singular conceptual basis of medication adherence is problematic and the assessment of adherence is a complex task. ${ }^{13}$ Concerning the reliability of the pill counts, the number of remaining pills reflects the number of pills used. This could be determined very accurately by counting the pills by two independent researchers, although it is not possible to say whether the pills were actually used by the patients. To reliable determine the number of pills used per day, besides accurate pill counts, accurate measurements of treatment duration are necessary. Despite several efforts to retrieve an accurate measure, it is possible that the treatment duration is overestimated in some cases (e.g. when a patient stopped treatment early but did not report this), which may have resulted in underestimation of adherence rates (i.e. pills counts present the number of pills used per treatment day). On the other hand, several patients did not return their medication jars, maybe because they were nonadherent, which leads to an overestimation of adherence in our patient sample in comparison to adherence in every day practice. The self-reported measures of adherence (self-perceived adherence and intake fidelity) might be biased by social desirability and require adequate awareness of the patient concerning his/her own medicine taking behaviour.

One of the strengths of this thesis is that it discusses several aspects of the patient's perspective on the management of dyspepsia, presenting a broad view on this relatively unknown research area. Furthermore, this thesis provides insight in several research populations, using and comparing observational and experimental research designs. Various patient adherence outcome measures were used, which enabled a comparison of these measures as advocated by DiMatteo. ${ }^{27}$ Moreover, the thesis shows that it can be valuable to combine several additional research questions into one trial and to make efficient use of the data, although some adjustments in the desired research design then need to be taken into account (e.g. the influence of placebo on the adherence to active pills). 


\subsection{Key Messages}

- There is a discrepancy between the patient's perspective (e.g. patient expectations, perception of the severity of dyspeptic complaints) and the GP's perspective which can lead to patient non-adherence and dissatisfaction with health care. Improving the communication between GPs and patients might reduce this discrepancy.

- Optimal adherence is required when acid-suppressants are used as a diagnostic tool. Since the chance of reaching optimal adherence to four times daily pills for more than two weeks treatment is relatively low, it is advocated to prescribe once daily pills for two weeks when optimal adherence is required.

- The most important predictors of patient adherence in the case of newly diagnosed dyspepsia are self-efficacy (i.e. the feeling that one is capable of following medication instructions) and forgetfulness. Therefore, before prescribing GPs need to elicit whether patients expect to experience difficulties in taking the acid-suppressants. Looking for solutions to overcome this problem (e.g. using reminders or storing PPIs next to an alarm clock) may prevent suboptimal adherence.

- The most common forms of non-adherence or partial adherence in the case of newly diagnosed dyspepsia are omitting doses or incorrect timing of intake. It should be checked at follow-up consultation whether doses were omitted or timing errors were made, especially when the complaints persist. The easiest way is to ask specific questions keeping in mind the possibility that patients are not fully aware of their own medicine-taking behaviour or give socially desirable answers. For research, to be able to evaluate patient adherence, several adherence outcome measures need to be used, since the measures are not interchangeable and all reflect other aspects of the complex medicine-taking behaviour.

- Although blinding treatment allocation is important to increase the internal validity of pragmatic RCTs, it decreases the external validity. One important consequence of blinding treatment allocation by adding placebos to the active pills was that the additional pills can have lowered the adherence rates of the active pills in comparison to every day practice. 


\subsection{Recommendations}

\section{General practice}

This thesis identified a number of problems in the (initial) treatment of patients with dyspepsia for instance patient expectations contrasting with reality, low agreement on severity of complaints between GP and patients and low patient adherence. Possible solutions for these problems might be found in simplifying treatment regimens and improving communication between GPs and patients.

As complex medication regimens with multiple dosing for a longer period have proven to reduce adherence rates, ${ }^{28-30}$ prescribed acid-suppressant regimens for a new episode of dyspepsia need to be as simple as possible. Therefore, we recommend to prescribe a once daily acid-suppressant (PPI) for a short period to optimize the chance that a patient is perfectly adherent.

Furthermore, effective communication can improve adherence ${ }^{11,31}$ by a) increasing patient knowledge and understanding, b) changing patient beliefs and attitudes, and c) increasing patient motivation by encouraging patients to actively participate in their health care. ${ }^{1}$ Several publications are available on improving provider-patient communication. For instance Alexander ${ }^{1}$ summarizes commonly recommended strategies to increase patient knowledge, to change patient beliefs and attitudes, and to increase patient motivation. Based on the results in this thesis it is especially important to elicit patients' self-efficacy and other expected problems in taking acidsuppressants according to the instructions. Furthermore, GPs should be extra alert on suboptimal adherence in younger patients, males, non-Caucasians, patients with a low educational level, patients who tend to seek distraction, patients who reconcile themselves to having dyspeptic symptoms (a passive coping style), patients who are not satisfied about their last consultation, and patients who felt that they did not receive enough information about their treatment.

\section{Future research}

This thesis showed that several adherence outcome measures were correlated, but it is still unclear in what way. Furthermore, measuring adherence in general practice as well as in research needs to be further improved by developing valid measures applicable in practice and getting more insight in the validity of adherence outcome measures. Moreover, the theoretical framework can be improved for instance by determining how the predictors are inter-correlated or by determining the influence of patient-physician interaction on patient adherence to prescribed acid-suppressive 
medication. Additionally, in this thesis it is recommended that simplifying treatment and improving communication increases the likelihood of reaching optimal adherence in the case of newly diagnosed dyspepsia. This needs to be confirmed in a pragmatic trial, to see if it is possible to improve provider-patient communication and to study what the effects of simplifying treatment and interventions to improve communication are on adherence, symptom relief, patient satisfaction, treatment course and costs of health care in every day practice.

\section{References}

1. Alexander SA, Sleath B, Golin CE, Kalinowski CT. Provider-patient communication and treatment adherence. In Patient treatment adherence. Concepts, interventions, and measurement. Edited by Bosworth HB, Oddone EZ, Weinberger M. Mahwah, New Jersey: Lawrence Erlbaum Associates, Inc; 2006: 329-72.

2. Brown JB, Stewart M, Ryan B. Outcomes of patient-provider interaction. In Handbook of health communication. Edited by Thompson TL, Dorsey AM, Miller KI, Parrott R. Mahwah, NJ: Lawrence Erlbaum Associates, Inc; 2003: $141-61$.

3. Dutta-Bergman MJ. The relation between health-orientation, provider-patient communication, and satisfaction: an individual-difference approach. Health Commun 2005, 18: 291-303.

4. Golin CE, DiMatteo MR, Gelberg L. The role of patient participation in the doctor visit. Implications for adherence to diabetes care. Diabetes Care 1996; 19: 1153-64.

5. Kaplan SH, Greenfield S, Ware JE, Jr. Assessing the effects of physicianpatient interactions on the outcomes of chronic disease. Med Care 1989; 27: S110-S127.

6. Roter DL, Stewart M, Putnam SM, Lipkin M, Jr., Stiles W, Inui TS. Communication patterns of primary care physicians. JAMA 1997; 277: 350-6.

7. Stewart M, Brown JB, Donner A, McWhinney IR, Oates J, Weston WW, et al. The impact of patient-centered care on outcomes. J Fam Pract 2000; 49: 796804.

8. The Dutch Institute for Healthcare Improvement (CBO), Dutch College of General Practitioners (NHG). Multidisciplairy Guideline Stomachcomplaints 
(Multidisciplinaire Richtlijn Maagklachten). 2004. Alphen aan den Rijn, Van Zuiden Communications.

9. Muris JW, Starmans R, Fijten GH, Knottnerus JA. One-year prognosis of abdominal complaints in general practice: a prospective study of patients in whom no organic cause is found. Br J Gen Pract 1996; 46: 715-9.

10. Quartero AO, Numans ME, Post MW, de Melker RA, de Wit NJ. One-year prognosis of primary care dyspepsia: predictive value of symptom pattern, Helicobacter pylori and GP management. Eur J Gastroenterol Hepatol 2002; 14: 55-60.

11. Butler CC, Rollnick S. Compliance. London: Elsevier Limited; 2004.

12. Meichenbaum D, Turk DC. Factors affecting adherence. In Facilitating treatment adherence. A practitioner's guidebook. Edited by Meichenbaum D, Turk DC. New York: Plenum Press; 1987:41-70.

13. Bosworth HB. Medication treatment adherence. In Patient treatment adherence. Concepts, interventions and measurement. Edited by Bosworth HB, Oddone EZ, Weinberger M. New Jersey: Lauwrence Erlbaum Associates Inc.; 2006.

14. Rudd P. Clinicians and patients with hypertension: unsettled issues about compliance. Am Heart J 1995; 130: 572-9.

15. Howden CW, Chey WD. Gastroesophageal reflux disease. J Fam Pract 2003; 52: 240-7.

16. Fransen GAJ, Mesters I, Van Marrewijk CJ, Mujakovic S, Knottnerus JA, Muris JWM. Leefstijladviezen, medicatie-instructies en het belang van therapietrouw bij maagklachten. [Lifestyle changes, medication instructions and the importance of adherence in case of dyspepsia]. Huisarts Wet 2007; 50: 44652

17. Krol N, Muris JW, Schattenberg G, Grol R, Wensing M. Use of prescribed and non-prescribed medication for dyspepsia. Scand J Prim Health Care 2004; 22: 163-7.

18. Van Soest EM, Siersema PD, Dieleman JP, Sturkenboom MC, Kuipers EJ. Persistence and adherence to proton pump inhibitors in daily clinical practice. Aliment Pharmacol Ther 2006; 24: 377-85.

19. Nederlands Huisartsen Genootschap NHG. NHG Standaard Maagklachten. http://nhg.artsennet.nl/upload/104/standaarden/M36/start.htm.

20. Haynes RB, McKibbon KA, Kanani R. Systematic review of randomised trials of interventions to assist patients to follow prescriptions for medications. Lancet 1996; 348: 383-6. 
21. Haynes RB, McDonald H, Garg AX, Montague P. Interventions for helping patients to follow prescriptions for medications. Cochrane Database Syst Rev 2002, CD000011.

22. Roter DL, Hall JA, Merisca R, Nordstrom B, Cretin D, Svarstad B. Effectiveness of interventions to improve patient compliance: a meta-analysis. Med Care 1998; 36: 1138-61.

23. Arrindell WA, Ettema JHM. SCL-90: manual for a multidimensional psychopathologic indicator [SCL-90: handleiding bij een multidimensionele psychopathologie-indicator]. Lisse: Swets Test Service; 1986.

24. Scheurs P, Van De Willige G, Brosschot J, Tellegen B, Graus G. De Utrechtse Coping Lijst (Utrecht Coping Questionnaire). Lisse: Swess and Zeitlinger; 1993.

25. Brazier J, Jones N, Kind P. Testing the validity of the Euroqol and comparing it with the SF-36 health survey questionnaire. Qual Life Res 1993; 2: 169-80.

26. Horne R, Weinman J. Patients' beliefs about prescribed medicines and their role in adherence to treatment in chronic physical illness. J Psychosom Res 1999; 47: 555-67.

27. DiMatteo MR. Variations in patients' adherence to medical recommendations: a quantitative review of 50 years of research. Med Care 2004; 42: 200-9.

28. Demyttenaere K. Compliance during treatment with antidepressants. J Affect Disord 1997; 43: 27-39.

29. Eldred LJ, Wu AW, Chaisson RE, Moore RD. Adherence to antiretroviral and pneumocystis prophylaxis in HIV disease. J Acquir Immune Defic Syndr Hum Retrovirol 1998; 18: 117-25.

30. Gatley MS. To be taken as directed. J R Coll Gen Pract 1968; 16: 39-44.

31. Dowell J, Jones A, Snadden D. Exploring medication use to seek concordance with 'non-adherent' patients: a qualitative study. Br J Gen Pract 2002; 52: 24-32. 
Dyspepsia in primary care: patient expectations, symptoms, and treatment adherence 


\section{Summary and conclusions}

This thesis reports on several aspects of dyspepsia and the initial management of newly diagnosed dyspepsia from the patient's point of view. 'A patient with newly diagnosed dyspepsia' was defined as 'a patient with dyspeptic symptoms who did not use any prescribed medication for dyspepsia during the last three months, and who had not had any diagnostic investigations during the last year'. For such patients, medical guidelines recommend to provide lifestyle advice and to prescribe short-term treatment with acid-suppressive medication such as antacids, H2-receptor antagonists (H2-RAs) or proton pump inhibitors (PPIs). This acid-suppressive medication is often used as a diagnostic aid: symptom relief increases the likelihood that the complaints are acid-related. But when symptoms are not relieved, the diagnosis needs to be reconsidered, which often results in referral for further diagnostic evaluation (usually endoscopy).

In Chapter one the studies presented in this thesis are introduced. An important part of this thesis focuses on patient adherence to prescribed acid-suppressive medication. Optimal adherence is required when these drugs are used as a diagnostic tool. Otherwise a lack of effect may be due to non-adherence. However, several studies show disappointing adherence rates. To be able to improve this insight is needed in the determinants of patient adherence to prescribed acid-suppressants. A theoretical framework was developed using literature and psychosocial models such as the I Change model and the Weiner's Attribution theory to hypothesize which patient related factors are likely to determine patient adherence. The core concepts in the model are intention to be adherent, attitude (necessity of and concerns about medication use), social influence, and self-efficacy.

In Chapter two the findings of a focus group study are described. This study aimed to investigate patient expectations and perceptions regarding dyspepsia and dyspepsia management of patients with persistent dyspeptic complaints for whom the cause of the complaints was unknown. The results showed that patients expected that the acid-suppressive medication prescribed would relief their complaints rather than just suppress them. Furthermore, they expected that the underlying cause of the symptoms would be investigated and could be identified by careful diagnostic investigations. Additionally, they thought that permanently using acid-suppressants would disguise the real problem. 
These expectations are in contrast with current medical views advocating empirical treatment and reserving immediate investigation only for elderly patients and those with alarm symptoms. This is based on the fact that in most patients with dyspeptic symptoms no apparent cause will be found during diagnostic investigations. The discrepancy between patient expectations and current medical views regarding the treatment of dyspeptic symptoms is important; when patient expectations are not fulfilled, this is likely to lead to low patient satisfaction and non-adherence.

Moreover, the focus group participants were afraid that gastro-oesophageal cancer would be missed. Usually, the presence of alarm symptoms (e.g. weight loss, signs of upper gastrointestinal bleeding, dysphagia, persisting vomiting) is used as an indication for a higher risk for upper gastrointestinal cancer. Therefore, the presence of alarm symptoms is supposed to lead to immediate endoscopic investigation. However, the predictive value of alarm symptoms is by no means clear. In Chapters three and four the predictive value of alarm symptoms for upper gastrointestinal cancer is further investigated by means of systematical review and meta-analysis of the existing literature on the topic. The first study included both case-series and cohort studies in a meta-analysis, in the second study the cohort studies were analyzed in more detail by means of an individual patient data analysis. Both studies showed that the value of alarm symptoms for predicting the presence of upper gastrointestinal cancer is limited: approximately a third of the patients diagnosed with cancer did not have any alarm symptom, while only a small number of the patients with alarm symptoms actually had cancer. This implicates that besides alarm symptoms other factors, such as age, should be taken into account in the difficult task to find patients with upper gastrointestinal cancer.

The focus group study also showed that several patients thought that their general practitioners (GPs) did not take their complaints seriously. To know whether GPs score the severity of dyspeptic complaints in the same degree as patients do, the interrater agreement between GP and patient on the severity of the patient's dyspeptic complaints was investigated in Chapter five. Both GPs and patients were asked to fill out a similar questionnaire measuring the patient's severity of eight upper gastrointestinal complaints on a seven-point Likert scale, at the same moment in time, both before and after PPI-treatment. The weighted kappa values indicated poor to moderate agreement. Several systematic differences in scoring were found: in comparison to patients GPs tended to underestimate the severity of belching, 
nausea, early satiety, vomiting, upper and lower abdominal pain. Furthermore, GPs were more optimistic than patients about the treatment results for belching and lower abdominal pain, but less optimistic about the treatment result for nausea. These findings implicate that the GP-patient communication on the severity of dyspeptic complaints can be improved. Furthermore, when the severity of dyspeptic complaints is assessed in research, that it is important to report who is assessing the symptoms and/or to assess both perspectives.

Chapter six reports on a prospective study, which aimed to investigate which patient related factors determine patient adherence to prescribed acid-suppressants (PPIs) for dyspepsia. Chronic users were excluded (i.e. patients who used prescribed acidsuppressants during the last month). The theoretical framework was used to predict self-perceived adherence, which was reported by patients after two weeks of treatment. Approximately one quarter of the patients indicated being non-adherent $(\mathrm{N}=347)$. Multiple linear regression analyses revealed several significant predictors that explained $44 \%$ of the variance in self-perceived adherence. Patients with a low educational level, patients who claimed to regularly forget their medication in general, patients with a low self-efficacy, or a low intention were less likely to be adherent. These results might indicate targets for interventions aimed at improving adherence to medical treatment for dyspepsia. For instance, asking about expected difficulties in taking acid-suppressants (e.g. forgetfulness or medication use during weekends) and making action plans to overcome these difficulties (e.g. using reminders) might result in improved adherence rates. This might improve adherence rates in a substantial number of patients, since one out of five patients experienced some difficulties in taking medication.

Chapter seven presents a reflection on designing and conducting a pragmatic randomised trial in primary care. This chapter explains the design of the DIAMOND-study and the rationale behind the choices made. The primary aim of the DIAMOND-study was to investigate the (cost-)effectiveness of two treatment strategies for newly diagnosed dyspepsia: 'step-up' treatment or 'step-down' treatment. 'Step-up' treatment meant that the patient started with an antacid (four times daily) in treatment step 1, and if the complaints persisted or recurred within four weeks, treatment step $2\left(\mathrm{H}_{2}\right.$-receptor antagonist, twice daily) was started. Subsequently, if the complaints persisted or recurred after this step, treatment step 3 was started (PPI once daily). In the 'step-down' treatment patients started with a 
PPI, followed if necessary by a $\mathrm{H}_{2}$ receptor antagonist and subsequently an antacid in treatment step 3. To blind treatment allocation, placebo pills were added in treatment step 1 and 3, resulting in an instruction to take five pills per day (either four tablets of antacid pills plus one tablet of placebo PPI or four tablets of placebo antacid plus one tablet of PPI). All treatment steps lasted maximally 30 days. In this thesis the data from the DIAMOND-study were used to investigate patient adherence and the determinants of patient adherence.

Chapter eight describes the patient adherence in the DIAMOND-study $(\mathrm{N}=653)$, reporting on the completeness (i.e. the number of pills used per day measured by pill counts) and on intake fidelity (i.e. how the medication was taken concerning timing, way of intake, dosing, etc. measured by self-reports). No relevant differences in patient adherence were found between the two treatment arms. In treatment step 1, patients used on average 3.9 pills/day (78\% of the prescribed dose), in step 21.7 pills/day ( $84 \%$ of the prescribed dose) and in step 33.6 pills/day (72\% of the prescribed dose). For the four times daily pills, half of the patients used less than $80 \%$ of the prescribed pills per day. This was one third for the twice daily pills and one quarter for the once daily pills. There were no differences between active or placebo medication.

The completeness for the four times daily pills was significantly lower than for the pills to be used once or twice daily. Concerning intake fidelity, $70 \%$ of the patients made one or more errors in the medication intake. The most common errors were made in the frequency of intake and in timing in relation to meals. These results implicate that there is room for improvement of adherence rates. To increase the chance of optimal adherence one can probably best prescribe once daily pills for a short treatment period.

In Chapter nine the theoretical framework was tested in the DIAMOND-population. The aim of the prospective study was to determine which patient related factors are associated with 1) completeness (i.e. the number of pills used per day), 2) intake fidelity (i.e. how the medication was taken concerning timing, way of intake, dosing, etc.), and 3) self-perceived adherence (i.e. the patient's perception of the degree to which he/she was adherent). The determinants in the theoretical framework were measured before or during treatment and the three adherence outcome measures after treatment. The study showed that the three adherence outcomes poorly correlated. Intention, self-efficacy, social influence, age, and forgetfulness were 
significantly correlated with both self-perceived adherence and pill counts in univariate analyses. In multiple regression analysis, the theoretical model best predicted self-perceived adherence, with an explained variance of $32 \%$. This analysis showed that patients with a passive reaction coping style (i.e. reconcile oneself to the situation), patients with a palliative coping style (i.e. seek distraction), and patients with a low self-efficacy (i.e. presuming not to be able to follow the instructions) were less likely to be adherent. Concerning completeness, the results showed that younger patients and patients who had more concerns about using medication used fewer pills per day. Concerning intake fidelity, men, nonCaucasians and patients without side effects were less likely to be adherent.

The last chapter, the general discussion, summarizes the main findings of this thesis and their implications, together with a brief reflection on the limitations and strengths of this thesis and recommendations for general practice and future research. 
Dyspepsia in primary care: patient expectations, symptoms, and treatment adherence 


\section{Samenvatting en conclusies}

Dit proefschrift bekijkt verschillende aspecten van dyspepsie (maagklachten) en de behandeling van patiënten met nieuwe dyspeptische klachten. 'Een patiënt met nieuwe dyspeptische klachten' is gedefinieerd als 'een patiënt met dyspeptische klachten die gedurende de laatste drie maanden geen voorgeschreven medicatie voor dyspepsia heeft gebruikt en die geen aanvullend onderzoek betreffende zijn dyspeptische klachten heeft gehad gedurende het laatste jaar'. De medische richtlijnen raden aan zulke patienten leefstijladviezen te geven en te behandelen met een korte kuur maagzuurremmende medicijnen, zoals antacida, $\mathrm{H}_{2}$-receptor antagonisten $\left(\mathrm{H}_{2} \mathrm{RAs}\right)$ of proton pomp remmers (PPIs). Deze zuurremmende medicatie wordt vaak gebruikt als een diagnostisch hulpmiddel: als de klachten goed reageren op de behandeling is de kans groter dat de klachten zuurgerelateerd zijn, als ze niet goed reageren moet de diagnose worden heroverwogen, hetgeen vaak leidt tot aanvullende diagnostiek (meestal d.m.v. gastroscopie).

Een groot deel van dit proefschrift gaat over het opvolgen van medicatie-instructies ofwel therapietrouw met voorgeschreven zuurremmende medicijnen. Als de zuurremmende medicijnen worden gebruikt in het kader van diagnostiek en het plannen van toekomstige behandeling, is optimale therapietrouw van belang: anders is het onzeker als de klachten aanhouden of dit komt door het niet of gedeeltelijk opvolgen van medicatie-instructies of doordat de behandeling niet werkt. Helaas laten verschillende onderzoeken zien dat de therapietrouw van veel patiënten teleurstellend is. Om de therapietrouw te kunnen verbeteren is het belangrijk om inzicht te krijgen determinanten van therapietrouw betreffende voorgeschreven zuurremmers. In hoofdstuk één staat een theoretisch raamwerk beschreven dat gebruikt is in twee studies om in kaart te brengen welke patiënt-gerelateerde factoren waarschijnlijk therapietrouw bepalen. Dit theoretische raamwerk is ontwikkeld op basis van literatuur en psychosociale modellen zoals het I Change Model en de Attributietheorie van Weiner. De kernconcepten in dit raamwerk zijn: de intentie om therapietrouw te zijn, de attitude (opvattingen over de voor- en nadelen van het gebruik van medicijnen), sociale invloed (bijvoorbeeld verwachte steun van omgeving bij medicatiegebruik), en eigen-effectiviteit (vertrouwen dat het lukt om medicatie-instructies op te volgen).

In hoofdstuk twee worden de resultaten van een focusgroep studie beschreven. Het doel van deze studie was om de verwachtingen en percepties van patiënten 
betreffende dyspepsie en de behandeling ervan te exploreren. Het betrof patiënten met aanhoudende dyspeptische klachten waarvan de oorzaak niet bekend was. De studie laat zien dat de geïnterviewde patiënten verwachtten dat de voorgeschreven medicatie hun dyspepsia geneest, en niet alleen maar tijdelijk hun klachten zou onderdrukken. Bovendien verwachtten ze dat er zou worden gezocht naar de oorzaak van hun klachten, en dat die oorzaak ook zou kunnen worden gevonden als er maar goed zou worden gezocht. Verder dachten ze dat chronisch gebruik van zuurremmers de echte oorzaak van de klachten zou verhullen.

Deze verwachtingen contrasteren bij de huidige medische visie, waarbij veel patiënten worden behandeld zonder nader onderzoek, en directe gastroscopie wordt gereserveerd voor oudere patiënten en patiënten met alarmsymptomen. Deze medische visie is gebaseerd op het feit dat bij nader onderzoek vaak geen duidelijke oorzaak gevonden wordt en het merendeel van de patiënten goed reageert op maagzuurremmende medicatie. De discrepantie tussen de patiëntenverwachtingen en de medische visie is zorgelijk, omdat niet waargemaakte verwachtingen kunnen leiden tot een lagere patiënttevredenheid en therapie-ontrouw.

Verder waren de patiënten uit de focusgroep studie bang dat hun klachten veroorzaakt werden door kanker van de maag of slokdarm en dat dit over het hoofd zou worden gezien. Om patiënten met een hoog risico op maag- of slokdarmkanker op te sporen wordt vaak gebruik gemaakt van de zogenaamde alarmsymptomen (zoals afvallen, bloedbraken, teerzwarteontlasting, het slecht passeren van voedsel door de slokdarm en aanhoudend braken). Als er alarmsymptomen zijn wordt verondersteld dat er meteen een gastroscopie moet worden verricht. Echter de daadwerkelijke voorspellende waarde van alarmsymptomen is onduidelijk. In hoofdstuk drie en vier wordt de voorspellende waarde van alarmsymptomen voor maag- en slokdarmkanker onderzocht in meta-analyses van de bestaande studies over dit thema. In hoofdstuk drie worden zowel series van patiënten met maag- en slokdarmkanker als cohorten endoscopie-patiënten (waarvan slechts een klein deel maag- of slokdarmkanker heeft) betrokken in een meta-analyse. In hoofdstuk vier worden de cohorten in meer detail onderzocht door meta-analyse van de oorspronkelijke gegevens van de individuele patiënten. Beide studies laten zien dat de waarde van alarmsymptomen voor het voorspellen van maag- of slokdarmkanker beperkt is: ongeveer een derde van de patiënten met kanker van de maag/slokdarm heeft geen enkel alarmsymptoom, terwijl van de patiënten met alarmsymptomen slechts een enkeling kanker van de maag of slokdarm heeft. Dit impliceert dat naast 
alarmsymptomen andere factoren zoals leeftijd moeten worden betrokken bij de moeilijke taak om de patiënten met maag/slokdarmkanker eruit te pikken.

Uit de focusgroep studie bleek ook dat verscheidene patiënten vonden dat hun huisarts hun klachten niet serieus nam. Om uit te zoeken of huisartsen de dyspeptische klachten van hun patiënten net zo ernstig inschatten als de patiënten zelf, is in hoofdstuk vijf de overeenkomst tussen de scores van huisartsen en de scores van patiënten voor de ernst van de symptomen van de patient onderzocht. Zowel huisartsen als patiënten werd gevraagd om dezelfde vragenlijst in te vullen waarin de ernst van acht dyspeptische symptomen kan worden aangegeven op een schaal van 0-6. De vragenlijsten werden op hetzelfde moment ingevuld, zowel voor als na behandeling met een proton pomp remmer. De gewogen kappa's gaven aan dat er sprake was van slechte tot matige overeenstemming in symptoomscores. Er werden verscheidene systematische verschillen gevonden tussen de scores: zo neigden de huisartsen ertoe om de ernst van boeren, misselijkheid, snel een vol gevoel hebben, braken, maagpijn en buikpijn lager te scoren. Bovendien waren huisartsen optimistischer dan patiënten over het behandelresultaat voor boeren en buikpijn, en minder optimistisch over het behandelresultaat voor misselijkheid. Deze bevindingen suggereren dat er ruimte is voor verbetering van de huisarts-patiënt communicatie over de ernst van dyspeptische klachten. Bovendien geven de resultaten aan dat het belangrijk is om in onderzoeken altijd te vermelden wie de ernst van de symptomen heeft ingeschat, ofwel de scores van zowel patiënt als huisarts te vermelden.

In hoofdstuk zes wordt een observationele prospectieve studie beschreven waarin onderzocht wordt welke patiëntgerelateerde factoren bepalen of patiënten therapietrouw zijn in het gebruik van een PPI bij dyspeptische klachten. Chronische gebruikers (patiënten die gedurende de maand voor inclusie al een PPI gebruikten) werden geëxcludeerd. Het (eerder genoemde) theoretisch model werd gebruikt om de 'self-perceived adherence' (d.w.z. de perceptie van de patiënt over in welke mate hij/zij de medicatie-instructie gevolgd heeft) te voorspellen: de determinanten werden voor de behandeling gemeten en 'self-perceived adherence' na 2 weken behandeling met een PPI. Ongeveer een kwart van de patiënten gaf aan niet of slechts gedeeltlijk therapietrouw te zijn $(\mathrm{N}=347)$. Uit de multipele lineaire regressie analyse kwamen verscheidene significante voorspellers, die samen $44 \%$ van de variantie in de 'self-perceived adherence' verklaarden. Patiënten met een laag 
opleidingsniveau, patiënten die beweerden in het algemeen regelmatig hun medicijnen te vergeten, met een lage eigen-efectiviteit of een lage intentie bleken minder vaak therapietrouw te zijn. Deze resultaten kunnen worden gebruikt om interventies gericht op het verbeteren van therapietrouw bij dyspepsie vorm te geven. Wellicht zou therapietrouw verbeterd kunnen worden door vóór de behandeling te vragen naar door de patiënt verwachte problemen bij het innemen van zuurremmers (bijv. vergeetachtigheid, of problemen in de weekenden), zodat actieplannen kunnen worden gemaakt om deze problemen te voorkomen (bijv. met reminders). Maar liefst een op de vijf mensen gaf aan problemen te ervaren met medicatiegebruik, het navragen van verwachte problemen kan dan snel veel mensen identificeren die een hogere kans hebben op therapie-ontrouw en mogelijkheden geven om dit te voorkomen.

In hoofdstuk zeven worden overwegingen besproken bij het opzetten en uitvoeren van praktijkgerichte gerandomiseerde studies in de eerstelijnszorg. In dit hoofdstuk wordt het ontwerp van de DIAMOND-studie toegelicht, alsmede de overwegingen bij de gemaakte keuzes. Het hoofddoel van de DIAMOND-studie was het vergelijken van de (kosten-)effectiviteit van twee behandelstrategieën voor patiënten met een nieuwe episode van maagklachten: 'step-up' of 'step-down' behandeling. 'Step-up' behandeling houdt in dat de patiënt start met een antacidum (4 keer per dag; stap 1), als de klachten aanhouden, of binnen vier weken terugkomen gevolgd door stap 2 (een $\mathrm{H}_{2}$-receptor antagonist, twee keer daags), zo nodig gevolgd door stap 3 ( 1 keer daags een proton pomp remmer). In de 'step-down' behandeling werd gestart met de proton pomp remmer, zo nodig gevolgd door de $\mathrm{H}_{2}$-receptor antagonist, op zijn beurt zo nodig gevolgd door het antacidum. Om de behandelstrategieën te blinderen werden placebo's toegevoegd aan stap 1 en stap 3, waardoor in die stappen in totaal 5 pillen per dag moesten worden ingenomen (ofwel 4 tabletten antacidum plus tablet 1 placebo-PPI, ofwel 4 tabletten placebo-antacidum plus een tablet PPI). Alle behandelstappen duurden maximaal 30 dagen. In dit proefschrift worden de gegevens van de DIAMOND-studie gebruikt om therapietrouw en de determinanten daarvan te onderzoeken.

In hoofdstuk acht wordt therapietrouw in de DIAMOND-studie beschreven $(\mathrm{N}=653)$ door middel van twee maten voor therapietrouw: 'completeness' (het aantal pillen genomen per dag) en 'intake fidelity' (hoe de medicatie werd genomen: wanneer, manier van inname, dosering, enz.). Er werden geen belangrijke verschillen 
gevonden in therapietrouw tussen de twee behandelstrategieën. In behandelstap 1 werden gemiddeld 3.9 tabletten per dag ingenomen (dit is $78 \%$ van het voorgeschreven aantal per dag), in stap 21.7 tabletten/dag (84\% van het voorgeschreven aantal), en in stap 33.6 pillen/dag (72\% van het voorgeschreven aantal). De helft van de patiënten nam minder dan $80 \%$ per dag in van de 4 keer daags voorgeschreven pillen. Dit was een derde voor de tabletten die twee keer daags werden voorgeschreven en een kwart voor de pillen die 1 keer daags moesten worden gebruikt. The 'completeness' was voor de vier keer daags te gebruiken pillen significant slechter dan voor de een of twee keer daags te gebruiken pillen.

Wat betreft 'intake fidelity' maakte $70 \%$ van de patiënten een of meer fouten bij het innemen van de medicijnen. De meest fouten werden gemaakt bij de tijdstip van inname in relatie tot de maaltijd (voor of na het eten) en het aantal pillen per dag.

Deze studie laat zien dat therapietrouw met voorgeschreven maagzurremers voor een eerste episode van dyspeptische klachten laag is. Om therapietrouw te verbeteren kan men het best pillen voorschrijven die slechts één keer daags hoeven te worden gebruikt gedurende een korte periode.

In hoofdstuk negen is het theoretisch model gebruikt in de DIAMOND-populatie om te onderzoeken welke patiënt-gerelateerde factoren geassocieerd zijn therapietrouw. De patient-gerelateerde factoren werden gemeten voor de behandeling, en therapietrouw werd gemeten tijdens en na behandelingstap 1. Het model werd drie keer gebruikt namelijk met drie verschillende afhankelijke variabelen: 1) 'completeness', 2) 'intake fidelity' en 3) 'self-perceived adherence'. Deze drie maten voor therapietrouw bleken onderling slecht te correleren. Intentie, eigeneffectiviteit, sociale invloed, leeftijd en vergeetachtigheid correleerden significant met zowel 'self-perceived adherence' als 'completeness' in univariate analyse. In multipele regressie analyse voorspelde het theoretisch model het best de 'selfperceived adherence' (met een verklaarde variantie van 32\%). Deze analyse liet zien dat patiënten met een passief reactieve copingstijl (d.w.z. zich neerleggen bij de situatie), met een palliatieve copingstijl (d.w.z. afleiding zoeken) en met een lage eigen-effectiviteit minder vaak therapietrouw waren. Wat betreft 'completeness' bleek dat jongere patiënten en patiënten die bezorgder waren over het gebruik van medicijnen minder pillen per dag hadden ingenomen. Wat betreft 'intake fidelity' bleek dat mannen, allochtonen en patiënten die geen last hadden van bijwerkingen minder vaak therapietrouw waren. 
In het laatste hoofdstuk, de algemene discussie, worden de belangrijkste bevindingen uit dit proefschrift en hun implicaties op een rij gezet, gevolgd door een beschrijving van de sterke punten en beperkingen van dit proefschrift, alsmede aanbevelingen voor de praktijk en voor toekomstig onderzoek. 


\section{Publicaties en presentaties}

\section{Publicaties en presentaties voortgekomen uit dit promotie-onderzoek}

Gepubliceerde artikelen

- Fransen GAJ, Janssen MJR, Muris JWM, Laheij RJF, Jansen JBMJ. The diagnostic value of alarm symptoms for upper gastrointestinal malignancy: a meta-analysis. Aliment Pharmacol Ther 2004; 20: 1045-52.

- Fransen GAJ, Van Marrewijk CJ, Mujakovic S, Muris JWM, Laheij RJF, Numans ME, De Wit NJ, Samsom M, Jansen JBMJ, Knottnerus JA. Pragmatic trials in primary care. Methodological challenges and solutions demonstrated by the DIAMOND-study. BMC Med Res Methodol 2007; 7: 16.

- Fransen GAJ, Janssen MJR, Muris JWM, Mesters I, Knottnerus JA. Measuring the severity of upper gastrointestinal complaints: does GP-assessment correspond with patients' self-assessment? Fam Pract 2007; 24: 252-8.

- Fransen GAJ, Mesters I, Van Marrewijk CJ, Mujakovic S, Knottnerus JA, Muris JWM. Leefstijladviezen, medicatie-instructies en het belang van therapietrouw bij maagklachten. Huisarts Wet 2007; 50: 446-52.

Gepubliceerde abstracts

- Fransen GAJ, Janssen MJR, Muris JWM, Laheij RJF, Jansen JBMJ. The predictive value of alarm symptoms for upper gastrointestinal malignancies: results of a meta-analysis. Gut 2003; 52 (Suppl. VI): A144.

- Fransen GAJ, Mesters I, Bonten E, Muris JWM. Expectations of patients regarding the management of gastrointestinal problems. Gut 2004; 53 (Suppl. VI): A284.

- Fransen GAJ, Janssen MJR, Muris JWM, Mesters I, Knottnerus JA. Measuring the severity of stomach complaints: do general practitioner and patient agree? Gut 2005; 54 (Suppl. VII): A100.

- Fransen GAJ, Van de Velde M, Mesters I, Van Marrewijk CJ, Mujakovic S, Knottnerus JA, Muris JWM. What lifestyle changes and medication instructions do Dutch GPs propose in case of dyspepsia? Gut 2006; 55 (Suppl. V): A261.

- Janssen MJR, Fransen GAJ, Voutilainen M, Adang RPR, Sung JJY, Numans ME, Thomson ABR, Boldys H, Manes G, Hammer J, Laheij RJF, Jansen JBMJ. Alarm symptoms for gastric/oesophageal malignancy: a meta-analysis using 
individual patient data. Gut 2005; 54 (Suppl. VII): A42. Beloond met een travel grant.

- Van Marrewijk CJ, Mujakovic S, Fransen GAJ, Numans ME, De Wit NJ, Muris JWM, Jansen JBMJ, Grobbee DE, Knottnerus JA, Laheij RJF. 'step-up' treatment with antacids, H2-receptor antagonists and proton pump inhibitors is more efficiënt than 'step-down' treatment in patients with new onset dyspepsia. Gut 2007; in press.

- Van Marrewijk CJ, Van Oijen MGH, Laheij RJF, Paloheimo LI, Mujakovic S, Fransen GAJ, Numans ME, De Wit NJ, Muris JWM, Grobbee DE, Knottnerus JA, Jansen JBMJ. The influence of gastric status on empirical dyspepsia treatment success. Gut 2007; in press.

- Mujakovic S, De Wit NJ, Van Marrewijk CJ, Fransen GAJ, Onnen-Moret NC, Laheij RJF, Muris JWM, Grobbee DE, Samsom M, Jansen JBMJ, Knottnerus JA, Ter Linde J, Numans ME. C178T Polymorphism in the 5HT3A receptor is associated with severity of dyspeptic symptoms. Gut 2007; in press.

- Mujakovic S, De Wit NJ, Van Marrewijk CJ, Fransen GAJ, Stijnenbosch P, Laheij RJF, Muris JWM, Grobbee DE, Samsom M, Jansen JBMJ, Knottnerus JA, Ter Linde J, Numans ME. CYP2C19*2 Polymorphism does not affect PPI treatment success in primary care patients with dyspepsia. Gut 2007; in press.

Presentaties

- Fransen GAJ, Janssen MJR, Muris JWM, Laheij RJF, Jansen JBMJ. The diagnostic value of alarm symptoms for upper gastrointestinal malignancy: a meta-analysis. Nederlandse Vereniging voor Gastroenterologie, Veldhoven, 2003, mondelinge presentatie.

- Fransen GAJ, Janssen MJR, Muris JWM, Laheij RJF, Jansen JBMJ. The diagnostic value of alarm symptoms for upper gastrointestinal malignancy: a meta-analysis. United European Gastroenterology Week, Madrid, 2003, poster presentatie, beloond met een travel grant.

- Fransen GAJ, Mesters I, Bonten E, Muris JWM. Management of upper gastrointestinal symptoms: the patient's perspective. United European Gastroenterology Week, Praag, 2004, poster presentatie.

- Fransen GAJ, Mesters I, Bonten E, Muris JWM. Management of upper gastrointestinal symptoms: the patient's perspective. Nederlands Huisarts Genootschap Wetenschapsdag, Leiden, 2004, mondelinge presentatie. 
- Fransen GAJ, Muris JWM, Laheij RJF, Van Marrewijk CJ, Mujakovic S, Numans ME, De Wit NJ, Samsom M, Jansen JBMJ, Knottnerus JA. Behandeling van patiënten met maagklachten met zuurremmers: 'step-up' of step-down? Nederlands Huisarts Genootschap Wetenschapsdag, Leiden, 2004, poster presentatie.

- Fransen GAJ, Muris JWM, Mesters I, Knottnerus JA. Therapietrouw bij maagklachten: welke factoren zijn van invloed? Nederlands Huisarts Genootschap Wetenschapsdag Rotterdam, 2005, mondelinge presentatie in consultatiesessie.

- Fransen GAJ, Janssen MJR, Voutilainen M, Adang RPR, Sung JJY, Numans ME, Thomson ABR, Boldys H, Manes G, Hammer J, Laheij RJF, Jansen JBMJ. Are there alarm symptoms for upper gastrointestinal malignancy? World Organization of Family Doctors (WONCA), Kos, 2005, mondelinge presentatie.

- Fransen GAJ, Mesters I, Bonten E, Muris JWM. Management of upper gastrointestinal symptoms: the patient's perspective. World Organization of Family Doctors (WONCA), Kos, 2005, mondelinge presentatie.

- Fransen GAJ, Janssen MJR, Muris JWM, Mesters I, Knottnerus JA. Severity of upper GI complaints: Do GP and patient agree? United European Gastroenterology Week, Copenhagen, 2005, poster presentatie.

- Fransen GAJ, Janssen MJR, Muris JWM, Mesters I, Knottnerus JA. Severity of upper GI complaints: Do GP and patient agree? Nederlandse Vereniging voor Gastroenterologie, Veldhoven, 2006, mondelinge presentatie.

- Fransen GAJ, Mesters I, Bonten E, Muris JWM. Management of upper gastrointestinal symptoms: the patient's perspective. Care and Public Health Research Institute (CAPHRI) Onderzoeksdag, Maastricht, 2006, poster presentatie, winnaar CAPHRI poster award.

- Fransen GAJ, Janssen MJR, Muris JWM, Mesters I, Knottnerus JA. Severity of upper GI complaints: Do GP and patient agree? Care and Public Health Research Institute (CAPHRI) Onderzoeksdag, Maastricht, 2006, poster presentatie.

- Fransen GAJ, Mesters I, Van Marrewijk CJ, Mujakovic S, Knottnerus JA, Muris JWM. What lifestyle changes and medication instructions do Dutch GPs propose for dyspepsia? United European Gastroenterology Week, Berlijn, 2006, poster presentatie. 
Overige gepubliceerde artikelen

- Fransen GAJ, Desgranges P, Laheij RJ, Harris PL, Becquemin JP; EUROSTAR Collaborators. Frequency, predictive factors, and consequences of stent-graft kink following endovascular AAA repair. J Endovasc Ther 2003; 10: 913-8.

- Fransen GAJ, Vallabhaneni SR Sr, van Marrewijk CJ, Laheij RJ, Harris PL, Buth J; EUROSTAR. Rupture of infra-renal aortic aneurysm after endovascular repair: a series from EUROSTAR registry. Eur J Vasc Endovasc Surg 2003; 26: 487-93.

- $\quad$ Buth J, Harris PL, Van Marrewijk C, Fransen G. Endoleaks during follow-up after endovascular repair of abdominal aortic aneurysm. Are they all dangerous? J Cardiovasc Surg (Torino). 2003; 44 : 559-66.

- Buth J, Harris PL, van Marrewijk C, Fransen G. The significance and management of different types of endoleaks. Semin Vasc Surg 2003; 16: 95102.

- Fikkers BG, Fransen GAJ, van der Hoeven JG, Briede IS, van den Hoogen FJ. Tracheostomy for long-term ventilated patients: a postal survey of ICU practice in The Netherlands. Intensive Care Med 2003; 29: 1390-3.

- Lottman PE, Van Marrewijk CJ, Fransen GAJ, Laheij RJ, Buth J. Impact of smoking on endovascular abdominal aortic aneurysm surgery outcome. Eur $\mathrm{J}$ Vasc Endovasc Surg 2004; 27: 512-8.

- Peppelenbosch N, Buth J, Harris PL, van Marrewijk C, Fransen G; EUROSTAR Collaborators. Diameter of abdominal aortic aneurysm and outcome of endovascular aneurysm repair: does size matter? A report from EUROSTAR. Vasc Surg 2004; 39: 288-97.

- Van Marrewijk CJ, Fransen G, Laheij RJ, Harris PL, Buth J; EUROSTAR Collaborators. Is a type II endoleak after EVAR a harbinger of risk? Causes and outcome of open conversion and aneurysm rupture during follow-up. Eur J Vasc Endovasc Surg 2004; 27: 128-37. 


\section{Dankwoord}

Het gedrag van mensen heeft mij altijd al geïnteresseerd: waarom doen mensen (bewust of onbewust) de dingen die ze doen, soms zelfs terwijl ze weten dat dit slecht voor ze kan zijn. Ik denk dat het antwoord te maken heeft met het feit dat het mensen iets oplevert: gemak, plezier, genot, geld, of status bijvoorbeeld. Bij het schrijven van dit dankwoord heb ik eens naar mijn eigen gedrag van de afgelopen jaren gekeken: het doen van promotieonderzoek en het schrijven van een proefschrift. Dit gedrag heeft mij zeker een aantal waardevolle dingen opgeleverd (al ben ik heel blij dat ik het niet gedaan heb om het geld). Als ik mijn gedrag zou willen verklaren in een theoretisch model zou dat wellicht er als volgt uit kunnen zien.

Een belangrijke voorspeller van gedrag is de intentie ofwel het van plan zijn. De intentie tot het promoveren is bij mij voor een deel bewust tot stand gekomen, maar ook voor een deel onbewust. Ruim 5 jaar geleden solliciteerde ik op een baan in het UMC St. Radboud, met als directe gevolg dat ik werd aangenomen voor een (leukere) baan in het bedrijf van Robert Laheij: Medical Science bv. Na ongeveer een jaar kreeg ik de kans om te mee te gaan werken aan een groot huisartsenonderzoek, de DIAMOND-studie. Dit bood me de kans om zelf een aantal interessante onderzoeksvragen op mijn vakgebied te bepalen en te onderzoeken en ik heb deze kans heel bewust aangegrepen. Ik leerde in Maastricht prof. André Knottnerus en Jean Muris kennen en samen met Ilse Mesters (die ik nog kende van de opleiding) zijn we enthousiast aan de slag gegaan met de onderzoeksvragen en het opzetten van het onderzoek. Dat dit moest leiden tot een promotieonderzoek leek ineens heel logisch en voordat ik het wist had ik dan ook de intentie om te gaan promoveren.

Maar of het nu bewust of onbewust tot stand gekomen is, een intentie ontstaat niet zomaar. Volgens verschillende theorieën (zie ook hoofdstuk 1, 6, 9 en 10) wordt intentie voor het uitvoeren van gedrag bepaald door attitude, sociale invloed, en eigen-effectiviteit. Zo zou het ook kunnen gelden voor het hebben van de intentie om te promoveren: de voordelen van promoveren moeten zwaarder wegen dan de nadelen (dan heb je een positieve attitude), je hebt veel steun nodig van je familie, vrienden en collega's en het kan ook helpen als je ziet hoe anderen in je omgeving 
promoveren (dat is sociale invloed), en je moet voldoende vertrouwen hebben dat je het kunt (dan heb je voldoende eigen-effectiviteit).

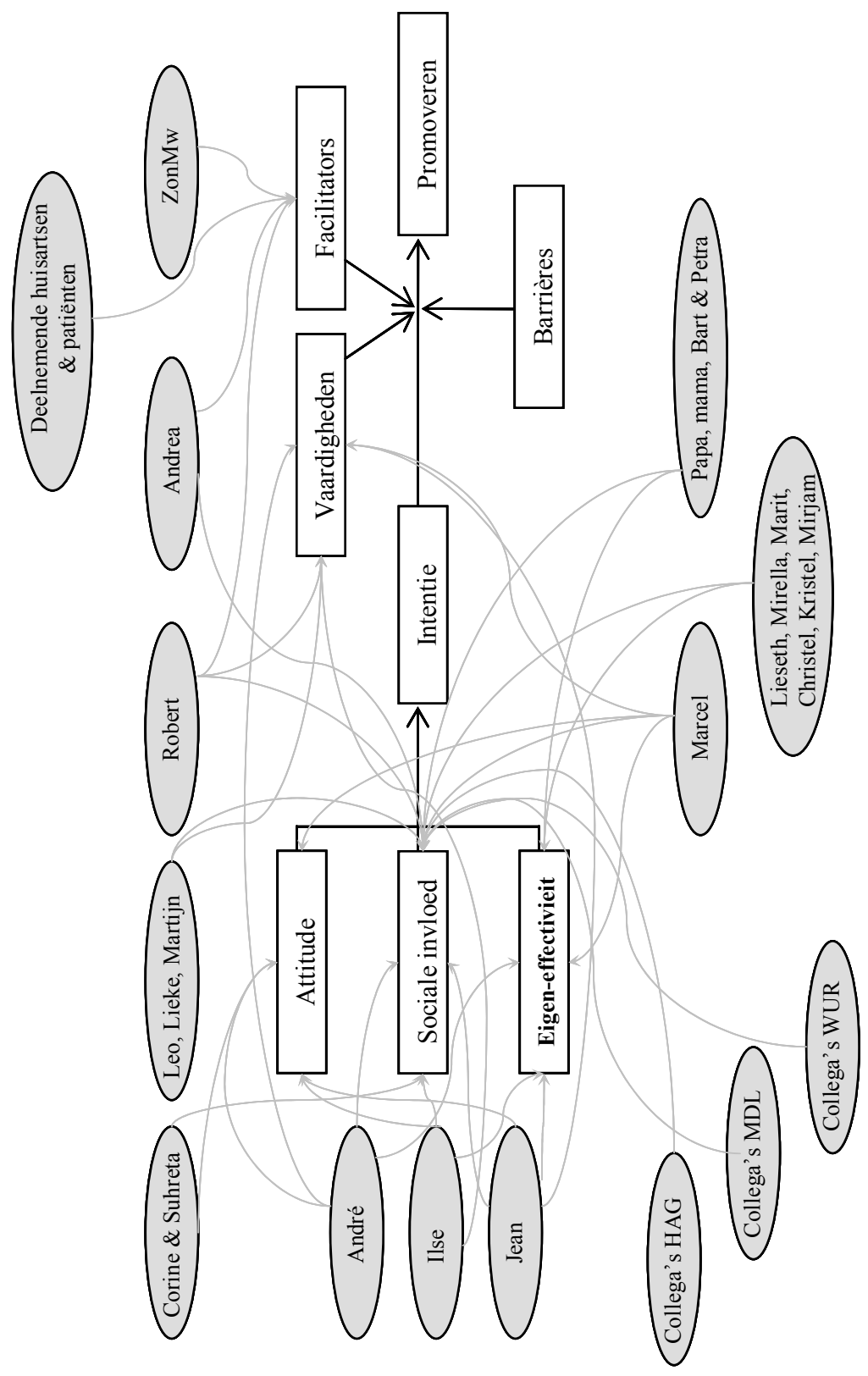


En als je de intentie hebt, wil dat nog niet zeggen dat het ook altijd lukt om te promoveren. Ik heb verschillende barrières ondervonden die me soms afgeleid hebben van promoveren, zoals een onvoorziene bocht in de snelweg, heel veel leuke verbouwingen in huis of een fulltime post-doc baan. Gelukkig hebben verschillende mensen mij geleerd hoe ik moest om gaan met deze barrières. Ze hebben een goede invloed gehad op mijn attitude, sociale invloed, eigen-effectiviteit, intentie en (omgaan met) barrières, ze hebben me vaardigheden geleerd en/of het promotieonderzoek gefaciliteerd. Mijn intentie was niet elke dag even hoog, maar dankzij deze mensen die soms dagelijks (bewust of onbewust) invloed op mij hebben uitgeoefend, heb ik mijn intentie om kunnen zetten in het daadwerkelijk schrijven van een proefschrift. Deze mensen zijn:

Prof. Knottnerus, André, je hebt met name veel invloed op mijn eigen-effectiviteit en mijn vaardigheden. Ik heb bewondering voor de wijze waarop je me begeleid hebt, je goede kritische blik op mijn artikelen heeft mij altijd gemotiveerd en heeft er voor gezorgd dat ik steeds kritischer naar mijn (en andersmans) teksten en statistische analyses ging kijken. Zelfs als ik artikelen te laat naar je stuurde en je ze niet had kunnen lezen, wist je toch in het gesprek meteen welke punten nog verbeterd moesten worden. Dank ook voor de complimentjes die je me bij ieder gesprek gaf: al zag ik het op dat moment even niet meer zitten, dan zorgde die complimentjes er toch voor dat ik er weer tegen aan kon.

Jean Muris, je staat altijd voor me klaar met een luisterend oor en motiverende woorden. Jouw nuchtere blik op mijn soms veel te ingewikkelde beschrijvingen heeft me gestimuleerd om eenvoudiger en beter te schrijven en tot concrete aanbevelingen voor huisartsen en onderzoekers te komen. Bedankt dat ik gebruik mocht maken van je kamer als ik (vaak onverwacht) in Maastricht was: dat waren vaak hele nuttige, productieve en hele gezellige dagen!

Ilse Mesters, bedankt voor je kritische blik en je altijd snelle reacties. Onze discussies over patiëntenvoorlichting hebben mij gestimuleerd en ik hoop dat wij in de toekomst al de goede ideeën die uit deze discussies voortkomen kunnen gaan uitwerken. Bij onze afspraken sta ik regelmatig het laatste half uur met de klink in mijn hand: het is zo gezellig dat we geen afscheid kunnen nemen! 
Corine en Suhreta; ik ben heel erg blij dat jullie aan mijn zijde willen staan 18 oktober, zoals jullie dat ook de afgelopen vier jaar hebben gedaan. Corine, onze discussies over promoveren die al in het Catharina Ziekenhuis begonnen hebben gezorgd voor een positieve attitude. Daarna vormden we als DIAMOND-girls met z'n drietjes een goed team: we sjeesden het land door op zoek naar huisartsen en patiënten, we hielden elkaar scherp, en vulden elkaar aan waar nodig. Ik heb veel van onze samenwerking geleerd en ben blij dat ik er twee vriendinnen aan over gehouden heb.

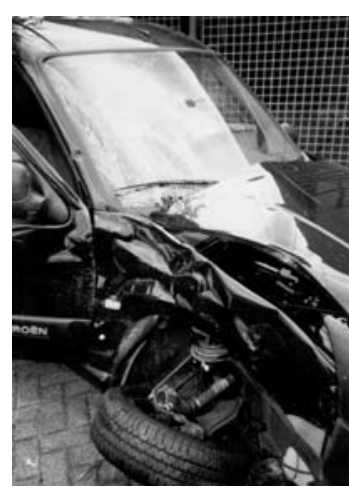

Robert; als werkgever en projectleider heb je gezorgd voor een prettige werksfeer, je liet me heel erg vrij en ik heb veel geleerd van je wetenschappelijk enthousiasme en creativiteit. Bedankt voor al je steun van de afgelopen jaren. Sorry van de auto.

Binnen ons kleine bedrijfje in de kelder wil ik graag nog een aantal mensen bedanken voor de gezellige werksfeer en het goede wetenschappelijke klimaat. Leo, dank je wel voor al je hulp als de database weer eens niet deed wat ik wilde, en natuurlijk ook voor het polijsten van de scherpe kantjes van drie diamantjes! Lieke, dank je wel voor alle hulp in drukke DIAMOND-tijden, en voor alle gezelligheid. Martijn, jouw enthousiasme voor wetenschap werkt zeer aanstekelijk, onze 'paranimfomanische' samenwerking van afgelopen juni was hartverwarmend en ik hoop dat we nog lang vrienden kunnen blijven!

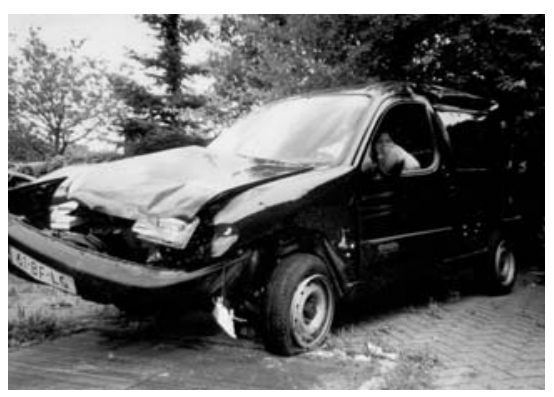

Een grote studie zoals DIAMOND heeft een gedegen stuurgroep nodig. Ik wil Niek de Wit, Mattijs Numans, Melvin Samsom van het UMC Utrecht en Jan Jansen van UMC St Radboud Nijmegen, hierbij hartelijk bedanken voor alle geboden steun en de prettige samenwerking.

Ik wil alle medewerkers van de afdeling Maag-, darm- en leverziekten van het UMC St. Radboud bedanken voor alle hulp bij presentaties, bij het labwerk en het versturen/ontvangen van post en die broodnodige faxen met meldingen van nieuw 
geworven patiënten. Daarnaast wil ik ook alle medewerkers van de afdeling Huisartsgeneeskunde in Maastricht bedanken. Ik kwam altijd onverwachts binnen vallen, maar ik heb genoten van de gastvrijheid en alle gezellige gesprekken op de gang of bij de koffieautomaat. Als externe voel ik me daardoor toch thuis bij jullie! Ook mijn nieuwe collega's in Wageningen wil ik bedanken: jullie hebben me ontzettend gesteund bij de laatste loodjes van dit proefschrift. Ik heb het erg goed naar mijn zin bij jullie. Wat is communicatie een breed veld, jullie hebben mij de link laten zien tussen voorlichting door huisartsen en voorlichting door dierenartsen! Femke, dank je wel voor je luisterend oor en al je hulp, jij bent in korte tijd een lieve vriendin geworden!

Vele huisartsen en patiënten hebben deelgenomen aan de onderzoeken beschreven in dit proefschrift. Bij dezen wil ik jullie allemaal hartelijk danken want als jullie niet de moeite hadden genomen om onder andere de benodigde vragenlijsten in te vullen, was dit proefschrift er niet gekomen.

Zonder de financiële steun van ZonMw en AstraZeneca BV was het onderzoek beschreven in dit proefschrift niet mogelijk geweest. Andrea Sellink, bedankt voor de fijne samenwerking en alle stimulerende meetings!

Sociale steun is nodig op het werk maar zeker ook daarbuiten. Daarom wil ik graag mijn lieve vriendinnetjes, Lieseth, Mirella, en de meiden van 'de treinclub' (Christel, Kristel, Marit en Mirjam) bedanken. Hoewel we al sinds ons afstuderen niet meer samen in de trein hebben gezeten (en zeker niet van Eindhoven naar Maastricht om 7.00u...), beschouwen we onszelf nog steeds als 'de treinclub', ondertussen waarschijnlijk berucht in menig restaurant in Eindhoven... Lieve vriendinnetjes, bij jullie kan ik altijd terecht en ik kan jullie niet meer missen!

Lieve Marcel, de afgelopen vier jaar heb jij altijd voor me klaar gestaan. Jouw bemoedigende woorden hebben mij gemotiveerd, jouw kritische blik en onze discussies hebben er toe geleid dat ik beter ben gaan schrijven, en je hebt gezorgd voor de broodnodige afleiding en ontspanning. Dank je wel voor alle hulp bij het opmaken van dit proefschrift en alle mooie foto's. Je hebt een bijzonder plekje in mijn hart veroverd.

Lieve papa, mama, Bart en Petra, ik hou van jullie! 
Dyspepsia in primary care: patient expectations, symptoms, and treatment adherence

210 


\section{Curriculum vitae}

Gerdine Fransen is geboren op 6 mei 1978 in het UMC St. Radboud te Nijmegen, waarna zij opgroeide in het Brabantse dorp Heesch. Zij genoot daar een fijne, zorgeloze jeugd, samen met haar broertje Bart en zusje Petra. In 1995 haalde ze haar HAVO diploma aan het Maasland College te Oss en begon ze met haar HBO-opleiding Voeding en Diëtetiek te Nijmegen. $\mathrm{Na}$ een plezierige paramedische stage in het St. Jansdal ziekenhuis te Harderwijk studeerde ze in 1999 af. Echter, ze wilde meer leren en besloot daarom meteen verder te gaan met studeren. Maar haar interesse in de voeding kon ze niet

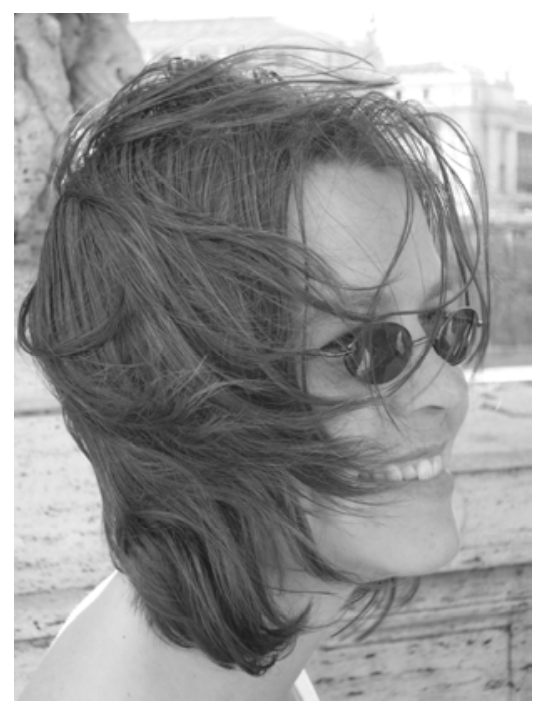
helemaal loslaten; tijdens en korte tijd na haar nieuwe studie werkte zij als diëtiste bij een afslankinstituut in Oss.

Die nieuwe studie betrof Gezondheidswetenschappen aan de Universiteit Maastricht, waarbij Gerdine koos voor de afstudeerrichting Gezondheidsvoorlichting (GVO). Haar afstudeerscriptie heeft ze geschreven onder begeleiding van Hans Brug en Ingrid Steenhuis. Deze ging over het gebruik van kant-en-klare maaltijden en waarom sommige mensen deze frequent kopen en anderen nooit. Voor dit afstudeeronderzoek maakte zij gebruik van focusgroep interviews en een enquête onder supermarktbezoekers door heel Nederland. In september 2001 is Gerdine afgestudeerd.

$\mathrm{Na}$ haar afstuderen heeft Gerdine korte tijd als verkoopster in een kledingzaak in Den Bosch gewerkt. Met een volle kledingkast en een lege portemonnee startte zij in maart 2002 als onderzoeker bij Medical Science BV. Dit was een klein onderzoeksbureau onder leiding van Robert Laheij, gevestigd in het UMC St. Radboud. Vanuit dit bedrijf werd zij gedetacheerd naar de afdeling Vaatchirurgie van het Catharina Ziekenhuis in Eindhoven. Samen met Corine van Marrewijk werkte zij daar als onderzoeker in een dataregistratie centrum betreffende endovasculaire ingrepen voor abdominale en thoracale aneurysma's van de aorta. Zij deed daar veel ervaring op met statistische analyses, management van grote hoeveelheden data en het publiceren van onderzoeksresultaten. 
In april 2003 haalden Robert en de DIAMOND stuurgroep een subsidie van ZonMw binnen om te onderzoeken welke medicamenteuze behandeling het meest kosteneffectief is voor maagklachten. Dit bleek een unieke kans om meerdere onderzoeksprojecten aan elkaar te koppelen en een samenwerking op te zetten met de Universiteit Maastricht en het UMC Utrecht. Het bood Gerdine de kans om een promotietraject in te slaan dat aansluit bij haar interesses, namelijk ziekte en behandeling bekeken vanuit het patiëntenperspectief, patiëntenvoorlichting en therapietrouw. Zij werd hierbij gedetacheerd naar de afdeling Huisartsgeneeskunde van de Universiteit Maastricht, alwaar zij ook haar banden met GVO weer kon aanhalen. Zij heeft, binnen de mogelijkheden van de DIAMOND-studie, onderzoeksvragen binnen haar vakgebied geformuleerd en een onderzoeksopzet geschreven en uitgevoerd. Tijdens de DIAMOND-studie heeft zij intensief samengewerkt met Corine van Marrewijk (UMC St. Radboud) en Suhreta Mujakovic (UMC Utrecht), de andere twee DIAMOND-promovendi. Met zijn drieën verstuurden zij vele vragenlijsten, verwerkten zij de geretourneerde vragenlijsten, namen bloed af en verwerkten dit in het laboratorium, en distribueerden de onderzoeksmedicatie onder de huisartsen. Gedurende ruim 2 jaar reden zij Zuid- en Midden-Nederland door om huisartsen te bezoeken en data te verzamelen. Deze intensieve werkzaamheden hebben geresulteerd in deelname van meer dan 300 huisartsen en de benodigde 664 patiënten.

Toen in januari 2007 het promotieonderzoek in de afrondende fase was aangekomen, is Gerdine als postdoc onderzoeker gaan werken bij de afdeling Communicatiewetenschappen van de WUR (Wageningen University and Research Centre). Zij heeft hier haar ervaring als diëtiste en GVO'er goed weten te combineren met haar ervaring in het doen van onderzoek onder huisartsen: ze is momenteel bezig met het ontwikkelen van een methode ter behandeling van overgewicht en obesitas. Het is de bedoeling dat deze methode huisartsen en praktijkondersteuners gaat helpen om overgewicht onder hun volwassen patiënten vaker en beter aan te pakken. 